\title{
Chromatographic separations of enantiomers and underivatized oligosaccharides
}

by

\author{
Ying Liu
}

\author{
A dissertation submitted to the graduate faculty \\ in partial fulfillment of the requirements for the degree of \\ DOCTOR OF PHILOSOPHY
}

\author{
Major: Analytical Chemistry \\ Program of Study Committee: \\ Daniel W. Armstrong, Major Professor \\ Robert S. Houk \\ Victor Shang-Yi Lin \\ Jacob W. Petrich \\ Bonita A. Glatz
}

Iowa State University

Ames, Iowa

2004

Copyright $($ Ying Liu, 2004. All rights reserved. 


\section{Graduate College \\ lowa State University}

This is to certify that the doctoral dissertation of

Ying Liu

has met the dissertation requirements of Iowa State University

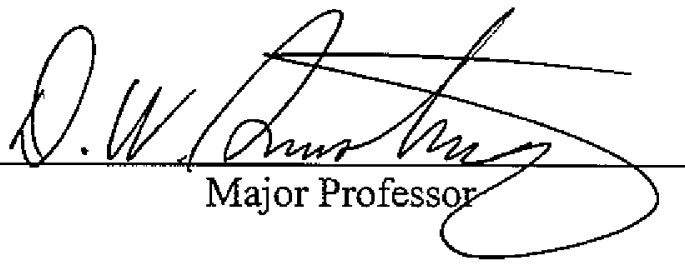

For the Major Program 
iii

This dissertation is dedicated to

My parents, who raised me and believe in me, My husband, who loves me and supports me, My instructors, who educated me and enriched me. 
TABLE OF CONTENTS

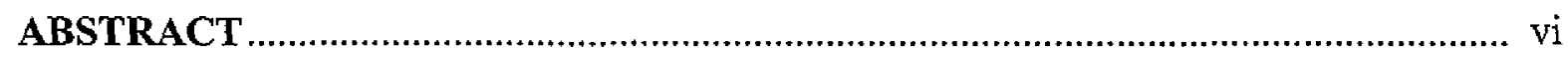

CHAPTER 1. GENERAL INTRODUCTION AND LITERATURE REVIEW

1.1. General Introduction ..................................................................... I

1.2. Dissertation Organization ...................................................................... 5

1.3. Literature Review................................................................................. 6

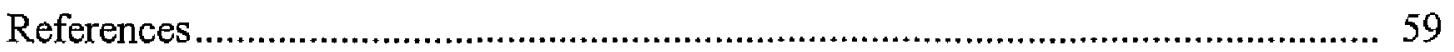

CHAPTER 2. SUPER/SUBCRITICAL FLUID CHROMOATOGRAPHY CHIRAL SEPARATIONS WITH MACROCYCLIC GLYCOPEPTIDE STATIONARY PHASES

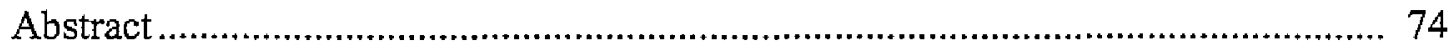

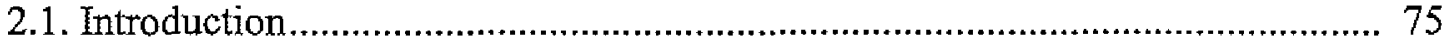

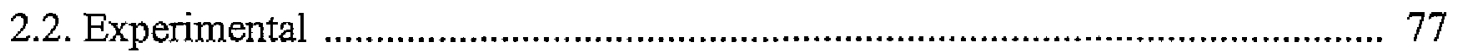

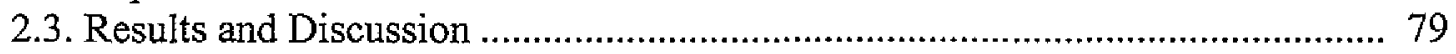

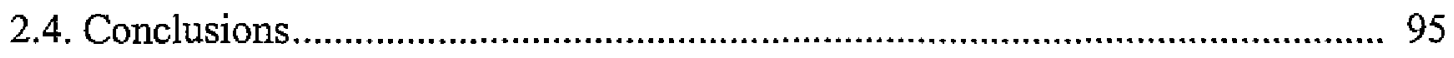

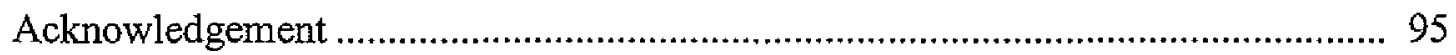

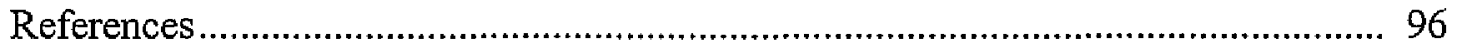

CHAPTER 3. FAST SUPER/SUBCRITICAL FLUID CHROMATOGRAPHY

ENANTIOMERIC SEPARATIONS OF DIHYDROFUROCOUMARIN

DERIVATIVES WITH MACROCYCLIC GLYCOPEPTIDE STATIONARY PHASES

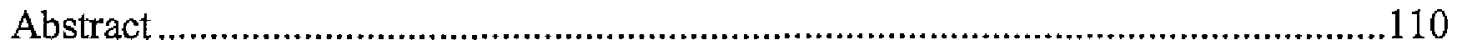

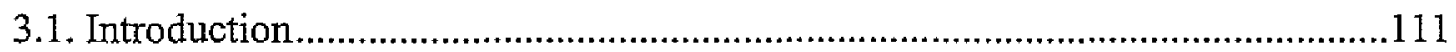

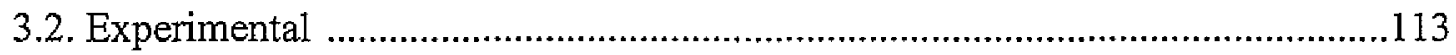

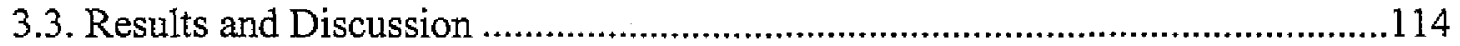

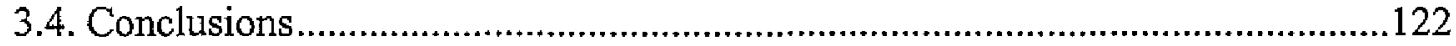

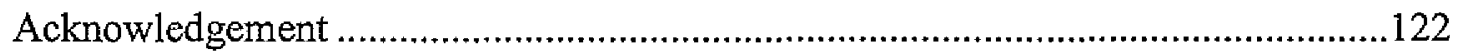

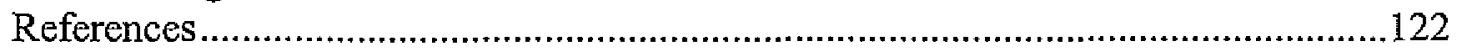

CHAPTER 4. ENANTIOSEPARATIONS OF DIHYDROFUROCOUMARIN DERIVATIVES BY VARIOUS SEPARATION MODES OF CAPILLARY ELECTROPHORESIS

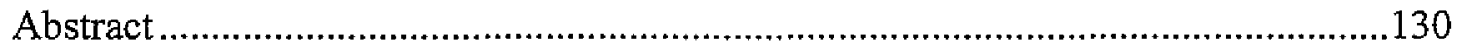

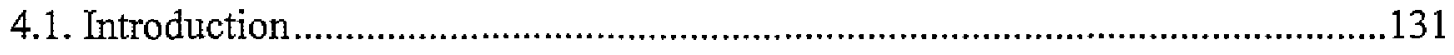

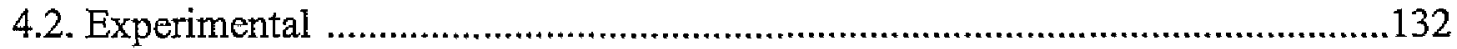




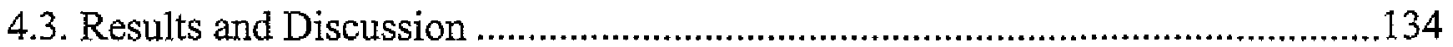

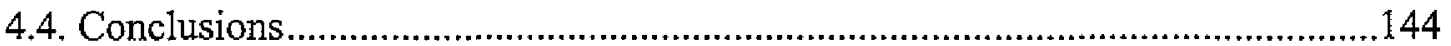

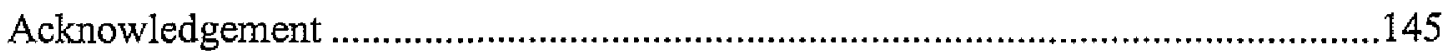

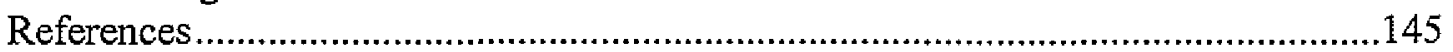

CHAPTER 5. BINDING CONSTANT STUDIES OF DRUGS AND PROTEINS USING FRONTAL ANALYSIS CAPILLARY ELECTROPHORESIS-LASER INDUCED FLUORESCENCE

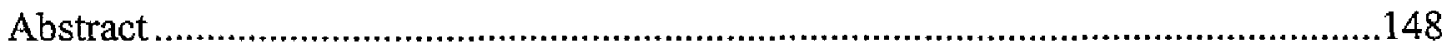

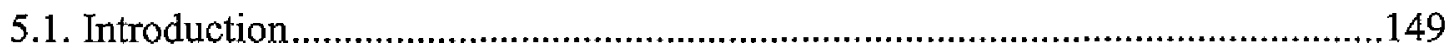

5.2. Binding constant study between coumarin 153 and apomyoglobin ...................153

5.3. Binding constant study between tetrols and Anti-PAH MAb.............................160

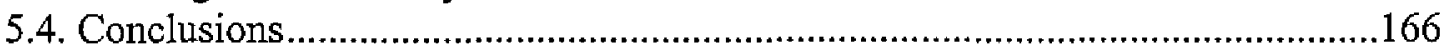

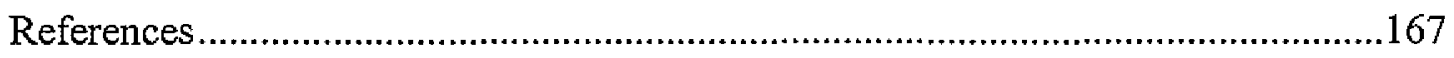

CHAPTER 6. SEPARATION AND CHARACTERIZATION OF UNDERIVATIZED OLIGOSACCHARIDES USING LC AND LC-ESI-MS

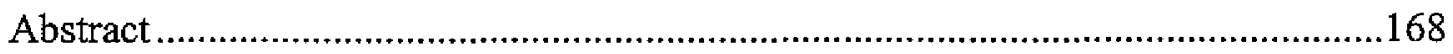

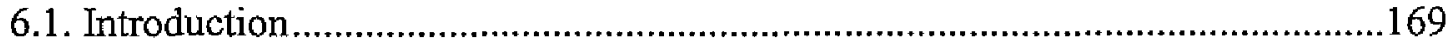

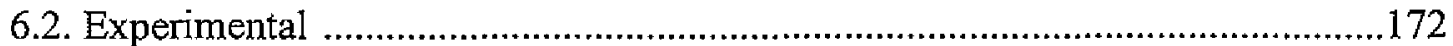

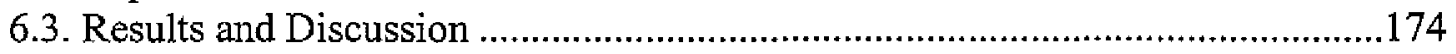

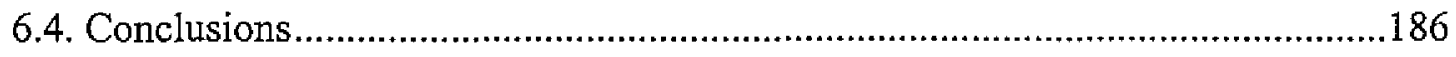

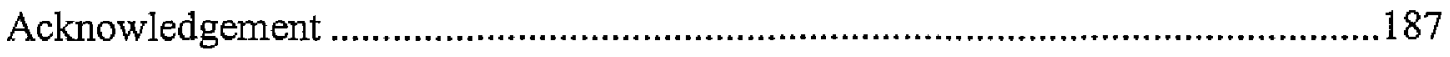

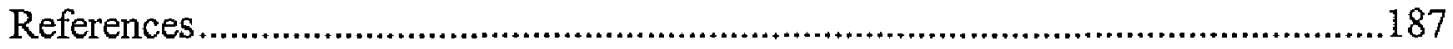

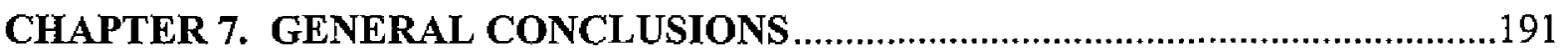

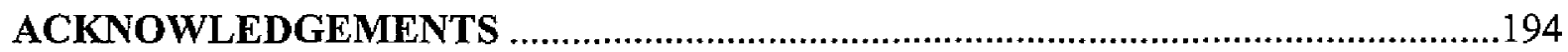




\begin{abstract}
My graduate research has focused on separation science and bioanalytical analysis, which emphasized in method development. It includes three major areas: enantiomeric separations using high performance liquid chromatography (HPLC), Super/subcritical fluid chromatography (SFC), and capillary electrophoresis (CE); drug-protein binding behavior studies using $\mathrm{CE}$; and carbohydrate analysis using liquid chromatograph-electrospray ionization mass spectrometry (LC-ESI-MS).
\end{abstract}

Enantiomeric separations continue to be extremely important in the pharmaceutical industry. An in-depth evaluation of the enantiomeric separation capabilities of macrocyclic glycopeptides CSPs with SFC mobile phases was investigated using a set of over 100 chiral compounds. It was found that the macrocyclic based CSPs were able to separate enantiomers of various compounds with different polarities and functionalities. Seventy percent of all separations were achieved in less than $4 \mathrm{~min}$ due to the high flow rate $(4.0 \mathrm{ml} / \mathrm{min})$ that can be used in SFC.

Drug-protein binding is an important process in determining the activity and fate of a drug once it enters the body. Two drug/protein systems have been studied using frontal analysis CE method. More sensitive fluorescence detection was introduced in this assay, which overcame the problem of low sensitivity that is common when using UV detection for drugprotein studies. In addition, the first usage of an argon ion laser with $257 \mathrm{~nm}$ beam coupled 
vii

with CCD camera as a frontal analysis detection method enabled the simultaneous observation of drug fluorescence as well as the protein fluorescence.

LC-ESI-MS was used for the separation and characterization of underivatized oligosaccharide mixtures. With the limits of detection as low as 50 picograms, all individual components of oligosaccharide mixtures (up to 11 glucose-units long) were baseline resolved on a Cyclobond I 2000 column and detected using ESI-MS. This system is characterized by high chromatographic resolution, high column stability, and high sensitivity. In addition, this method showed potential usefulness for the sensitive and quick analysis of hydrolysis products of polysaccharides, and for trace level analysis of individual oligosaccharides or oligosaccharide isomers from biological systems. 


\section{CHAPTER 1}

\section{GENERAL INTRODUCTION AND LITERATURE REVIEW}

\subsection{GENERAL INTRODUCTION}

Enantiomeric separations and analysis have become increasingly important in many areas of science and technology. In pharmaceutical and medicinal science, drug chirality is extremely important because of variations in enantiomeric uptake, disposition, elimination and overall effect. Guidelines, originally set forth by the U.S. Food and Drug Administration, require that individual stereoisomers must be thoroughly evaluated and continuously assayed throughout development and, ultimately, production. The impetus for these guidelines was provided by advances in LC enantiomeric separations in the 1980's that permitted facile pharmacokinetic and pharmacodynamic studies of drug antipodes (as well as product assays) for the first time. Subsequently, there has been a dramatically increase in the number of drugs marketed as single isomers. Chiral drugs comprised nearly a \$146 billion market in 2001 (compared to $\$ 123$ billion in 2000 , an increase of $18.7 \%$ ), of which approximately $36 \%$ were sold as single enantiomers (compared to approximately $30 \%$ in 2000 , a $20 \%$ increase). These numbers will continue to increase in the future. In addition, the top two drugs in terms of global sales-Lipitor and Zocor, with combined sales of almost $\$ 14$ billion in 2002--are all singleenantiomer small-molecule drugs. As a result, there has been a substantial increase in research and development related to chirality over the last twenty years. Besides traditional crystallization techniques, promising asymmetric synthetic methods, newly introduced biotransformation studies, and powerful enantiomeric separation approaches continue to be 
refined as effective procedures to obtain single enantiomers. To analyze the enantiomeric distribution of pharmacologically and biologically active compounds, various analytical scale separation techniques have been used including high performance liquid chromatography (HPLC), supercritical fluid chromatography (SFC), capillary electrophoresis (CE), capillary electrochromatography (CEC), gas chromatography (GC). Among these aforementioned separation techniques, HPLC is still one of the most widely used enantiomeric separation techniques both analytically and preparatively. In this dissertation, besides the HPLC technique, I will mainly focus on the investigation of enantiomeric separations using SFC and $\mathrm{CE}$.

The concept of utilizing macrocyclic glycopeptides as chiral stationary phases for HPLC separations was first introduced by Armstrong et al. in 1994. Since then, the macrocyclic glycopeptide CSPs, as multi-modal CSPs, have proven to have broad enantioselectivities for most types of neutral, acidic, and basic compounds including amino acids and peptides, derivatized amino acids, alcohols, sulfoxides, etc. Four types of glycopeptide-based CSPs are now available commercially. They are vancomycin (Chirobiotic V), ristocetin A (Chirobiotic R), teicoplanin (Chirobiotic T), and teicoplanin aglycon (with sugar moieties removed from teicoplanin, Chirobiotic TAG). They can be used effectively not only in the reversed-phase and polar organic phase modes, but also in the normal phase mode without any irreversible change in enantioselectivity or denaturation. However, the enantioselectivity usually is different in each mode. 
Recently, supercritical fluid chromatography has become a promising chiral separation technique that is increasingly used in industrial applications due to its fast separation speed and suitability for preparative analysis. The goal of this part of the research is to expand the applications of macrocyclic glycopeptide CSPs with SFC mobile phases. In other words, our goal is not only to show how to correlate a HPLC separation conditions to SFC conditions and how to optimize separations in SFC, but also to demonstrate the possible groups of chiral compounds that can be successfully separated with SFC mobile phase on these macrocyclic glycopeptide CSPs.

Drug-protein binding is an important process in determining the activity and fate of a drug once it enters the body. In biological system, unbound drugs in plasma can easily reach the target organ, whereas bound drugs are hard to pass through the blood capillary wall. Therefore, understanding the binding behavior between plasma protein and drugs is essential for drug development because the concentration of unbound drugs shows a better correlation to the pharmacological activity than the total drug concentration. In addition, many pharmacokinetic properties such as hepatic metabolism rate, renal excretion rate, biomembrane partition rate and steady-state distribution volume are a function of unbound drug fraction (unbound/bound concentration ratio). Therefore, better understanding drugprotein binding is also essential to pharmacokinetic study and therapeutic dosing regimen.

Currently, capillary electrophoresis (CE) has been proven a new attractive analytical tool for examining the nature and strength of biological interactions between drug and protein. Various CE methods exist and capillary electrophoresis-frontal analysis (FA) has been 
focused on the interactions of drugs with plasma proteins. The goal of this part of the research is to expand the potential usefulness of CE-FA applications by coupling with the more sensitive laser induced fluorescence detection. In addition, we first introduced the use of an UV laser (excitation at $257 \mathrm{~nm}$ ) coupled with CCD camera as a FA detection method. Not only can this detection method overcome the low sensitivity problem commonly encountered when using UV detection for drug-protein studies, but also it enables simultaneous observation of drug fluorescence as well as protein fluorescence.

The separation and characterization of underivatized oligosaccharides have continued to gain attention in recent years due to their ubiquity in nature and their significant roles and uses in industry, consumer products and biology where they are crucial for the development, growth, function or survival of an organism. Identification of the carbohydrate substituents on glycoproteins and glycopeptides (which affect or control their function) is an important and often difficult endeavor. A variety of chromatographic methods have been used to separate saccharides and oligosaccharides. However, most of the columns used have problems, particularly in terms of column stability, lifetime and separation reproducibility. In addition, most of the techniques involve an introduction of a derivatization reagent in order to enhance detectability during chromatographic analysis, and most derivatization techniques require tedious procedures, and often suffer from poor reproducibility. Our goal was to establish a highly selective and sensitive method to separate and characterize oligosaccharide mixtures without further derivatization by using high performance liquid chromatography coupled with electrospray ionization mass spectrometry technique. In this work, a native betacyclodextrin stationary phase (Cylcobond I 2000) was used to separate a variety of related 
oligosaccharides using MS compatible mobile phase. With limits of detection as low as 50 picograms, all individual components of oligosaccharide mixtures (up to 11 glucose-units long) were baseline resolved on a Cyclobond I 2000 column and detected using ESI-MS. Low flow rates and narrow ID columns increase the ESI-MS sensitivity significantly. The method showed potential usefulness for the sensitive and quick analysis of hydrolysis products of polysaccharides, and for trace level analysis of individual oligosaccharides or oligosaccharide isomers from biological systems.

\subsection{DISSERTATION ORGANIZATION}

This dissertation is presented with a general introduction and literature review plus three parts containing a total of five scientific papers. Finally there is a general conclusion that summarizes the work. The focus of the first part is on method development and mechanism studies for enantiomeric separations using two different separation techniques: super/subcritical fluid chromatography and capillary electrophoresis. This part includes three papers, which are listed as Chapters 2,3 , and 4, respectively. Basically it involves an indepth evaluation of the enantiomeric separation capabilities of macrocyclic glycopeptide CSPs with SFC mobile phases using a set of 111 chiral compounds in one study, and a unique series of chiral substituted dihydrofurocoumarin derivatives using both $\mathrm{SFC}$ and $\mathrm{CE}$ in the other studies. All of these applications were successful and mechanistic considerations of the enantiomeric separations were examined as well. The second part of this dissertation (Chapter 5) described the successful binding studies between drugs and proteins using frontal analysis-capillary electrophoresis coupled with laser induced fluorescence detection. The last 
part (Chapter 6) involves the separation and characterization of underivatized oligosaccharides using LC and LC-ESI-MS.

\subsection{ENANTIOMERIC SEPARATION LITERATURE REVIEW}

A review paper published in Journal of liquid chromatography and related technologies ${ }^{1}$

Ying Liu, Andrew W. Lantz, and Daniel W. Armstrong

\section{Introduction}

Enantiomeric separations and analysis have become increasingly important in many areas of science and technology. In pharmaceutical and medicinal science, drug chirality is extremely important because of variations in enantiomeric uptake, disposition, elimination and overall effect (1). Guidelines, originally set forth by the U.S. Food and Drug Administration, require that individual stereoisomers must be thoroughly evaluated and continuously assayed throughout development and, ultimately, productions (2). The impetus for these guidelines was provided by advances in LC enantiomeric separations in the 1980's that permitted facile pharmacokinetic and pharmacodynamic studies of drug antipodes (as well as product assays) for the first time (1-4). Subsequently, there has been a dramatically increase in the number of drugs marketed as single-isomers. Chiral drugs comprised nearly a $\$ 146$ billion market in 2001 (compared to $\$ 123$ billion in 2000 , an increase of $18.7 \%$ ), of which approximately $36 \%$ were sold as single enantiomers (compared to approximately $30 \%$ in 2000 , a $20 \%$ increase) (5). These numbers will continue to increase in the future. In the environmental area, many chiral pesticides and herbicides also have enantioselective effects and biodegradation rates $(6,7)$. In addition, food and beverage companies have increasing interests in the analysis of 
enantiomers that can affect flavor, nutrition and fragrance $(8,9)$. As a result, there has been a substantial increase in research and development related to chirality over the last twenty years (10-19). Besides traditional crystallization techniques, promising asymmetric synthetic methods, newly introduced biotransformation studies, and powerful enantiomeric separation approaches continue to be refined as effective procedures to obtain single enantiomers. To analyze the enantiomeric distribution of pharmacologically and biologically active compounds, various analytical scale separation techniques have been used including high performance liquid chromatography (HPLC), supercritical fluid chromatography (SFC), capillary electrophoresis (CE), capillary electrochromatography (CEC), gas chromatography (GC), and thin layer chromatography (TLC). Each separation technique has unique and often complementary properties. This overview will not consider enantiomeric separations using GC and TLC, but will examine the other aforementioned chromatographic separation techniques. We will focus on the evolution of chiral selectors, their use and overall effectiveness. Representative applications of each method are presented as well.

\section{Liquid Chromatography}

In the past two decades, high-performance liquid chromatography used for enantiomeric separations has developed dramatically. It has become the most widespread and useful enantiomeric separation technique dealing with drugs, agrochemicals, natural products, etc. The use of HPLC as an enantiomeric separation technique can be used not only for the determination of enantiomeric purity, but also for obtaining stereoisomers in a large scale. The first two chiral stationary phases (CSPs) to become available commercially were the 3,5dinitrobenzoyl phenylglycine CSP by Regis Technologies (20) and the $\beta$-cyclodextrin CSP 
by Advanced Separation Technologies (21). Since their inception, both types of CSPs have been mimicked, copied, and reproduced by companies and individuals worldwide. These initial CSPs were followed by two protein-based CSPs that utilized bovine serum albumin (BSA) (22) and $\alpha_{1}$-acid glycoprotein (23) as chiral selectors. Now numerous chiral stationary phases have been prepared and over 200 CSPs have been commercialized. The CSPs usually consist of either small chiral molecules or chiral polymers immobilized onto a support such as silica gel. There are several ways to classify chiral selectors. In this overview, the chiral selectors will be discussed as they are classified in Table 1. Table 1 also indicates the separation modes in which these chiral selectors have been successfully utilized.

\begin{tabular}{|c|c|c|c|}
\hline Chiral selectors & $\mathrm{LC}$ & SFC & $\mathrm{CE}$ \\
\hline \multicolumn{4}{|l|}{ Macrocyclic } \\
\hline Cyclodextrins and derivatives & - & - & - \\
\hline Glycopeptides (macrocyclic antibiotics) & - & $\bullet$ & - \\
\hline Chiral crown ether & - & & - \\
\hline \multicolumn{4}{|l|}{ Polymeric } \\
\hline Proteins & - & & - \\
\hline Native and Derivatized carbohydrates & - & • & - \\
\hline Synthetic polymers & - & - & • \\
\hline$\pi$-Complex & - & $\bullet$ & \\
\hline Ligand exchange & - & & \\
\hline Chiral surfactants & & & - \\
\hline Miscellaneous and hybrid types & - & • & - \\
\hline
\end{tabular}

Table 1. Classes of chiral selectors used in liquid chromatography, supercritical fluid chromatography and capillary electrophoresis.

\section{MACROCYCLIC CHIRAL SELECTORS}

Macrocyclic chiral selectors have had a great impact on modern enantiomeric separations. Three main types of chiral selectors belong to this particular group. They are cyclodextrins 
and their derivatives, glycopeptides, and chiral crown ethers. Altogether, this particular group of macrocyclic compounds is responsible for over $90 \%$ of $\mathrm{GC}$ and $\mathrm{CE}$ enantiomeric separations, (Derivatized cyclodextrins dominate chiral GC, while the cyclodextrins and glycopeptides are the most useful chiral selectors for CE enantioseparations). In HPLC, however, the field is more divided among several classes of chiral selectors. Cyclodextrin and macrocyclic glycopeptide CSPs are multi-modal. That is, they can be used in the reversed-phase and polar organic separation modes as well as the normal phase mode. However, chiral crown ether CSPs are mainly used in the reversed-phase mode.

\section{Cyclodextrins and their Derivatives}

Cyclodextrins (CDs) are cyclic oligosaccharides produced naturally from starch by the enzyme cyclodextrin transglycosylase. Cyclodextrins containing six, seven, and eight glucose units linked via $\alpha$ (1-4) glycosidic linkage are most common, and they are called $\alpha$ cyclodextrin, $\beta$-cyclodextrin, and $\gamma$-cyclodextrin, respectively (Figure 1a). Native $\mathrm{CD}$ is a hollow, truncated cone having a cavity with primary hydroxyl groups $(\mathrm{C}(6)$ position) around its narrower rim and, secondary hydroxyl groups $(\mathrm{C}(2)$ and $\mathrm{C}(3)$ positions) on the opposite, more open rim $(3,4,21,28)$. The interior cavity consists of the glycosidic bonds and carbon skeleton. Hence, the inner cavity of CDs is hydrophobic, while the outer surface is hydrophilic in nature (Figure 1b). Because the size of the internal cavity of the cyclodextrins increases with the increase of the number of glucose units involved, this implies that different sized cyclodextrins will accommodate analyte molecules differently. 


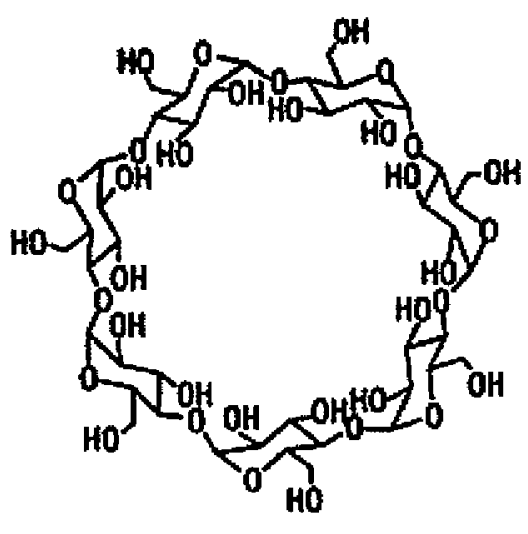

(a)

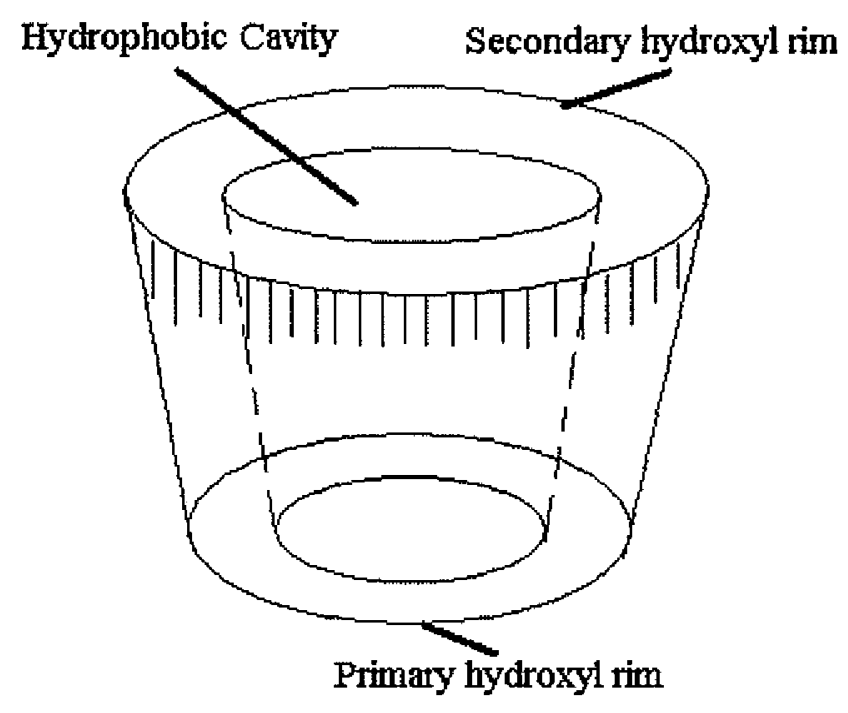

(b)

Figure 1. (a) Structure of $\beta$-cyclodextrin (b) Simplified depiction of the toroidal shape of a cyclodextrin molecule.

As mentioned previously, cyclodextrin bonded stationary phases developed by Armstrong et al. were the first commercially available reversed-phase chiral stationary phases. Since then, a wide variety of derivatized cyclodextrin CSPs have been developed and used (24-28). The different moieties used to functionalize cyclodextrins can greatly alter their enantioselectivity. Figure 2 shows different derivatives of cyclodextrins that have became successful CSPs. Although methylated and acetylated cyclodextrin CSPs (i.e. Cyclobond I DM, and Cyclobond I AC), along with native cyclodextrin CSPs, can provide good enantioselectivity in certain cases, the most widely used and effective cyclodextrin CSPs are the hydroxypropyl- $\beta$-cyclodextrin CSP (Cyclobond I RSP) and aromatic derivatized cyclodextrin CSPs, such as dimethylphenylcarbamate- $\beta$-cyclodextrin (Cyclobond I DMP) and naphthylethylcarbamate- $\beta$-cyclodextrin (Cyclobond I RN or SN depending on the 


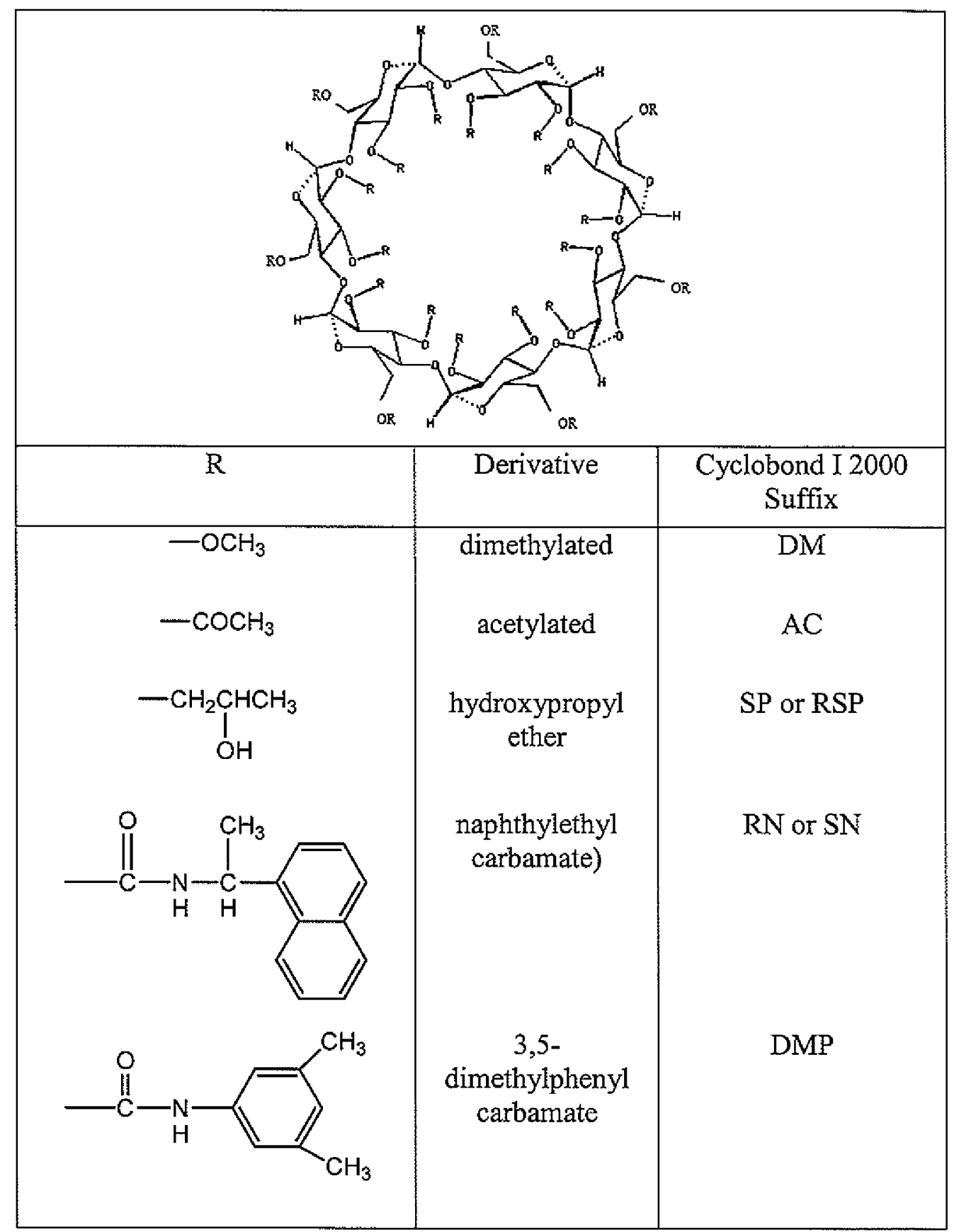

Figure 2. Different Derivatives of Cyclodextrins available as Chiral Stationary Phases (CSPs)

configuration). CSPs based on cyclodextrins and their derivatives are good for most reversed-phase and polar organic mode separations. So far, a wide variety of compounds, 
including $\beta$-blockers, alkaloids, carboxylic acids, neutral molecules, etc, have been successfully separated on these CSPs (28). However, it should be pointed out that the Cyclobond I RN and SN CSPs also work well in normal phase mode because the aromatic functionalized cyclodextrins can be used as $\pi$-complex $\operatorname{CSPs}(\pi$-electron donor). Any analyte that is a $\pi$-electron acceptor is capable of being resolved on these CSPs (28).

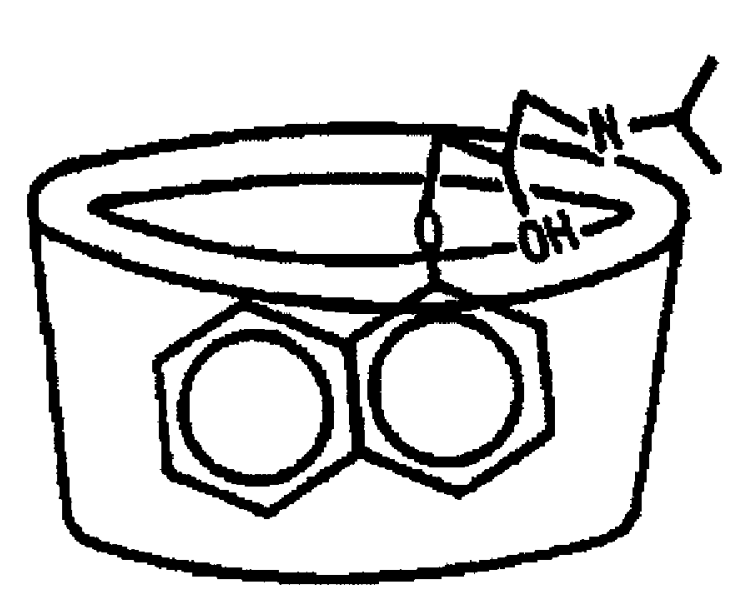

(a)

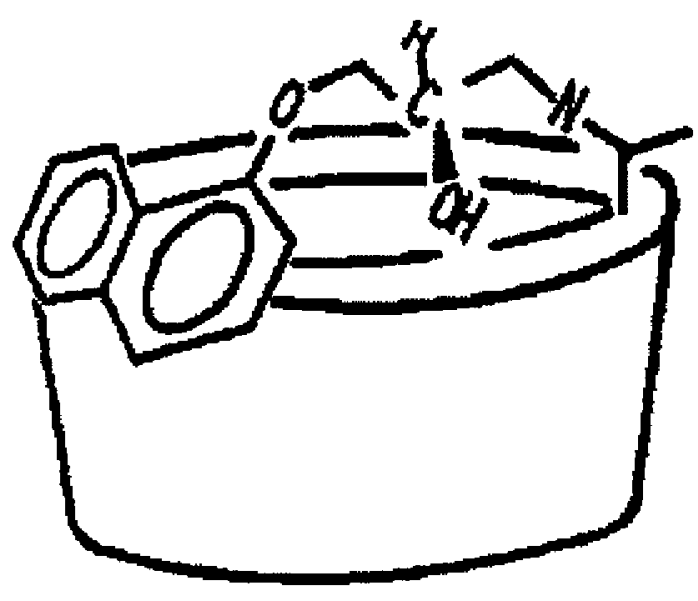

(b)

Figure 3. Simplified schematic illustrating two different enantioselective retention mechanisms for the native $\beta$-cyclodextrin/propranolol system. (a) In the reversed-phase mode, retention is mainly due to hydrophobic inclusion complexation, while enantioselectivity also requires hydrogen bonding and steric interactions at the mouth of the cyclodextrin cavity. (b) The polar-organic mode where acetonitrile occupies the hydrophobic cavity and the analyte is retained via a combination of hydrogen bonding and dipolar interactions at the mouth of the cyclodextrin. Steric interactions also can contribute to chiral recognition. (From Ref. 30)

There are two different enantioselective retention mechanisms possible with cyclodextrinbased CSPs (Figure 3). In case A, in aqueous and hydro-organic solutions (reversed-phase mobile phases), the retention is mainly due to hydrophobic inclusion complexation. 
Enantioselectivity also requires hydrogen bonding and steric interactions at the mouth of the cyclodextrin cavity. In order to obtain the best enantiomeric separations, the hydrophobic group of the chiral analyte has to have comparable size with the cyclodextrin hydrophobic cavity. Structural features such as an aromatic ring system in the $\alpha$ or $\beta$ position to the stereogenic center, at least one hydrogen-bonding group near the stereogenic center, and a second $\pi$ system (e.g. a carbonyl group, imine, etc) somewhere on the molecule are also beneficial to reversed-phase enantioseparations (29). In case B, the polar-organic mode, the presence of nonpolar solvents (such as acetonitrile) suppress or prevent the formation of an inclusion complex between the trace levels of the sample and the cyclodextrin. It is thought that the analyte is retained via a combination of hydrogen bonding and dipole-dipole interactions at the mouth of the cyclodextrin (30). Steric interactions also can contribute to chiral recognition. The polar organic mode of enantiomeric separations seems to prefer more polar molecules. Structural features that are necessary for chiral recognition and enantiomeric separation include a minimum of two separate hydrogen-bonding groups (one of which should be on or near the stereogenic center), and a bulky moiety close to the stereogenic center $(31,32)$. Cyclodextrin-based CSPs have and will continue to play an important role in the field of enantiomeric separations $(19,24-34)$.

\section{Glycopeptide Antibiotics}

Macrocyclic glycopeptide CSPs are among the newest and fastest developing chiral stationary phases. Four types of glycopeptide-based CSPs are now available commercially. They are vancomycin (Chirobiotic V), ristocetin A (Chirobiotic R), teicoplanin (Chirobiotic T), and teicoplanin aglycon (with sugar moieties removed from teicoplanin, Chirobiotic 
TAG). Their structures and physicochemical characteristics are shown in Figure 4 and Table 2 , respectively (35).

(a)

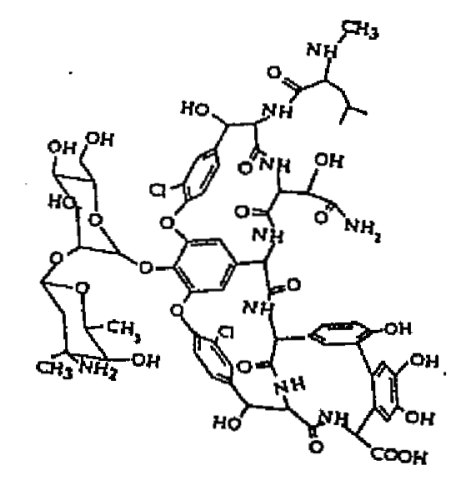

(c)

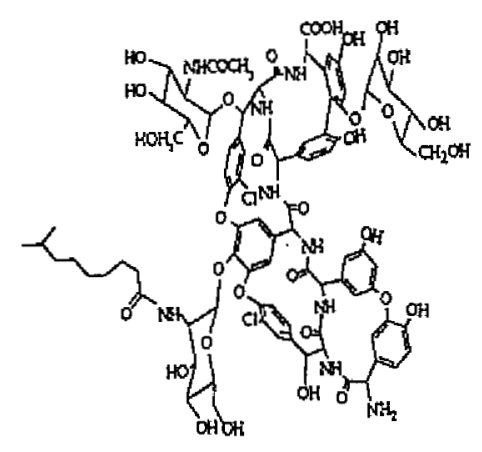

(b)

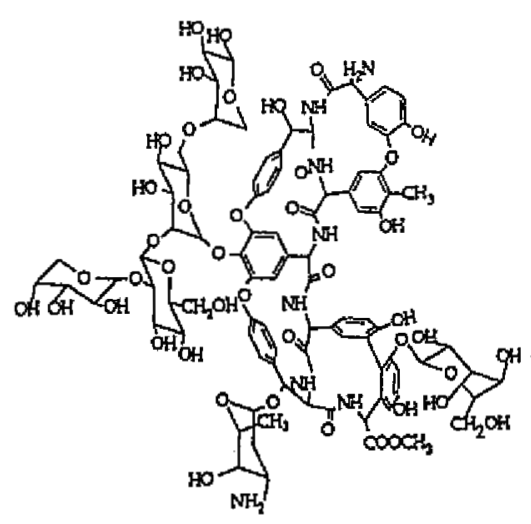

(d)

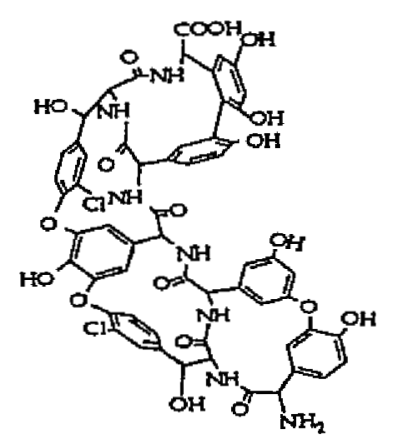

Figure 4. Structures of the macrocyclic glycopeptides. (a) Vancomycin (b) Ristocetin A (c) Teicoplanin (d) Teicoplanin aglycon (From Ref. 44.)

All the related glycopeptide antibiotic compounds consist of an aglycon "basket" and pendent carbohydrate moieties (except for the teicoplanin aglycon). The aglycon portion of these related compounds is made up of 3 or 4 macrocyclic rings, which contain ether, amide and peptide linkages. In addition, one or more carbohydrate moieties are attached at various locations to each of the aglycons. Vancomycin only has a single attached disaccharide 
consisting of D-glucose and vancosamine, while teicoplanin has three attached monosaccharides, one of which has an associated nine-carbon hydrophobic "tail". Ristocetin A has a pendant tetrasaccharide and two monosaccharide moieties. Generally speaking, the aglycon basket is semi-rigid and can flex somewhat, but the carbohydrate moieties are relatively mobile and free to change orientation. In addition, the aglycon portion has an amine moiety, a carboxylic acid moiety (esterified in ristocetin A) and phenolic moieties. These ionizable groups, along with the attached amino-saccharides, control the charge of

Table 2. Comparison of the Physicochemical Properties of Vancomycin, Ristocetin A, Teicoplanin and Teicoplanin aglycon Macrocyclic Antibiotics

\begin{tabular}{|c|c|c|c|c|}
\hline Characteristics & Vancomycin & Ristocetin A & Teicoplanin & $\begin{array}{l}\text { Teicoplanin } \\
\text { aglycon }\end{array}$ \\
\hline Molecular weight & 1449 & $2066^{a}$ & $1877^{b}$ & 1197 \\
\hline no. of stereogenic centers & 18 & 38 & 20 & 8 \\
\hline $\begin{array}{l}\text { Produced from fermentation } \\
\text { product of }\end{array}$ & $\begin{array}{l}\text { Streptomyces } \\
\text { orientalis }\end{array}$ & $\begin{array}{l}\text { Nocardia } \\
\text { Lurida }\end{array}$ & $\begin{array}{l}\text { Actinoplanes } \\
\text { teicomyceticus }\end{array}$ & $\begin{array}{l}\text { Synthesis } \\
\text { frotn } \\
\text { teicoplanin }\end{array}$ \\
\hline no. of macrocycles & 3 & 4 & 4 & 4 \\
\hline $\begin{array}{l}\text { no. of monomer sugar } \\
\text { moieties }\end{array}$ & 2 & 6 & 3 & 0 \\
\hline hydrophobic tail & 0 & 0 & 1 & 0 \\
\hline no. of $\mathrm{OH}$ groups ${ }^{c}$ & $9(3)$ & $21(4)$ & $14(4)$ & $7(6)$ \\
\hline no. of amine groups & 2 & 2 & 1 & 1 \\
\hline no. of carboxylic acid groups & 1 & 0 & 1 & 1 \\
\hline no. of amido groups & 7 & 6 & 8 & 6 \\
\hline no. of aromatic groups ${ }^{d}$ & $5(2)$ & $7(0)$ & $7(2)$ & $7(2)$ \\
\hline methyl esters & 0 & 1 & 0 & 0 \\
\hline $\mathrm{p} I^{\mathrm{e}}$ & 7.2 & 7.5 & $4.2,6.5$ & $\mathrm{~N} / \mathrm{A}$ \\
\hline relative stability & $1-2$ weeks & 3-4 weeks & $2-3$ weeks & $\mathrm{N} / \mathrm{A}$ \\
\hline aggregational behavior & no & no & yes & no \\
\hline
\end{tabular}

${ }^{a}$ Ristocetin A is a mixture of two structurally similar compounds differing by the number of carbons in one of its sugar moieties. The mixture used in this study is $>90 \%$ ristocetin A. ${ }^{b}$ Teicoplanin is a mixture of five closely related compounds differing by the number of carbons (i.e., (C10-C11) and substituted groups attached to the fatty acid side chain terminating off the amino sugar (see Figure 4). ${ }^{\circ}$ The number in parentheses corresponds to phenolic moieties. ${ }^{d}$ The number in parentheses corresponds to the number of chlorinated substituents attached to the aglycon baskets. ${ }^{e}$ The $\mathrm{p} I$ values were determined using dilute solutions of the respective macrocyclic antibiotics in $0.1 \mathrm{M}$ phosphate buffer. Methanol was used as the EOF marker ${ }^{f}$ This is the aggregation behavior under the buffered conditions. (Revised From Ref. 35) 
these glycopeptides and are thought to play an important role in enantioselective recognition of chiral analytes. For example, the aglycon "basket" provides hydrophobic sites, hydrogenbonding sites, dipolar sites, and $\pi$-interaction sites.

The concept of utilizing macrocyclic glycopeptides as chiral stationary phases for HPLC separations was first introduced by Armstrong, et al. in 1994 (36). Since then, the macrocyclic glycopeptide CSPs, as multi-modal CSPs, have proven to have broad enantioselectivities for most types of neutral, acidic, and basic compounds including amino acids and peptides, derivatized amino acids, alcohols, sulfoxides, etc (15,36-44). They can be used effectively not only in the reversed-phase and polar organic phase modes, but also in the normal phase mode without any irreversible change in enantioselectivity or denaturation. However, the enantioselectivity usually is different in each mode. They can be used in preparative scale separations as well.

One of the greatest advantages of the glycopeptide CSPs is that native, underivatized amino acids can be effectively separated on the teicoplanin-based CSPs (41-43). The separations can simply be done with an alcohol-water mobile phase (Figure 5c) in which ethanol is the preferred organic modifier. In addition, somewhat different selectivities can also be obtained with the ristocetin A CSP.

Besides the unique selectivity characteristics for each of these four CSPs, they have also been found to offer "complementary" separations $(37,45)$. That means if a partial separation is obtained on one CSP, in most cases, a baseline separation can be obtained on one of the other 
related glycopeptide CSPs without dramatically changing the separation conditions. The reason for this is thought to be due to the subtle differences in diastereomeric binding sites between the four phases.

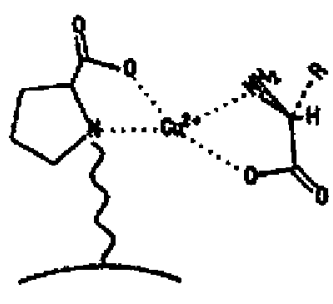

(a)

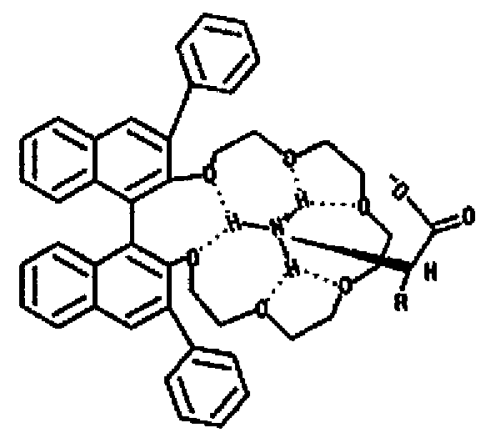

(b)

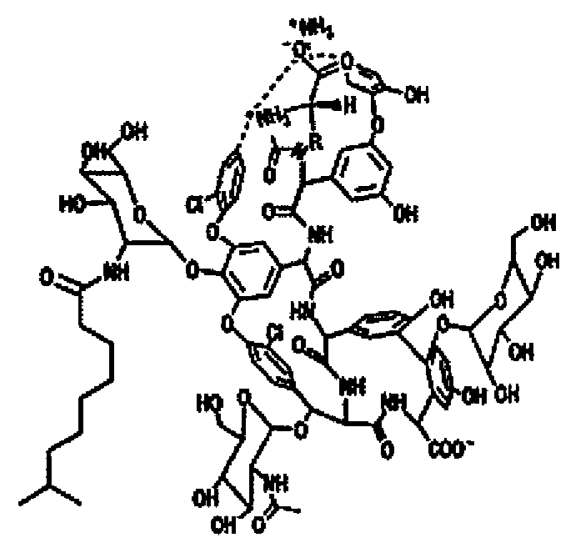

(c)

Figure 5. Structural diagrams showing the chiral selector and interaction for the (a) ligand-exchange, (b) Chiral crown ether, and (c) teicoplanin chiral stationary phases. (From Ref. 18)

\section{Chiral Crown Ethers}

Cram and co-workers first introduced chiral crown ether CSPs $(46,47)$. They attached the synthetic chiral crown ether to the polymeric support and used it to separate amino acid enantiomers chromatographically. This method works only for primary amines and amino acids, and the separations must be performed with an acidic mobile phase. This is because the primary amine functional group must be in the ammonium ion form, which is necessary for inclusion complex formation with the chiral crown ether (Figure 5b). Ions such as potassium that are comparable in size to the ammonium ion should be excluded from the mobile phase because these species compete with ammonium ion for inclusion in the crown ether. However, in certain cases, some inorganic modifiers, such as ammonium acetate, 
potassium chloride, etc, were deliberately added to the aqueous mobile phase in order to reduce the retention in resolving some primary amino compounds $(48,49)$.

In general, perchloric acid has been widely and successfully used as an acidic modifier in the resolution of primary amino compounds (50-52). However, the addition of perchloric acid to the mobile phase can cause problems especially when performing preparative separations because evaporating the solvent can leave an explosive mixture of perchlorate and organic chemicals.

So far, several chiral crown ether CSPs have been developed. They can be chiral crown ethers incorporating a chiral binaphthyl unit $(46-48,50)$, or chiral crown ethers based on tartaric acid units $(53,54)$. The performances of all these CSPs were found to be quite dependent on the composition of mobile phases. The structural characteristics of selected crown ether-based CSPs, analyte characteristics, and several separation factors were recently reviewed by Hyun (55). Among the various factors, the column temperature and the inorganic modifier in the mobile phase equally influence the chiral separations for the selected crown ether-based CSPs. In contrast, the organic and acidic modifier used in the aqueous mobile phase caused different behaviors in the enantioseparations.

Although a primary amino group had been believed to be the essential functionality of analytes resolvable on crown ether-based CSPs, recently, Steffeck, et al. first reported the enantiomeric separation of racemic secondary amines including $\beta$-blockers on $(+)$ - or $(-)-(18-$ crown-6)-2,3,11,12-tetracarboxylic acid CSP (56). It is thought that the separation 
mechanism is based on the secondary amine forming a complex that includes crown ether coordination and electrostatic interaction of the positively charged amine with a carboxylate anion of immobilized crown ether (56). These findings are expected to further expand the use of crown ether-based CSPs in the future.

\section{POLYMERIC STATIONARY PHASES}

Polymeric chiral stationary phases can be classified as natural polymers, synthetic polymers, and the widely used semi-synthetic polymers. Proteins can be thought as naturally occurring chiral polymers, and they were among the important CSPs in the mid to late 1980s and early 1990s. Although academically interesting, synthetic polymer CSPs have not played a significant practical role in HPLC enantioseparations. However, they demonstrated the feasibility of coated-type CSPs. This approach was widely used for other derivatized polysaccharides (semi-synthetic polymers), which later became one of the most important and effective polymeric CSPs.

\section{Carbohydrates}

Cellulose and amylose are among the most common naturally occurring chiral polymers. They are very poor chiral selectors in their native state. However, they become highly effective chiral selectors when their hydroxyl functional groups are derivatized, particularly with aromatic moieties through ester or carbamate linkages. The first derivatized polysaccharide CSP was microcrystalline triacetylcellulose (MCTA), which was made by Hesse and Hagel in 1973 (57). Several groups reported the enantiomeric separation of many aromatic and aliphatic racemates based on this type of CSP $(58,59)$. Despite its reasonable 
applicability and the high loading ability of this material, it had limited mechanical and physical properties as a HPLC stationary phase. In 1984, Okamoto and co-workers $(60,61)$ and Ichida, et al. (62) improved these CSPs by adsorbing polysaccharide derivatives onto macroporous $\gamma$-aminopropyl silanized silica. This resulted in stable and highly efficient CSPs with broad applicability, especially in the normal phase mode of separation. Now CSPs based on the derivatized polysaccharides are widely used in enantiomeric separations. Table 3 shows the structures of the derivatized polysaccharide polymers that are available as commercial CSPs. Nowadays, the most widely applicable CSPs are the 3,5-dimethylphenyl derivatives (Chiralcel OD and Chiralpak AD, Daicel). They seem to be capable of resolving almost as many compounds as all of the other carbohydrate-based CSPs combined (18).

The polysaccharide derivatized CSPs are most often used in the normal phase mode. However, some versions of these columns have been conditioned for the reversed-phase mode as well (63) (e.g. the Chiralcel OD-R and Chiralcel OJ-R). Although they basically consist of the same packing materials, it should be noted that one should not use the same column in both normal phase and reversed-phase modes as they were conditioned differently. The mobile phase can alter the configuration of chiral polymers, often irreversibly. Hence, a column should be dedicated to either the normal phase mode or the reversed-phased mode. Nowadays, polysaccharide-based CSPs have become some of the most popular CSPs, and they can be used to separate a wide range of racemates including aliphatic and aromatic compounds as well as many drugs from analytical to preparative scale (64). 
Table 3. Coated chiral stationary phases consisting of derivatives of cellulose and amylose

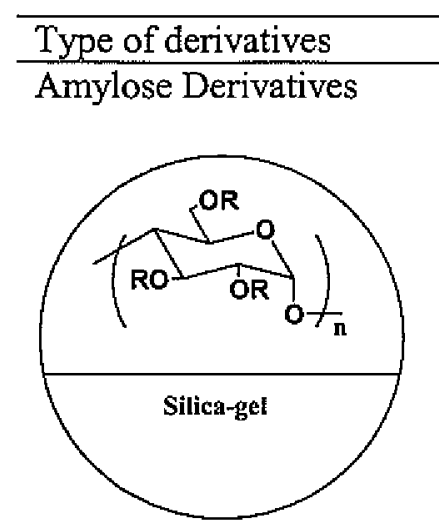

Celfulose Derivatives

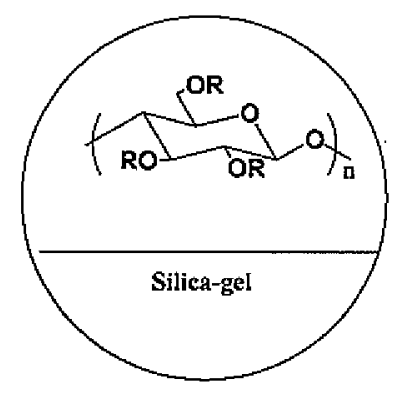

Derivative<smiles>CC(=O)Nc1cc(C)cc(C)c1</smiles>

tris(3,5-dimethylphenyl carbamate)<smiles>CC(=O)NC(C)c1cc(C)cc(C)c1</smiles>

AS

Tris(S)- $\alpha$-methylbenzyl carbamate<smiles>CC(C)=O</smiles>

Cellulose triacetate<smiles>CC(=O)c1ccccc1</smiles>

Cellulose tribenzoate

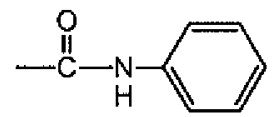

OC

Tris (phenyl carbamate)<smiles>CC(=O)Nc1cc(C)cc(C)c1</smiles>

OD

Tris (3,5-dimethylphenyl carbamate)<smiles>CC(=O)Nc1ccc(Cl)cc1</smiles>

OF

Tris (4-chlorophenyl carbamate)<smiles>CC(=O)Nc1ccc(C)cc1</smiles>

OG

Tris (4-methylphenylcarbamate)<smiles>CC(=O)c1ccc(C)cc1</smiles>

OJ

Tris (4-methylbenzoate)

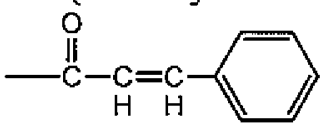

OK 
The main drawback of these CSPs is related to the solubility of the chiral selectors in a number of solvents, which limits their applicability and compromises their stability. Because most of the commercially available polysaccharide derivatives were coated onto silanized wide-pore silica gel, they are only compatible with a limited choice of solvents. In order to increase the column durability, chemically bonded-type polysaccharide-based stationary phases can be prepared $(14,65)$. Derivatized polysaccharides can be bonded to silica gel using 4,4-diphenylmethylene as a spacer to improve durability (66), through radical polymerization of allyl groups of silica gels and a polysaccharide derivative bearing vinyl groups (67), or using a cross-linking technique (68). The bonded-type polysaccharides CPSs show greater durability in a wide variety of organic solvents including tetrahydrofuran (THF) and chloroform. However, these bonded CSPs show slightly lower chiral recognition than the coated-type CSPs because much of the bonding process may occur through some functional groups of the polysaccharides, which will cause structural alteration of the polysaccharides.

\section{Proteins}

Proteins are naturally occurring chiral polymers, but not all the proteins have the ability to separate a wide range of enantiomeric molecules or make effective CSPs. Protein-based CSPs developed thus far include bovine serum albumin (BSA) (22), human serum albumin (HSA) (69), $\alpha_{1}$-acid glycoprotein (AGP) (23), ovomucoid from chicken egg whites (OMCHI) (70), and avidin (AVI) (71), cellobiohydrolase I (CBH I) (72), pepsin (73), ovotransferrin (74) and $\beta$-lactoglobulin (75). Most of these CSPs are commercially available (Table 4). Different versions of BSA and HSA CSPs have also been commercially available with differences in the type of silica used and the amount of protein crosslinking. Therefore, 
these CSPs differ in the enantioselectivity as well as in stability. The AGP CSP can successfully separate secondary amines, cyclic amines, some acids and neutral molecules (23). Bovine serum albumin (BSA) has also been proven to be able to separate certain acidic compounds including some aromatic amino acids and amino acid derivatives (22). In addition, the enzyme cellobiohydrolase prefers amine-containing compounds such as $\beta$ blocking agents (76). It was found that electrostatic, hydrophobic, and hydrogen-bonding interactions were responsible for chiral recognition on protein-based CSPs.

Table 4. Representative Proteins used as HPLC Chiral Stationary Phases

\begin{tabular}{llll}
\hline Proteins & $\begin{array}{l}\text { Molecular } \\
\text { Weight }\end{array}$ & $\begin{array}{l}\text { Isoelectric } \\
\text { point }\end{array}$ & Trade Name \\
\hline Albumins & 66,000 & 4.7 & $\begin{array}{l}\text { CHIRAL BSA; RESOLVOSIL } \\
\text { BSA }\end{array}$ \\
& 69,000 & 4.8 & $\begin{array}{l}\text { BSA-7, BSA-7PX; USTRON ES- } \\
\text { CHIRAL HSA; CHIRAL -HSA }\end{array}$ \\
HSA & & & \\
Glucoproteins & 41,000 & 2.7 & CHIRAL-AGP \\
$\begin{array}{l}\alpha_{1} \text {-Acid glycoprotein (AGP) } \\
\text { Ovomucoid (OMCHI) }\end{array}$ & 55,000 & 4.1 & ULTRON ES-OVM \\
$\begin{array}{l}\text { Ovoglycoprotein (OGCHI) } \\
\text { Avidin (AVI) }\end{array}$ & 29,700 & 4.1 & N/A \\
& 66,000 & 1.0 & Bioptic AV-1 \\
$\begin{array}{l}\text { Enzymes } \\
\text { Cellobiohydrolase 1 (CBH I) }\end{array}$ & 64,000 & 3.9 & CHIRAL-CBH \\
Pepsin & 34,600 & $<1.0$ & ULTRON ES-PEPSIN \\
Others & & & \\
Ovotansferrin & & & N/A \\
\hline
\end{tabular}

The advantages of protein-based CSPs generally include the use of an aqueous mobile phase (good for biological systems), wide enantioselectivity, and direct analysis without 
derivatization. However, the application of protein-based CSPs has declined in the past few years because they can only be used in the reversed-phase mode and also they are less stable

than most other CSPs. In addition, they have the least capacity because of the large size of the chiral selector, so that they are not useful for preparative separations. They are among the most expensive CSPs as well. Recently, CSPs based on a protein fragment or protein domain have been prepared $(77,78)$. These CSPs might provide higher capacity because only the active protein mass is used, however, the results showed that these CSPs often possessed . inferior chiral recognition abilities compared to the parent proteins. Nevertheless, in the future, a protein fragment or protein domain could be prepared by over-expression with genetic technology, which makes it possible to produce the most suitable protein fragment or protein domain based-chiral selector for a specific target molecule (79).

\section{Synthetic Polymers}

Chiral stationary phases based on synthetic polymers were first developed by Okamoto and co-workers $(80,81)$. They succeeded in making synthetic helical vinylpolymer with a predominantly one-handed screw-sense by asymmetric polymerization of triphenylmethyl methacrylate with chiral catalysts. Depending on the catalysts used, they can form either a right-hand or left-hand helical coil $(82,83)$. They found when the resulting optically active poly(triphenylmethyl methacrylate) $((+)$-PtrMA) was adsorbed on the wide-pore silica gel to form a CSP, it was capable of resolving some specific racemic compounds with aromatic groups $(81,84-85)$. Since the development of the helix-sense-selective polymerization of TrMA, various TrMA-analogue CSPs have been synthesized. However, only PtrMA and poly (diphenyl-2-pyridylmethylmethacrylate (poly (D2PyMa) (85) thus far have shown 
reasonable resolving power towards racemic compounds. Therefore, most of the research still emphasizes the enhancement in the performance and durability of these CSPs (86-88). Although the CSPs made from chiral synthetic polymer have never played a significant practical role in enantiomeric separations, they demonstrated the usefulness of coated-type CSPs. This approach was used with derivatized polysaccharides, which became popular and effective CSPs.

Recently, enantioselective imprinted polymers, first introduced by Wulff (89), have become very attractive because people can create specific enantioselective binding sites with welldefined shapes and functionalities in a prearranged fashion $(90,91)$. Generally speaking, molecular imprinting is a technique of creating three-dimensional networks that have a memory of the shape as well as functional groups at specific positions of the template molecule. Therefore, the resulting molecular imprint polymers (MPs) can selectively recognize the template molecules used in the imprinting process, even in the presence of compounds with structure and functionality similar to those of the template. In addition, the elution order is often predicable because the isomer used as a template for the preparation of the MIP is always the one that is more strongly retained. Therefore, MIP based CSPs usually provide predetermined selectivity and can be custom-made. Now the chirally imprinted polymer CSPs have shown enantiomeric separations for some amino acids, amino acid derivatives, peptides and amino alcohols (91-93). But these kinds of CSPs suffer from limited lifetime, low loading capacity and binding site heterogeneity problems. With the formation of more stable template-functional polymer complexes and application of 
multifunctional cross-linking strategies, chirally imprinted polymer CSPs may become important for target molecules by creating specific binding sites.

\section{$\pi-\pi$ INTERACTION CHIRAL SELECTORS}

The earliest successful CSPs utilized $\pi-\pi$ association (94-97) and the first commercialized $\pi$ $\pi$ interaction CSP was ionically bonded (-) 3,5-dinitrobenzylphenylglycine (a $\pi$-electron acceptor type) (20). Clearly, enantiomeric separations using these CSPs require the $\pi-\pi$ association between the chiral selector and analyte of interest. Other simultaneous interactions must occur as well such as hydrogen bonding, dipole-dipole interaction, and steric repulsion. Since the addition of polar solvents lessens $\pi$ - $\pi$, hydrogen bonding, and dipolar interaction, these CSPs are generally used in the normal phase mode. The binding sites of these CSPs can be $\pi$-electron donor types ( $\pi$-basic) or $\pi$-electron acceptor types ( $\pi$ acidic). If the chiral selector is a $\pi$ electron donor, the analyte has to be a $\pi$ electron acceptor, and vice versa. But not all compounds of interest contain $\pi$-acid or $\pi$-base moieties. Therefore, an achiral derivatization step may be necessary in order to achieve the enantiomeric separation.

Various $\pi-\pi$ interaction chiral selectors (Figure 6) have been developed in recent years (98110), and most of these CSPs provide good enantioselectivity to derivatized amino acids, amino alcohols, amines, other acidic racemates, etc. Many of the $\pi-\pi$ interaction CSPs developed by a variety of research groups are still closely related to the original stationary phases developed by Pirkle and co-workers (99), based on amino acid derivatives carrying $\pi$ - 
acidic and/or $\pi$-basic sites (100-102). The $\pi$-complex CSPs that contain both $\pi$-acid and $\pi$ base moieties tend to be more widely applicable (103-105). Some other chiral selectors of this class were assembled around a 1,3,5-triazine skeleton (106, 107). Chiral stationary phases with selectors derived from tartaric (108), cholic (109) and deoxycholic acids (110) were also described. Most of the $\pi-\pi$ interaction CSPS are useful in the normal phase mode, however, a chiral stationary phase containing an alkaloid was prepared and shown to be effective in the resolution of acidic compounds in buffered aqueous solutions (111). As mentioned previously, aromatic functionalized cyclodextrins (i.e. Cyclobond RN and SN) can also be used as $\pi$-complex CSPs, and tend to be more widely used as well (28).

Most of the $\pi-\pi$ interaction CSPs are based on low-molecular-mass chiral selectors; hence, they usually have good loading ability, which make them good for preparative separations. If both enantiomers of the chiral selectors are available, one can obtain the opposite chromatographic retention order when needed. This will allow for the use of one CSP in determining the enantiomeric purity if the late eluting enantiomer exhibits poor efficiency. In addition, novel synthetic $\pi-\pi$ interaction CSPs that incorporate highly pre-organized, receptor-like chiral selectors have also been described recently (98). They have demonstrated to be powerful tools in the study of enantiorecognition processes characterized by high degrees of selectivity (98). 
(a) Whelk-O 1

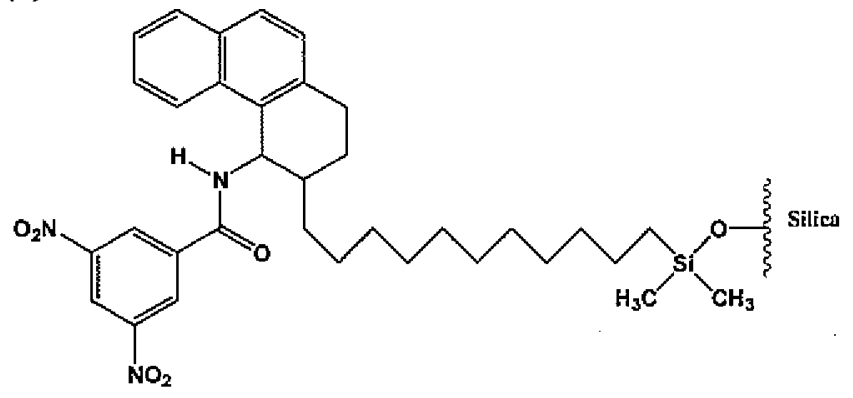

(b) Naproxen-derived CSP

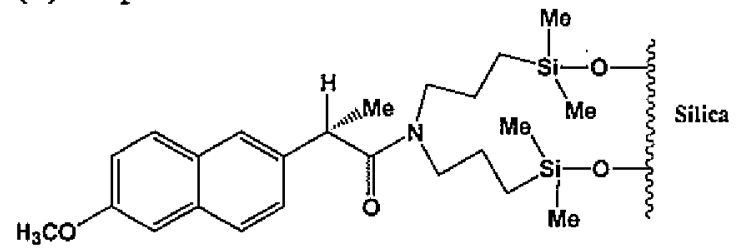

(c) Amino-acid-derived CSPs<smiles>CCCNC(=O)C(NCCC)c1ccc(OCCCC(C)(C)C)cc1</smiles><smiles>CC(C)CC(NC(=O)c1cc([N+](=O)[O-])cc([N+](=O)[O-])c1)C(=O)N(CCCC(C)(C)C)c1ccccc1</smiles>

(d) CSP with selector assembled around 1,3,5-triazine

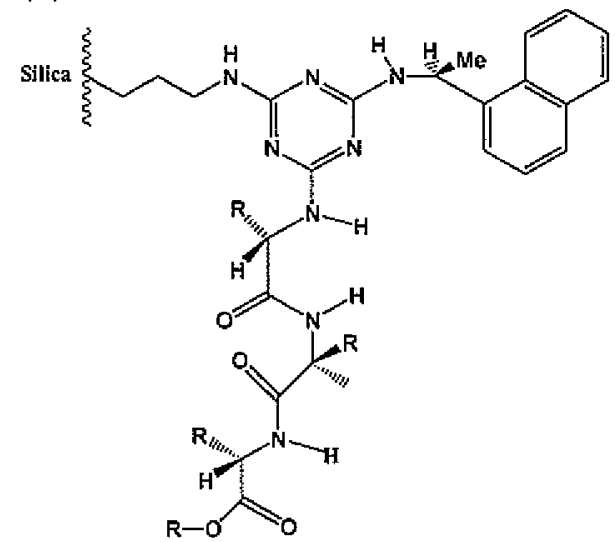

(e) Tartaric acid-derived CSP<smiles>CC(C)(C)CCCCNC(=O)[C@@H](O)[C@@H](O)C(=O)Nc1ccc(Cl)cc1</smiles>

Figure 6. Examples of $\pi$-complex chiral stationary selectors that have been immobilized on silica gel to form chiral stationary phases. 


\section{LIGAND EXCHANGE CHIRAL SELECTORS}

Chiral ligand exchange chromatography was invented by Davankov and co-workers in the early 1970s $(112,113)$. This was the first liquid chromatographic technique successfully applied for the resolution of amino acids and other solutes, which are able to form coordination compounds with metal ions. These CSPs consist of a chiral bidentate ligand such as proline or hydroxyproline attached to a solid support. A transition metal such as copper (II) must be added to the mobile phase. The copper serves as a bridge to connect the chiral selector on the stationary phase and the free amino acid analyte to form transient diastereomeric tertiary complex (Figure 5 a). The observed enantioselectivity of the chromatographic system depends on the surface coverage of the CSPs, the kind of anchor molecule used to attach the chiral ligand to the support surface, and the concentration of metal ion and other modifiers in the mobile phase $(114,115)$. In addition, the chiral selectors can also be used as chiral mobile phase additives $(116,117)$, the diastereomeric complexes are formed in the bulk of the mobile phase and then they are adsorbed on the achiral stationary phase. Several papers reviewed the history of the discovery and some benchmark achievements of enantioselective ligand exchange chromatography $(118,119)$. The most popular chiral selectors are $\alpha$-amino acids and their N-substituted derivatives. Recently, six $\mathrm{N}$-substituted (S)-phenylglycinol chiral selectors (120) and N- (1-carboxyalkyl) chitosan CSPs were also reported (121).

Ligand exchange chromatographic methods have some limitations. For example, it only works for analytes that can act as bidentate ligands, including amino acids, $\alpha$ hydroxycarboxylic acids, some diamines, etc. Additionally, because copper (II) or other 
transition metal ions need to be added to the mobile phase, there is some background signal if using UV detection. Also, those transition metal ions should be removed when doing preparative separations.

\section{MISCELLANEOUS/HYBRID CHIRAL SELECTORS}

The classification about the chiral selectors is not absolute. In some cases, a chiral selector can contain the characteristics of more than one class. For example, the $(R)$ or $(S)$ naphthethylcarbamate derivative of $\beta$-cyclodextrin (Cyclobond $\mathrm{RN}$ or $\mathrm{SN}$ ) is clearly a macrocyclic chiral selector and can form inclusion complex in the reversed-phase mode, but it acts as a $\pi-\pi$ interaction CSP in the normal phase mode (28). In addition, a side chainmodified analog of Whelk-O-1, the polyWhelk-O, was obtained by the incorporation of the same selector into a polysiloxane backbone. This CSP has a fairly similar application spectrum but exhibits higher selectivity with less retention and efficiency than its brush-type analog $(122,123)$. Although polyWhelk-O CSP is still a $\pi-\pi$ interaction CSP, it is also a synthetic polymer.

Recently described stationary phases having tert-butylcarbamoylated quinine (an anionexchanged stationary phase based on derivatized $\pi$-acidic, or $\pi$ basic moieties) linked to mercaptopropylsilica were able to separate the enantiomers of N-3, 5-dinitrobenzoylated leucine and phenylalanine with $\alpha$-values of 15.87 and 10.78 , respectively, in buffered aqueous solution (124). 


\section{Supercritical Fluid Chromatography}

Supercritical fluid chromatography (SFC) is now a well-established enantiomeric separation technique both analytically and preparatively for a wide range of compounds. Chiral separations in SFC are generally divided into open tubular and packed column approaches. Open tubular columns, designed for SFC, have the internal diameters in the range of $50-100$ $\mu \mathrm{m}$. Cyclodextrin derivatives and $\pi$-complex types of columns are among the most widely used CSPs for open tubular SFC (125-127). Flame ionization detection (FID) has often been used in conjunction with open tubular SFC for chiral separations (128). Because most of the organic modifiers are not compatible with FID detection, the mobile phase for open tubular SFC is usually pure carbon dioxide. The eluent strength is often changed by modifying the density of the supercritical carbon dioxide through changing the temperature and pressure. However, these changes cannot satisfy the solvent strength necessary to elute most polar compounds, which limits the application of open tubular SFC. In addition, the low sample capacity and lack of commercially available CSPs resulted in open tubular SFC never becoming a mainstream method.

Chiral separations by packed column SFC was first proposed for the separation of chiral phosphorous-containing derivatives by Mourier et al. in 1985 (129). Since then, packed column SFC has become a promising chiral separation technique that is increasingly used in industrial applications $(8,9,130-133)$. Because the applicability and selectivity of SFC are very similar to those of normal phase HPLC, nowadays, SFC is more frequently being used as a replacement for normal phase HPLC separations $(134,135)$. Among all the HPLC chiral 
selectors, suitable chiral stationary phases for SFC separations include bonded cyclodextrins, bonded antibiotics, derivatized cellulose and amylose, helical polymers and $\pi$-complex-type stationary phases (Table 1). Other HPLC stationary phases based on proteins, ligand exchange and chiral crown ethers are either unstable or ineffective under SFC conditions. The following section will focus on the chiral selectors that work well in packed column SFC separations. Comparisons with normal phase HPLC also will be discussed.

\section{MACROCYCLIC CHIRAL SELECTORS}

\section{Cyclodextrins and their Derivatives}

Most cyclodextrin columns have not been extensively used in SFC because these CSPs are generally used in the reversed phase mode or polar organic mode in HPLC. Only a few early papers reported the enantiomeric separations based on the native or derivatized cyclodextrins $(136,137)$. Nowadays, the most widely used cyclodextrin-based CSPs in SFC are the aromatic functionalized cyclodextrins (i.e. Cyclobond $\mathrm{RN}$ and $\mathrm{SN}$ ) because these cyclodextrins can be used as $\pi$-complex CSPs $(138,139)$. Interestingly, Williams, et al. demonstrated that compounds previously resolved not only on the normal-phase, but also on reversed-phase or polar organic modes on the Cyclobond RN or SN CSPS in HPLC can also be resolved in SFC using a simple carbon dioxide-alcohol eluent (139). Furthermore, the SFC separations tended to provide rapid optimization of selectivity and improved resolution compared to HPLC separations. 


\section{Glycopeptide/Antibiotic CSPs}

The macrocyclic glycopeptide chiral stationary phases have been widely used with SFC mobile phases. A vancomycin based CSP was able to separate the enantiomers of $\beta$ adrenergic blocking agents and other pharmaceuticals (140). Cyclic ketones and dioxalene derivatives were separated by chiral SFC using teicoplanin and vancomycin-based CSPs (141). The ristocetin A CSP was tested with SFC mobile phases and found to resolve enantiomers of acidic drugs (142). Forty-four racemates were evaluated for separations on teicoplanin and vancomycin CSPs with SFC mobile phases (143). Recently, we reported an in-depth evaluation of the capabilities of macrocyclic glycopeptide-based CSPs with SFC mobile phases (144). The 111 compounds separated included heterocycles, analgesics (nonsteroidal anti-inflammatory compounds), $\beta$-blockers, chiral sulfoxides, $\mathrm{N}$-protected amino acids, and native amino acids (144). In addition, twenty-four chiral dihydrofurocoumarin derivatives and structurally related compounds were also separated on macrocyclic glycopeptide CSPs (145). Generally speaking, the teicoplanin aglycon and teicoplanin CSPs seem to have better enantioselectivity than ristocetin A and vancomycin CSPs. It is also worthwhile to point out that most of the separations were done in less than 15 minutes and over $70 \%$ of separations were achieved in less than 4 minutes (with a flow rate at $\left.4.0 \mathrm{ml} \mathrm{min}^{-1}\right)(145)$.

\section{POLYSACCHARIDE CHIRAL SELECTORS}

Various derivatives of cellulose and amylose adsorbed on silica gel have proven to have wide applicability in normal phase HPLC separations, as well as in SFC separations. The derivatized cellulose and amylose stationary phases are stable under SFC conditions even 
though the selector is coated and not bonded to the silica support. Antifungal drugs were separated based on derivatized polysaccharides with different substituent groups such as 3,5 dimethylphenylcarbamate and (R)-phenylethylcarbamate (146). Bernal, et al. further evaluated the enantiomeric separations of several compounds including an antifugal drug and several of its precursors on Chiralpak $\mathrm{AD}$ and Chiralcel OD CSPs using both HPLC and SFC (147). The results showed that the separations obtained by SFC were better, in terms of higher resolution and shorter analysis times, than those obtained by HPLC. Separations of $\beta$ blockers on Chiralcel OD have been reported by several groups $(148,149)$. Other compounds separated on derivatized polysaccharide CSPs by packed column SFC include enantiomers of diltiazem hydrochloride (150), phenylpropanols and related compounds (151). Medvedovici, et al. evaluated polysaccharide CSPs along with other commercially available CSPs for the enantiomeric separation of a wide variety of compounds using the modifier (methanol containing $0.1 \%$ trifluoroacetic acid and $0.1 \%$ triethylamine) varied from $5 \%$ ( 5 min) to 30 $\%$ at $5 \% \min ^{-1}$ (143). Chiralpak AD provided the best enantioselectivity with $70 \%$ of the 44 tested chiral compounds separated followed by Chiralcel OD (66\%). Recently, separations of albendazole sulfoxide enantiomers by SFC were also studied using Chiralpak $\mathrm{AD}$ and Chiralcel OD columns (152).

\section{$\pi-\pi$ INTERACTION CHIRAL SELECTORS}

As mentioned previously, the first demonstration of packed column chiral SFC was done using (R)-N-(3,5-dinitrobenzoyl)-phenylglycine, a $\pi-\pi$ interaction CSP (129). Separations of chiral phosphine oxides were obtained using alcohols or alcohol-water mixtures as modifiers. 
Since then, enantiomeric separations on $\pi$-complex types of CSPs using SFC have been widely reported $(143,153-157)$. The chiral selector (S)-indoline-2-carboxylic acid combined with (R)-1-( $\alpha$-naphthyl) ethylamine via a urea linkage (Chirex 3022) was developed and used to separate some underivatized $\beta$-blockers and $\beta$-agonists (153). The newest $\pi$-complex CSPs containing both $\pi$-acid and $\pi$-base moieties tended to be more widely applicable $(154,155)$. A variety of enantiomers with different functional groups were resolved on Whelk $\mathrm{O}-1$ column (154). Pirkle, et al. further modified the Whelk-O-1 and analogous chiral selectors by incorporating them into polysiloxanes, which was then immobilized on silica $(122,155)$. The resulting CSPs are stable to normal and reversed-phase conditions and throughout a wide range of temperatures, mobile phases and additives. These CSPs often afforded greater enantioselectivity, better band shapes and reduced capacity factors in SFC. In addition, these CSPs separated a variety of chiral compounds, such as underivatized amines, alcohols, carboxylic acids, and heterocyclic atropoisomers, etc. High-speed separations of $\beta$-blockers were also successfully obtained (analysis times less than $2 \mathrm{~min}$ ) using a short column packed with ChyRoSine-A CSP (tyrosine-derived CSPs) by Bargmann, et al. (156). Recently, Schurig, et al. described the use of complexation SFC for enantiomeric separations of Lewis bases on chiral nickel (II)- and zinc (II)-bis[(3-heptafluorobutanoyl)-10-methylene-(1R)camphorate] chemically bonded to poly(dimethylsiloxane) (Chirasil-nickel and Chirasil-zinc) and employed as Lewis acid selectors (157). This method is especially well suited for less volatile and configurationally labile racemates. 


\section{OTHER CHIRAL SELECTORS}

Other chiral polymers also can be used as chiral selectors for SFC separations. Kromasil CHI-TBB, an acylated N, N'-diallyl-1-tartardiamide network polymers covalently bound to functionalized Kromasil silica, produced the best separation properties for ibuprofen among eleven different CSPs tested (158). It may be the most suitable CSP for scaling to preparative

(I)

(a) HPLC

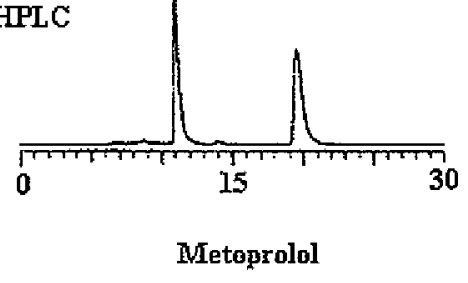

(b) SFC

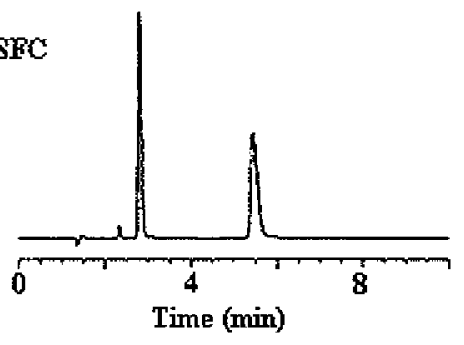

(II)
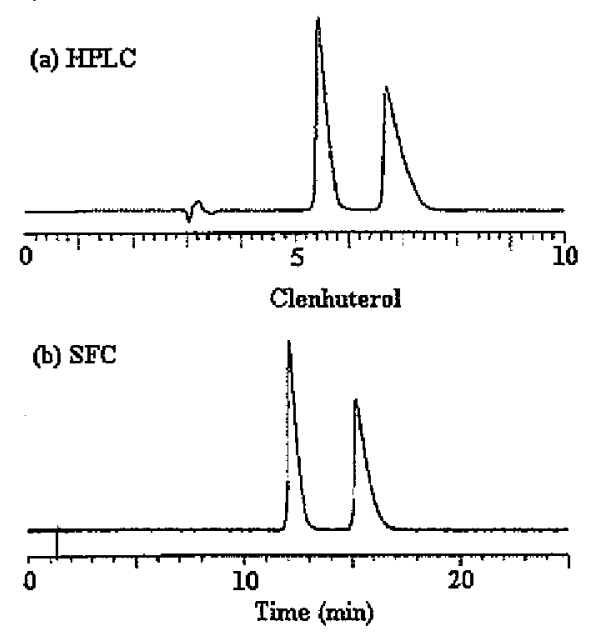

Figure 7. Comparison of LC and SFC enantiomeric separations.

(I). Enantioseparations of metoprolol on the Chiralcel OD CSP. Chromatographic conditions: (a) hexane-2-propanol-diethylamine (80:20:0.1, v/v/v), $0.5 \mathrm{ml} \mathrm{min}^{-1}$, UV detection at $280 \mathrm{~nm}$; (b) carbon dioxide-methanol-isopropylamine $(80: 20, \mathrm{v} / \mathrm{v}), 2.0 \mathrm{ml} \mathrm{min}^{-1}, 30^{\circ} \mathrm{C}, 15 \mathrm{MPa}$, UV detection at $280 \mathrm{~nm}$. (II) Enantiomeric separations of clenbuterol on the Chirex 3022 CSP. Chromatographic conditions:

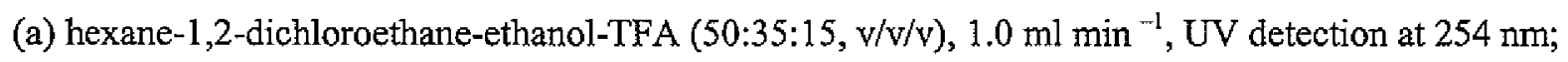
(b) carbon dioxide-methanol $(85: 15, \mathrm{v} / \mathrm{v}), 2.0 \mathrm{ml} \mathrm{min}^{-1}, 30^{\circ} \mathrm{C}, 15 \mathrm{MPa}$, UV detection at $254 \mathrm{~nm}$ (From Ref, 153.)

separations of ibuprofen. Wu investigated the enantiomeric separation of pharmaceutical compounds using supercritical and subcritical fluid ion-pairing chromatography (159). 
Several chiral counter ions such as quinine, quinidine, and (+)-10-camphorsulfonic acid were chosen as chiral selectors for the separation of amino acids and amino alcohols. The effect of counter-ion's binding functions and structural features on the stereoselectivity was discussed.

\section{COMPARISON WITH NORMAL PHASE HPLC}

One of the most important advantages of the use of SFC compared to normal phase HPLC is the speed of separation. The low viscosity of supercritical fluids produces a low-pressure drop and allows the use of high flow rates (up to $6.0 \mathrm{ml} \mathrm{min}^{-1}$ ). In addition, the optimum linear velocity is shifted to higher values in SFC than in LC, because solutes have higher diffusion coefficients in supercritical fluids than in liquids (160). Therefore, higher flow rates often can be used in SFC to reduce analysis time without excessively compromising efficiency (161). But analysis times are not always shorter in SFC than in HPLC (Figure 7). Williams, et al. compared three different types of commercially available CSPs for enantiomeric separations (153). Faster separations were usually obtained on derivatized polysaccharide-based CSPs and cyclodextrin-based CSPs with SFC mobile phases. Macrocyclic glycopeptide CSPs also normally demonstrated faster enantioseparations in SFC (144). However, for Chirex 3022, a $\pi$-donor CSP, most of the compounds examined were strongly retained on the CSP in SFC compared to HPLC (Figure 7B, 153). Similar results have also been reported for comparisons of HPLC and SFC on other $\pi-\pi$ interaction CSPs (155). The diminished eluent strength in SFC also highlights the fact that solute-mobile phase and mobile phase-stationary phase interactions are not equivalent for HPLC and SFC (162). Although SFC is often compared with normal phase HPLC, the similarities in enantioselectivity between the two techniques are not absolute, but are compound specific 
(153). In addition, studies of the Cyclobond I RN and SN CSPS demonstrated that separations achieved under reversed phase or polar organic LC modes could also be duplicated in SFC with carbon dioxide-methanol eluents (139).

Another key advantage in the use of supercritical fluid chromatography is that it is often possible to simplify the operation conditions relative to conventional HPLC. Overall, SFC provides rapid method development due to its relatively short analysis time, rapid column equilibration, and simple mobile phase composition. In addition, SFC is advantageous for preparative separations with its easy solute recovery and solvent disposal. As a result, SFC will likely continue to have significant impacts on analytical and preparative methodologies for chiral separations. Further improvements in commercial instruments will also help to solidify the position of SFC in analytical laboratories.

\section{Capillary Electrophoresis}

The inherent advantages of capillary electrophoresis (CE), including small sample size, fast analysis times, plug flow, and low solvent consumption, make it an attractive alternative to LC for enantiomeric separations. In general, capillary electrophoresis separates compounds by their mass-to-charge ratio via an applied voltage across a capillary. Anions migrate towards the anode while cations travel toward the cathode. Neutral molecules traverse the capillary with the bulk solution by means of an electroosmotic flow (EOF). This EOF is produced as a result of the build-up of positive buffer ions along the negatively charged silanol groups of the capillary wall. These cations, being more highly solvated by the aqueous solution than the buffer anions, produce a net flow of solution towards the negative 
electrode. $\mathrm{pH}$ and ionic strength of the buffer solution can affect the magnitude of the EOF. Acidic pHs can decrease the EOF by protonating these silanol groups, and can effectively suppress the EOF below $\mathrm{pH} 2.5$. High ionic strengths also diminish the EOF by reducing the double layer thickness at the capillary wall. Additives may be used in the run buffer to act as pseudo-phases to further separate analytes.

Many of the chiral selectors used in LC can be easily transferred to capillary zone electrophoresis (CZE) as run buffer additives, enabling a wide variety of analytes to be separated. However, unlike LC, these additives are free within the buffer solution instead of statically bonded or coated to a stationary phase. While this totally dynamic system can limit run-to-run reproducibility, it also allows considerable control over the factors that determine selectivity. The most common chiral selectors used in CE include the macrocyclic chiral selectors (cyclodextrin, chiral crown ethers, and antibiotics), chiral surfactants, and acyclic carbohydrates (163).

\section{MACROCYCLIC CFIRAL SELECTORS}

\section{Cyclodextrins}

Cyclodextrins and their derivatives are clearly the dominant class of chiral selectors used in $\mathrm{CE}$ enantiomeric separations. Over 50 different derivatized $\mathrm{CD}$ are available commercially, providing a wide variety of selectors from which to choose (164). Because of this diverse selection, a majority of chiral compounds can be separated with these selectors. Compared to other chiral selectors, cyclodextrins are relatively inexpensive. In addition, cyclodextrins are UV transparent allowing absorbance detection to be easily applied. Both native and 
derivitized cyclodextrins are commonly used. Numerous reviews have been written concerning the use of cyclodextrins in CE (165-168). Before choosing a cyclodextrin for a specific separation, the charge of both the analyte and the chiral selector must be examined. Neutral cyclodextrins, such as the native forms, hydroxypropyl cyclodextrin (HP-CD), and dimethyl cyclodextrin (DM-CD), travel with the EOF. In order to achieve enantiomeric separation, the analyte must have a different mobility than the chiral selector. Therefore, neutral cyclodextrins are generally only useful for charged analytes. However, neutral analytes may be separated with neutral cyclodextrins by use of a charged secondary pseudophase, such as an ionic micelle or another charged cyclodextrin (169). This secondary pseudophase may or may not be chirally selective.

Cyclodextrins with ionizable groups, such as sulfated-CD and carboxymethyl-CD, are usually charged when in aqueous or hydroorganic solution, allowing neutral analytes to be easily separated. In addition, oppositely charged species are attracted to these cyclodextrins via electrostatic interactions, thus increasing their level of interaction with the chiral selector. This feature, however, may increase or diminish separation depending on the magnitude of the interaction. The hydrophobic cavity of CDs is particularly beneficial when separating enantiomers of aqueous-insoluble or weakly soluble analytes. The presence of the $\mathrm{CD}$ increases the analyte solubility considerably by providing a hydrophobic micro-environment (163). However, if the inclusion complex is so strong that the analyte virtually never leaves the cyclodextrin, an organic additive may be added to the run buffer in order for the anatyte to achieve equilibrium between the cyclodextrin and the bulk solution. The percentage of organic content in the buffer solution can effectively control the level of selectivity by 
shifting the equilibrium constant. Methanol and acetonitrile are common organic modifiers that are used for this purpose.

Overall, cyclodextrins are a highly versatile class of chiral selectors. Numerous racemates have been separated with cyclodextrins including organic acids (170), amino acids (171-173), various pharmaceuticals and drugs (174), and highly hydrophobic compounds (175).

Several other factors can alter the selectivity of separations involving cyclodextrins. These conditions include cyclodextrin concentration, the degree of substitution of derivitized cyclodextrins, buffer $\mathrm{pH}$ and ionic strength. In $\mathrm{CE}$, selectivity is highly dependent on the concentration of chiral selector in the run buffer. Generally, increasing the $\mathrm{CD}$ concentration leads to an increase in resolution by effectively forcing more frequent analyte complexation with the cyclodextrin. However because separation requires a difference in interaction between the two enantiomeric analyte moieties, an excessive level of additive will reduce the selectivity since both enantiomers will be nearly always complexed. The advantage of this phenomenon is that great control over selectivity can be achieved by merely modifying the additive concentration. Moderately selective cyclodextrins can produce satisfactory resolutions by using a significantly higher concentration. Increased viscosity of the buffer solution can also be experienced with $\mathrm{CD}$ concentrations above $10 \mathrm{mg} / \mathrm{mL}$, resulting in longer migration times and lower separation currents for neutral CDs.

The solubility of the cyclodextrin in water must be taken into account, due to the aqueous nature of CE. The selectivity of many CDs is limited by their solubility in the run buffer. 
Derivitized cyclodextrins tend to have an increased solubility as compared to their native forms, with the exception of those with highly hydrophobic substituents. For example, native $\beta$-CD has a solubility of $\sim 20 \mathrm{mg} / \mathrm{mL}$ while DM- $\beta$-CD is soluble up to $\sim 330 \mathrm{mg} / \mathrm{mL}$ (163). High concentrations of Urea may be added to increase the solubility of CD in the run buffer. Concentrations up to $7 \mathrm{M}$ have been utilized in many cases (176-178). The exact mechanism of this effect is not totally understood.

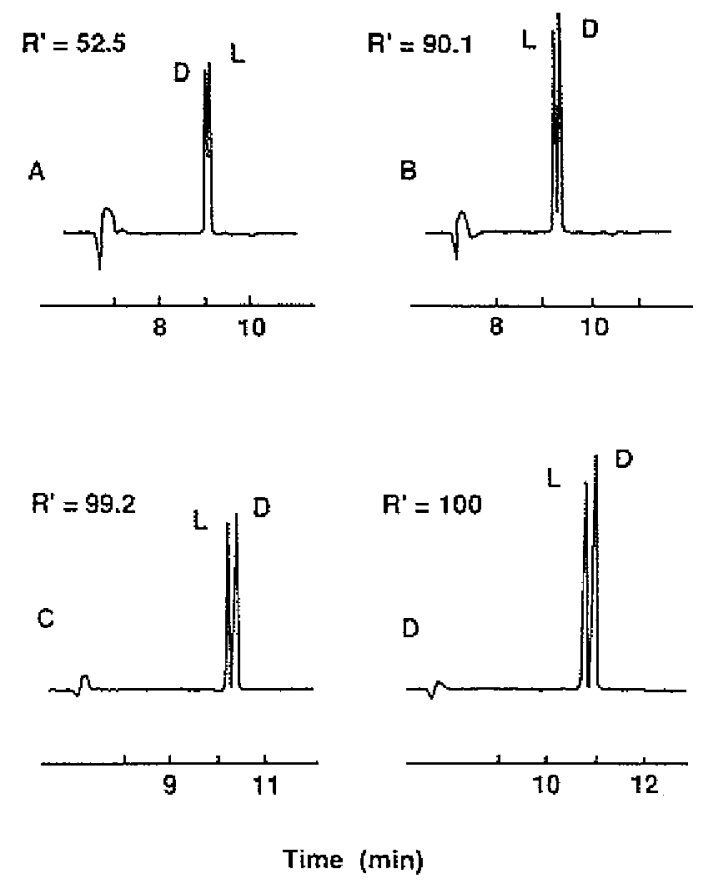

Figure 8. The effect of degree of substitution of methylated- $\beta$-CD on the separation of dansyl-DLleucine. All separations performed with $0.1 \mathrm{M}$ borate- $0.05 \mathrm{M}$ sodium phosphate buffer at $\mathrm{pH} 9.0$, and $10 \mathrm{mM}$ (A) $\beta-\mathrm{CD}$, (B) 3-MM- $\beta-\mathrm{CD}$, (C) 2,3-DM- $\beta-\mathrm{CD}$, and (D) 2,3,6-TM- $\beta$-CD. $72 \mathrm{~cm}$ capillary $(50 \mathrm{~cm}$ effective length) was used with $50 \mu \mathrm{m} \mathrm{I.D.} \mathrm{Voltage} \mathrm{run} \mathrm{at} 20 \mathrm{kV}$. (From Ref. 172.)

The degree of substitution (DS) and position of the functional groups on derivatized $\mathrm{CD}$ can greatly affect their selectivity as well. The 2- and 3-hydroxyl groups on the outer rim as well as the 6-hydroxyl on the smaller opening are available for derivitization on free $\mathrm{CD}$, allowing 
up to three substituents per glucose unit. Due to the significant contribution of these substituents on chiral selectivity, the difference in capabilities between a mono- and trisubstituted $C D$ can be dramatic. Figure 8 shows the effect of the DS and position of substitutents in methyl- $\beta-C D$ on the separation of dansyl-DL-leucine (172). Most commercially available derivitized CDs contain a mixture of compounds of varying degree and position of substitution (179). For example, a sample of DM- $\beta$-CD may have an average DS of 1.8, with a varying blend of 2,3- and 2,6-substitution. Trace impurities of 2,3,6trimethyl- $\beta$-CD and monomethylated form may also be present. As a result, different batches of supposedly identical CD may produce significantly different results (Figure 8). In fact, in some cases the mixture of CD isomers may produce better results than the pure form. Reproducibility, therefore, relies on the ability to use a single CD batch for every separation, possibly requiring large quantities to be ordered at one time.

In addition to affecting the magnitude of the EOF, changes in $\mathrm{pH}$ and ionic strength of the run buffer may affect the enantiomeric separation as well. In cases involving analytes and cyclodextrins with ionizable substituents, the $\mathrm{pH}$ of the bulk solution can dictate the charge of these species. These charges directly correlate with the difference in electrophoretic mobility between the analyte and the chiral selector, therefore affecting the resolution of the separation (180). For separations involving electrostatic attraction between the analyte and cyclodextrin, the level of ionic strength of the run buffer can modify the intensity of these interactions. High ionic strength solutions can solvate ionic species and mask them from other oppositely charged molecules, effectively reducing interaction between the analyte and the chiral selector. 


\section{Chiral Crown Ethers}

Utilizing crown ethers as chiral selectors in CE was first accomplished by Kuhn et al. with the separation of simple aromatic amino acids enantiomers (181). Currently, 18-crown-6 tetracarboxylic acid $\left(18 \mathrm{C} 6 \mathrm{H}_{4}\right)$ is the only chiral crown ether that has been used effectively in CE (182). Due to its ability to complex cations within its polyether cavity via electron donating oxygen atoms, crown ethers are particularly useful for the separation of racemates with a primary amine group near its chiral center. Amino acids and their analogues are separated most frequently with this class of additive, as well as peptides and other amines (183-185). The theory behind this mechanism in CE is currently being studied.

The concentration of crown ether in the bulk solution directly correlates with the enantiomeric resolution, in a manner analogous to what occurs with cyclodextrins. However, migration times are generally not increased as greatly as when cyclodextrins are used (186). This phenomenon may be due to the weaker, yet selective, analyte-crown ether complexation.

The four carboxylic acid groups on 18-crown-6 tetracarboxylic acid have $\mathrm{pK}_{\mathrm{a}} \mathrm{s}$ of $\sim 2.1,2.8$, 4.3, and 4.9 (187). Therefore, small $\mathrm{pH}$ changes in the acidic range can significantly modify the mobility of the crown ether. The magnitude of the negative charge on the crown ether increases with increasing $\mathrm{pH}$. This factor must be controlled carefully, especially when separating negatively charged analytes to ensure that the chiral selector and analyte have sufficiently different mobilities. 
In addition to $\mathrm{pH}$, the composition of the buffer solutions must be examined. Crown ethers are known to complex with many alkali and alkali earth metal ions, particularly $\mathrm{K}^{+}$, as well as ammonium ions. Therefore it is necessary to avoid the use of these ions in the run buffer as they may compete with the analyte for crown ether inclusion. In fact, the stabilities of these ion complexes are almost ten times higher than that of primary amines (188). Other buffer additives, such as Tris or secondary and tertiary amines, are suitable for use in the bulk solution due to their lower inclusion stability. Various studies have been performed concerning the effect of buffer composition on chiral separations (189).

A combination of cyclodextrin and crown ether has been shown in some cases to produce more efficient separations than with either additive alone. A dual complexation mechanism between both chiral selectors and the analyte $\left(\mathrm{CD}\right.$-analyte- $\left.18 \mathrm{C}^{-\mathrm{H}_{4}}\right)$ is a likely cause for these results (190). This effect is magnified as the concentration of both selectors is increased beyond $10 \mathrm{mM}$ (191).

\section{Macrocyclic Glycopeptides (Antibiotics)}

First demonstrated by Armstrong et al. in chiral separations with TLC, HPLC, and CE, macrocyclic glycopeptide antibiotics are a highly selective and useful class of chiral selectors (36). Several recent reviews cover these macrocycles as enantiomeric selectors, and discuss their use in detail $(15,166,192,193)$. A wide range of both anionic and cationic enantiomers have been separated in CE with these additives. The glycopeptides ristocetin A, vancomycin, and teicoplanin have been particularly beneficial for the separation of anionic analytes (194-196). This effect and their affinity towards compounds containing carboxylic 
acid groups can be traced to the protonated amine groups on the antibiotic at low pHs. The ansamycin, rifamycin $\mathrm{B}$, has been applied as a negatively charged selector for the resolution of cationic compounds with up to two aromatic rings, while rifamycin SV is normally neutral and used for anionic samples of two or more aromatic rings $(197,195)$.

The large number of stereogenic centers on macrocyclic antibiotics allows for broad selectivity. High efficiency is also maintained due to fast analyte complexation kinetics. As a result, many separations utilizing antibiotics as a chiral selector surpass the resolution by cyclodextrins (198). In addition, the large molecular weight of these antibiotics limits their rate of diffusion, thus further enhancing the separation efficiency. Figure 9 shows the high selectivity and efficiency of vancomycin for the anionic derivative of pyrroquinoline quinone.

Each of these macrocyclic antibiotics is highly soluble in aqueous and polar aprotic environments, easily allowing application to CE. Teicoplanin exhibits the unique characteristic of micelle formation, due to the possession of a hydrophobic side chain attached to its 2-amino-2-deoxy- $\beta$-D-glucopyranolsyl group (CMC of $\sim 0.18 \mathrm{mM}$ ) (35). As with many other chiral selectors the $\mathrm{pH}$ of the run buffer can affect the charge and mobility of the antibiotic and analyte by modifying their ionizable groups. Generally, a pH between 4 and 7 is used to prevent hydrolysis of amide bonds and minimize conformational changes. The $\mathrm{pK}_{\mathrm{a}} \mathrm{s}$ of the antibiotic functional groups must be examined in order to determine the 


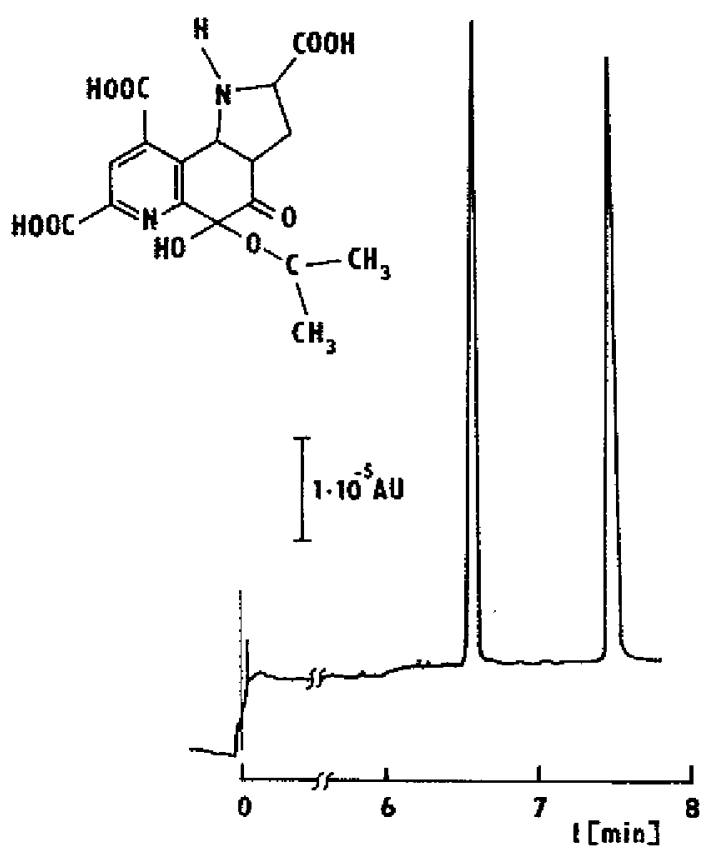

Figure 9. Enantiomeric separation of the acetone adduct of pyrroquinoline quinone. Buffer is 0.7 $\mathrm{mM}$ vancomycin in $50 \mathrm{mM}$ MOPS-Tris buffer at $\mathrm{pH} 7 .-8.5 \mathrm{kV}$ applied voltage, on $50 \mu \mathrm{m} \mathrm{I.D.,} 37.8$ cm capillary (30cm effective length). (From Ref. 198)

proper $\mathrm{pH}$ for a given separation system. The use of organic modifiers and additional pseudo-stationary phases can also enhance resolution in some cases. Micelles present in the run buffer may interact with both the analyte and the antibiotic, and result in a reversal of the enantiomer migration order by changing the mobility of the antibiotic. SDS in solution can also prevent adsorption of the antibiotic to the capillary wall, which is one difficulty of utilizing these chiral selectors in CE (199).

Untreated silica capillaries allow many of these antibiotics to adsorb, resulting in reduced efficiency and resolution, and diminished EOF. Vancomycin adsorbs most strongly of the group, while teicoplanin adsorbs least due to its aggregate formation (35). Organic additives 
and coated capillaries can also be implemented to alleviate this obstacle, as well as running at a $\mathrm{pH}$ near the $\mathrm{pI}$ of the antibiotic.

Macrocyclic antibiotics are strong absorbers in the UV region, which is commonly used for detection in $\mathrm{CE}$. However under low concentrations of antibiotic, a wavelength of $254 \mathrm{~nm}$ can be used for direct detection due to its decreased absorbance above $250 \mathrm{~nm}$. Because of the high selectivity of this class of chiral selectors, a sufficient separation can usually still be performed even at lower concentrations. Otherwise, a counter-current partial-filling method can be performed, in which the antibiotic and the analyte migrate in opposite directions (192). A plug of antibiotic can be inserted into the capillary that travels away from the detector, while the analyte travels toward the detector. Therefore, the antibiotic never reaches the detection window.

\section{CHIRAL SURFACTANTS}

Chiral surfactants are another class of additives commonly used in CE for the separation of optically active compounds. Micellar and pseudo-phase liquid chromatography was first developed by Armstrong during the late 70's and early 80's (200-204), and its principles were easily transferred to CE (205) for chiral separations. These chiral selectors are usually low molecular weight compounds that contain a hydrophilic chiral head group and a large hydrophobic tail. In aqueous solution, surfactant monomers aggregate to form micelles when above their critical micelle concentration (CMC). The polar head groups align to form a surface in contact with the water, while the hydrophobic groups form a nonpolar environment in the interior of the micelle. Generally, chiral recognition is achieved via interactions with 
the chiral head groups, while partitioning within the hydrophobic region. This mechanism is particularly useful for compounds that are weakly soluble in aqueous solution. Chiral surfactants can be divided into two categories: natural surfactants such as bile salts, and synthetic surfactants (206).

\section{Natural Surfactants}

Bile salts are the most popular chiral surfactants for $\mathrm{CE}$. These compounds consist of a four ring steroidal structure with hydroxyl groups, and a carboxylic group bonded to glycine or taurine substituent (Figure 10). The micelle is formed by the hydrophobic attraction of the bulky nonpolar ring faces, resulting in a low aggregation number of only between 4 and 10 (207). The most widely used bile salt is sodium taurodeoxycholate (STDC), due to its good aqueous solubility and high enantioselectivity of a wide range of compounds. Bile salts without taurine groups require a $\mathrm{pH}>7$ for proper solubility. Bile salts have the ability to resolve simple compounds such as amino acid derivatives (208), or more complicated polycyclic compounds (209).

Digitonin and saponins are other natural surfactants that may be used for chiral recognition, however they are much less popular due to several drawbacks. Digitonin contains no ionizable groups, and is therefore mostly insoluble in water. However, mixed micelles with a charged surfactant, such as SDS, can be formed allowing this surfactant to be used in aqueous separations with CE (210). When SDS is added to saponins though, a gel-like mixture may form (163). Therefore saponins can be very difficult to utilize in mixed micelle systems. 


\section{Synthetic Surfactants}

Synthetic surfactants are constructed with a chiral polar head group attached to a long hydrophobic alkyl chain. Head groups are often chiral amino acids $(211,212)$, sugar derivatives (213), or other acids (Figure 10). These surfactants are highly soluble in aqueous solution when compared to natural surfactants. Amino acid and glucosidic surfactants have been used for a variety of enantiomeric separations (211-213), as well as mixed micelle systems (214).

(A)<smiles>[R6]C(C)(C)OC(=O)CCC(C)C1CCC2C3C(C[C@H](O)C12C)C1(C)CC[C@H](O)CC1C[C@H]3[B]</smiles>

(B)<smiles>[10B]C(NC(=O)CCCCCCCCCCCC)C(=O)O</smiles>

(C)

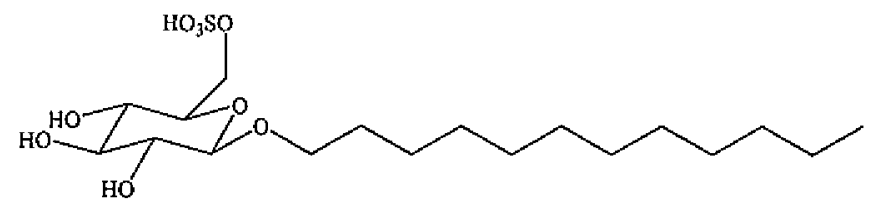

(D)<smiles>CCCCCCCCCCCCC1SCC(C(=O)O)N1C(C)=O</smiles>

Figure 10. Structures of various natural and synthetic chiral surfactants used in CE: (A) Steroid skeleton of bile salts, (B) dodecyl-amino acid ester derivatives, (C) dodecyl-glucopyranosyl derivatives, and (D) 2-undecyl-4-thiazolidine carboxylic acid. 
As with any additive with ionizable functional groups, chiral surfactants are dependent on $\mathrm{pH}$ to determine their charge and mobility in aqueous solution. Amine groups in particular are affected by this trend, while most carboxylic groups will be deprotonated unless an extremely low $\mathrm{pH}$ is implemented. The CMC of a surfactant, however, is independent of the $\mathrm{pH}$ of the surrounding solution, as it is a function of the solvation properties of the surfactant monomer by the solvent.

Organic modifiers may be used in the buffer solution to allow highly hydrophobic analytes to achieve equilibrium between the micelle and the bulk solution. But based on the type and amount of organic additive, the micellar aggregation may be disrupted by the polarity change of the environment. These changes may increase or decrease the selectivity depending on the analyte and the surfactant used.

\section{Polymeric Surfactants}

Polymeric chiral surfactants have been discovered to be highly effective for enantiomeric separations in CE as well. Work performed by Warner and co-workers in 1994, utilized surfactant polymers for the first time in CE with the chiral separation of naphthol and laudanosine derivatives (215). Polymeric chiral surfactants have several advantages over traditional non-polymerized micelles. Micelles are highly dynamic systems in which surfactant monomers are in constant equilibrium between the micelle and free solution. This phenomenon can often limit the micelle's ability to adequately discriminate enantiomers, due to the small difference in interaction between the two moieties. Polymeric micelles, being covalently bound, eliminate this dynamic system and are therefore able to distinguish 
enantiomers more effectively. In addition, these additives exhibit higher stability, structural rigidity, and more controllable aggregate size than non-polymerized micelles (206). Spectroscopic studies indicate that polymeric micelles generally have a more compact structure than normal micelles, limiting the depth of analyte interaction within the micelle (216). As a result, faster mass transfer is observed with polymeric micelles allowing higher efficiencies to be obtained. These chiral selectors have also been used for separating various acidic, basic, and neutral drugs (217). Other reviews and publications further describe the factors and methods for polymeric chiral surfactants in CE (206).

\section{POLYMERIC CHIRAL SELECTORS}

\section{Linear Carbohydrates}

In addition to cyclic carbohydrates, such as cyclodextrins, linear carbohydrates are effective additives for enantioselectivity in CE (Figure 11). The use of oligosaccharides as chiral selectors in CE was first demonstrated by D'Hulst and Verbeke, by the separation of various anti-inflammatory and anticoagulant drugs $(218,219)$. Several classes of oligo- and polysaccharides are now commonly used in CE. Maltodextrins are neutral polymers consisting of D-glucose units linked by $\alpha(1-4)$ linkages. Dextrin, a common maltodexrin, shows a wide range of selectivity towards charged analytes $(220,221)$. Dextran possesses a similar structure to maltodextrins, however units are linked via $\alpha(1-6)$ linkages (221). A charged derivative of dextran, dextran sulfate, may be applied to separations of neutral enantiomers. Three sulfate groups exist at the 2,3 , and 4 positions of the glucose subunit, providing a strong negative charge at most $\mathrm{pHs}$ used in $\mathrm{CE}$. Chondroitin sulfate $\mathrm{A}, \mathrm{B}$, and $\mathrm{C}$ (221) may also be used as charged additives for chiral resolution, and differ only by the 
position and orientation of its sulfate and carboxylic functional groups. Heparin, another $\alpha$ (1-4) linked polysaccharide, is composed of variably sulfonated D-glucosamine with either L-iduronic or D-glucuronic acids. This highly anionic linear carbohydrate shows excellent resolution for both cationic and amine containing chiral analytes $(222,223)$. More recently, pentosan polysulfate has been found to be quite effective for the separation of analytes with one or more basic functional groups. Its structure, primarily of D-xylopyranose units connected by $\beta$ (1-4) linkages, contains numerous ionizable groups per subunit, allowing strong electrostatic interactions with cationic analytes (224).

The selectivity of linear carbohydrates is similar to that of cyclodextrins, and efficiency increases with the length of the polysaccharide chain (220). Obviously only carbohydrates with good aqueous solubility may be utilized in $\mathrm{CE}$. Therefore, it is important to note that as the length of the polysaccharide increases, its solubility decreases. With most commercially available polysaccharides, the size of the polymer chain is characterized by its degree of polymerization (DP). For maltodextrins, the dextrose equivalent value (DE) indicates the level of hydrolyzed glucose units in a given mixture, and is related to extent of polymer fragmentation. In general, higher $\mathrm{DP}$ and lower $\mathrm{DE}$ values (longer, less fragmented chains) produce better enantioseparation (225).

Linear carbohydrates with $\alpha(1-4)$ linkages are thought to exist in aqueous solutions in a segmented helix conformation, leading to the creation of an interior hydrophobic region. At least 6 glucose units are required for a full helix (226). Upon interaction with an analyte, the chain may contort to include the compound. The flexibility of the polymer allows a wide 
range of molecules to interact, making them relatively versatile (163). $\alpha$ (1-6) linkages limit the carbohydrate's ability to form helical structures, resulting in their inability to resolve some compounds that are separated with $\alpha(1-4)$ polysaccharides (218).

\section{Dextrin}

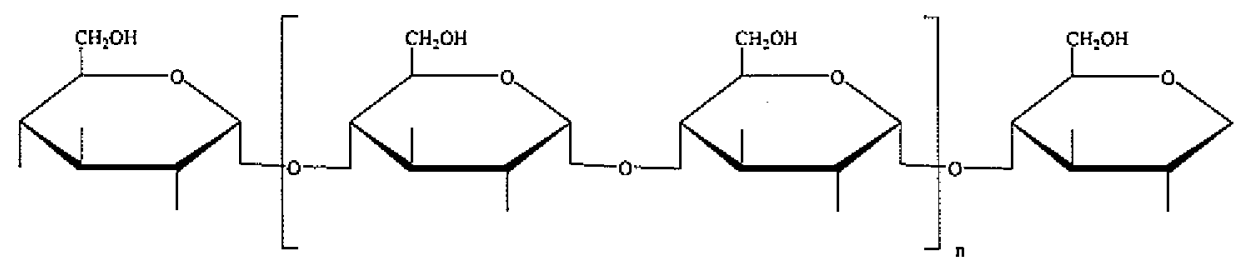

Dextran

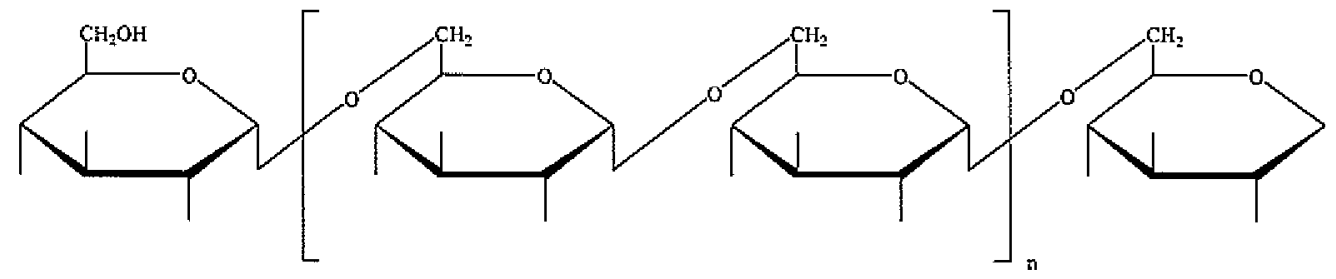

Heparin

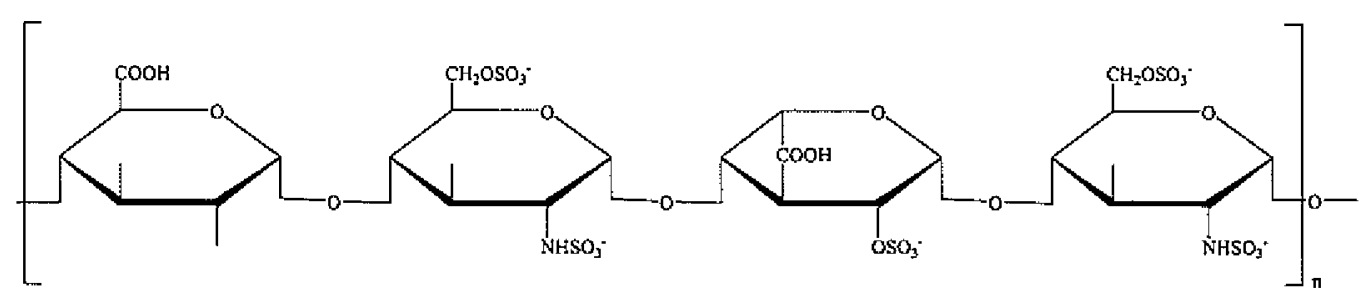

Chondroitin Sulfate A

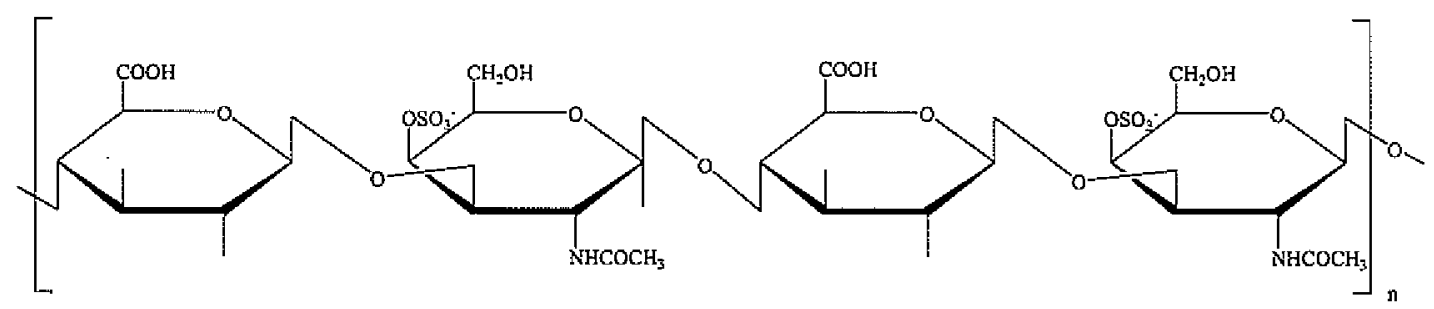

Figure 11. Examples of linear polysaccharide structures used as chiral selectors in capillary electrophoresis: dextran, dextrin, heparin, and chondroitin sulfate A. 
The buffer composition and $\mathrm{pH}$ have a large impact on the selectivity of linear carbohydrates. Changes in the conformation of the polymer can be induced by modifying the buffer, which can affect analyte interaction. For charged polysaccharides, pH can also change its mobility by protonating or deprotonating ionizable functional groups.

\section{Proteins}

Another class of polymeric chiral selectors that are less frequently used in $C E$ is proteins. These large biopolymers, consisting of amino acid residues, form complicated conformations based on the interactions between the amino acid functional groups and the formation of hydrophobic regions inside the protein. This elaborate structure enables a wide range of molecules to be resolved. Numerous sites for chiral recognition are available on a single protein, utilizing H-bonding, hydrophobic and electrostatic interactions, and steric effects. The conformation of the protein is highly important to its selectivity and is significantly dependent on the conditions of the run buffer.

The most commonly studied proteins in CE are bovine serum albumin (BSA) (227) and human serum albumin (HSA). Others include $\alpha_{1}$-acid glycoprotein, ovomucoid (228), conalbumin, and pepsin. Pharmaceutical drugs are often common analytes for this class of chiral selectors $(229,230)$.

The interactions between proteins and racemic analytes are generally very strong, as well as highly selective. Binding constants tend to be within the $10^{3}-10^{6}$ range (231). This effect is especially pronounced for hydrophobic analytes that include strongly within the protein. As 
a result, proteins produce highly selective separations with relatively low efficiency in pure aqueous environments. Organic modifiers are an extremely effective method of tuning the separation system. Increasing the level of nonpolar character of the buffer will lower the effective binding of hydrophobic analytes to the protein. In addition, nonpolar solvents greatly induce conformational changes to the protein, which in turn affects selectivity.

Proteins, like many other chiral additives, are highly UV absorbing due to their UV active residues, such as tryptophan. As a result, a partial filling technique is often used when utilizing an absorbance detector. Many proteins also adsorb onto uncoated capillary walls easily due to their high number of functional groups. As a result, proteins are not used as widely as other chiral selectors in CZE. Several recent reviews cover the protein types and separation conditions used in CE more in depth $(232,233)$.

\section{Capillary Electrochromatography}

Most of the discussed chiral selectors, with the exception of chiral surfactants, may be applied to capillary electrochromatography (CEC) as an alternative method of separation. By immobilizing the chiral additive onto a stationary phase within the capillary, problems such as aqueous solubility and high UV absorption can be alleviated. This stationary phase may be either a chemically bonded coating on the inner capillary wall or particles packed throughout the capillary. The resulting system therefore parallels closely to reversed phase LC. Micelles, however, may be used additionally as a third phase within the run buffer, in order to increase enantiomeric resolution. Numerous examples of capillary electrochromatography are available in literature utilizing proteins (234), native (235) and 
derivitized cyclodextrins $(236,237)$, cellulose derivatives (238), and macrocyclic glycopeptides $(239,240)$. While electrochromatographic systems allow higher sample capacities than some of the chiral selectors mentioned previously (such as surfactant micelles), the slow mass transfer between the stationary phase and the liquid mobile phase in capillaries $>50 \mu \mathrm{m}$ I.D. can significantly limit efficiency (241). Another difficulty of CEC is the strong EOF dependence on the composition of the stationary phase. As a result, the magnitude and direction of the EOF can be unpredictable and unreliable (166). However, with further development of methodologies and instrumentation, the use of CEC for enantiomeric separations may increase greatly.

\section{Conclusions}

There is no doubt that chromatography can be considered a powerful tool for enantiomeric separations for wide varieties of compounds at both analytical and preparative scales. Nowadays, numerous chiral stationary phases have been developed, of which, over 200 CSPs have been commercialized. However, since there is no universal CSP available, most pharmaceutical companies often use high throughput chiral screening technologies to meet the need of enantiomeric separations at the analytical scale. Therefore, elucidation of the chiral discrimination mechanism on CSPs at the molecular level becomes essential for further developments in chiral separations. Several approaches to clarify the chiral recognition mechanism on CSPs for HPLC have been attempted by means of chromatography, NMR, and computational methods. The results will serve to develop more effective CSPs. Overall, with the better understanding of the molecular principles/mechanisms governing chiral 
recognitions, one day people may choose and create suitable chiral selectors for given enantiomers.

With increasing environmental concern, SFC has also become a popular enantiomeric separation technique because of its easy solvent disposal and low waste generated. In addition, SFC provides fast separation because high flow rates can be used. With all the aforementioned advantages, enantioseparations by SFC will maintain and even gain a higher importance in the future not only at the analytical scale, but at the preparative scale as well.

Recently, CE has become a useful complimentary chiral separation technique. Although CE is more often used by academic researchers, it provides fast separation, high efficiency with low waste generated. These characteristics best meet the future demands in terms of speed and cost. However, CE can only be used for analytical scale separations because of its small sample capacity. With the better understanding of CE instrumentation and methodology, as well as the further development of microchip CE devices, chiral separation based on CE may become more routine in the future.

\section{ACKNOWLEDGEMENT}

Support of this work by the National Institutes of Health (NIH 5RO1GM53825-08) is gratefully acknowledged. 


\section{References}

1. Jenner, P.; Testa, B. Drug. Metab.Rev. 1973, 2 (2), 117-184.

2. U.S. Food and Drug Administration, Chirality 1992, 4, 338-340.

3. Armstrong, D.W. J. Liq. Chromatogr. 1984, 7, 353-376.

4. Armstrong, D.W. Anal. Chem. 1987, 59 (2), 84A-91A.

5. Rouhi, A.M. Chem. Eng. News, 2002, 80 (23), 43-50.

6. Armstrong, D.W.; Reid, G.L.; III; Hilton, M.L.; Chang, C.D. Environ Pollution, 1993, 79 (1), 51-58.

7. Schneiderheinze, J.M.; Armstrong, D.W.; Berthod, A. Chirality, 1999, 11(4), 330-337.

8. Armstrong, D.W.; Chang, C.D.; Li, W.Y. J. Agric. Food. Chem, 1990, 38 (8), 1674-1677.

9. Ekborg-ott, K.H.; Armstrong, D.W. in: S Ahuja, ed. Chiral separations. Washington, DC: American Chemical Society, 1997, p. 201

10. Ward, T.J. Anal. Chem. 2002, 74 (12), 2863-2872.

11. Phiney, K.W. Anal. Chem. 2000, 72 (5), 204 A-211 A.

12. Schurig, V. J. Chromatogr.A 2001, 906 (1-2), 275-299.

13. Chankyetadze, B.; Blaschke, G. J. Chromatogr. A 2001, 906 (1-2), 309-363.

14. Yashima, K. J. Chromatogr. A 2001, 906 (1-2), 105-125.

15. Ward, T. J.; Farris, A. B. III. J. Chromatogr. A 2001, 906 (1-2), 73-89.

16. Scriba, G.K.E. Eletrophoresis 2003, 24 (15), 2409-2421.

17. Kang, J.; Wistuba, D. Schurig, V. Electrophoresis 2002, 23 (22-23), 4005-4021.

18. Armstrong, D.W. The Evolution of Chiral Stationary Phases for Liquid Chromatography. LC-GC, current issues in HPLC Technology, May 1997, S20-S28.

19. Fanali, S. J. Chromatogr. A 2000, $875(1+2), 89-122$. 
20. Pirke, W.H.; Finn, J.M.; Schreiner, J.L.; Hamper, B.C. J. Am. Chem. Soc, 1981, 103 (13), 3964-3966.

21. Armstrong, D.W.; DeMond, W. J. Chromatogr. Sci, 1984, 22, 411-415.

22. Allenmark, S.; Bomgren, B.; Borén, H. J. Chromatogr. 1983, 264, 63-68.

23. Hermansson, J. J. Chromatogr. 1983, 269, 71-80.

24. Armstrong, D.W.; Bertrand, G.L.; Ward, K.D.; Ward, T.J.; Secor, H.V.; Seeman, J.I. Anal. Chem. 1990, 62(4), 332-338.

25. Stalcup, A.M.; Chang, S.C.; Armstrong, D.W. J. Chromatogr. 1991, 540, 113-128.

26. Stalcup, A.M. Chang, S.C.; Armstrong, D.W.; Pitha, J. J. Chromatogr.1990, 513, 181194.

27. Armstrong, D.W.; Hilton, M.; Coffin, L. LC-GC, 1991,9 (9), 646, 648-652.

28. Cyclobond Handbook, $6^{\text {th }}$ Edition. Advanced Separation Technology, Inc., Whippany, NJ, 2002.

29. Armstrong, D.W.; Han, S.M.; Han, Y.I. Anal. Chim. Acta 1988, 208, 275-281.

30. Armstrong, D.W.; Chang, X.; Chang, L.W.; Ibrahim, H.; Reid, G.R., II; Beesley, T.E. J. Liq. Chromatogr. Related Technol. 1997, 20 (20), 3279-3308.

31. Chang, S.C.; Reid, G.L. III; Chen, S.; Chang, C.D., Armstrong, D.W. Trends in Anal. Chem. 1993, 12 (4), 144-153.

32. Armstrong, D.W.; Chen, S.; Chang, C.; Chang, S. J. Liq. Chromatogr. 1992, 15 (3), 545556.

33. Ward, T.J. Armstrong, D.W. J. Liq. Chromatogr. 1986, 9, 407-423.

34. Armstrong, D.W. Anal. Chem, 1987, 59, 84 A-91 A. 
35. Gasper, M.P.; Berthod, A.; Nair, U.B.; Armstrong, D.W. Anal. Chem. 1996, 68, 25012514.

36. Armstrong, D.W.; Tang, Y.; Chen, S.; Zhou, Y.; Bagwill, C.; Chen, J. Anal. Chem. 1994, $66,1473-1484$

37. Chirobiotic Handbook, $4^{\text {th }}$ Edition. Advanced Separations Technologies, Inc., Whippany, NJ, 2002.

38. Armstrong, D.W.; Liu, Y.; Ekborg-Ott, K.H. Chirality, 1995, 7, 474-497.

39. Ekborg-Ott, K.H.; Liu, Y.; Armstrong, D.W. Chirality, 1998, 10, 434-483.

40. Ekborg-Ott, K.H.; Wang, X.; Armstrong, D.W. Microchem. J. 1999, 62, 26-49.

41. Berthod, A.; Liu, Y.; Bagwill, C., Armstrong, D.W. J. Chromatogr. A 1996, 731, $123-$ 137.

42. Peter, A.; Torok, G.; Armstrong, D.W. J. Chromatogr. A, 1998, 793, 283-296.

43. Berthod, A.; Chen, X.; Kullman, J.P.; Armstrong, D.W.; Gasparrini, F.; D'Acquarica, I.;

Villani, C.; Carotti, A. Anal. Chem. 2000, 72, 1767-1780.

44. Xiao, T.L., Rozhkov, R.V., Larock, R.C., Armstrong, D.W. Anal. Bioanal. Chem. 2003, $377,639-654$

45. Chen, S.; Liu, Y.; Armstrong, D.W.; Borrell, J.I.; Martinez-Teipel, B.; Matallana, J.L. J. Liq. Chromatogr. 1995, 18 (8), 1495-1507.

46. Kyba, E.P.; Siegel, M.G.; Sousa, L.R. Sogah, G.D.Y.; Cram, D.J. J. Am. Chem. Soc. $1973,95(8), 2691-2692$.

47. Helgeson, R.C.; Timko, J.M.; Moreau, P.; Peacock, S.C.; Mayer, J.M.; Cram, D.J. J. Am. Chem. Soc. 1974, $96(21), 6762-6763$. 
48. Hyun, M.H.; Han, S.C.; Lipshutz, B.H.; Shin, Y.-J.; Welch, C.J. J. Chromatogr. A 2001, $910,359-365$.

49. Nishi, H.; Nakamura, K.; Nakai, H.; Sato, T. J. Chromatogr. A 1997, 757, 225-235.

50. Shinbo, T.; Yamaguchi, T.; Nishimura, K.; Sugiura, M. J Chromatogr. 1987, 405, 145153.

51. Okamoto, M.; Takahashi, K.I.; Doi, T. J. Chromatogr. A 1994, 675, 244-247.

52. Peter, A.; Lazar, L.; Fulop, F.; Armstrong, D.W. J. Chromatogr. A 2001 926, 229-238.

53. Behr, J.-P.; Girodeau, J.-M.; Hayward, R.C.; Lehn, J.-M.; Sauvage, J.-P. Hel. Chim. Acta. 1980, 63, 2096-2111.

54. Machida, Y.; Nishi, H.; Nakamura, K.; Nakai, H.; Sato, T. J. Chromatogr. A 1998, 805, $85-92$.

55. Hyun, M.H. J. Sep. Sci. 2003, 26, 242-250.

56. Steffeck, R.J.; Zelechonok, Y.; Gahm, K.H. J. Chromatogr. A 2002, 947, 301-305.

57. Hesse, G.; Hagel, R. Chromatogrphia, 1973, 6 (6), 277-280.

58. Lindner, K.R.; Mannschreck, A. J. Chromatogr. 1980, 193 (2), 308-310.

59. Blaschke, G. J. Liq. Chromatogr. 1986, 9 (2-3), 341-368.

60. Okamoto, Y.; Kawashima, M.; Yamamoto, K.; Hatada, K. Chem. Lett. 1984, 5, 739-742.

61. Okamoto, Y.; Kawashima, M.; Hatada, K. J. Am. Chem. Soc. 1984, 106 (18), 5357-5359.

62. Ichida, A.; Shibata, T.; Okamoto, I.; Yuki, Y.; Namikoshi, N.; Toga, Y.

Chromatographia, 1984, 19, 280-294.

63. Tachibana, K.; Ohnishi, A. J. Chromatogr. A 2001, 906 (1-2), 127-154.

64. Okamoto, Y.; Yashima, E. Angew. Chem. Int. Ed. 1998, 37, 1020-1043. 
65. Franco, P.; Senso, A.; Oliveros, L.; Minguillón C. J. Chromatogr. A 2001, 906 (1-2), $155-170$.

66. Yashima, E.; Fukaya, H.; Okamoto, Y. J. Chromatogr. A 1994, 677 (1), 11-19.

67. Franco, P.; Senso, A.; Minguillón, C.; Oliveros, L. J. Chromatogr. A 1998, 796, 265-272.

68. Oliveros, L.; López, P.; Minguillón, C.; Franco, P. J. Liq. Chromatogr. 1995, 18 (8), $1521-1532$.

69. Domenici, E.; Bertucci, C.; Salvadori, P.; Felix, G.; Cahagne, I.; Montellier, S.; Wainer, I.W. Chromatographia, 1990, $29(3-4), 170-176$.

70. Miwa, T.; Ichikawa, M.; Tsuno, M.; Hattori, T.; Miyakawa, T.; Kayano, M.; Miyake, Y. Chem. Pharm. Bull. 1987, 35 (2), 682-686.

71. Miwa, T.; Miyakawa, T.; Miyake, Y. J. Chromatogr. 1988, 457, 227-233.

72. Erlandsson, P.; Marle, I.; Hansson, L.; Isaksson, R.; Petterson, G.; Petterson, C. J. Am. Chem. Soc. 1990, $112(11), 4573-4574$.

73. Haginaka, J.; Miyano, Y.; Saizen, Y.; Seyama, C.; Murashima, T. J. Chromatogr. A, $1995,708,161-168$.

74. Mano, N.; Oda, Y.; Miwa, T.; Asakawa, N.; Yoshida, Y.; Sato, T. J. Chromatogr. 1992, $603(1-2), 105-109$

75. Massolini, G.; De Lorenzi, E.; Lloyd, D.K.; McGann, A.M.; Caccialanza, G. J Chromatogr. B 1998, $712(1+2), 83-94$.

76. Marle, I.; Erlandsson, P.; Hansson, L.; Isaksson, R.; Pettersson, C.; Pettersson, G. J. Chromatogr. 1991, 586, 233-248.

77. Erlandsson, P.; Nilsson, S. J. Chromatogr. 1990, 482, 35-51. 
78. Pinkerton, T.C.; Howe, W. J; Ulrich, E.L.; Comiskey, J.P.; Haginaka, J.; Murashima, T.; Walkenhorst, W. F.; Westler, W.M.; Markley, J.L. Anal. Chem. 1995, 67, 2354-2367.

79. Haginaka, J. J. Chromatogr. A 2001, 906 (1-2), 253-273.

80. Okamoto, Y.; Suzuki, K.; Ohta, K.; Hatada, K.; Yuki, H. J. Am. Chem. Soc. 1979, 101 (16), 4763-4765.

81. Yuki, H.; Okamoto, Y.; Okamoto, I. J. Am.Chem. Soc. 1980, 102 (20), 6356-6358.

82. Okamoto, Y.; Honda, S.; Okamoto, I.; Yuki, H.; Murata, S.; Noyori, R.; Takaya, H. J. Am. Chem. Soc. 1981, 103 (23), 6971-6973.

83. Okamoto, Y. Nakano, T. Chem. Rev. 1994, 94 (2), 349-372.

84. Okamoto, Y.; hatada, K. J. Liq. Chromatogr. 1986, 9 (2-3), 369-384.

85. Nakano,T. J.Chromatogr. A 2001, 906, 205-225.

86. Okamoto, Y.; Mohri, H.; Hatada, K. Polym. J. (Tokyo, Japan) 1989, 21 (5), 439-445.

87. Nakano, T.; Matsuda, A.; Mori, M.; Okamoto, Y. Polym. J. (Tokyo, Japan) 1996, 28 (4), $330-336$.

88. Nakano, T.; Satoh, Y.; Okamoto, Y. Polym. J. (Tokyo, Japan) 1998, 30 (8), 635-640.

89. Wulff, G. Angew. Chem. Int. Ed. Engl. 1995, 34 (17), 1812-1832.

90. Remcho, V.T.; Tan, Z.J. Anal. Chem. 1999, 7l(7), 248A-255A.

91. Takeuchi, T.; Haginaka, J. J. Chromatogr. B 1999, 728(1), 1-20.

92. Vidyasankar, S. Ru, M.; Arnold, F.H. J. Chromatogr. A 1997, 775, 51-63.

93. Ramström, O.; Ye, L.; Gustavsson, P.E. Chromatographia, 1998, 48 (3/4), 197-202.

94. Klemm, L.H.; Reed, D. J.Chromatogr.1960, 3, 364-368.

95. Mikes, F.; Boshart, G.; Gil-Av, E. J. Chromatogr. 1976, 122, 205-221.

96. Mikes, F.; Boshart, G. J. Chromatogr. 1978, 149, 455-464. 
97. Mikes, F.; Boshart, G. Chem Commun. 1978, 4, 173-175.

98. Gasparrini, F.; Misiti, D.; Villani, C. J. Chromatogr. A 2001, 906, 35-50.

99. Welch, C.J. J. Chromatogr. A 1994, 666, 3-26.

100. Hyun, M.H.; Min, C.S. Tetrahedron Lett. 1997, 38 (11), 1943-1946.

101. Hyun, M.H.; Kang, M.H.; Han, S.C. J. Chromatogr. A 2000, 868 (1), 31-39.

102. Pirkle, W.H.; Murray, P.G.; Wilson, S.R. J. Org. Chem. 1996, 61 (14), 4775-4777.

103. Pirkle, W.H.; Welch, C.J.; Lamm, B. J. Org. Chem. 1992, 57 (14), 3854-3860.

104. Oi, N.; Nagase, M.; Inda, Y.; Doi, T. J. Chromatogr. 1983, 265 (1), 111-116.

105. Pirkle, W.H.; Liu, Y. J. Chromatorgr. A 1996, 749, 19-24.

106. Lin, C.-E.; Lin, C.-H.; Li, F.-K. J. Chromatogr. A 1996, 722, 189.

107. Lin, C.-E.; Li, F.-K. J. Chromatogr. A 1996, 722, 199-209.

108. Machida, Y.; Nishi, H.; Nakamura, K.; Nakai, H.; Sato, T. J. Chromatogr. A 1997, 757, 73-79.

109. Vaton-Chanvrier, L.; Peulon, V.; Combret, Y.; Combret, J.C. Chromatographia 1997, 46 $(11 / 12), 613-622$.

110. Iuliano, A.; Salvadori, P.; Felix, G. Tetrahedron: Asymmetry 1999, 10 (17), 3353-3364.

111. Messina, A.; Girelli, A.M.; Flieger, M.; Sinibaldi, M.; Sedmera, P.; Cvak, L. Anal.

Chem. 1996, 68, 1191-1196.

112. Davankov, V.A.; Rogozhin, S.V. J. Chromatogr. 1971, 60, 284-312.

113. Davankov, V.A.; Rogozhin, S.V.; Semechkin,A.V.; Sachkova, T.P. J. Chromatogr. $1973,82,359-365$.

114. Roumeliotis, P.; Unger, K.K.; Kurganov, A.A.; Davankov, V.A. J. Chromatogr. 1983, $255,51-66$. 
115. Roumeliotis, P.; Kurganov, A.A; Davankov, V.A. J. Chromatogr. 1983, 266, 439-450.

116. Hare, P.E.; Gil-Av, E. Science 1979, 204 (4398), 1226-1228.

117. Gil-Ac, E.; Tishbee, A.; Hare, P.E. J. Am. Chem. Soc. 1980, 102 (15), 5115-5117.

118. Kurganov, A. J. Chromatogr. A, 2001, 906, 51-57.

119. Davankov, V.A. Enantiomer 2000, 5 (3-4), 209-223.

120. Śliwka, M.; Ślebioda, M.; Kolodziejczyk, A.M. J. Chromatogr. A, 1998, 824, 7-14.

121. Yoshida, A.; Kuroda, K.; Kurauchi, Y.; Inoue, T.; Ohga, K. Kichin, Kitosan Kenkyu, $1999,5(2), 188-189$.

122. Pirkle, W.H.; Brice, L.J.; Terfloth, G.J. J. Chromatogr. A. 1996, 753 (1), 109-119.

123. Wolf, C.; Pirkle, W. H. J. Chromatogr. A 1998, 799 (1+2), 177-184.

124. Mandl, A.; Nicoletti, L.; Lammerhofer, M.; Lindner, W. J. Chromatogr. A 1999, 858,111.

125. Schmalzing, D.; Nichlson, G.J.; Jung, M.; Schurig, V. J. Micro. Sep. 1992, 4 (1), 23-28.

126. Armstrong, D.W.; Tang, Y.; Ward, T.; Nichols, M. Anal. Chem. 1993, 65, 1114-1117.

127. Schurig, V.; Jung, M.; Mayer, S.; Fluck, M.; Negura, S.; Jakubetz, H. J. Chromatogr. A, $1995,694,119-128$.

128. Röeder, W.; Ruffing, F.-J.; Schomburg, G.; Pirkle, W.H. J. High Resolut. Chromatogr. $1987,10(12), 665-667$.

129. Mourier, P.A.; Eliot, E.; Caude, M.; Rosset, R.; Tambute, A. Anal. Chem. 1985, 57 (14), 2819-2823.

130. Whatley, J. J. Chromatogr. A $1995,697,251-255$.

131. Gyllenhaa, O.; Karlsson, A.; Vessman, J. In: Supercritical fluid chromatography with packed columns, Anton, K; Berger, C. (eds) Marcel Dekker, New York, 1998. 
132. Anton, K; Siffrin, C. Analusis 1999, 27 (8), 691-701.

133. Williams, K.L.; Sander, L.C. J. Chromatogr. A 1997, 785, 149-158.

134. Berger, T.A. Packed Column SFC, Royal Society of Chemistry, Cambridge, 1995.

135. Berger, T.A.; Smith, J.; Fogelman, K.; Kruluts, K. American Lab. 2002, 34 (21), 14-20.

136. Macaudiere, P.; Caude, M.; Rosset, R.; Tambute, A. J. Chromatogr. 1987, 405, 135-143.

137. Macaudiere, P.; Caude, M.; Rosset, R.; Tambute, A. J. Chromatogr. Sci. 1989, 27 (10), $583-591$.

138. Williams, K.L.; Sander, L.C.; Wise, S.A. Chirality 1996, 8 (4), 325-331.

139. Williams, K. L.; Sander, L.C.; Wise, S.A. J. Chromatogr. A, 1996, 746 (1), 91-101.

140. Dönnecke J.; Svensson, L.A.; Gyllenhaal, O.; Karlsson, K-E.; Karlsson, A.; Vessman, J.

J. Microcol. Sep. 1999, 11 (7), 521-533.

141. Toribio, L.; David, F.; Sandra, P. Quimica Analitica, 1999, 18, 269-273.

142. Svensson, L.A.; Ovens, P.K. Analyst, 2000, 125, 1037-1039.

143. Medvedovici, A.; Sandra, P.; Toribio, L.; David, F. J. Chromatogr. A 1997, 785, 159171.

144. Liu, Y.; Rozhkov, R.; Larock, R.C.; Xiao, T.L.; Armstrong, D.W. Chromatographia, 2003 (in press)

145. Liu, Y.; Berthod, A.; Metchell, C.R.; Xiao, T.L.; Zhang, B. J. Chromatogr. A 2002, 978 , $185-204$.

146. Thienpont, A.; Gal, J.; Aeschlimann, C.; Felix, G. Analusis 1999, 27 (8), 713-718.

147. Bernal, J.L.; Toribio, L.; del Nozal, M.J.; Nieto, E.M.; Montequi, M.I. J. Biochem. Biophys. Methods, 2002, 54, 245-254.

148. Biermanns, P.; Miller, C.; Lyon, V.; Wilson, W. LC-GC 1993, 11 (10), 744-747. 
149. Bargmann-Leyder, N.; Tambuté, A.; Caude, M.; Chirality 1995, 7 (5), 311-325.

150. Yaku, K.; Aoe, K.; Nishimura, N.; Sato, T.; Morishita, F. J. Chromatogr. A, 1997, 785, 185-193.

151. Smith, R.M.; Ma, L. J. Chromatogr. A, 1997, 785, 179-184.

152. del Nozal, M.J.; Toribio, L.; Bernal, J.L.; Nieto, E.M.; Jiménez, J.J. J. Biochem.

Biophys. Methods, 2002, 54, 339-345.

153. Williams, K.L.; Sander, L.C.; Wise, S.A. J. Pharm. Biomed. Analysis 1997, 15 (11), 1789-1799.

154. Blum, A.M.; Lynam, K.G.; Nicolas, E.C. Chirality, 1994, 6 (4), 302-313.

155. Terfloth, G.J.; Pirkle, W.H.; Lynam, K.G.; Nicolas, E.C. J. Chromatogr. A, 1995, 705

(2), 185-194.

156. Bargmann-Leyder, N.; Thiebaut, D.; Vergne, F; Begos, A.; Tambute, A.; Caude, M. Chromatograhphia, 1994, 39 (11/12), 673-681.

157. Schurig, V.; Fluck, M. J. Biochem. Biophys. Methods, 2000, 43 (1-3), 223-240.

158. Johannsen, M. J. Chromatogr. A, 2001, 937, 135-138.

159. Wu, Y. Book of Abstracts, $219^{\text {th }}$ ACS National Meeting, San Francisco, CA, March 2000.

160. Petersen, M. J. Chromatogr. 1990, 505, 3-18

161. Lee, C.R.; Porziemsky, J.-P.; Aubert, M.-C.; Krstulovic, A.M. J. Chromatogr. 1991, $539,55-69$.

162. Anton, K.; Eppinger, J.; Frederiksen, L.; Francotte, E.; Berger, T.A.; Wilson, W.H. J. Chromatogr. A, 1994, 666, 395-401. 
163. Camilleri, P. Separation of Enantiomers. Capillary Electrophoresis: Theory and

Practice, 2nd Edition; CRC Press: Boca Raton, FL, 1998; 183-247.

164. Schmitt, U.; Branch, S. K.; Holzgrabe, U. J. Sep. Sci. 2002, 25, 959-974.

165. Wren, S. Chromatographia 2001, 54, S59-S77.

166. Vespalec, R.; Bocek, P. Chem. Rev. 2000, 100, 3715-3753.

167. Lurie, I. S. J. Chromatogr. A 1997, 792, 297-307.

168. Marina, M. L.; Crego, A. L. J. Liq. Chromatogr. Related Technol. 1997, 20, 1337-1365.

169. Furuta, R.; Doi, T. Electrophoresis 1994, 15, 1322-1325.

170. Valkó, I. E.; Billiet, H. A.H.; Frank, J.; Luyben, K. Ch.A.M. J. Chromatogr. A 1994, $678,139-144$.

171. Ueda, T.; Mitchell, R.; Kitamura, F.; Metcalf, T. J. Chromatogr. 1992, 593, 265-274.

172. Yoshinaga, M.; Tanaka, M. J. Chromatogr. A 1994, 679, 359-365.

173. Gahm, K.; Stalcup, A. M. Anal. Chem. 1995, 67, 19-25.

174. Fanali, S.; Aturki, Z. J. Chromatogr. A 1995, 694, 297-305.

175. Egger, M. D.; Liu, Y.; Sevcik, J.; Tesarova, E.; Rozhkov, R.; Larock, R. C.; Armstrong, D. W. Electrophoresis 2003, 24, 2650-2656.

176. Pharr, D. Y.; Fu, Z. S.; Smith, T. K.; Hinze, W. L. Anal. Chem. 1989, 6l, 275-279.

177. Hinze, W. L.; Pharr, D. Y.; Fu, Z. S.; Burkert, W. G. Anal. Chem. 1989, 61, 422-428.

178. Yoshinaga, M.; Tanaka, M. J. Chromatogr. A 1995, 710, 331-337.

179. Salvador, A.; Varesio, E.; Dreux, M.; Veuthey, J. Electrophoresis 1999, 20, 2670-2679.

180. Schmitt, T.; Engelhardt, H. Chromatographia 1993, 37, 475-481.

181. Kuhn, R.; Emi, F.; Bereuter, T.; Häusler, J. Anal. Chem. 1992, 64, 2815-2820.

182. Kuhn, R. Electrophoresis 1999, 20, 2605-2613. 


183. Kuhn, R.; Wagner, J.; Walbroehl, Y.; Bereuter, T. Electrophoresis 1994, 15, 828-834.

184. Walbroehl, Y.; Wagner, J. J. Chromatogr. A 1994, 685, 321-329.

185. Schmid, M. G.; Gübitz, G. J. Chromatogr. A 1995, 709, 81-88.

186. Kuhn, R.; Stoecklin, F.; Emi, F. Chromatographia 1992, 33, 32-36.

187. Dutton, P. J.; Fyles, T. M.; McDermid, S. J. Chem. 1988, 66, 1097-1108.

188. Behr, J. P.; Lehn, J. M.; Vierling, P. Helv. Chim. Acta. 1982, 65, 1853-1867.

189. Jang, J.; Cho, S. II; Chung, D. Electrophoresis 2001, 22, 4362-4367.

190. Armstrong, D.W.; Chang, L.W.; Chang, S.S.C. J. Chromatogr. A 1998, 793, 115-134.

191. Kuhn, R.; Steinmetz, C.; Bereuter, T.; Haas, P.; Erni, F. J. Chromatogr. A 1994, 666, $367-373$.

192. Desiderio, C.; Fanali, S. J. Chromatogr. A 1998, 807, 37-56.

193. Aboul-Enein, H.Y.; Ali, I. Chromatographia 2000, 52, 679-691.

194. Armstrong, D. W.; Gasper, M. P.; Rundlett, K. L. J. Chromatogr. A 1995, 689, 285-304.

195. Ward, T. J.; Dann, C., III; Blaylock, A. J. Chromatogr. A 1995, 715, 337-344.

196. Rundlett, K. L.; Gasper, M. P.; Zhou, E. Y.; Armstrong, D. W. Chirality 1996, 8, 88107.

197. Armstrong, D. W.; Rundlett, K.; Reid, G. L., III. Anal. Chem. 1994, 66, 1690-1695.

198. Vespalec, R.; Billiet, H. A. H.; Frank, J.; Bocek, P. Electrophoresis 1996, 17, 12141221.

199. Rundlett, K. L.; Armstrong, D. W. Anal. Chem. 1995, 67, 2088-2095.

200. Armstrong D. W.; Seguin R.; Fendler J. H. Journal of Molecular Evolution. 1977, 10, $241-250$.

201. Armstrong, D. W.; Terrill, R. Q. Anal. Chem. 1979, 51, 2160-2163. 
202. Armstrong, D. W.; Henry, S. J. J. Liq. Chromatogr. 1980, 3, 657-662.

203. Armstrong, D. W. J. Liq. Chromatogr. 1980, 3, 895-900.

204. Armstrong, D. W.; Nome, F. Anal. Chem. 1981, 53, 1662-1666.

205. Terabe, S.; Otsuka, K.; Ichikawa, K.; Tsuchiya, A.; Ando, T. Anal. Chem. 1984, 56, $111-113$.

206. Shamsi, S. A.; Warner, I. M. Electrophoresis. 1997, 18, 853-872.

207. Bjørnsdottir, I.; HonoréHansen, S.; Terabe, S. J. Chromatogr. A 1996, 745, 37-44.

208. Terabe, S.; Shibata, M.; Miyashita, Y. J. Chromatogr. 1989, 480, 403-411.

208. Nishi, H.; Fukuyama, T.; Matsuo, M. J. Chromatogr. 1990, 515, 233-243.

210. Otsuka, K.; Terabe, S. J. Chromatogr. 1990, 515, 221-226.

211. Mazzeo, J. R.; Grover, E. R.; Swartz, M. E.; Petersen, J. S. J. Chromatogr. A 1994, 680, $125-135$.

212. Dobashi, A.; Hamada, M.; Dobashi, Y. Anal. Chem. 1995, 67, 3011-3017.

213. Tickle, D. C.; Okafo, G. N.; Camilleri, P.; Jones, R. F. D.; Kirby, A. Anal. Chem. 1994, $66,4121-4126$.

214. Dobashi, A.; Ono, T.; Hara, S.; Yamaguchi, J. Anal. Chem. 1989, 61, 1986-1988.

215. Wang, J.; Warner, I. M. Anal. Chem. 1994, 66, 3773-3776.

216. Paleos, C. M.; Stassinopoulou, C. I.; Malliaris, A. J. Phys. Chem. 1983, 87, 251-254.

217. Agnew-Heard, K. A.; Peňa, M. S.; Shamsi, S. A.; Warner, I. M. Anal. Chem. 1997, 69, 985-964.

218. D'Hulst, A.; Verbeke, N. J. Chromatogr. 1992, 608, 275-287.

219. D'Hulst, A.; Verbeke, N. Chirality 1994, 6, 225-229. 
220. Kano, K.; Minami, K.; Horiguchi, K.; Ishimura, Ta.; Kodera, M. J. Chromatogr. A $1995,694,307-313$.

221. Nishi, H. J. Chromatogr. A 1996, 735, 345-351.

222. Stalcup, A. P.; Agyel, N. M. Heparin: Anal. Chem. 1994, 66, 3054-3059.

223. Jin, Y.; Stalcup, A. M. Electrophoresis. 1998, 19, 2119-2123.

224. Wang, X.; Lee, J.; Armstrong, D. W. Electrophoresis. 1999, 20, 162-170.

225. Chankvetadze, B.; Saito, M.; Yashima, E.; Okamoto, Y. J. Chromatrogr. A 1997, 773, $331-338$.

226. Rundle, R. E.; Foster, J. F.; Baldwin, R. R. J. Am. Chem. Soc. 1944, 66, 21 16-2120.

227. Busch, S.; Kraak, J. C.; Poppe, H. J. Chromatogr, 1993, 635, 119-126.

228. Ishihama, Y.; Oda, Y.; Asakawa, N.; Yoshida, Y.; Sato, T. J. Chromatogr. A 1994, 666, 193-201.

229. Matsunaga, H.; Haginaka, J. Electrophoresis 2001, 22, 3251-3256.

230. Valtcheva, L.; Mohammad, J.; Pettersson, G.; Hjertén, S. J. Chromatogr. 1993, 638, 263-267.

231. Lloyd, D. K.; Aubry, A.; De Lorenzi, E. J. Chromatogr. A 1997, 792, 349-369.

232. Haginaka, J. J. Chromatogr. A 2000, 875, 235-254.

233. Hage, D. S. Electrophoresis 1997, 18, 2311-2321.

234. Li, S.; Lloyd, D. K. Anal. Chem. 1993, 65, 3684-3690.

235. Li, S.; Lloyd, D. K. J. Chromatogr. A 1994, 666, 321-335.

236. Meyer, S.; Schurig, V. Electrophoresis 1994, 15, 835-841.

237. Schurig, V.; Wistuba, D. Electrophoresis 1999, 20, 2313-2328.

238. Francotte, E.; Jung, M. Chromatographia 1996, 42, 521-527. 
239. Karlsson, C.; Wikström, H.; Armstrong, D.W.; Owens, P.K. J. Chromatogr. A 2000, $897,349-363$.

240. Karlsson, C.; Karlsson, K.; Armstrong, D.W.; Owens, P.K. Anal. Chem. 2000, 72, $4394-4401$.

241. Desbène, P. L.; Fulchic, C. E. J. Chromatogr. A 1996, 749, 257-269. 


\title{
CHAPTER 2
}

\section{SUPER/SUBCRITICAL FLUID CHROMOATOGRAPHY CHIRAL SEPARATIONS WITH MACROCYCLIC GLYCOPEPTIDE STATIONARY PHASES}

\author{
A paper published in Journal of Chromatography A \\ Ying Liu, Alain Berthod, Clifford R. Mitchell, Tom L. Xiao, Bo Zhang, William S. Jenks, \\ Daniel W. Armstrong
}

\begin{abstract}
The chiral recognition capabilities of three macrocyclic glycopeptide chiral selectors, namely teicoplanin (Chirobiotic $\otimes$ T), its aglycone (Chirobiotic TAG) and ristocetin (Chirobiotic R), were evaluated with supercritical and subcritical fluid mobile phases. A set of 111 chiral compounds including heterocycles, analgesics (nonsteroidal anti-inflammatory compounds), $\beta$-blockers, sulfoxides, $N$-blocked amino-acids and native amino-acids was separated on the three chiral stationary phases (CSP). All separations were done with an outlet pressure regulated at $100 \mathrm{bar}, 31^{\circ} \mathrm{C}$ and at $4 \mathrm{~mL} / \mathrm{min}$. Various amounts of methanol ranging from 7 to $67 \% \mathrm{v} / \mathrm{v}$ were added to the carbon dioxide along with small amounts $(0.1$ to $0.5 \% \mathrm{v} / \mathrm{v})$ of triethylamine and/or trifluoroacetic acid. The Chirobiotic TAG CSP was the most effective closely followed by the Chirobiotic T column. Both columns were able to separate, partially or fully, $92 \%$ of the enantiomers of the compound set. The ristocetin chiral selector could partially or baseline resolve only $60 \%$ of the enantiomers tested. All separations were done in less than $15 \mathrm{~min}$ and $70 \%$ were done in less than $4 \mathrm{~min}$. The speed of the separations is
\end{abstract}


the main advantage of the use of SFC compared to normal phase HPLC. In addition, SFC is advantageous for preparative separations with easy solute recovery and solvent disposal.

\subsection{Introduction}

The use of supercritical fluids as eluents for chromatographic separations was first proposed by Klesper et al. in 1962 [1]. The advantages of supercritical fluids were numerous: reduced viscosity giving low pressure drop and allowing high flow rates or long columns, high solute diffusion coefficients giving fast mass transfer and high efficiency, ease of disposal and solute recovery in preparative modes, and the ability to use GC-type detectors. Unfortunately in the 1980 s, studies greatly overestimated the solvent strength of supercritical $\mathrm{CO}_{2}$ and led to some disappointment in applicability of supercritical fluid chromatography (SFC) [2]. It was rapidly realized that the polarity of supercritical $\mathrm{CO}_{2}$ was similar to pentane. It was necessary to add significant amounts of polar solvents to the $\mathrm{CO}_{2}$ eluent to obtain a useful solvent strength. These solvent additions greatly limited the advantages of pure $\mathrm{CO}_{2}$, and the use of capillary SFC never became a mainstream method.

With the increased environmental concerns, SFC with packed columns recently saw a rebirth as a potential replacement for normal-phase liquid chromatography [3]. The use of packedcolumn SFC grew relative to capillary SFC, which also had limited sample capacity and lacked preparative capabilities. Instrumentation for packed-column SFC was made more reliable using many of the same components as traditional LC [2]. A LC pump with a chilled head is used to measure $\mathrm{CO}_{2}$ in the liquid state and a second LC pump dispenses the organic modifier. The composition of the eluent is controlled by varying the flows delivered by each 
pump as in any LC gradient system [3]. A backpressure regulator is required at the system outlet to control the pressure and prevent expansion of the eluent into a gas in the detector cell. This implies that the detector cell, which is similar to a LC UV detector, must be capable of withstanding elevated pressure.

Chiral SFC with packed columns was first proposed for the separation of chiral phosphorouscontaining derivatives by Mourier et al. in 1985 [4]. The properties of supercritical fluids are especially useful in chiral separations that use almost exclusively subcritical mobile phases containing large amounts of modifier and mild conditions [5]. Using SFC for chiral separations, it is expected that the increased diffusivity will lead to sharper peaks and increased resolution. The low viscosity of SFC eluents should allow faster separations and rapid method development. The last point is essential. With rapid column equilibration, simple mobile phase composition and a reduced number of columns to evaluate, SFC is selected as the first try for chiral separations in some industrial cases [6].

The macrocyclic glycopeptide chiral stationary phases has been found to be extremely useful in the chiral separation of native amino acids [7-9], food flavors [10], so-called enantiomerically pure reagents and catalysts $[11,12]$, and a wide variety of compounds of various polarities [13-15]. Macrocyclic antibiotic columns were used with SFC mobile phases. A vancomycin based CSP was able to separate the enantiomers of $\beta$-adrenergic blocking agents and other pharmaceuticals [16]. Cyclic ketones and dioxalene derivatives were separated by chiral SFC using teicoplanin and vancomycin based columns [17]. A ristocetin CSP was tested with SFC mobile phases to resolve the enantiomers of acidic drugs 
[18]. 44 racemates were evaluated for separation on teicoplanin and vancomycin CSPs with SFC mobile phases [19].

An in depth evaluation of the capabilities of macrocyclic glycopeptide-based CSPs used with SFC mobile phases has not been reported to our knowledge. In this work a set of 111 chiral compounds with widely differing functionalities, acids, bases, heterocyclic compounds, $\beta$ blockers, chiral sulfoxides, derivatized and native amino-acids, was tested with three commercially available macrocyclic based CSPs: teicoplanin (T), ristocetin (R) and the

recently introduced teicoplanin aglycone (TAG) [20]. Experimental conditions were deliberately chosen to favor fast (high flow rates) rather than efficient (high plate number) separations. The results obtained on the three CSPs are compared and discussed in terms of enantiorecognition capabilities.

\subsection{Experimental}

\section{SFC Chromatograph}

A Berger Instrument SFC with a flow control module, an automatic injector, a diode array detector and a Berger Instruments ChemStation (Berger Instruments, Newark, DE, USA) was used. The chromatograph had two reciprocating pumps, one with a refrigerated head was dispensing the liquid $\mathrm{CO}_{2}$, the second one controlled the organic modifier. A personal scale was placed under the $\mathrm{CO}_{2}$ cylinder as a gauge indicating the amount of $\mathrm{CO}_{2}$ remaining in it. 


\section{Chiral Stationary Phases}

Three different $25 \mathrm{~cm} \times 4.6 \mathrm{~mm}$ i.d. columns were obtained from Astec, Whippany, NJ, USA. They were Chirobiotic $\otimes ~ T$, Chirobiotic $R$ and Chirobiotic TAG whose chiral selectors were, respectively, the teicoplanin, $\mathrm{C}_{88} \mathrm{H}_{97} \mathrm{Cl}_{2} \mathrm{~N}_{9} \mathrm{O}_{33}$, m.w. 1878, and ristocetin, $\mathrm{C}_{95} \mathrm{H}_{110} \mathrm{~N}_{8} \mathrm{O}_{44}$, m.w. 2066, macrocyclic glycopeptides and the aglycone core of teicoplanin, $\mathrm{C}_{58} \mathrm{H}_{45} \mathrm{Cl}_{2} \mathrm{~N}_{7} \mathrm{O}_{18}$, m.w. 1197. These chiral stationary phases (CSPs) were extensively described in previous articles [8-14].

\section{The Solutes}

111 solutes of a wide variety of functionalities were evaluated on the three Chirobiotic CSPs. They were sorted in 6 classes referred to by letters A to F. Class A contains a variety of heterocyclic compounds that are mainly amides (oxazolidinone or imidazolidinone) and esters (lactone, furanone). Three compounds of this class, hydrobenzoin (A15), N,Sdimethyl-S-phenylsulfoximine (A16) and norgestrel (A18) are not heterocyclic compounds. Class B is made of chiral acids, especially anti-inflammatory molecules (the "profen" family) and propionic acid derivatives. Class $\mathrm{C}$ is the $\beta$-blockers compounds. Class $\mathrm{D}$ is made of 31 chiral sulfoxides, many of them especially synthesized by the group of Dr. Jenks at Iowa State University. Class E compounds are dinitrophenyl (DNP), dinitropyridyl (DNPyr) or carboxybenzyl (CBZ) $N$-derivatized amino-acids. Class $\mathrm{F}$ gathers underivatized aminoacids. 


\section{Other Chemicals}

Only SFC grade $\mathrm{CO}_{2}$ (Matheson Gas, Chicago, $\mathrm{IL}$, USA) in $17.7 \mathrm{~kg}$ cylinders was used. Triethylamine (TEA) and dimethylamine (DMA) were purchased from Aldrich (Milwaukee, WI, USA). Methanol, trifluoroacetic acid (TFA) and glycerol were from Fisher Scientific (Fairlawn, NJ, USA). The chiral sulfoxides were synthesized by the Jenks' group at Iowa State University (Ames, IA, USA). All the other chiral compounds were obtained from Sigma (St Louis, MO, USA).

\section{Protocol}

The solutes were dissolved in methanol (concentration between 1 and $5 \mathrm{mg} / \mathrm{mL}$ ) except native amino-acids that were dissolved in water ( $\mathrm{pH}$ 1). All separations were done in isocratic condition at $31^{\circ} \mathrm{C}$ and regulating the pressure at the detector outlet at $100 \mathrm{~kg} / \mathrm{cm}^{2}$ (100 bar, $10 \mathrm{MPa}$ or 1430 p.s.i.). The organic additive pump was fed by the methanol + TFA and/or TEA mixture. Small amounts of glycerol and/or water were added to elute native amino-acids. Three wavelengths, 214, 220 and $254 \mathrm{~nm}$, were continuously monitored.

\subsection{Results and Discussion}

\section{Selecting the experimental conditions}

All previous studies using SFC and macrocyclic glycopeptide CSPs have shown that the enantioselectivity factors decreased as the temperature increased [17-19]. So a constant and low temperature, $31^{\circ} \mathrm{C}$, was selected for all separations. Similarly, it was found that raising the pressure decreased the enantioresolution factors [17]. A constant outlet pressure of 100 bar (10 MPa or 1430 p.s.i.) was used in all cases. The SFC instrument controls the mobile 
phase pressure at the column outlet, after the detector cell (see Experimental). This means that the actual inlet pressure is not the same for all experiments although it is constant during a given isocratic separation. The inlet pressure depends on the column permeability and on the mobile phase composition. Since the mobile phase viscosity increases when the methanol percentage increases, the inlet column pressure is higher, at constant flow rate, when a high percentage of methanol is added to $\mathrm{CO}_{2}$.

It can be argued that the mobile phases used are not all supercritical fluids. However, it was demonstrated that the changes in viscosity and solute diffusion coefficients between supercritical and subcritical or liquid mobile phases were continuous $[2,21]$. The mobile phase compositions used in this work contained between 4 and $60 \% \mathrm{v} / \mathrm{v}$ methanol as organic modifier. When $60 \%$ methanol is "added" to $\mathrm{CO}_{2}$, it can clearly be considered that it is actually $40 \% \mathrm{CO}_{2}$ that is "added" to liquid methanol. At $31^{\circ} \mathrm{C}$ and more than 100 bar of pressure, the physico-chemical properties of the methanol- $\mathrm{CO}_{2}$ mixtures change gradually from a pure supercritical state (no methanol) to a pure liquid (100\% methanol) through the subcritical state. No phase separation occurs $[3,21]$. So, all $\mathrm{CO}_{2}$-methanol mixtures will be called SFC mobile phases, the S standing for "supercritical" in $\mathrm{CO}_{2}$ rich mobile phases and for "subcritical" in methanol-rich mobile phase.

Trifluoroacetic acid (TFA) and/or triethylamine (TEA) were also added to the SFC mobile phases. Obviously, addition of TFA will protonate the solute and/or stationary phase basic sites and TEA additions will neutralize analyte and/or stationary phase acid sites. These ionization changes greatly affect the solute retention behavior and enantioselectivity. A 
milliliter of TFA and TEA correspond respectively to 13.5 and 7.2 millimoles. Then, when equal volumes of TFA and TEA are added to a mobile phase, it remains acidic. The amount of TFA and TEA added to the SFC mobile phases depends on the solutes studied.

\section{Overall CSP Effectiveness}

Compound D27, methyl hexyl sulfoxide, is the only compound whose enantiomers could not be separated at all $(\mathrm{Rs}=0)$. The enantiomers of all other 110 compounds could be fully separated $(\mathrm{Rs}>1.5)$ by at least one of the macrocyclic glycopeptide CSPs. Table 1 lists the results. By chance, the two teicoplanin based chiral selectors were able to resolve fully (Rs= 1.5 or greater) or partially $(0.4<\mathrm{Rs}<1.5)$ the enantiomers of exactly the same number of compounds: 63 compounds (57\%) were baseline separated by the two Chirobiotic $\mathrm{T}$ and TAG columns and $39(35 \%)$ were partially separated. The enantiomers of 9 compounds only (8\%) could not be resolved. These identical numbers do not correspond to the same compounds. The Chirobiotic $\mathrm{T}$ column was the only one able to separate the enantiomers of compounds A8, A16, D2 and D16 (Table 1). Similarly, the enantiomers of compounds C1, C2, C7 and F11 were separated only with the Chirobiotic TAG column.

The Chirobiotic R column was significantly less successful. It could separate, with baseline return between peaks, the enantiomers of 25 compounds (22\%, Table 1). 42 more compounds (38\%) were partially resolved and there were no separations for the 44 remaining compounds (40\%). However, the enantiomers of D17 and D20 could be separated only by the ristocetin CSP. 


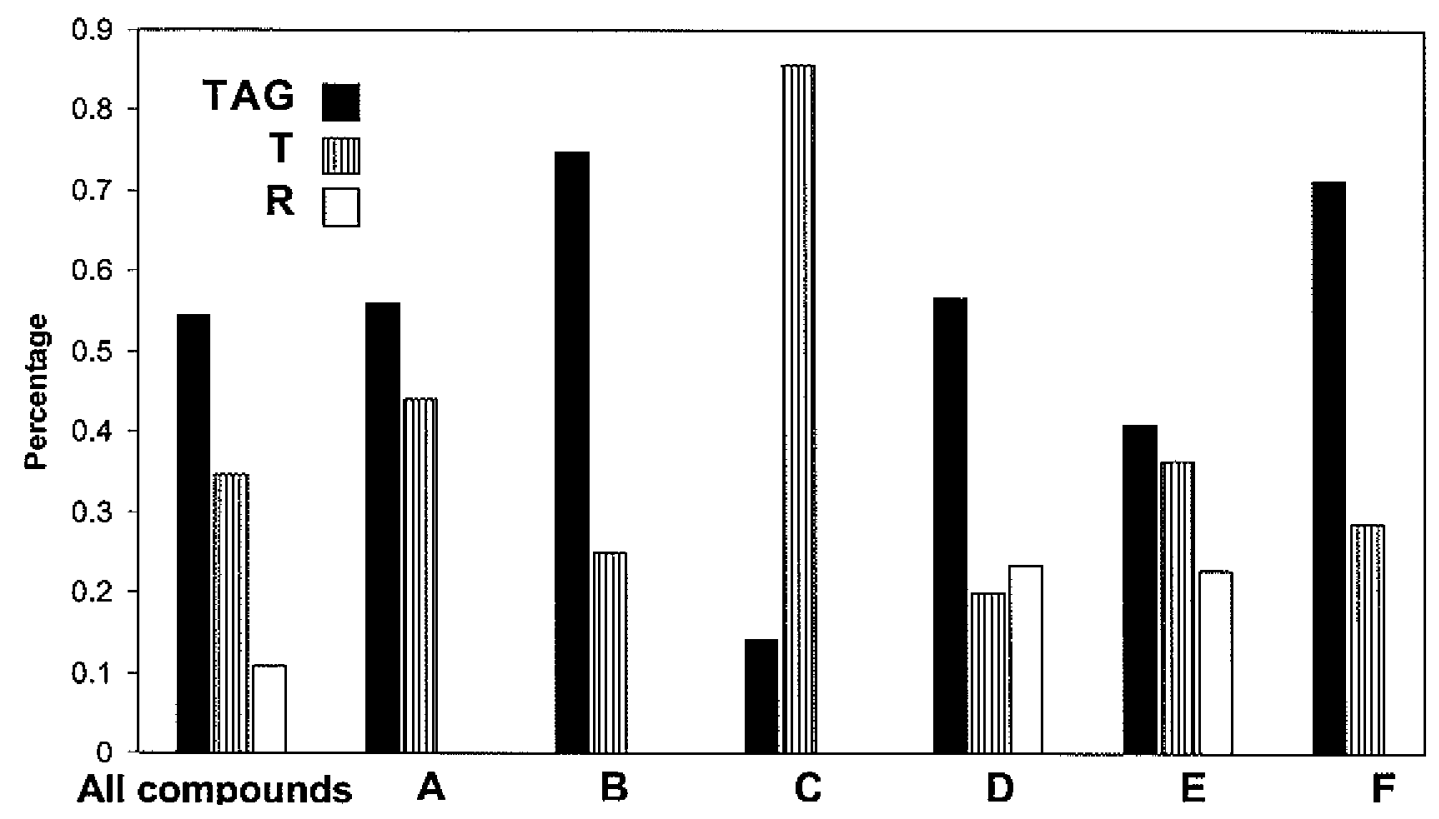

Figure 1. Most effective CSP in the separation of the enantiomers of the 6 classes of compounds. A $=$ heterocyclic compounds, $\mathrm{B}=$ chiral acids, $\mathrm{C}=\beta$-blockers, $\mathrm{D}=$ chiral sulfoxides, $\mathrm{E}=N$-blocked amino acids, $\mathrm{F}=$ native amino-acids.

Table 1 shows that the resolution factors obtained for the same compound with the 3 different columns may differ widely. Figure 1 shows the number of best enantioseparations obtained for each class of compounds and each CSP. Clearly, the Chirobiotic TAG column shows a better effectiveness except in the separation of $\beta$-blockers enantiomers (Class $\mathrm{C}$ ) where the Chirobiotic $\mathrm{T}$ column is clearly superior. Of the whole set of enantiomers, $55 \%$ ( 61 compounds) are best separated by the Chirobiotic TAG column, 35\% (38 compounds) by the Chirobiotic T column and 10\% (11 compounds) by the Chirobiotic R column (Figure. 1). 


\section{Class A, Heterocyclic Compounds}

Most of the compounds in this class have a stereogenic center that is part of a heterocyclic ring. This structural configuration introduces some rigidity in and around the stereogenic center and renders the two enantiomers easier to differentiate compared to stereogenic centers with four freely rotating substituents [22]. This may be the reason why the three highest resolution factors obtained with Chirobiotic $\mathrm{T}$ and $\mathrm{TAG}$ columns correspond to the Class-A compounds. For Chirobiotic T, the Rs values for Compounds A6, A11 and A3 were 12.2, 9.0 and 6.2, respectively (Table 1). For Chirobiotic TAG, the Rs values were 9.1, 8.0 and 6.9 obtained for Compounds A11, A2 and A6, respectively. A Rs value of 8.0 was also obtained on the Chirobiotic R column for the A6 compound. Compounds A15 and A16 are not heterocyclic compounds. They were included with the Class A compounds to compare the enantioresolution obtained with two chiral compounds with a free stereogenic center and compounds with ring-blocked stereogenic centers. A15 and A16 are significantly less enantioresolved by the three CSPs, compared to most other Class-A compounds.

The speed of these enantiomeric separations should be noted. With the standard experimental conditions used, $100 \mathrm{bar}, 31^{\circ} \mathrm{C}$ and $4 \mathrm{~mL} / \mathrm{min}$, and different methanol content as listed in Table 1, all heterocyclic compounds were eluted in less than 10 min. 18 class-A compounds $(70 \%)$ were eluted in less than 5 min. Several compounds of this class were separated by HPLC with similar resolution factors, but the duration of analysis was commonly three times higher [13]. 


\section{Class B, Chiral Acids}

The ristocetin chiral selector is not able to separate the enantiomers of the Class B chiral acids as well as the teicoplanin and its aglycone analogue do. All 12 acids are resolved, at least partially by the Chirobiotic T and TAG columns. The Chirobiotic R column could separate only three.

From a mechanistic point of view, it should be noted that the enantiomers of the acid compounds are separated with two very different mobile phase compositions. They are either acidic SFC mobile phases containing low amounts of methanol $(15 \% \mathrm{v} / \mathrm{v}$ or less) or basic SFC mobile phases with a high methanol content (more than $40 \% \mathrm{v} / \mathrm{v}$ ) (Table 1 ). With TFA containing mobile phases, the class-B solutes are in their molecular form and the CSPs are positively charged since their carboxylic acid groups are neutral and their amine groups are protonated. Acidic polar organic mobile phases are used to separate these compounds by HPLC [11,12]. With basic mobile phases, the acid solutes are negatively charged and so are the CSPs. Table 1 shows that good separation of enantiomeric pairs could be obtained in these conditions with methanol rich SFC mobile phases. Figure 2 illustrates this point with the Chirobiotic T column. Figure 2A shows the separation of Compound B12 with a SFC mobile phase containing $7 \%$ added methanol. The enantiomers are partially separated with tailing peaks in less than 5 min. If a small amount of TFA $(0.1 \% \mathrm{v} / \mathrm{v})$ is added, the enantioseparation is lost (Figure 2B). With an equal $0.1 \%$ amount of TEA and TFA added to the $7 \%$ methanol, the SFC mobile phase is still acidic and one tailing peak is still obtained (Figure $2 \mathrm{C}$ ). When $0.1 \% \mathrm{v} / \mathrm{v}$ TEA is added to the mobile phase, the enantiomers are separated but the retention times increased to over 20 min. Increasing the methanol content 
to $40 \%$, with the $0.1 \% \mathrm{v} / \mathrm{v}$ TEA allows baseline resolution $(\mathrm{Rs}=1.6)$ to be obtained in less than $3 \min$ (Fig. 2D).
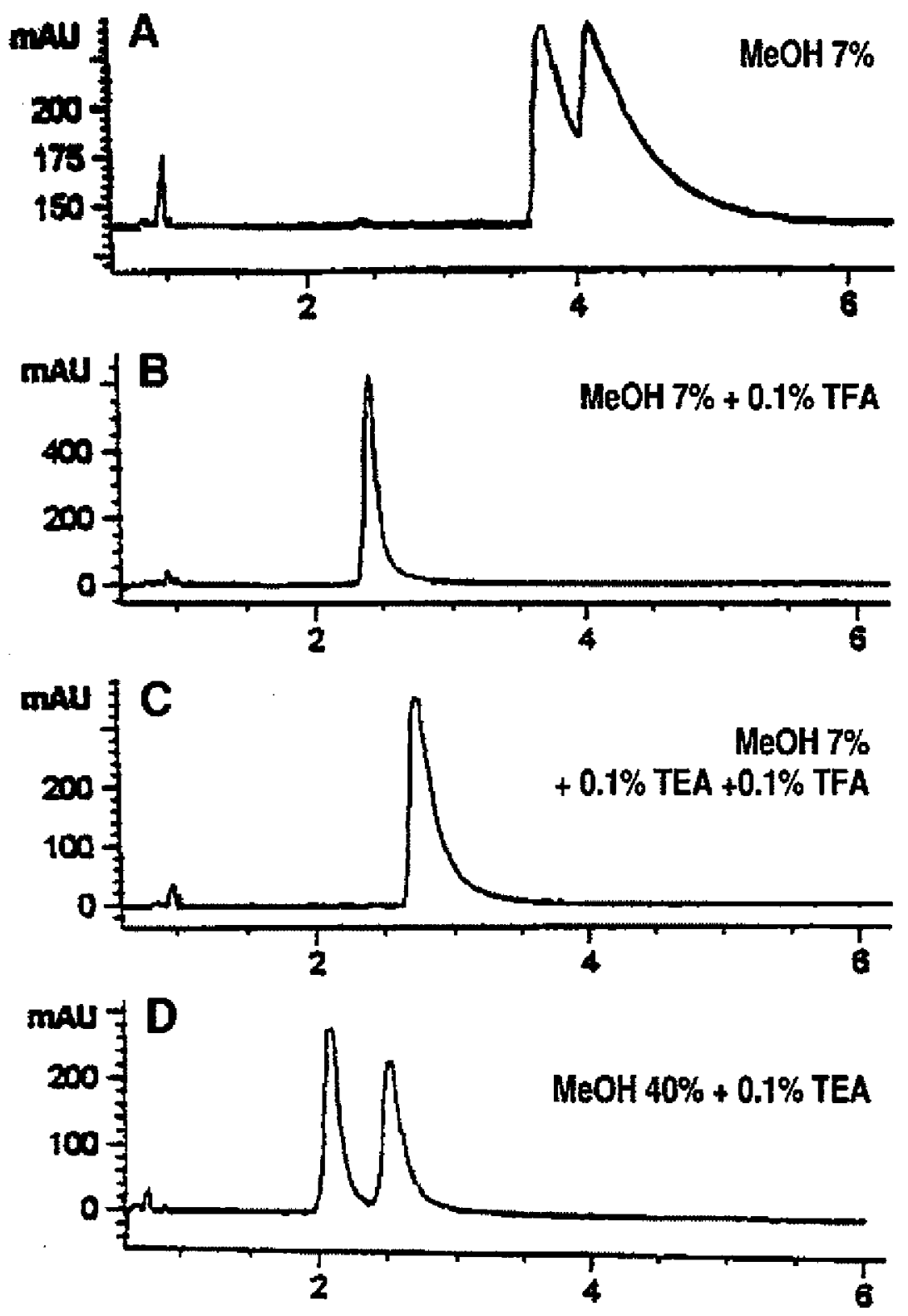

Figure 2. Effect on additives on the separation of the enantiomers of B12, 2-(4-chlorophenoxy) propionic acid. $\mathrm{A}: \mathrm{CO}_{2}+7 \% \mathrm{v} / \mathrm{v}$ methanol, $4 \mathrm{~mL} / \mathrm{min}, 100$ bar outlet pressure, $31^{\circ} \mathrm{C}$; $\mathrm{B}$ : Same as $\mathrm{A}$ except $0.1 \%$ trifluoroacetic acid were added to methanol; C: Same as A except $0.1 \%$ trifluoroacetic acid and $0.1 \%$ triethylamine were added to methanol; D: Same as A except $40 \%$ methanol and $0.1 \%$ triethylamine were added to $\mathrm{CO}_{2}$. 


\section{Class C, $\beta$-blockers}

The $\beta$-adrenergic blockers are all secondary amines with very similar molecular structures (i.e., $\left.\mathrm{R}-\mathrm{O}-\mathrm{CH}_{2}-\mathrm{C}{ }^{*} \mathrm{HOH}-\mathrm{CH}_{2}-\mathrm{NH}-\mathrm{CH}\left(\mathrm{CH}_{3}\right)_{2}\right)$. The $\mathrm{R}$ substituent is always aromatic. It was necessary to use high amounts of methanol (more than $20 \% \mathrm{v} / \mathrm{v}$ ) and to add $0.1 \% \mathrm{v} / \mathrm{v}$ of both TEA and TFA to most SFC mobile phases. These mixtures are acidic since $0.1 \% \mathrm{v} / \mathrm{v}$ TEA (7.3 mM) is completely neutralized by $0.1 \% \mathrm{v} / \mathrm{v}$ TFA $(13.5 \mathrm{mM})$. It means the $\beta$-blockers are in their protonated cationic form when separated by the glycopeptide-based CSP columns.

The ristocetin chiral selector was unable to resolve enantiomers of any Class $\mathrm{C}$ compounds. Teicoplanin was the best chiral selector for this set of compounds. The teicoplanin aglycone was able to approach the results obtained with teicoplanin for three compounds (C3, C4 and C5) and to match them for C6 (propanolol, Table 1). All successful chiral separations were obtained with more than $40 \% \mathrm{v} / \mathrm{v}$ methanol.

\section{Class D, Chiral Sulfoxides}

Trivalent sulfur compounds such as sulfoxides have non-planar geometries and, when asymmetrically substituted, can be found as stable enantiomers at room temperature [23]. Traditionally, the sulfoxide group has been represented in illustrations as $\mathrm{S}=\mathrm{O}$, implying the existence of a second bond between the two atoms. A more modern understanding is that the S-O bond is more ylide-like, i.e. the molecule bears no overall charge but has a negatively charged oxygen atom bonded to a positively charged sulfur atom [24]. The sulfur stereogenic center is pyramidal, with a lone pair occupying the fourth position of the 
pseudotetrahedral center. We demonstrated in recent work that the Chirobiotic T, TAG and $R$ were very effective in separating sulfoxide enantiomers in the normal phase mode (hexaneethanol $90-10 \% \mathrm{v} / \mathrm{v}$ mobile phases) [25]. It was then logical to try SFC conditions to separate these compounds with the same Chirobiotic CSPs.

No additive other than methanol in small amounts $(7 \%$ or $15 \% \mathrm{v} / \mathrm{v})$ was needed to obtain the enantioseparations. Fig. 1 shows that the TAG CSP was the most effective stationary phase for this class of compounds. The Chirobiotic TAG column could separate the enantiomers of 28 sulfoxides (90\%) of which 17 sulfoxides $(55 \%)$ were baseline separated. The teicoplanin based CSP could separate 25 compounds (80\%) and $15(48 \%)$ with baseline return. The Chirobiotic R column could separate 16 compounds (52\%) with only $6(20 \%)$ at baseline. Compounds D2 and D16 were separated by the TAG CSP only. Similarly, Compounds D17 and D20 showed enantioresolution with the R CSP only.

These results correspond to what was obtained with the same columns and hexane-ethanol $90-10 \% \mathrm{v} / \mathrm{v}$ or hexane-isopropyl alcohol $90-10 \% \mathrm{v} / \mathrm{v}$ normal mobile phases [25]. Figure 3 compares the enantioselectivity factors obtained with SFC and HPLC (hexane-ethanol 90-10 $\% \mathrm{v} / \mathrm{v}$ normal mobile phase) for the ortho, meta and para isomers of the methyl, chloro and bromo methyl-phenyl sulfoxides, Compounds D2-D4, D6-D8 and D9-D11, respectively. The similarity of the results is striking. The enantioselectivity factor on the TAG CSP and teicoplanin CSP shows a maximum for all meta isomers, in SFC as well as in HPLC in the normal-phase mode. The enantioselectivity factors obtained with HPLC are slightly (teicoplanin) or significantly (TAG) higher than those obtained with SFC (Fig. 3). D27, the 
only compound that was not separated in SFC, was also not separated in HPLC with the same three CSPs and normal-phase mobile phases. Though, D27 was baseline separated by the teicoplanin and TAG columns with a methanol-pH 4.1 buffer $20-80 \% \mathrm{v} / \mathrm{v}$ reversed mobile phase [25]. It seems that the chiral recognition mechanism for the sulfoxides is very similar with $\mathrm{CO}_{2}$-methanol mobile phases and normal phase hexane-alcohol mobile phases.
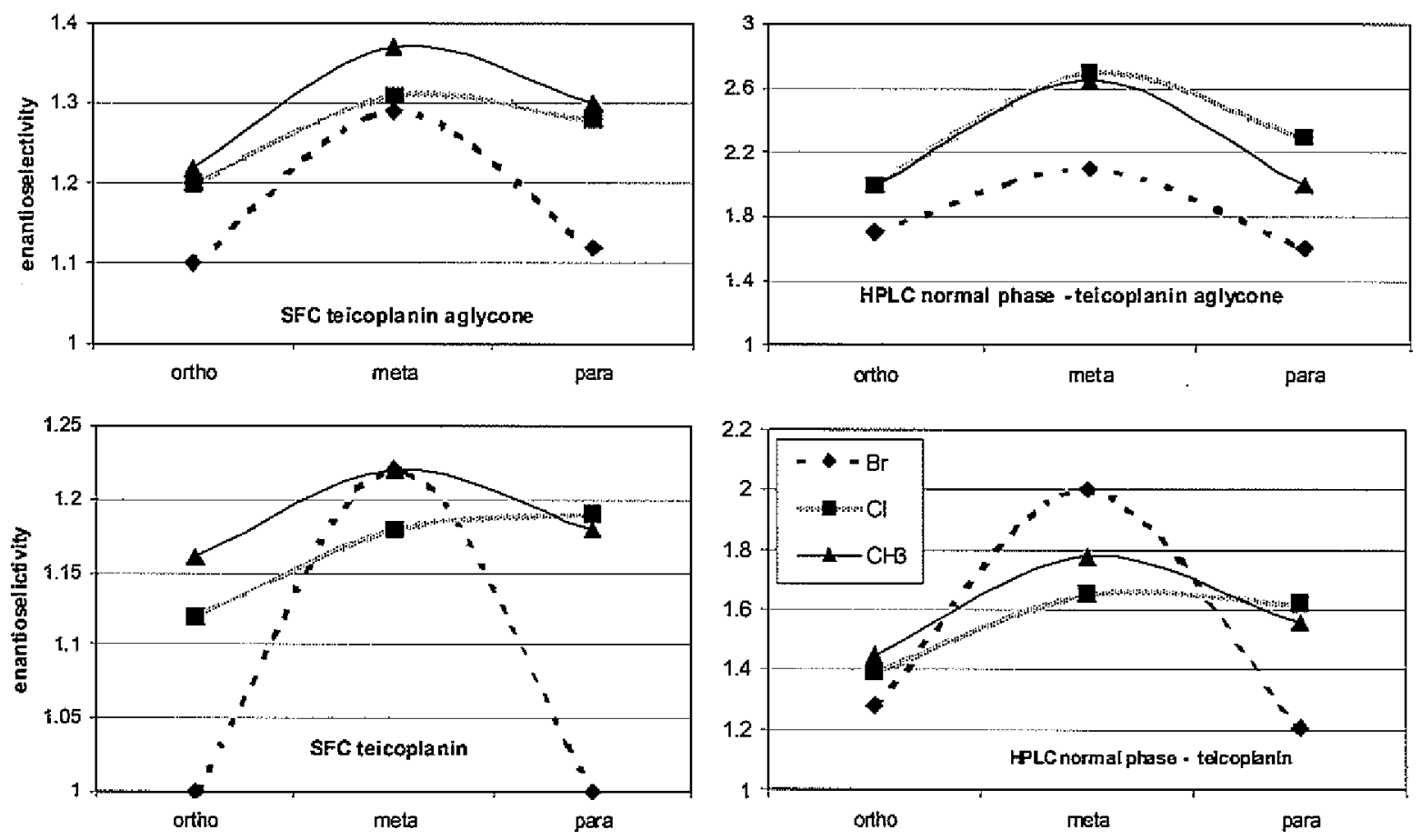

Figure 3: Comparing SFC and HPLC enantioselectivity for ortho, meta and para substituted phenyl methyl sulfoxides. Top figures: column Chirobiotic TAG. Bottom figures: column Chirobiotic T. Left figures: SFC with $7 \% \mathrm{v} / \mathrm{v}$ methanol, $100 \mathrm{bar}, 31^{\circ} \mathrm{C}, 4 \mathrm{~mL} / \mathrm{min}$. Right figures: HPLC with hexane-isopropyl alcohol $(90-10 \% \mathrm{v} / \mathrm{v}), 1 \mathrm{~mL} / \mathrm{min}$, data from [25].

The similarities between the HPLC findings and the SFC results were not absolute. For example, the ristocetin chiral selector was least effective for sulfoxide enantioresolution; it is, however, the only one that separated the enantiomers of compounds D17 and D20 and the 
most effective selector for compounds D18 and D19 with SFC mobile phases. All four compounds are derivatives of phenyl benzyl sulfoxides. With HPLC normal-phase mobile phases, compound D19 was the only one that matched the SFC results. It was partially resolved by the ristocetin CSP only [25]. D17, D18 and D20 were better resolved by the Chirobiotic T and TAG CSPs. Compound D17 was partially separated by the TAG CSP only; compounds D18 was partially resolved by the three CSPs, and compound D20 was partially separated by the teicoplanin and TAG CSPs, and not by the ristocetin CSP, an opposite result compared to SFC.

\section{Class E, N-blocked Amino-Acids}

$\mathrm{N}$-blocked amino-acids are acidic compounds. So they should be separated using conditions similar to the ones used for Class $\mathrm{B}$ acidic compounds. It turned out that the $7 \% \mathrm{v} / \mathrm{v}$ methanol $0.5 \%$ TFA SFC mobile phase was not useful in separating the enantiomers of these compounds. The methanol rich SFC mobile phases were much more successful. Most baseline separations were obtained with $40 \%$ or $60 \%$ methanol in the SFC mobile phases. Addition of $0.1 \% \mathrm{v} / \mathrm{v}$ TEA was often needed to obtain the enantioseparation, which means the solutes and the stationary phase were in negatively charged forms.

Figure 4 illustrates the additive effect with the Chirobiotic $\mathrm{T}$ column and Compound E4 (DNPyr-leucine). Figure 4A shows that a baseline separation is obtained with $15 \%$ methanol and no other additives. The peaks are tailing somewhat. The separation is lost when $0.1 \%$ TFA is added (Figure 4B). Adding both TEA and TFA (0.1\%) partially restores the enantioseparation (Figure 4C). Adding only $0.1 \%$ TEA produced an excellent separation but 
retention times greater than $25 \mathrm{~min}$ (not shown). Increasing the methanol content to $40 \% \mathrm{v} / \mathrm{v}$ decreased the retention times below $4 \mathrm{~min}$ as shown by Figure 4D with enantioselectivity and resolution factors as high as 2.3 and 5.4 , respectively.

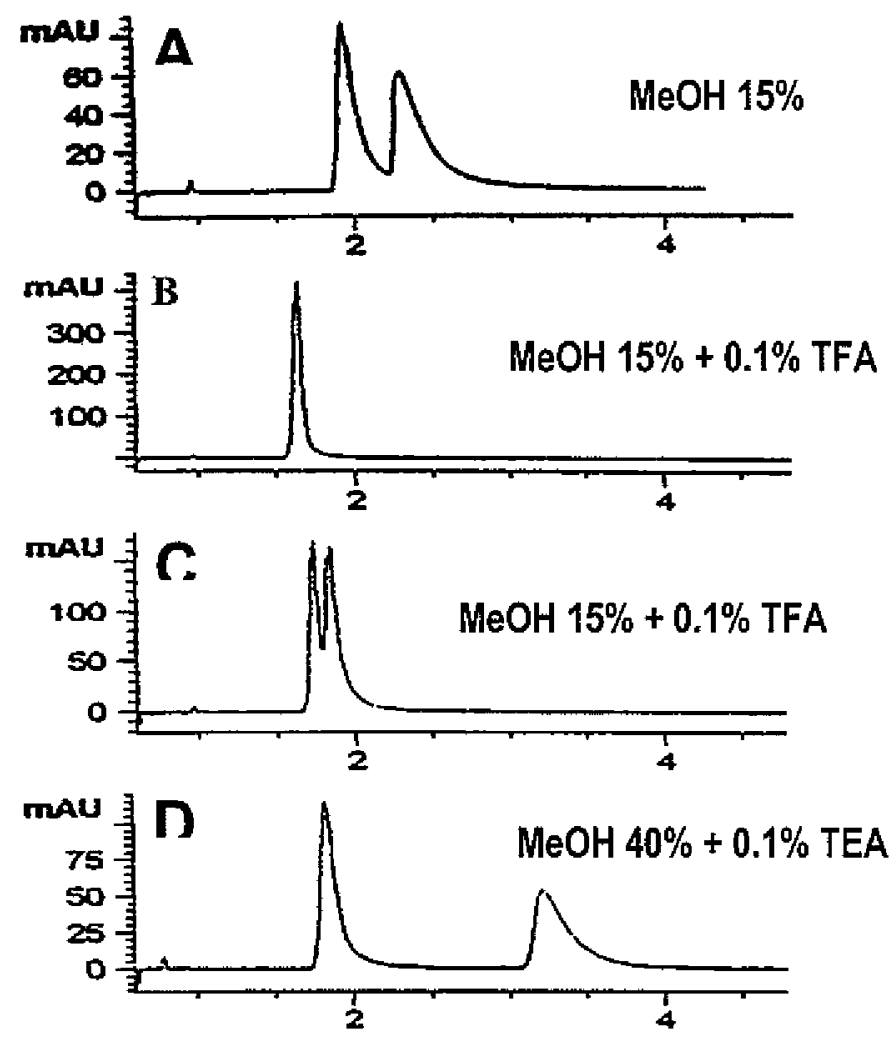

Figure 4. Effect on additives on the separation of the enantiomers of E4, DNPyr-leucine. $\mathrm{A}: \mathrm{CO}_{2}+$ $15 \% \mathrm{v} / \mathrm{v}$ methanol, $4 \mathrm{~mL} / \mathrm{min}, 100$ bar outlet pressure, $31^{\circ} \mathrm{C} ; \mathrm{B}$ : Same as A except $0.1 \%$ trifluoroacetic acid were added to methanol; C: Same as A except $0.1 \%$ trifluoroacetic acid and $0.1 \%$ triethylamine were added to methanol, separation is partially restored (compare with Fig. 2C); D: Same as A except $40 \%$ methanol and $0.1 \%$ triethylamine were added to $\mathrm{CO}_{2}$.

The enantiomers of the DNPyr or CBZ derivatives of alanine (E3 and E17, respectively) were extremely well separated on all three CSPs without any optimization. The 
enantioselectivity factors were higher than 1.6 and the enantioresolution factors were higher than 2.5 (Table 1). This is due to the natural antibiotic property of the three CSPs that bind to the D-Ala-D-Ala terminal group of the terminal dipeptide of the microbial cell wall of Gram+ bacteria [26]. The chiral selectors have a high affinity for the D-Ala amino-acid and the L-Ala form is much less retained. Since the amine group of alanine is derivatized, it shows that the carboxylic acid group is essential in the recognition mechanism [8-12]. Changing the methyl group attached to the stereogenic center of alanine for other groups produces the other amino acids that are also enantiodifferenciated by the CSPs, but somewhat less well than alanine (Table 1).

Figure 5 compares the separation of E19 (CBZ-norvaline) in HPLC with a classical methanol-pH 4.1 buffer (20-80\% v/v) and the SFC separation with $40 \%$ methanol on both the Chirobiotic $\mathrm{T}$ and $\mathrm{R}$ columns. In all cases, the enantiomers were baseline separated. The peak shape obtained with the classical reversed phase mobile phases is better than the one obtained with the SFC mobile phases. But the HPLC separations that needed 18 min or 13 min on ristocetin or teicoplanin CSPs, respectively, were performed in less than 3 min with SFC mobile phases (Fig. 5).

\section{Class F, Native Amino Acids.}

It was mentioned in the introduction that SFC is a useful substitute to normal phase chromatography. In this work, polar compounds such as native, underivatized amino acids, that require reversed phase polar mobile phases in HPLC, were tested to see if they could be enantioresolved by SFC. Two problems were encountered: 1) native amino acids lacking an 
aromatic substituent poorly absorb UV light making them difficult to detect. Only the 214 $\mathrm{nm}$ detector wavelength gave some absorbance. 2) Following the example of Medvedovici et al., small amounts of water and/or glycerol can be added to the mobile phase to enhance the solubility of polar analytes and to improve peak shape [19].
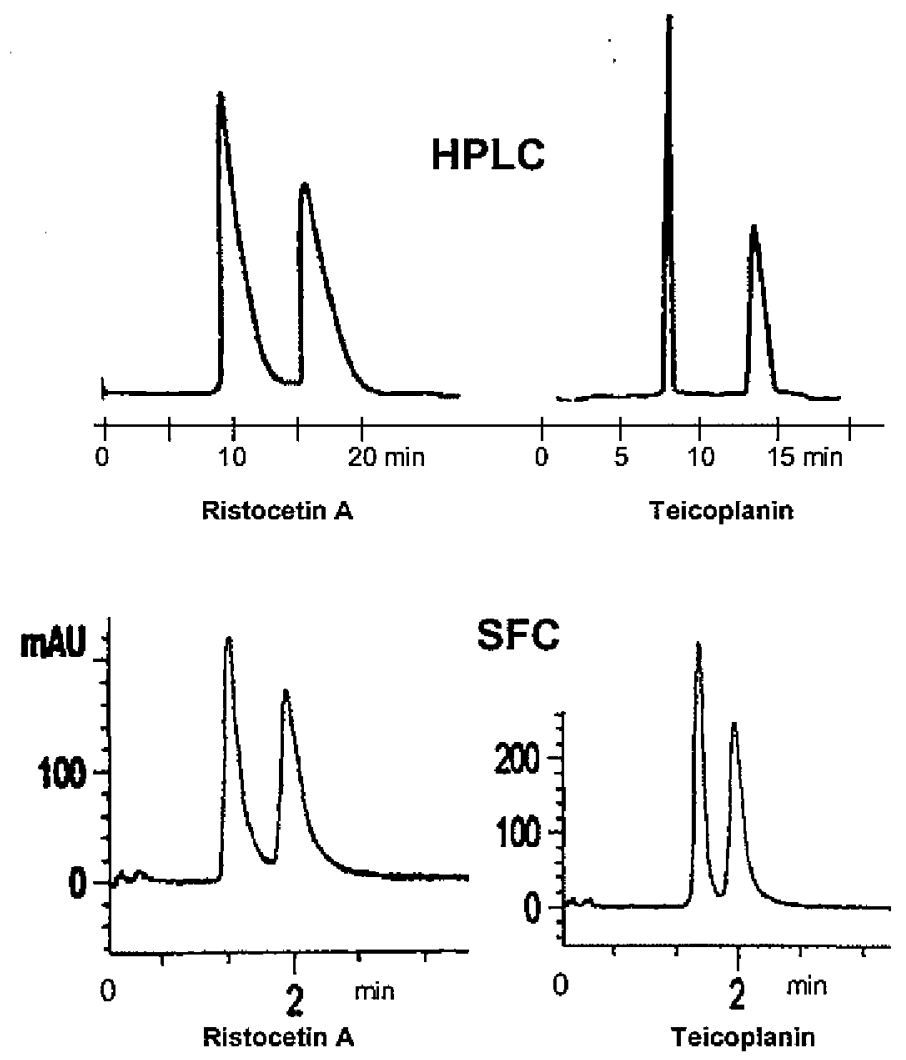

Figure 5: Comparison of HPLC (top) and SFC (bottom) enantiomer separations of E19 (CBZnorvaline) on Chirobiotic R (left) and Chirobiotic $\mathrm{T}$ (right) columns. HPLC: pH 4.1 buffer-methanol $(80: 20 \% \mathrm{v} / \mathrm{v})$ mobile phase, $1 \mathrm{~mL} / \mathrm{min}$, room temperature. SFC: $\mathrm{CO}_{2}$-methanol-TEA (60:40:0.1\% v/v) mobile phase, $4 \mathrm{~mL} / \mathrm{min}, 31^{\circ} \mathrm{C}, 100$ bar.

All 24 underivatized amino-acids were enantioseparated almost always to baseline by the three macrocyclic glycopeptide CSPs with mobile phase containing more than $47.5 \% \mathrm{v} / \mathrm{v}$ methanol, $2 \%$ or more water, $0.1 \%$ or more TEA, $0.1 \%$ or more TFA and $0.3 \%$ glycerol. 
Figure 6 shows the separation of F7 (phenylalanine) on the Chirobiotic T and R columns, comparing the SFC and classical reversed phase mobile phases. It can be seen that the reversed phase HPLC separation of phenylalanine is as good as or even better than the corresponding separation by SFC. The retention time is slightly lower with SFC but the peak shape is significantly poorer as well.
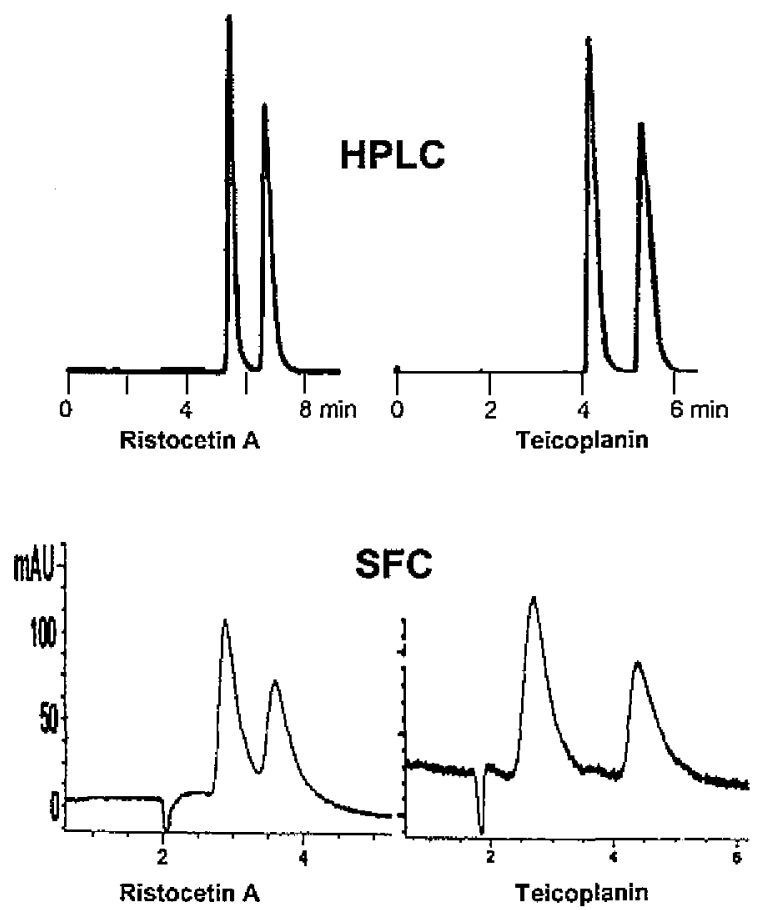

Figure 6: Comparison of HPLC (top) and SFC (bottom) enantiomer separations of F7 (phenylalanine) on Chirobiotic $\mathrm{R}$ (left) and Chirobiotic $\mathrm{T}$ (right) columns. HPLC and ristocetin: water-methanol $(50: 50 \% \mathrm{v} / \mathrm{v})$ mobile phase; HPLC and teicoplanin: water-ethanol $(50: 50 \% \mathrm{v} / \mathrm{v})$ mobile phase, $1 \mathrm{~mL} / \mathrm{min}$, room temperature. SFC: $\mathrm{CO}_{2}$-methanol-water-glycerol-TEA-TFA (49.5:48:2:0.3:0.1:0.1\% v/v) mobile phase, $4 \mathrm{~mL} / \mathrm{min}, 31^{\circ} \mathrm{C}, 100$ bar. 


\section{Elution Order}

It is often of great interest to know the enantiomeric elution order of chiral separations. A change in the elution order of some compounds was observed with the same mobile phase when changing the chiral selector [27]. Pure enantiomers are needed to identify the compounds and determine the elution order. It was not possible to have such pure enantiomers for all 111 compounds. Table 2 lists the compounds for which the elution order could be determined.

Table 2. Elution order of the compounds eluted by SFC on the three CSPs

\begin{tabular}{llll}
\hline Compound & teicoplanin & TAG & ristocetin \\
\hline A1 & $(\mathrm{R}),(\mathrm{S})$ & $(\mathrm{R}),(\mathrm{S})$ & no separation \\
A2 & $(\mathrm{R}),(\mathrm{S})$ & $(\mathrm{R}),(\mathrm{S})$ & $(\mathrm{R}),(\mathrm{S})$ \\
A3 & $(\mathrm{R}),(\mathrm{S})$ & $(\mathrm{R}),(\mathrm{S})$ & $(\mathrm{R}),(\mathrm{S})$ \\
A4 & $(\mathrm{R}),(\mathrm{S})$ & $(\mathrm{R}),(\mathrm{S})$ & $(\mathrm{R}),(\mathrm{S})$ \\
A5 & $(4 \mathrm{~S}, 5 \mathrm{R}),(4 \mathrm{R}, 5 \mathrm{~S})$ & $(4 \mathrm{R}, 5 \mathrm{~S}),(4 \mathrm{~S}, 5 \mathrm{R})$ & $(4 \mathrm{~S}, 5 \mathrm{R}),(4 \mathrm{R}, 5 \mathrm{~S})$ \\
A6 & $(4 \mathrm{~S}, 5 \mathrm{R}),(4 \mathrm{R}, 5 \mathrm{~S})$ & $(4 \mathrm{~S}, 5 \mathrm{R}),(4 \mathrm{R}, 5 \mathrm{~S})$ & $(4 \mathrm{~S}, 5 \mathrm{R}),(4 \mathrm{R}, 5 \mathrm{~S})$ \\
A7 & $(4 \mathrm{R}, 5 \mathrm{~S}),(4 \mathrm{~S}, 5 \mathrm{R})$ & $(4 \mathrm{R}, 5 \mathrm{~S}),(4 \mathrm{~S}, 5 \mathrm{R})$ & no separation \\
A9 & $(\mathrm{S}),(\mathrm{R})$ & $(\mathrm{S}),(\mathrm{R})$ & $(\mathrm{S}),(\mathrm{R})$ \\
C6 & $(\mathrm{S}),(\mathrm{R})$ & $(\mathrm{S}),(\mathrm{R})$ & $(\mathrm{S}),(\mathrm{R})$ \\
D compounds* & $(\mathrm{S}),(\mathrm{R})$ & $(\mathrm{S}),(\mathrm{R})$ & $(\mathrm{R}),(\mathrm{S})$ \\
E compounds* & $(\mathrm{L}, \mathrm{D})$ & $(\mathrm{L}, \mathrm{D})$ & $(\mathrm{L}, \mathrm{D})$ \\
F compounds* & $(\mathrm{L}, \mathrm{D})$ & $(\mathrm{L}, \mathrm{D})$ & $(\mathrm{L}, \mathrm{D})$ \\
\hline
\end{tabular}

* for the separated enantiomers

In most cases, the same elution order was obtained with the three CSPs. For the compounds that were tested for elution order, only A5 and C6 showed inversion of the elution order with 
the TAG column compared to the $\mathrm{T}$ and $\mathrm{R}$ columns (Table 2). The sulfoxide compounds (Class D) are exceptions. All chiral sulfoxides showed the $(\mathrm{S})-(+)$ as the first eluting enantiomer on the teicoplanin and TAG columns. The (R)-(-) sulfoxide enantiomer was first eluted with the ristocetin A column. The high affinity of the natural chiral selector for the Dform $(R)$ of the amino-acids makes this enantiomer always more retained than the L-amino acid (S form).

\subsection{Conclusions}

The separation time factor is the greatest advantage of the SFC mobile phases. As can be seen in Table 1, all separations done with subcritical mobile phases were performed in less than $15 \mathrm{~min}, 70 \%$ of the separations being done in less than $4 \mathrm{~min}$. The peak shape is not as symmetrical as that obtained in the corresponding HPLC separations. It should also be pointed out that the column equilibrates much faster with $\mathrm{CO}_{2}$-containing mobile phases than in normal phase HPLC. This work also showed that the macrocyclic based CSPs are able to separate enantiomers of widely different compounds with various functionalities and polarities. The teicoplanin aglycone and teicoplanin CSPs seem to be the most effective stationary phase with SFC mobile phases.

\section{Acknowledgements}

Berger Instruments (Newark, DE, USA) is gratefully thanked for the loan of a full analytical SFC system. Dr. Jenks and his group at Iowa State University are thanked for providing most of the chiral sulfoxide compounds tested. A. Berthod thanks the French National Center for 
Scientific Research (CNRS ERS2007 FRE2394) for sabbatical leave at ISU. Support by the National Institute of Health NIH R01 GM 53825 is also gratefully acknowledged.

\section{References}

1. E. Klesper, A.H. Corwin, D.A. Turner, J. Org. Chem. 27 (1962) 700-701.

2. K.W. Phinney, Anal. Chem. 72 (2000) 204A-211A.

3. T.A. Berger, Packed Column SFC, Royal Society of Chemistry, Cambridge, 1995.

4. P.A. Mourier, E. Eliot, M. Caude, R. Rosset, A. Tambute, Anal. Chem. 57 (1985) 28192827.

5. G. Terfloth, I. Chromatogr. A, 906 (2001) 301-307.

6. C.J. Welch, Merck \& Co, Rahway, $\mathrm{NJ}$, presentation at Iowa State University, Feb. 15, 2002.

7. A. Berthod, Y. Liu, C. Bagwill, D.W. Armstrong, J. Chromatogr. A, 731 (1996) 123-137.

8. D.W. Armstrong, Y. Tang, S. Chen, Y. Zhou, C. Bagwill, J.R. Chen, Anal. Chem., 66 (1994) 1473-1484.

9. A. Peter, G. Torok, D.W. Armstrong, J. Chromatogr, A, 793 (1998) 283-296.

10. K.H. Ekborg-Ott, D.W. Armstrong, in Chiral Separations: Application and Technology, ACS, Washington, DC, Ch. 9, pp. 201-270, 1997.

11. K.H. Ekborg-Ott, Y. Liu, D.W. Armstrong, Chirality, 10 (1998) 2043-2064.

12. D.W. Armstrong, L. He, T. Yu, J.T. Lee, Y. Liu, Tetrahedron: Asymmetry, 10 (1999) 3760.

13. Chirobiotic Handbook, $4^{\text {th }}$ ed, 2002; http://www.astecusa.com 
14. A. Berthod, X. Chen, J.P. Kullman, D.W. Armstrong, F. Gasparrini, I. D'Aquarica, C. Villani, A. Carotti, Anal. Chem., 72 (2000) 1767-1780.

15. T.J. Ward, A.B. Farris, J. Chromatogr. A, 906 (2001) 73-89.

16. J. Dönnecke, L.A. Svensson, O. Gyllenhaal, K.E. Karlsson, A. Karlsson, J. Vessman, $J$. Microcol. Sep., 11 (1999) 521-533.

17. L. Toribio, F. David, P. Sandra, Quimica Analitica, 18 (1999) 269-273.

18. L.A. Svensson, P.K. Ovens, Analyst, 125 (2000) 1037-1039.

19. A. Medvedovici, P. Sandra, L. Toribio, F. David, J. Chromatogr. A, 785 (1997) 159-171.

20. A. Berthod, X. Chen, J.P. Kullman, D.W. Armstrong, F. Gasparrini, I. D'Acquarica, A. Carotti, A. Villani, Anal. Chem. 72 (2000) 1767-1780.

21. T.A. Berger, J. Chromatogr. A, 785 (1997) 3-33.

22. A. Berthod, C. Bagwill, U. Nair, D.W. Armstrong, Talanta, 43 (1996) 1767-1782.

23. K. Mislow, A.J. Gordon, D.R. Rayner, J. Amer. Chem. Soc., 90 (1968) 4854-4859.

24. J.A. Dobado, H. Martinez-Garcia, J.M. Molina, M.R. Sundberg, J. Amer. Chem. Soc., 121 (1999) 3156-3160.

25. A. Berthod, T.L. Xiao, Y. Liu, W.S. Jenks, D.W.Armstrong, J. Chromatogr. A, (2002), $955(1), 53-69$.

26. D.J. Tipper (Ed.), Antibiotic Inhibitors of Bacterial Cell Wall Biosynthesis, Pergamon Press, New York, 1987.

27. T.L. Xiao, B. Zhang, J.T. Lee, F. Hui, D.W. Armstrong, J. Liq. Chrom. \& Rel. Technol, 24 (2001) 2673-2684. 
Table 1. Enantiomeric separations on three chirobiotic CSPs by subcritical fluid chromatography

\begin{tabular}{|c|c|c|c|c|c|c|c|}
\hline$\overline{\text { Code }}$ & Compound name and formula & $\operatorname{CSP}$ & $t_{l}$ & $\alpha$ & Rs & $\begin{array}{l}\mathrm{MeOH} \\
\% \mathrm{v} / \mathrm{v}\end{array}$ & $\begin{array}{c}\begin{array}{c}\text { Other } \\
\text { additive }\end{array} \\
\end{array}$ \\
\hline & Class A: heterocyclic compounds & 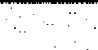 & 3 & $\because$ & $\because$ & 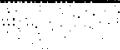 & $\because \because$ \\
\hline$\overline{\mathrm{A} 1}$ & -benzyl-2-oxazolidinone & $\mathrm{T}$ & 3.73 & 1.39 & 2.3 & 40 & \\
\hline & & TAG & 3.76 & 1.55 & 3.9 & 50 & \\
\hline & & $\mathrm{R}$ & 1.64 & 1.02 & 0.3 & 40 & \\
\hline A2 & 5,5-dimethyl-4-phenyl-2-oxazolidinone & $\mathrm{T}$ & 1.87 & 1.56 & 4.0 & 40 & \\
\hline & & TAG & 2.30 & 2.94 & 8.0 & 40 & \\
\hline & & $\mathrm{R}$ & 1.19 & 1.08 & 0.8 & 40 & \\
\hline A3 & enzyl-5,5-dimethyl-2-oxazolidinone & $\mathrm{T}$ & 2.01 & 2.96 & 6.2 & 40 & \\
\hline & & TAG & 2.52 & 1.87 & 4.1 & 40 & \\
\hline & & $\mathrm{R}$ & 1.23 & 1.36 & 1.6 & 40 & \\
\hline A4 & diphenylmethyl-2-oxazolidinone & $\mathrm{T}$ & 2.61 & 1.82 & 4.1 & 40 & \\
\hline & & TAG & 2.83 & 1.52 & 3.0 & 40 & \\
\hline & & $\mathrm{R}$ & 1.49 & 1.23 & 1.4 & 40 & \\
\hline A5 & R)-( $\div /$-)-cis-4,5-diphenyl-2- & $\mathrm{T}$ & 2.11 & 1.74 & 4.3 & 40 & \\
\hline & & TAG & 4.09 & 1.23 & 1.6 & 40 & \\
\hline & & $\mathrm{R}$ & 1.38 & 1.25 & 1.8 & 40 & \\
\hline A6 & ,5R)-(+/-)-4-methyl-5-phenyl-2- & $\mathrm{T}$ & 1.96 & 3.17 & 12.2 & 40 & \\
\hline & & TAG & 3.62 & 2.53 & 6.9 & 40 & \\
\hline & & $\mathbf{R}$ & 1.28 & 3.26 & 8.0 & 40 & \\
\hline A7 & ,5R) $(+/-)-1,5$-dimethyl-4-phenyl-2- & $\mathrm{T}$ & 1.27 & 1.14 & 1.3 & 40 & \\
\hline & & TAG & 1.65 & 1.42 & 3.3 & 40 & \\
\hline & & R & 6.25 & 1.04 & 0.9 & 7 & \\
\hline A8 & 1-benzyloxycarbonyl-2-tert-butyl-3-methyl-4- & $\mathrm{T}$ & 1.73 & 1.00 & 0.0 & 7 & \\
\hline & & TAG & 3.69 & 1.05 & 0.8 & 10 & \\
\hline & & $\mathrm{R}$ & 2.80 & 1.00 & 0.0 & 5 & \\
\hline A9 & 4-hydroxy-2-pyrrolidinone & $\mathrm{T}$ & 2.47 & 1.05 & 0.5 & 40 & \\
\hline & & TAG & 3.53 & 1.16 & 1.7 & 40 & \\
\hline & & $\mathrm{R}$ & 2.42 & 1.08 & 0.9 & 40 & \\
\hline
\end{tabular}


Table 1 continued

\begin{tabular}{|c|c|c|c|c|c|c|c|}
\hline$\overline{\text { Code }}$ & Compound name and formula & $\operatorname{csP}$ & $t_{1}$ & $\alpha$ & Rs & $\begin{array}{l}\mathrm{MeOH} \\
\% \mathrm{v} / \mathrm{v}\end{array}$ & $\begin{array}{c}\text { Other } \\
\text { additive }\end{array}$ \\
\hline \multirow[t]{3}{*}{$\overline{\mathrm{A} 10}$} & \multirow[t]{3}{*}{$\mathrm{RS}(+/ \pi)-5$-(hydroxymethyl)-2-pyrrolidinone } & $T$ & 2.47 & 1.20 & 1.5 & 40 & \multirow[t]{6}{*}{$\begin{array}{l}0.1 \text { TEA } \\
\text { TFA }\end{array}$} \\
\hline & & TAG & 3.61 & 1.22 & 1.6 & 60 & \\
\hline & & $\mathrm{R}$ & 2.32 & 1.05 & 0.7 & 40 & \\
\hline \multirow[t]{3}{*}{ A11 } & \multirow{3}{*}{ 5-methyl-5-phenylhydantoin } & $\mathrm{T}$ & 2.32 & 1.05 & 0.7 & 40 & \\
\hline & & TAG & 3.20 & 3.87 & 9.1 & 40 & \\
\hline & & $\mathrm{R}$ & 2.00 & 1.39 & 2.2 & 40 & \\
\hline \multirow[t]{3}{*}{$\mathrm{A} 12$} & \multirow[t]{3}{*}{ 5-(3-hydroxyphenyl)-5-phenyl-hydantoin } & $\mathrm{T}$ & 6.97 & 1.16 & 1.4 & 40 & \multirow{6}{*}{$\begin{array}{c}0.1 \text { TEA } \\
\text { TFA } \\
0.1 \text { TEA } \\
\text { TFA }\end{array}$} \\
\hline & & TAG & 4.58 & 1.38 & 2.0 & 60 & \\
\hline & & $\mathrm{R}$ & 4.14 & 1.18 & 0.9 & 40 & \\
\hline \multirow[t]{3}{*}{$\mathrm{A} 13$} & \multirow{3}{*}{ DL-5-(4-hydroxyphenyl)-5-phenylhydantoin } & $\mathrm{T}$ & 8.27 & 1.16 & 1.3 & 40 & \\
\hline & & TAG & 6.14 & 1.08 & 0.6 & 60 & \\
\hline & & $\mathrm{R}$ & 4.35 & 1.12 & 0.7 & 40 & \\
\hline \multirow[t]{3}{*}{ A14 } & \multirow[t]{3}{*}{ Chlorthalidon } & $\mathrm{T}$ & 3.61 & 1.37 & 2.9 & 40 & \multirow[t]{18}{*}{$\begin{array}{l}0.1 \text { TEA } \\
\text { TFA. }\end{array}$} \\
\hline & & TAG & 4.72 & 1.82 & 3.6 & 45 & \\
\hline & & $\mathrm{R}$ & 8.65 & 1.08 & 1.0 & 30 & \\
\hline \multirow[t]{3}{*}{ Als } & \multirow{3}{*}{ 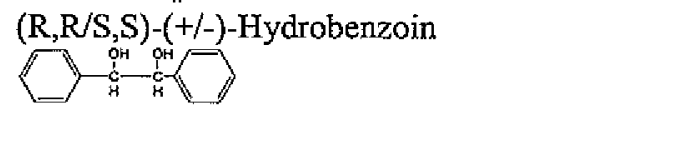 } & $\mathrm{T}$ & 6.70 & 1.04 & 0.6 & 7 & \\
\hline & & TAG & 6.59 & 1.04 & 0.7 & 10 & \\
\hline & & $\mathrm{R}$ & 4.75 & 1.00 & 0.0 & 10 & \\
\hline \multirow[t]{3}{*}{ A 16} & \multirow{3}{*}{$(\mathrm{R}, \mathrm{S})-(+/-)-N, S$-dimethyl-S-phenylsulfoximine } & $\mathrm{T}$ & 4.41 & 1.00 & 0.0 & 5 & \\
\hline & & TAG & 4.80 & 1.06 & 0.6 & 7 & \\
\hline & & $\mathrm{R}$ & 3.98 & 1.00 & 0.0 & 5 & \\
\hline \multirow[t]{3}{*}{ A.17 } & \multirow[t]{3}{*}{ 1. methyl-a-phenyl-succinimide } & $\mathrm{T}$ & 1.60 & 1.26 & 3.0 & 2 & \\
\hline & & TAG & 2.83 & 1.47 & 4.5 & 15 & \\
\hline & & $\mathrm{R}$ & 4.58 & 1.03 & 0.6 & 7 & \\
\hline \multirow[t]{3}{*}{ A 18} & \multirow[t]{3}{*}{ Norgestrel } & $\mathrm{T}$ & 11.92 & 1.05 & 1.0 & 7 & \\
\hline & & TAG & 8.08 & 1.08 & 0.9 & 15 & \\
\hline & & $\mathrm{R}$ & 10.49 & 1.02 & 0.6 & 7 & \\
\hline \multirow[t]{3}{*}{ A19 } & \multirow{3}{*}{$\begin{array}{l}(1 \mathrm{R}, 5 \mathrm{~S} / 1 \mathrm{~S}, 5 \mathrm{R})-(+/-)-2-O x a b i c y c l o[3,3,0] \text {-oct-6- } \\
\text { en-3-one }\end{array}$} & $\mathrm{T}$ & 1.11 & 1.51 & 2.9 & 40 & \\
\hline & & TAG & 1.63 & 1.53 & 2.7 & 30 & \\
\hline & & $\mathrm{R}$ & 0.90 & 1.20 & 1.0 & 40 & \\
\hline
\end{tabular}


Table 1 continued

\begin{tabular}{|c|c|c|c|c|c|c|c|}
\hline$\overline{\text { Code }}$ & Compound name and formula & CSP & $t_{1}$ & $\alpha$ & Rs & $\begin{array}{l}\mathrm{MeOH} \\
\% \mathrm{v} / \mathrm{v}\end{array}$ & $\begin{array}{c}\text { Other } \\
\text { additive }\end{array}$ \\
\hline \multirow[t]{3}{*}{ A20 } & \multirow{3}{*}{$\begin{array}{l}\text { (R,S)-(+/-)-Dihydro-5-(hydroxymethyl)-2(3H)- } \\
\text { furanone }\end{array}$} & $\mathrm{T}$ & 1.31 & 1.11 & 0.8 & 40 & \\
\hline & & TAG & 1.63 & 1.12 & 0.7 & 20 & \\
\hline & & $\mathrm{R}$ & 1.21 & 1.00 & 0.0 & 40 & \\
\hline \multirow[t]{3}{*}{ A21 } & 5-hydroxymethyl-)-2-(5H)-furanone & $\mathrm{T}$ & 5.25 & 1.13 & 1.3 & 40 & \\
\hline & & TAG & 4.93 & 1.14 & 1.2 & 15 & \\
\hline & & $\mathrm{R}$ & 4.72 & 1.00 & 0.0 & 10 & \\
\hline \multirow[t]{3}{*}{$\mathrm{A} 22$} & $\gamma$-nonanoic lactone & $\mathrm{T}$ & 1.53 & 1.14 & 1,1 & 7 & \\
\hline & & TAG & 1.35 & 1.13 & 0.8 & 15 & \\
\hline & & $\mathbf{R}$ & 2.79 & 1.11 & 0.8 & 5 & \\
\hline \multirow[t]{3}{*}{$\mathrm{A} 23$} & tyrolactone & $\mathrm{T}$ & 2.35 & 1.29 & 1.8 & 7 & \\
\hline & & TAG & 1.75 & 1.54 & 2.4 & 25 & \\
\hline & & $\mathrm{R}$ & 5.16 & 1.03 & 0.6 & 5 & \\
\hline \multirow[t]{3}{*}{ A24 } & tone & $\mathrm{T}$ & 1.67 & 1.11 & 1.5 & 15 & \\
\hline & & TAG & 2.13 & 1.23 & 2.3 & 15 & \\
\hline & & $\mathrm{R}$ & 7.85 & 1.00 & 0.0 & 5 & \\
\hline \multirow[t]{4}{*}{ A25 } & tyrolactone & $\mathrm{T}$ & 2.65 & 1.12 & 0.8 & 7 & \\
\hline & & TAG & 3.04 & 1.18 & 1.4 & 5 & \\
\hline & & $\mathrm{R}$ & 2.48 & 1.00 & 0.0 & 5 & \\
\hline & class $B$, chiral acids & & & 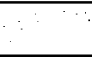 & & & 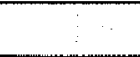 \\
\hline \multirow[t]{3}{*}{$\mathrm{B} 1$} & Flu & $T$ & 4.05 & 1.07 & 1.2 & 5 & $0.5 \mathrm{TFA}$ \\
\hline & & $\mathrm{TAG}$ & 6.44 & 1.06 & 1.2 & 5 & $0.5 \mathrm{TFA}$ \\
\hline & & $\mathrm{R}$ & 2.93 & 1.00 & 0.0 & 7 & $0.5 \mathrm{TFA}$ \\
\hline \multirow[t]{3}{*}{$\mathrm{B} 2$} & Fen & $\mathrm{T}$ & 3.95 & 1.07 & 1.2 & 5 & $0.5 \mathrm{TFA}$ \\
\hline & & TAG & 5.73 & 1.05 & 1.1 & 5 & 0.5 TFA \\
\hline & & $\mathrm{R}$ & 2.90 & 1.00 & 0.0 & 7 & $0.5 \mathrm{TFA}$ \\
\hline \multirow[t]{3}{*}{ B3 } & Indo & $\mathrm{T}$ & 6.99 & 1.11 & 1.9 & 15 & 0.5 TFA \\
\hline & & TAG & 8.60 & 1.14 & 1.6 & 20 & $0.5 \mathrm{TFA}$ \\
\hline & & $\mathrm{R}$ & 6.63 & 1.00 & 0.0 & 15 & 0.5 TFA \\
\hline \multirow[t]{3}{*}{ B4 } & Ibu & $\mathrm{T}$ & 1.89 & 1.13 & 1.5 & 7 & 0.5 TFA \\
\hline & & TAG & 2.25 & 1.14 & 2.2 & 7 & 0.5 TFA \\
\hline & & $\mathrm{R}$ & 2.25 & 1.14 & 2.2 & 7 & 0.5 TFA \\
\hline \multirow[t]{3}{*}{ B5 } & $c$ acid & $\mathrm{T}$ & 8.45 & 1.07 & 1.3 & 7 & $0.5 \mathrm{TFA}$ \\
\hline & & TAG & 3.95 & 1.07 & 1.3 & 15 & $0.5 \mathrm{TFA}$ \\
\hline & & $\mathrm{R}$ & 5.85 & 1.00 & 0.0 & 7 & $0.5 \mathrm{TFA}$ \\
\hline
\end{tabular}


Table 1 continued

\begin{tabular}{|c|c|c|c|c|c|c|c|}
\hline Code & Compound name and formula & CSP & $\mathrm{t}_{\mathrm{l}}$ & $\alpha$ & Rs & $\begin{array}{l}\mathrm{MeOH} \\
\% \mathrm{v} / \mathrm{v}\end{array}$ & $\begin{array}{l}\text { Other } \\
\text { additive }\end{array}$ \\
\hline \multirow[t]{3}{*}{ B6 } & henyl acetic acid & $\mathrm{T}$ & 3.90 & 1.04 & 0.5 & 7 & 0.5 TFA \\
\hline & & $\mathrm{TAG}$ & 8.47 & 1.09 & 1.2 & 5 & $0.5 \mathrm{TFA}$ \\
\hline & & $\mathrm{R}$ & 3.47 & 1.24 & 1.8 & 7 & $0.5 \mathrm{TFA}$ \\
\hline \multirow[t]{3}{*}{ B7 } & opentaneacetic acid & $\mathrm{T}$ & 6.84 & 1.04 & 0.9 & 5 & $0.2 \mathrm{TFA}$ \\
\hline & & TAG & 4.28 & 1.06 & 1.1 & 5 & $0.5 \mathrm{TFA}$ \\
\hline & & $\mathrm{R}$ & 3.17 & 1.04 & 0.8 & 5 & $0.2 \mathrm{TFA}$ \\
\hline \multirow[t]{3}{*}{ B8 } & jionic acid & $\mathrm{T}$ & 2.09 & 1.10 & 1.5 & 7 & $0.5 \mathrm{TFA}$ \\
\hline & & TAG & 2.64 & 1.12 & 1.5 & 7 & 0.5 TFA \\
\hline & & $\mathrm{R}$ & 2.11 & 1.00 & 0.0 & 7 & $0.5 \mathrm{TFA}$ \\
\hline \multirow[t]{3}{*}{ B9 } & ropionic acid & $\mathrm{T}$ & 3.34 & 1.09 & 0.6 & 7 & $0.1 \mathrm{TFA}$ \\
\hline & & TAG & 1.50 & 1.72 & 2.6 & 60 & $0.1 \mathrm{TEA}$ \\
\hline & & $\mathrm{R}$ & 2.43 & 1.00 & 0.0 & 7 & $0.5 \mathrm{TFA}$ \\
\hline \multirow[t]{3}{*}{ B10 } & 2-(2-chlorophenoxy) propionic acid & $\mathrm{T}$ & 2.01 & 1.51 & 1.7 & 40 & $0.1 \mathrm{TEA}$ \\
\hline & & TAG & 2.05 & 1.61 & 1.6 & 40 & $0.1 \mathrm{TEA}$ \\
\hline & & $\mathrm{R}$ & 2.74 & 1.00 & 0.0 & 7 & 0.5 TFA \\
\hline \multirow[t]{3}{*}{$\mathrm{B} \perp 1$} & hlorophenoxy) propionic acid & $\mathrm{T}$ & 2.02 & 1.53 & 0.9 & 40 & $0.1 \mathrm{TEA}$ \\
\hline & & TAG & 2.88 & 1.37 & 1.7 & 40 & $0.1 \mathrm{TEA}$ \\
\hline & & $\mathrm{R}$ & 2.42 & 1.00 & 0.0 & 7 & $0.5 \mathrm{TFA}$ \\
\hline \multirow[t]{4}{*}{$\mathrm{B} 12$} & oxy) propionic acid & $\mathrm{T}$ & 2.07 & 1.59 & 1.8 & 40 & $0.1 \mathrm{TEA}$ \\
\hline & & TAG & 2.45 & 1.74 & 2.3 & 40 & $0.1 \mathrm{TEA}$ \\
\hline & & $\mathrm{R}$ & 2.44 & 1.00 & 0.0 & 7 & 0.5 TFA \\
\hline & -blockers & & & & & & \\
\hline \multirow[t]{3}{*}{$\mathrm{C} 1$} & & $\mathrm{~T}$ & 10.63 & 1.15 & 1.5 & 70 & $\begin{array}{c}0.1 \text { TFA } \\
\text { TEA }\end{array}$ \\
\hline & & TAG & 4.93 & 1.00 & 0.0 & 60 & $\begin{array}{c}0.1 \mathrm{TFA} \\
\text { TEA }\end{array}$ \\
\hline & & $\mathrm{R}$ & 10.62 & 1.00 & 0.0 & 40 & $\begin{array}{c}0.1 \text { TFA } \\
\text { TEA }\end{array}$ \\
\hline \multirow[t]{3}{*}{$\mathrm{C} 2$} & Oxp & $\mathrm{T}$ & 4.75 & 1.14 & 1.8 & 60 & $0.1 \mathrm{TEA}$ \\
\hline & & TAG & 3.75 & 1.00 & 0.0 & 40 & $\begin{array}{c}0.1 \text { TFA } \\
\text { TEA }\end{array}$ \\
\hline & & $\mathrm{R}$ & 6.61 & 1.00 & 0.0 & 20 & $\begin{array}{c}0.1 \text { TFA } \\
\text { TEA }\end{array}$ \\
\hline \multirow[t]{3}{*}{$\mathrm{C} 3$} & Metoprolol & $\mathrm{T}$ & 2.67 & 1.14 & 1.5 & 40 & $\begin{array}{c}0.1 \text { TFA } \\
\text { TEA }\end{array}$ \\
\hline & & TAG & 3.97 & 1.07 & 0.8 & 60 & $\begin{array}{c}0.1 \text { TFA } \\
\text { TEA }\end{array}$ \\
\hline & & $\mathrm{R}$ & 7.99 & 1.00 & 0.0 & 20 & $\begin{array}{c}0.1 \mathrm{TFA} \\
\text { TEA }\end{array}$ \\
\hline
\end{tabular}


Table 1 continued

\begin{tabular}{|c|c|c|c|c|c|c|c|}
\hline Code & Compound name and formula & $\operatorname{CSP}$ & $t_{1}$ & $\alpha$ & Rs & $\begin{array}{l}\mathrm{MeOH} \\
\% \mathrm{v} / \mathrm{v}\end{array}$ & $\begin{array}{c}\text { Other } \\
\text { additive }\end{array}$ \\
\hline & Alpr & $\mathrm{T}$ & 2.06 & 1.15 & 1.5 & 40 & $\begin{array}{c}0.1 \mathrm{TFA} \\
\text { TEA }\end{array}$ \\
\hline & & TAG & 5.19 & 1.08 & 1.0 & 30 & $\begin{array}{c}0.1 \text { TFA } \\
\text { TEA }\end{array}$ \\
\hline & & $\mathrm{R}$ & 4.89 & 1.00 & 0.0 & 20 & $\begin{array}{c}0.1 \text { TFA } \\
\text { TEA }\end{array}$ \\
\hline \multirow[t]{3}{*}{$\mathrm{C} 5$} & Ace & $\mathrm{T}$ & 8.90 & 1.10 & 1.1 & 60 & 0.1 TEA \\
\hline & & TAG & 12.49 & 1.11 & 1.0 & 40 & $\begin{array}{c}0.1 \text { TFA } \\
\text { TEA }\end{array}$ \\
\hline & & $\mathrm{R}$ & 4.14 & 1.00 & 0.0 & 40 & $\begin{array}{c}0.1 \text { TFA } \\
\text { TEA }\end{array}$ \\
\hline \multirow[t]{3}{*}{ C6 } & & $\mathrm{T}$ & 3.08 & 1.16 & 1.8 & 40 & $\begin{array}{c}0.1 \text { TFA } \\
\text { TEA }\end{array}$ \\
\hline & & TAG & 2.89 & 1.38 & 2.0 & 50 & $\begin{array}{c}0.1 \text { TFA } \\
\text { TEA }\end{array}$ \\
\hline & & $\mathrm{R}$ & 9.35 & 1.00 & 0.0 & 20 & $\begin{array}{c}0.1 \text { TFA } \\
\text { TEA }\end{array}$ \\
\hline \multirow[t]{3}{*}{ C7 } & Pir & $\mathrm{T}$ & 4.41 & 1.12 & 1.4 & 40 & $\begin{array}{c}0.1 \text { TFA } \\
\text { TEA }\end{array}$ \\
\hline & & TAG & 8.11 & 1.00 & 0.0 & 40 & $\begin{array}{c}0.1 \text { TFA } \\
\text { TEA }\end{array}$ \\
\hline & & $\mathrm{R}$ & 8.71 & 1.00 & 0.0 & 30 & $\begin{array}{c}0.1 \mathrm{TFA} \\
\text { TEA } \\
\end{array}$ \\
\hline & class D, chiral sulfoxides & $\therefore$ & & & & & \\
\hline \multirow[t]{3}{*}{ D1 } & & $\mathrm{T}$ & 5.14 & 1.03 & 0.4 & 7 & \\
\hline & & TAG & 8.52 & 1.14 & 0.9 & 7 & \\
\hline & & $\mathrm{R}$ & 4.17 & 1.06 & 0.9 & 7 & \\
\hline \multirow[t]{3}{*}{ D2 } & & $\mathrm{T}$ & 5.37 & 1.00 & 0.0 & 7 & \\
\hline & & TAG & 9.54 & 1.12 & 1.2 & 7 & \\
\hline & & $\mathrm{R}$ & 3.97 & 1.00 & 0.0 & 7 & \\
\hline \multirow[t]{3}{*}{ D3 } & & $\mathrm{T}$ & 4.37 & 1.22 & 3.1 & 7 & \\
\hline & & $\mathrm{TAG}$ & 3.18 & 1.29 & 3.2 & 15 & \\
\hline & & $\mathrm{R}$ & 3.56 & 1.03 & 0.5 & 7 & \\
\hline \multirow[t]{3}{*}{ D4 } & & $\mathrm{T}$ & 4.90 & 1.00 & 0.0 & 7 & \\
\hline & & TAG & 3.77 & 1.10 & 1.1 & 15 & \\
\hline & & $\mathrm{R}$ & 3.88 & 1.06 & 0.9 & 15 & \\
\hline \multirow[t]{3}{*}{ D5 } & & $\mathrm{T}$ & 4.3 & 1.15 & 2.4 & 7 & \\
\hline & & TAG & 7.28 & 1.32 & 3.6 & 7 & \\
\hline & & $\mathrm{R}$ & 3.4 & 1.00 & 0.0 & 7 & \\
\hline \multirow[t]{3}{*}{ D6 } & & $\mathrm{T}$ & 4.81 & 1.19 & 1.9 & 7 & \\
\hline & & TAG & 8.86 & 1.28 & 2.3 & 7 & \\
\hline & & $\mathrm{R}$ & 4.0 & 1.00 & 0.1 & 7 & \\
\hline
\end{tabular}


Table 1 continued

\begin{tabular}{|c|c|c|c|c|c|c|c|}
\hline$\overline{\text { Code }}$ & Compound name and formula & $\mathrm{CSP}$ & $t_{1}$ & $\alpha$ & Rs & $\begin{array}{l}\mathrm{MeOH} \\
\% \mathrm{~V} / \mathrm{v}\end{array}$ & $\begin{array}{c}\text { Other } \\
\text { additive }\end{array}$ \\
\hline \multirow[t]{3}{*}{ D7 } & & $\mathrm{T}$ & 4.31 & 1.18 & 2.8 & 7 & \\
\hline & & TAG & 3.43 & 1.31 & 3.4 & 15 & \\
\hline & & $\mathrm{R}$ & 3.93 & 1.00 & 0.0 & 7 & \\
\hline \multirow[t]{3}{*}{ D8 } & & $\mathbf{T}$ & 3.37 & 1.12 & 1.8 & 7 & \\
\hline & & TAG & 3.06 & 1.20 & 1.8 & 15 & \\
\hline & & $\mathrm{R}$ & 2.86 & 1.00 & 0.0 & 7 & \\
\hline \multirow[t]{3}{*}{ D9 } & & $\mathrm{T}$ & 5.75 & 1.18 & 2.6 & 7 & \\
\hline & & TAG & 11.21 & 1.30 & 3.5 & 7 & \\
\hline & & $\mathrm{R}$ & 4.62 & 1.03 & 0.8 & 7 & \\
\hline \multirow[t]{3}{*}{ D10 } & & $\mathrm{T}$ & 4.98 & 1.22 & 3.0 & 7 & \\
\hline & & TAG & 4.04 & 1.37 & 4.0 & 15 & \\
\hline & & $\mathrm{R}$ & 4.52 & 1.00 & 0.0 & 7 & \\
\hline \multirow[t]{3}{*}{ D11 } & & $\mathrm{T}$ & 4.09 & 1.16 & 1.8 & 7 & \\
\hline & & TAG & 3.91 & 1.22 & 2.3 & 15 & \\
\hline & & $\mathrm{R}$ & 3.41 & 1.00 & 0.0 & 7 & \\
\hline \multirow[t]{3}{*}{ D12 } & & $T$ & 2.65 & 1.04 & 0.8 & 7 & \\
\hline & & TAG & 3.65 & 1.10 & 1.3 & 7 & \\
\hline & & $\mathrm{R}$ & 2,2 & 1.00 & 0.0 & 7 & \\
\hline \multirow[t]{3}{*}{ D13 } & & $\mathrm{T}$ & 9.3 & 1.12 & 1.7 & 7 & \\
\hline & & TAG & 8.09 & 1.06 & 0.8 & 15 & \\
\hline & & $\mathrm{R}$ & 7.19 & 1.00 & 0.0 & 7 & \\
\hline \multirow[t]{3}{*}{ D14 } & & $\mathrm{T}$ & 2.73 & 1.07 & 1.0 & 7 & \\
\hline & & TAG & 1.95 & 1.19 & 1.8 & 15 & \\
\hline & & $\mathrm{R}$ & 2.66 & 1.11 & 1.4 & 7 & \\
\hline \multirow[t]{3}{*}{ D15 } & & $\mathrm{T}$ & 3.32 & 1.11 & 2.0 & 7 & \\
\hline & & TAG & 2.68 & 1.18 & 2.7 & 15 & \\
\hline & & $\mathrm{R}$ & 3.21 & 1.00 & 0.0 & 7 & \\
\hline \multirow[t]{3}{*}{ D16 } & & $\mathrm{T}$ & 5.25 & 1.00 & 0.0 & 7 & \\
\hline & & TAG & 10.62 & 1.02 & 0.4 & 7 & \\
\hline & & $\mathrm{R}$ & 5.25 & 1.00 & 0.0 & 7 & \\
\hline \multirow[t]{3}{*}{ D17 } & & $\mathrm{T}$ & 5.63 & 1.00 & 0.0 & 7 & \\
\hline & & TAG & 4.22 & 1.00 & 0.0 & 15 & \\
\hline & & $\mathrm{R}$ & 4.89 & 1.11 & 1.7 & 7 & \\
\hline \multirow[t]{3}{*}{ D18 } & & $\mathrm{T}$ & 4.79 & 1.05 & 0.8 & 7 & \\
\hline & & TAG & 4.15 & 1.04 & 0.7 & 15 & \\
\hline & & $\mathrm{R}$ & 4.70 & 1.24 & 2.6 & 7 & \\
\hline
\end{tabular}


Table 1 continued

\begin{tabular}{|c|c|c|c|c|c|c|c|}
\hline Code & Compound name and formula & $\mathrm{CSP}$ & $t_{1}$ & $\alpha$ & Rs & $\begin{array}{l}\mathrm{MeOH} \\
\% \mathrm{v} / \mathrm{v}\end{array}$ & $\begin{array}{c}\text { Other } \\
\text { additive }\end{array}$ \\
\hline \multirow[t]{3}{*}{$\overline{\text { D19 }}$} & & $\bar{T}$ & 8.55 & 1.03 & 0.6 & 7 & \\
\hline & & $\mathrm{TAG}$ & 5.89 & 1.07 & 1.0 & 15 & \\
\hline & & $\mathrm{R}$ & 7.1 & 1.21 & 1.8 & 7 & \\
\hline \multirow[t]{3}{*}{ D20 } & & $\mathrm{T}$ & 5.07 & 1.00 & 0.0 & 7 & \\
\hline & & TAG & 10.01 & 1.00 & 0.0 & 7 & \\
\hline & & $\mathrm{R}$ & 4.87 & 1.01 & 0.4 & 7 & \\
\hline \multirow[t]{3}{*}{$\mathrm{D} 21$} & & $\mathrm{~T}$ & 5.98 & 1.19 & 3.1 & 7 & \\
\hline & & TAG & 11.73 & 1.19 & 2.4 & 7 & \\
\hline & & $\mathrm{R}$ & 2.39 & 1.20 & 2.1 & 15 & \\
\hline \multirow[t]{3}{*}{$\mathrm{D} 22$} & & $\mathrm{~T}$ & 4.8 & 1.05 & 0.6 & 7 & \\
\hline & & TAG & 3.39 & 1.10 & 1.1 & 15 & \\
\hline & & $\mathrm{R}$ & 4.14 & 1.05 & 1.0 & 7 & \\
\hline \multirow[t]{3}{*}{ D23 } & & $\mathrm{T}$ & 3.63 & 1.17 & 2.1 & 7 & \\
\hline & & TAG & 5.94 & 1.22 & 1.9 & 7 & \\
\hline & & $\mathrm{R}$ & 3.59 & 1.23 & 3.7 & 7 & \\
\hline \multirow[t]{3}{*}{ D24 } & & $\tau$ & 3.69 & 1.07 & 1.2 & 7 & \\
\hline & & TAG & 6.03 & 1.15 & 1.5 & 7 & \\
\hline & & $\mathrm{R}$ & 3.67 & 1.05 & 0.9 & 7 & \\
\hline \multirow[t]{3}{*}{ D25 } & & $\mathrm{T}$ & 7 & 1.29 & 4.5 & 7 & \\
\hline & & TAG & 5.21 & 1.35 & 3.8 & 15 & \\
\hline & & $\mathrm{R}$ & 4.98 & 1.00 & 0.0 & 7 & \\
\hline \multirow[t]{3}{*}{$\mathrm{D} 26$} & & $\mathrm{~T}$ & 3.55 & 1.37 & 5.7 & 7 & \\
\hline & & TAG & 2.53 & 1.52 & 4.7 & 15 & \\
\hline & & $\mathrm{R}$ & 2.61 & 1.00 & 0.0 & 7 & \\
\hline \multirow[t]{3}{*}{ D27 } & & $\mathrm{T}$ & 3.59 & 1.00 & 0.0 & 7 & \\
\hline & & TAG & 2.37 & 1.00 & 0.0 & 15 & \\
\hline & & $\mathrm{R}$ & 2.79 & 1.00 & 0.0 & 7 & \\
\hline \multirow[t]{3}{*}{ D28 } & & $T$ & 8.29 & 1.03 & 0.7 & 15 & \\
\hline & & TAG & 6.55 & 1.05 & 0.7 & 25 & \\
\hline & & $\mathrm{R}$ & 7.12 & 1.02 & 0.5 & 15 & \\
\hline \multirow[t]{3}{*}{ D29 } & & $\mathrm{T}$ & 6.81 & 1.06 & 1.0 & 15 & \\
\hline & & TAG & 5.74 & 1.05 & 0.7 & 25 & \\
\hline & & $\mathrm{R}$ & 5.96 & 1.00 & 0.0 & 15 & \\
\hline \multirow[t]{3}{*}{ D30 } & & $\mathrm{T}$ & 8.06 & 1.24 & 2.8 & 7 & \\
\hline & & TAG & 6.62 & 1.36 & 2.9 & 15 & \\
\hline & & $\mathrm{R}$ & 5.88 & 1.08 & 0.9 & 7 & \\
\hline
\end{tabular}


Table 1 continued

\begin{tabular}{|c|c|c|c|c|c|c|c|}
\hline Code & Compound name and formula & $\mathrm{CSP}$ & $t_{1}$ & $\alpha$ & Rs & $\begin{array}{l}\mathrm{MeOH} \\
\% \mathrm{v} / \mathrm{v}\end{array}$ & $\begin{array}{c}\text { Other } \\
\text { additive }\end{array}$ \\
\hline \multirow[t]{3}{*}{ D31 } & & $\mathrm{T}$ & 9.18 & 1.05 & 0.9 & 7 & \\
\hline & & TAG & 7.23 & 1.11 & 1.4 & 15 & \\
\hline & & $\mathrm{R}$ & 8.54 & 1.11 & 1.5 & 7 & \\
\hline & -blocked amino-acids & $\because$ & 8 & 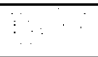 & 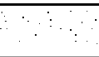 & 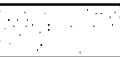 & $\ldots$ \\
\hline \multirow[t]{3}{*}{ E1 } & $\mathrm{N}-3,5-\mathrm{DNP} y \mathrm{r}-\mathrm{DL}-$ serine & $\mathrm{T}$ & 4.09 & 1.74 & 3.1 & 25 & \\
\hline & & TAG & 4.36 & 1.52 & 1.5 & 40 & \\
\hline & & $\mathrm{R}$ & 5.83 & 1.30 & 1.5 & 40 & \\
\hline \multirow[t]{3}{*}{$\mathrm{E} 2$} & DL-phenylalanine & $\mathrm{T}$ & 1.44 & 1.50 & 1.5 & 40 & \\
\hline & & $\mathrm{TAG}$ & 2.51 & 1.29 & 0.9 & 40 & \\
\hline & & $\mathrm{R}$ & 3.00 & 2.95 & 6.9 & 40 & \\
\hline \multirow[t]{3}{*}{$\mathrm{E} 3$} & $\mathrm{~N}-3,5-\mathrm{DNP}$ & $\mathrm{T}$ & 1.80 & 2.07 & 4.2 & 25 & \\
\hline & & TAG & 3.49 & 1.80 & 2.6 & 25 & \\
\hline & & $\mathrm{R}$ & 2.36 & 1.61 & 3.3 & 40 & \\
\hline \multirow[t]{3}{*}{ E4 } & N-3,5-DNPyr-DL-leucine & $\mathrm{T}$ & 1.82 & 2.25 & 5.4 & 40 & $0.1 \mathrm{TEA}$ \\
\hline & & TAG & 2.86 & 1.47 & 1.9 & 15 & \\
\hline & & $\mathrm{R}$ & 2.87 & 1.52 & 2.9 & 25 & \\
\hline \multirow[t]{3}{*}{ E5 } & N-2,4-DNP-DL-ethionine & $\mathrm{T}$ & 1.91 & 1.62 & 2.0 & 40 & \\
\hline & & TAG & 4.33 & 1.72 & 2.0 & 40 & \\
\hline & & $\mathrm{R}$ & 2.28 & 1.05 & 0.5 & 40 & 0.1 TEA \\
\hline \multirow[t]{3}{*}{ E6 } & -DL-norvaline & $\mathrm{T}$ & 2.22 & 1.57 & 2.4 & 25 & \\
\hline & & TAG & 4.76 & 1.46 & 1.6 & 25 & \\
\hline & & $\mathrm{R}$ & 4.66 & 1.00 & 0.0 & 40 & $0.1 \mathrm{TEA}$ \\
\hline \multirow[t]{3}{*}{$\mathrm{E} 7$} & N-2,4-DNP-DL-methionine & $\mathrm{T}$ & 1.94 & 1.89 & 2.4 & 40 & \\
\hline & & TAG & 4.96 & 2.06 & 2.5 & 40 & \\
\hline & & $\mathrm{R}$ & 6.53 & 1.06 & 0.8 & 40 & $0.1 \mathrm{TEA}$ \\
\hline \multirow[t]{3}{*}{ E8 } & N-2,4-DNP-DL-norleucine & $\mathrm{T}$ & 2.14 & 1.41 & 2.2 & 25 & \\
\hline & & TAG & 4.28 & 1.29 & 1.0 & 25 & \\
\hline & & $\mathrm{R}$ & 3.79 & 1.00 & 0.0 & 40 & $0.1 \mathrm{TEA}$ \\
\hline \multirow[t]{3}{*}{ E9 } & $\alpha$-amino-n-caprylic acid & $\mathrm{T}$ & 3.03 & 1.48 & 2.8 & 40 & $0.1 \mathrm{TEA}$ \\
\hline & & TAG & 5.13 & 1.21 & 1.0 & 40 & $0.1 \mathrm{TEA}$ \\
\hline & & $\mathrm{R}$ & 3.08 & 1.00 & 0.0 & 40 & $0.1 \mathrm{TEA}$ \\
\hline \multirow[t]{3}{*}{ E10 } & N-2,4-DNP-DL- $\alpha$-amino-n-butyric acid & $\mathrm{T}$ & 5.78 & 1.28 & 1.8 & 40 & $0.1 \mathrm{TEA}$ \\
\hline & & $\mathrm{TAG}$ & 4.61 & 1.12 & 0.7 & 60 & $0.1 \mathrm{TEA}$ \\
\hline & & $\mathrm{R}$ & 5.85 & 1.31 & 2.4 & 40 & 0.1 TEA \\
\hline \multirow[t]{3}{*}{ E11 } & N-CBZ-DL-1 & $\mathrm{T}$ & 6.56 & 1.06 & 0.8 & 7 & \\
\hline & & TAG & 3.96 & 1.10 & 1.0 & 15 & \\
\hline & & $\mathrm{R}$ & 1.82 & 1.00 & 0.0 & 40 & $0.1 \mathrm{TEA}$ \\
\hline
\end{tabular}


Table 1 continued

\begin{tabular}{|c|c|c|c|c|c|c|c|}
\hline$\overline{\text { Code }}$ & Compound name and formula & CSP & $t_{1}$ & $\alpha$ & Rs & $\begin{array}{l}\mathrm{MeOH} \\
\% \mathrm{v} / \mathrm{v}\end{array}$ & $\begin{array}{c}\text { Other } \\
\text { additive }\end{array}$ \\
\hline \multirow[t]{3}{*}{ E12 } & DL-phen & $\mathrm{T}$ & 2.41 & 1.25 & 1.0 & 40 & $0.1 \mathrm{TEA}$ \\
\hline & & TAG & 3.06 & 1.27 & 1.2 & 40 & $0.1 \mathrm{TEA}$ \\
\hline & & $\mathrm{R}$ & 3.16 & 1.53 & 2.2 & 40 & 0.1 TEA \\
\hline \multirow[t]{3}{*}{ E13 } & L-serine & $\mathrm{T}$ & 4.05 & 1.39 & 1.0 & 40 & 0.1 TEA \\
\hline & & $\mathrm{TAG}$ & 1.87 & 1.66 & 1.8 & 60 & $0.1 \mathrm{TEA}$ \\
\hline & & $\mathrm{R}$ & 5.69 & 1.25 & 1.7 & 40 & 0.1 TEA \\
\hline \multirow[t]{3}{*}{ E14 } & N-CBZ-DL-leucine & $\mathrm{T}$ & 6.15 & 1.29 & 2.2 & 15 & 0.1 TEA \\
\hline & & $\mathrm{TAG}$ & 3.03 & 1.24 & 1.7 & 15 & \\
\hline & & $\mathrm{R}$ & 3.56 & 1.12 & 0.9 & 15 & \\
\hline \multirow[t]{3}{*}{ E15 } & N-CBZ-DL-tryptophan & $\mathrm{T}$ & 4.31 & 1.15 & 0.7 & 40 & $0.1 \mathrm{TEA}$ \\
\hline & & TAG & 7.24 & 1.25 & 1.2 & 40 & $0.1 \mathrm{TEA}$ \\
\hline & & $\mathrm{R}$ & 5.39 & 1.39 & 2.1 & 40 & $0.1 \mathrm{TEA}$ \\
\hline \multirow[t]{3}{*}{ E16 } & Z-DL-Norlet & $\mathrm{T}$ & 1.43 & 1.45 & 1.4 & 40 & $0.1 \mathrm{TEA}$ \\
\hline & & $\mathrm{TAG}$ & 1.60 & 1.76 & 2.5 & 40 & $0.1 \mathrm{TEA}$ \\
\hline & & $\mathrm{R}$ & 1.55 & 1.20 & 1.0 & 40 & 0.1 TEA \\
\hline \multirow[t]{3}{*}{ E17 } & L-alanine & $\mathrm{T}$ & 1.89 & 1.66 & 2.4 & 40 & $0.1 \mathrm{TEA}$ \\
\hline & & TAG & 2.43 & 2.32 & 3.3 & 40 & $0.1 \mathrm{TEA}$ \\
\hline & & $\mathrm{R}$ & 2.34 & 1.51 & 2.8 & 40 & $0.1 \mathrm{TEA}$ \\
\hline \multirow[t]{3}{*}{ E18 } & L-valine & $\mathrm{T}$ & 1.42 & 1.18 & 0.8 & 40 & $0.1 \mathrm{TEA}$ \\
\hline & & TAG & 1.61 & 1.37 & 1.3 & 40 & $0.1 \mathrm{TEA}$ \\
\hline & & $\mathrm{R}$ & 1.61 & 1.22 & 1.1 & 40 & $0.1 \mathrm{TEA}$ \\
\hline \multirow[t]{3}{*}{ E19 } & $\underset{c \text { COH }}{\text { Z-DL-norvaline }}$ & $\mathrm{T}$ & 1.51 & 1.54 & 1.6 & 40 & $0.1 \mathrm{TEA}$ \\
\hline & & TAG & 1.69 & 1.90 & 2.6 & 40 & $0.1 \mathrm{TEA}$ \\
\hline & & $\mathrm{R}$ & 1.68 & 1.33 & 1.6 & 40 & $0.1 \mathrm{TEA}$ \\
\hline \multirow[t]{3}{*}{$\mathrm{E} 20$} & N-CBZ-DL-methionine & $\mathrm{T}$ & 2.21 & 1.50 & 1.8 & 40 & $0.1 \mathrm{TEA}$ \\
\hline & & $\mathrm{TAG}$ & 2.70 & 1.82 & 2.8 & 40 & $0.1 \mathrm{TEA}$ \\
\hline & & $\mathrm{R}$ & 2.61 & 1.35 & 2.1 & 40 & 0.1 TEA \\
\hline \multirow[t]{3}{*}{$\mathrm{E} 21$} & N-CBZ-DL-asparagine & $\mathrm{T}$ & 2.72 & 1.19 & 0.8 & 60 & $0.1 \mathrm{TEA}$ \\
\hline & & $\mathrm{TAG}$ & 4.06 & 1.16 & 0.8 & 60 & 0.1 TEA \\
\hline & & $\mathrm{R}$ & 4.07 & 1.11 & 0.8 & 60 & 0.1 TEA \\
\hline \multirow[t]{3}{*}{$\mathrm{E} 22$} & DL-alanine-2-naphthylamide hydrochloride & $\mathrm{T}$ & 4.51 & 1.00 & 0.0 & 40 & $\begin{array}{l}0.1 \mathrm{TFA} \\
\text { TEA }\end{array}$ \\
\hline & & TAG & 5.09 & 1.11 & 0.9 & 40 & $\begin{array}{c}0.1 \mathrm{TFA} \\
\text { TEA }\end{array}$ \\
\hline & & $\mathrm{R}$ & 3.88 & 1.19 & 1.8 & 40 & $\begin{array}{l}0.1 \text { TFA } \\
\text { TEA }\end{array}$ \\
\hline
\end{tabular}


Table 1 continued

\begin{tabular}{|c|c|c|c|c|c|c|c|}
\hline$\overline{\text { Code }}$ & Compound name and formula & $\mathrm{CSP}$ & $t_{1}$ & $\alpha$ & Rs & $\begin{array}{c}\mathrm{MeOH} \\
\% \mathrm{v} / \mathrm{v}\end{array}$ & $\begin{array}{c}\text { Other } \\
\text { additive }\end{array}$ \\
\hline & class $F$, Native amino-acids & & & & & a & \\
\hline \multirow[t]{3}{*}{ F1 } & \multirow{3}{*}{ 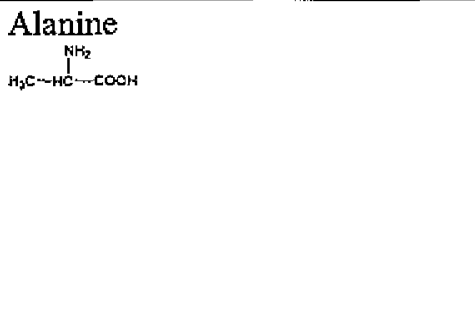 } & $\bar{T}$ & 2.60 & 1.94 & 3.1 & 48 & $\begin{array}{l}0.1 \text { TEA TFA } \\
2 \mathrm{H}_{2} \mathrm{O} 0.3 \text { gly }\end{array}$ \\
\hline & & TAG & 4.41 & 2.06 & 5.0 & 47.5 & $\begin{array}{c}0.15 \mathrm{TEA} \\
\text { TFA } \\
2.5 \mathrm{H}_{2} \mathrm{O}, 0.3 \\
\text { gly }\end{array}$ \\
\hline & & $\mathrm{R}$ & 2.80 & 1.39 & 1.3 & 48 & $\begin{array}{l}0.1 \text { TEA TFA } \\
2 \mathrm{H}_{2} \mathrm{O}\end{array}$ \\
\hline \multirow[t]{3}{*}{$\mathrm{F} 2$} & \multirow{3}{*}{ 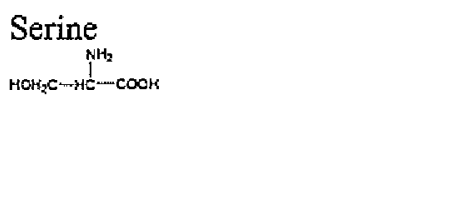 } & $\mathrm{T}$ & 3.20 & 1.40 & 1.8 & 46.5 & $\begin{array}{c}0.1 \text { TEA TFA } \\
3.5 \mathrm{H}_{2} \mathrm{O}\end{array}$ \\
\hline & & TAG & --- & --- & -- & & t detected \\
\hline & & $\mathrm{R}$ & 4,32 & 1.17 & 1.1 & 48 & $\begin{array}{l}0.1 \text { TEA TFA } \\
2 \mathrm{H}_{2} \mathrm{O}\end{array}$ \\
\hline \multirow[t]{3}{*}{ F3 } & \multirow[t]{3}{*}{ Asparagine } & $\mathrm{T}$ & 4.02 & 1.54 & 1.6 & 57.6 & $\begin{array}{c}0.15 \text { TEA } \\
\text { TFA } \\
2.4 \mathrm{H}_{2} \mathrm{O}\end{array}$ \\
\hline & & $\mathrm{TAG}$ & 2.18 & 2.24 & 3.8 & 67.2 & $\begin{array}{c}0.15 \mathrm{TEA} \\
\mathrm{TFA} \\
2.8 \mathrm{H}_{2} \mathrm{O}\end{array}$ \\
\hline & & $\mathrm{R}$ & 4.06 & 1.36 & 1.8 & 47.5 & $\begin{array}{c}0.15 \mathrm{TEA} \\
\text { TFA } \\
2.5 \mathrm{H}_{2} \mathrm{O} 0.3 \\
\text { gly }\end{array}$ \\
\hline \multirow[t]{3}{*}{ F4 } & \multirow[t]{3}{*}{ 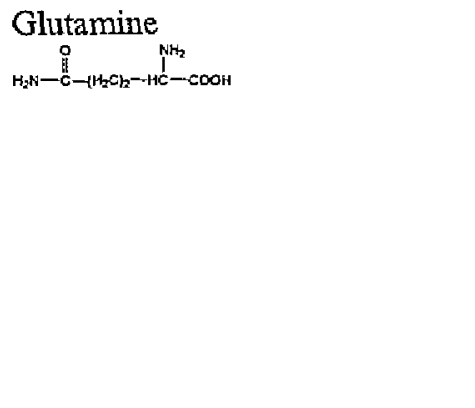 } & $\mathrm{T}$ & 4.06 & 1.36 & 1.8 & 57.6 & $\begin{array}{c}0.15 \text { TEA } \\
\text { TFA } \\
2.4 \mathrm{H}_{2} \mathrm{O}\end{array}$ \\
\hline & & TAG & 2.07 & 1.50 & 1.5 & 67.2 & $\begin{array}{c}0.15 \text { TEA } \\
\text { TFA } \\
2.8 \mathrm{H}_{2} \mathrm{O}\end{array}$ \\
\hline & & $\mathrm{R}$ & 3.37 & 1.21 & 1.2 & 47.5 & $\begin{array}{c}0.15 \text { TEA } \\
\text { TFA } \\
2.5 \mathrm{H}_{2} \mathrm{O} 0.3 \\
\text { gly }\end{array}$ \\
\hline \multirow[t]{3}{*}{ F5 } & \multirow[t]{3}{*}{$\begin{array}{l}\text { Methionine } \\
\mathrm{H}_{\mathrm{H}, \mathrm{C}-\mathrm{S}-\mathrm{H}_{\mathrm{H}} \mathrm{C}-\mathrm{C}-\mathrm{H} \mathrm{C}-\mathrm{COOH}}\end{array}$} & $\mathrm{T}$ & 2.55 & 2.14 & 3.0 & 48 & $\begin{array}{l}0.1 \text { TEA TFA } \\
2 \mathrm{H}_{2} \mathrm{O} 0.3 \mathrm{gly}\end{array}$ \\
\hline & & TAG & 2.25 & 4.09 & 3.7 & 48 & $\begin{array}{l}0.1 \text { TEA TFA } \\
2 \mathrm{H}_{2} \mathrm{O} 0.3 \text { gly }\end{array}$ \\
\hline & & $\mathrm{R}$ & 2.59 & 1.32 & 1.1 & 48 & $\begin{array}{l}0.1 \text { TEA TFA } \\
2 \mathrm{H}_{2} \mathrm{O}\end{array}$ \\
\hline \multirow[t]{3}{*}{ F6 } & \multirow{3}{*}{ Tryptophan } & $\mathrm{T}$ & 3.61 & 1.71 & 1.8 & 48 & $\begin{array}{l}0.1 \text { TEA TFA } \\
2 \mathrm{H}_{2} \mathrm{O} 0.3 \mathrm{gly}\end{array}$ \\
\hline & & TAG & 3.33 & 2.02 & 2.3 & 48 & $\begin{array}{l}0.1 \text { TEA TFA } \\
2 \mathrm{H}_{2} \mathrm{O} 0.3 \mathrm{gly}\end{array}$ \\
\hline & & $\mathrm{R}$ & 4.10 & 1.20 & 0.7 & 48 & $\begin{array}{l}0.1 \text { TEA TFA } \\
2 \mathrm{H}_{2} \mathrm{O} 0.3 \mathrm{gly} \\
\end{array}$ \\
\hline
\end{tabular}


Table 1 continued

\begin{tabular}{|c|c|c|c|c|c|c|c|}
\hline Code & Compound name and formula & CSP & $t_{1}$ & $\alpha$ & Rs & $\begin{array}{l}\mathrm{MeOH} \\
\% \mathrm{v} / \mathrm{v}\end{array}$ & $\begin{array}{c}\text { Other } \\
\text { additive }\end{array}$ \\
\hline \multirow[t]{3}{*}{$\overline{\text { F7 }}$} & \multirow{3}{*}{ Phenylalanine } & $\mathrm{T}$ & 2.72 & 1.89 & 2.2 & 48 & $\begin{array}{l}0.1 \text { TEA TFA } \\
2 \mathrm{H}_{2} \mathrm{O} 0.3 \text { gly }\end{array}$ \\
\hline & & TAG & 2.24 & 2.55 & 2.4 & 48 & $\begin{array}{l}0.1 \text { TEA TFA } \\
2 \mathrm{H}_{2} \mathrm{O} 0.3 \text { gly }\end{array}$ \\
\hline & & $\mathrm{R}$ & 2.90 & 1.37 & 1.2 & 48 & $\begin{array}{l}0.1 \text { TEA TFA } \\
2 \mathrm{H}_{2} \mathrm{O} 0.3 \text { gly }\end{array}$ \\
\hline \multirow[t]{3}{*}{ F8 } & \multirow[t]{3}{*}{ 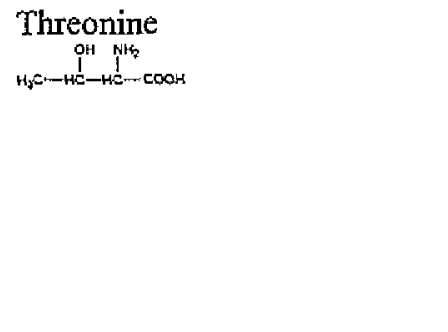 } & $\mathrm{T}$ & 2.97 & 1.52 & 2.0 & 48 & $\begin{array}{l}0.1 \text { TEA TFA } \\
2 \mathrm{H}_{2} \mathrm{O} 0.3 \text { gly }\end{array}$ \\
\hline & & $\mathrm{TAG}$ & 2.30 & 2.18 & 3.8 & 47.5 & $\begin{array}{c}0.15 \text { TEA } \\
\text { TFA } \\
2.5 \mathrm{H}_{2} \mathrm{O} 0.3 \\
\text { gly }\end{array}$ \\
\hline & & $\mathrm{R}$ & 3.45 & 1.27 & 1.2 & 48 & $\begin{array}{l}0.1 \text { TEA TFA } \\
2 \mathrm{H}_{2} \mathrm{O} 0.3 \text { gly }\end{array}$ \\
\hline \multirow[t]{3}{*}{ F9 } & \multirow{3}{*}{ Tyrosine } & $\mathrm{T}$ & 2.87 & 1.77 & 1.4 & 48 & $\begin{array}{l}0.1 \text { TEA TFA } \\
2 \mathrm{H}_{2} \mathrm{O} 0.3 \text { gly }\end{array}$ \\
\hline & & $\mathrm{TAG}$ & 2.40 & 2.63 & 2.4 & 48 & $\begin{array}{l}0.1 \text { TEA TFA } \\
2 \mathrm{H}_{2} \mathrm{O} \quad 0.3 \text { gly }\end{array}$ \\
\hline & & $\mathrm{R}$ & 3.18 & 1.31 & 1.1 & 48 & $\begin{array}{l}0.1 \text { TEA TFA } \\
2 \mathrm{H}_{2} \mathrm{O} 0.3 \text { gly }\end{array}$ \\
\hline \multirow[t]{3}{*}{ F10 } & \multirow{3}{*}{ Histidine } & $\mathrm{T}$ & 3.18 & 1.31 & 1.1 & 48 & $\begin{array}{l}0.1 \text { TEA TFA } \\
2 \mathrm{H}_{2} \mathrm{O} 0.3 \mathrm{gly}\end{array}$ \\
\hline & & $\mathrm{TAG}$ & 3.51 & 1.64 & 1.7 & 67.2 & $\begin{array}{c}0.15 \text { TEA } \\
\text { TFA } \\
2.8 \mathrm{H}_{2} \mathrm{O}\end{array}$ \\
\hline & & $\mathrm{R}$ & 7.95 & 1.09 & 0.4 & 47.5 & $\begin{array}{c}0.15 \text { TEA } \\
\text { TFA } \\
2.5 \mathrm{H}_{2} \mathrm{O} 0.3 \\
\text { gly }\end{array}$ \\
\hline \multirow[t]{3}{*}{ F11 } & \multirow[t]{3}{*}{ 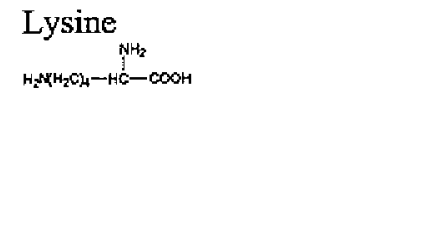 } & $\mathrm{T}$ & 1.85 & 1.60 & 2.7 & 67.2 & $\begin{array}{c}0.15 \mathrm{TEA} \\
\mathrm{TFA} \\
2.8 \mathrm{H}_{2} \mathrm{O}\end{array}$ \\
\hline & & TAG & $-\cdots$ & --- & $\cdots$ & \multirow{2}{*}{\multicolumn{2}{|c|}{$\begin{array}{l}\text { Not detected } \\
\text { Not detected }\end{array}$}} \\
\hline & & $\mathrm{R}$ & --- & --- & -- & & \\
\hline \multirow[t]{3}{*}{$\mathrm{F} 22$} & \multirow[t]{3}{*}{ 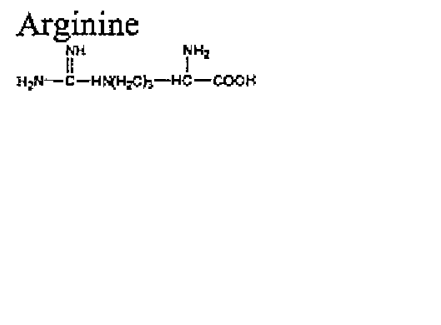 } & $\mathrm{T}$ & 4.71 & 1.80 & 3.4 & 57.6 & $\begin{array}{c}0.15 \mathrm{TEA} \\
\text { TFA } \\
2.4 \mathrm{H}_{2} \mathrm{O}\end{array}$ \\
\hline & & $\mathrm{TAG}$ & --- & -- & --- & & ot detected \\
\hline & & $\mathrm{R}$ & 4.04 & 1.50 & 1.8 & 47.5 & $\begin{array}{c}0.15 \mathrm{TEA} \\
\text { TFA } \\
2.5 \mathrm{H}_{2} \mathrm{O} 0.3 \\
\text { gly } \\
\end{array}$ \\
\hline
\end{tabular}


Table 1 continued

\begin{tabular}{|c|c|c|c|c|c|c|c|}
\hline Code & Compound name and formula & $\mathrm{CSP}$ & $\mathrm{t}_{\mathrm{I}}$ & $\alpha$ & Rs & $\begin{array}{l}\mathrm{MeOH} \\
\% \mathrm{v} / \mathrm{v}\end{array}$ & $\begin{array}{c}\text { Other } \\
\text { additive }\end{array}$ \\
\hline \multirow[t]{3}{*}{$\bar{F} 23$} & \multirow{3}{*}{ 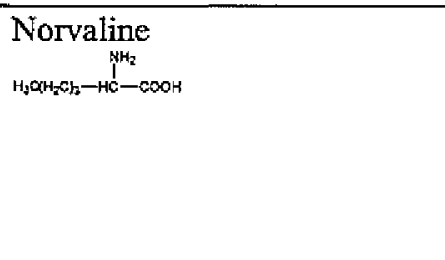 } & $\mathrm{T}$ & 2.62 & 1.66 & 1,7 & 48 & $\begin{array}{l}0.1 \text { TEA T'FA } \\
2 \mathrm{H}_{2} \mathrm{O} \quad 0.3 \mathrm{gly}\end{array}$ \\
\hline & & TAG & 2.42 & 2.10 & 1.9 & 48 & $\begin{array}{l}0.1 \text { TEA TFA } \\
2 \mathrm{H}_{2} \mathrm{O} 0.3 \mathrm{gly}\end{array}$ \\
\hline & & $\mathrm{R}$ & 2.73 & 1.38 & 1.2 & 48 & $\begin{array}{l}0.1 \text { TEA TFA } \\
2 \mathrm{H}_{2} \mathrm{O} 0.3 \text { gly }\end{array}$ \\
\hline \multirow[t]{3}{*}{$\mathrm{F} 24$} & \multirow{3}{*}{ DL-4-chlorophenylalanine } & $\mathrm{T}$ & 1.82 & 1.80 & 2.0 & 60 & 0.1 TEA TFA \\
\hline & & TAG & 1.51 & 2.17 & 2.1 & 60 & 0.1 TEA TFA \\
\hline & & $\mathrm{R}$ & 2.22 & 1.25 & 0.7 & 60 & 0.1 TEA TFA \\
\hline
\end{tabular}

Chromatographic conditions: pressure $100 \mathrm{bar}$, temperature $31 \mathrm{C}$, flow rate $4 \mathrm{~mL} / \mathrm{min}$; UV detection at $254 \mathrm{~nm}$, $220 \mathrm{~nm}$ and $214 \mathrm{~nm}$ with a diode array detector. TEA = triethylamine, TFA = trifluoroacetic acid, gly = glycerol. 


\title{
CHAPTER 3
}

\section{FAST SUPER/SUBCRITICAL FLUID CHROMATOGRAPHY ENANTIOMERIC SEPARATIONS OF DIHYDROFUROCOUMARIN DERIVATIVES WITH MACROCYCLIC GLYCOPEPTIDE STATIONARY PHASES}

\author{
A paper published in Chromatographia \\ Ying Liu, Roman V. Rozhkov, Richard C. Larock, Tom Ling Xiao, Daniel W. Armstrong
}

\begin{abstract}
Twenty-four chiral dihydrofurocoumarin derivatives and structurally related compounds were separated using super/subcritical fluid chromatography (SFC) on three macrocyclic glycopeptide chiral stationary phases (CSPs). All the dihydrofurocoumarin derivatives could be resolved on at least one of the macrocyclic glycopeptide CSPs, and the Chirobiotic $\mathrm{T}$ column showed the best enantioselectivity for 21 of the dihydrofurocoumarins studied. The Chirobiotic TAG and Chirobiotic R CSPs separated similar numbers of chiral dihydrofurocoumarin derivatives (16 on Chirobiotic TAG and 15 on Chirobiotic R), but the Chirobiotic TAG column baseline resolved more samples than the Chirobiotic $\mathrm{R}$ column under similar experimental conditions. All separations were done isocratically with an outlet pressure regulated at $100 \mathrm{bar}$, a column temperature of $31^{\circ} \mathrm{C}$, and a flow rate of 3.0 $\mathrm{mL} \cdot \mathrm{min}^{-1}$. Various amounts of methanol ranging from 2 to $25 \%(\mathrm{v} / \mathrm{v})$ were added to the supercritical carbon dioxide in order to optimize the enantiomeric separations. All of the
\end{abstract}


separations were completed in less than $15 \mathrm{~min}$, and $81 \%$ of the separations were done in less than $10 \mathrm{~min}$. The separation speed is one of the main advantages of SFC.

\subsection{Introduction}

Drug chirality continues to be extremely important in the pharmaceutical industry because various health problems have been associated with the use of an impure drug or an undesired enantiomer. Strict guidelines, set forth by the U.S. Food and Drug Administration, require compounds developed by pharmaceutical companies to meet special qualifications related to purity and other physical and chemical properties [1]. To meet this requirement, there has been a substantial increase in research and development related to drug chirality over the last twenty years $[2-5]$.

Chiral separations by packed column SFC was first proposed for the separation of chiral phosphorous-containing derivatives by Mourier et al in 1985 [6]. Today, supercritical fluid chromatography has become a promising chiral separation technique that is increasingly used in industrial applications [7-15]. Its advantages include the low viscosity of the supercritical fluid, which provides low pressure-drops, which in turn permit the use of high flow rates and long columns. The applicability and selectivity of SFC is very similar to that of normal phase HPLC. Hence, it is more frequently being used as a replacement for normal phase HPLC separations [16].

Macrocyclic glycopeptide CSPs were. first introduced by Armstrong et al in 1994 [17], and soon were found to be extremely useful in chiral separations of underivatized amino acids 
$[18,19]$, food flavors [20], and a wide variety of compounds with different polarities and different functionalities [21-23]. Chiral separations employing macrocyclic glycopeptide CSPs with SFC mobile phases have been reported recently [11-14]. Forty-four racemates have been evaluated on six CSPs, including Chirobiotic V and Chirobiotic T, with SFC mobile phases [14]. Recently, we reported an in-depth evaluation of the capabilities of macrocyclic glycopeptide-based CSPs with SFC mobile phases based on a set of 111 chiral compounds [10].

Dihydrofurocoumarin derivatives occur commonly in plants and fruits and are an important class of pharmacologically active compounds. In addition to anti-coagulant properties [24], other coumarin derivatives have been found to have antibacterial [25], anti-parasitic [26], anti-HIV [27,28], anti-inflammatory [29], anti-platelet [30], and anti-allergic properties [31]. Clearly, the potential pharmaceutical applications of dihydrofurocoumarin derivatives are significant. Since many of these derivatives are chiral, the elucidation of possible pharmacological differences of the two enantiomers becomes essential. So far, no successful asymmetric syntheses have been reported for this class of compounds. A very effective general synthesis of racemic dihydrofurocoumarins has been reported recently [32]. A few papers have reported the enantiomeric separation of coumarin-type anticoagulants, such as warfarin and warfarin analogues, using liquid chromatography on several CSPs $[14,33,34]$. However, these compounds are very different in their size, charge and action from the substituted tetrahydrofurocoumarins. This paper first reports rapid and successful SFC enantiomeric separations of chiral dihydrofurocoumarin derivatives based on macrocyclic glycopeptide chiral stationary phases. 


\subsection{Experimental}

A Berger analytical SFC with a Berger Instruments Chemstation (Berger Instruments, Newark, DE, USA) was used. The Berger SFC chromatography used was equipped with a fluid control module, a thermal control module, an automatic liquid sampler, a photodiode array detector (Agilent Technologies, Palo Alto, CA), a column selection valve and a solvent selection valve (Valco Instruments co. Inc., USA). The automated column selection valve and cabinet allow up to 6 analytical columns to be used. Additionally, the solvent switching valves allow the pumping of six different organic solvents one at a time.

Three different macrocyclic glycopeptide chiral stationary phases, Chirobiotic R, Chirobiotic $\mathrm{T}$, and Chirobiotic TAG ( $25 \mathrm{~cm} \times 4.6$ I.D. mm columns, $5 \mu \mathrm{M}$ particle size) were obtained from Advanced Separation Technologies Inc. (Whippany, NJ, USA).

SFC grade $\mathrm{CO}_{2}$ (Air Products and Chemicals, Inc. Allentown, PA) was used. HPLC grade methanol was purchased from Fisher Scientific (Fairlawn, NJ, USA). All chiral dihydrofurocoumarin derivatives were synthesized by Rozhkov et al at Iowa State University [32] (Ames, IA, USA) via the palladium-catalyzed annulation of 1,3-dienes by oiodoacetoxycoumarins. These samples were dissolved in methanol with a concentration from 1 to $5 \mathrm{mg} \cdot \mathrm{mL}^{-1}$. All separations were done under isocratic conditions at $31{ }^{\circ} \mathrm{C}$ and a flow rate of $3.0 \mathrm{~mL} \cdot \mathrm{min}^{-1}$, while regulating the pressure at the detector outlet at $100 \mathrm{bar}$. The organic solvent pump was fed by methanol. UV detection was carried out at $214 \mathrm{~nm}$ and $254 \mathrm{~nm}$ simultaneously with a photodiode array detector. 


\subsection{Results and Discussion}

\section{Overall CSP effectiveness}

The enantioselectivity of three commercially available macrocyclic glycopeptide-based CSPs, teicoplanin (Chirobiotic T), Ristocetin A (Chirobiotic R), and the recently introduced teicoplanin aglycon (Chirobiotic TAG), was evaluated with a set of twenty-four chiral dihydrofurocoumarin derivatives. Experimental conditions were deliberately chosen to favor fast (short retention times), rather than highly efficient (high plate number) separations. All chromatograms were obtained within $15 \mathrm{~min}$ at a flow rate of $3.0 \mathrm{~mL} \cdot \mathrm{min}^{-1}$. The results obtained on the three CSPs are listed in Table $\mathbf{I}$.

All of the twenty-four dihydrofurocoumarin derivatives could be baseline resolved on at least one of the macrocyclic glycopeptide CSPs, and 17 of these analytes were fully separated $\left(R_{\mathrm{s}}\right.$ $>1.5$ ) within $15 \mathrm{~min}$. The Chirobiotic $\mathrm{T}$ column produced the broadest enantioselectivity (i.e. separated the most dihydrofurocoumarins) followed by the Chirobiotic TAG column (see Figure 1). The teicoplanin CSP shows enantioselectivity $(\alpha>0.5)$ for 21 chiral dihydrofurocoumarin derivatives and baseline resolves $\left(R_{\mathrm{s}}>1.5\right) 15$ of those within 15 min. In addition, the teicoplanin aglycone and ristocetin A CSPs show enantioselectivity for an almost equal number of the dihydrofurocoumarin derivatives tested (16 on teicoplanin aglycone column and 15 on ristocetin A column). However, the Chirobiotic TAG column can baseline resolve more compounds ( 9 dihydrofurocoumarin derivatives) compared to the Chirobiotic R column (only 4 compounds) under similar experimental conditions. Although the Chirobiotic R column is the least enantioselective CSP for these dihydrofurocoumarins, it happened to be the most successful CSP for the class C compounds listed in Table I. All four 
structurally related coumarin derivatives can be separated by the Chirobiotic R column. But the two teicoplanin-based chiral selectors only show enantioselectivity for one of these compounds.

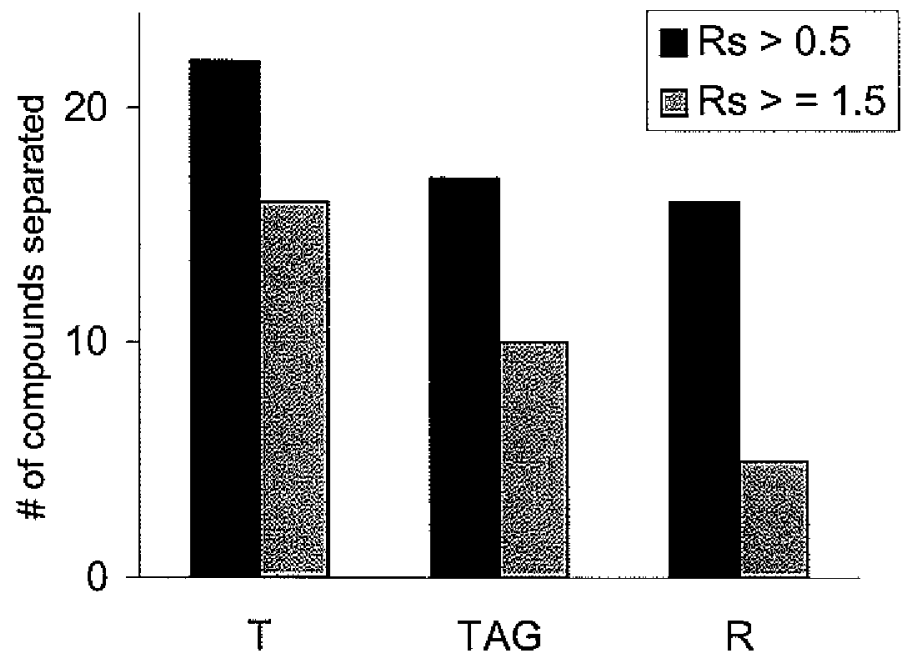

Figure 1. Overview of successful separation of 24 chiral substituted dihydrofurocoumarin separated on the three Chirobiotic CSPs: $\Upsilon$ (teicoplanin CSP); TAG (teicoplanin aglycon CSP); R (ristocetin A CSP).

\section{Selecting the experimental conditions}

All of the chiral dihydrofurocoumarin derivatives and related compounds analyzed in this study are neutral molecules. Experimental results showed that there were no pronounced differences in retention or in the enantioresolution factors when a small amount of acidic, basic or both additives were used in the mobile phases (data not shown). Occasionally, ionization of the CSP can affect the separation of neutral molecules [17], but that was not observed in this study. Because all of the neutral dihydrofurocoumarin derivatives tested are relatively nonpolar, only small amounts of methanol were required in order to elute these compounds (Table I). Based on the retention behavior of different compounds on different 
CSPs, the percentage of methanol in the supercritical $\mathrm{CO}_{2}$ can be adjusted in order to achieve enantioseparation within a certain time range (i.e. within $15 \mathrm{~min}$ in this study). In most cases, less than $5 \%$ of methanol was added when using the Chirobiotic R column. Up to $10 \%$ methanol was needed for the Chirobiotic $\mathrm{T}$ column and up to $20 \%$ methanol was used with the Chirobiotic TAG column. These results are consistent with those obtained for other compounds where it was reported that removing the sugar moieties from teicoplanin to produce the teicoplanin aglycon (i.e. Chirobiotic TAG) produced a CSP with increased retention properties [38].

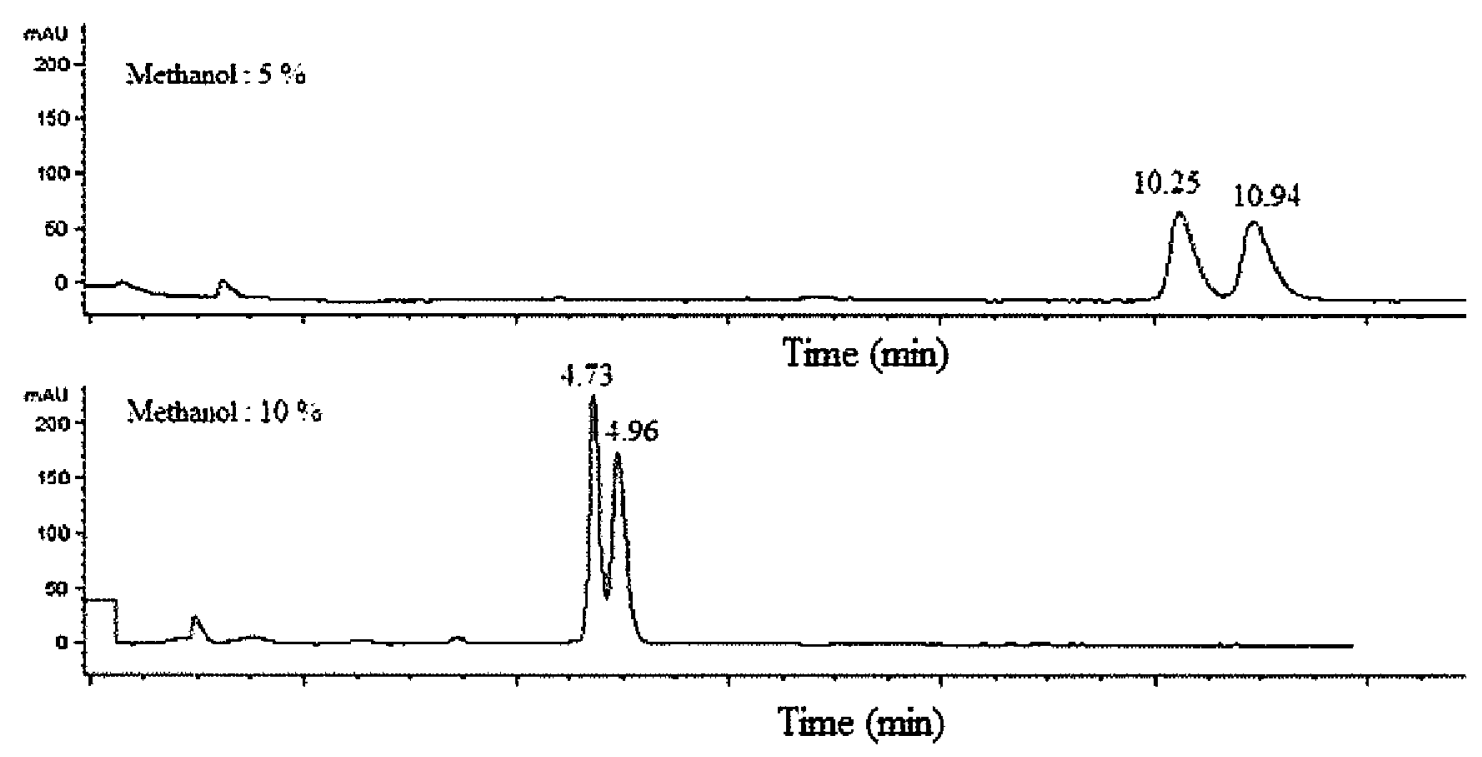

Figure 2. Effect of methanol concentration on the separation of the enantiomers of $B 4$.

Chromatographic conditions: Chirobiotic T column, $25 \times 0.46 \mathrm{~cm} \mathrm{I.D.,} 3.0 \mathrm{~mL} \cdot \mathrm{min}^{-1}$ of indicated SFC mobile phases, $31^{\circ} \mathrm{C}, 100$ bar, UV detection at $214 \mathrm{~nm}$.

Figure 2 shows the effect of methanol concentration on the separation of enantiomers of compound $\mathrm{B} 4$ on the Chirobiotic $\mathrm{T}$ column. With $10 \%$ methanol present in the mobile phase, partial separation with resolution factor (Rs) 1.1 was observed around 5 minute, when 
the methanol percentage was reduced to $5 \%$, baseline separation $(\mathrm{Rs}=1.5)$ can be achieved but the retention time doubled. Basically, for these neutral chiral dihydrofurocoumarin derivatives, the enantioresolution can be improved simply by decreasing the percentage of organic modifier in the $\mathrm{CO}_{2}$ eluent. The trade-off is a concurrent increase in the retention time.

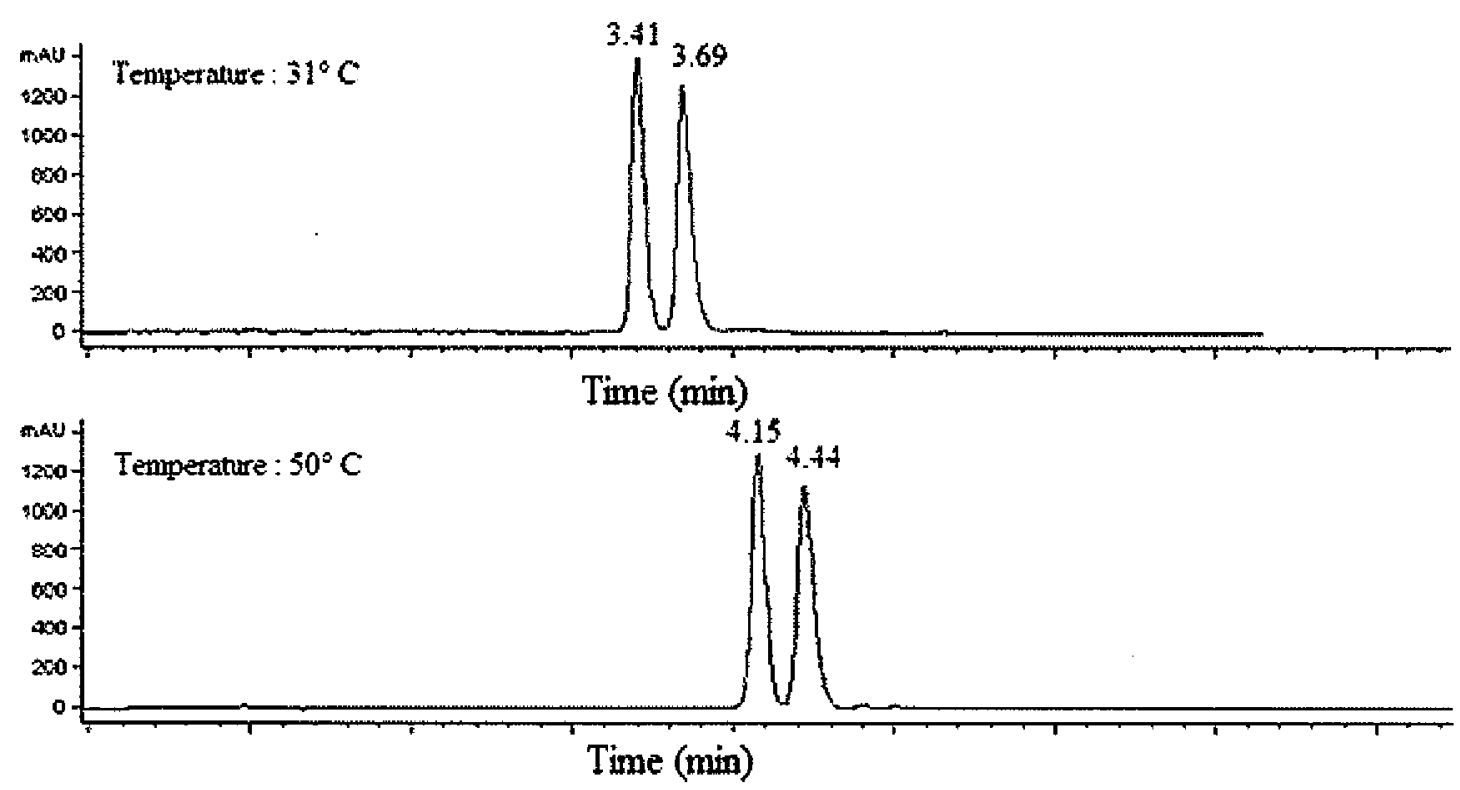

Figure 3. Effect of temperature on the separation of the enantiomers of All. Chromatographic conditions: Chirobiotic T column, $25 \times 0.46 \mathrm{~cm}$ I.D., $3.0 \mathrm{~mL} \cdot \mathrm{min}^{-1}, 5 \%(v / v)$ methanol added to supercritical $\mathrm{CO}_{2}, 100 \mathrm{bar}$, UV detection at $214 \mathrm{~nm}$.

Effects of temperature and pressure were also investigated. The effects of temperature and pressure on these separations were very similar to previously reported results $[10,39]$. Two different temperature $\left(31^{\circ} \mathrm{C}\right.$ and $50^{\circ} \mathrm{C}$ ) were investigated for the enantiomeric separation of sample $A 11$ on the Chirobiotic $\mathrm{T}$ column. Figure 3 shows that retention increases with increasing temperature at constant pressure 100 bar, which is different from HPLC. In HPLC, increasing temperature will decrease retention time because elevated temperature increases the solubility and diffusivity. But in SFC, the increased retention time with increasing 
temperature is due to the lower mobile phase density and the associated reduction in its solubilizing power [3]. Figure 3 also shows that the enantioresolution factor slightly decreases as the temperature increased, so a constant and low temperature 31 degree was selected for all separations.
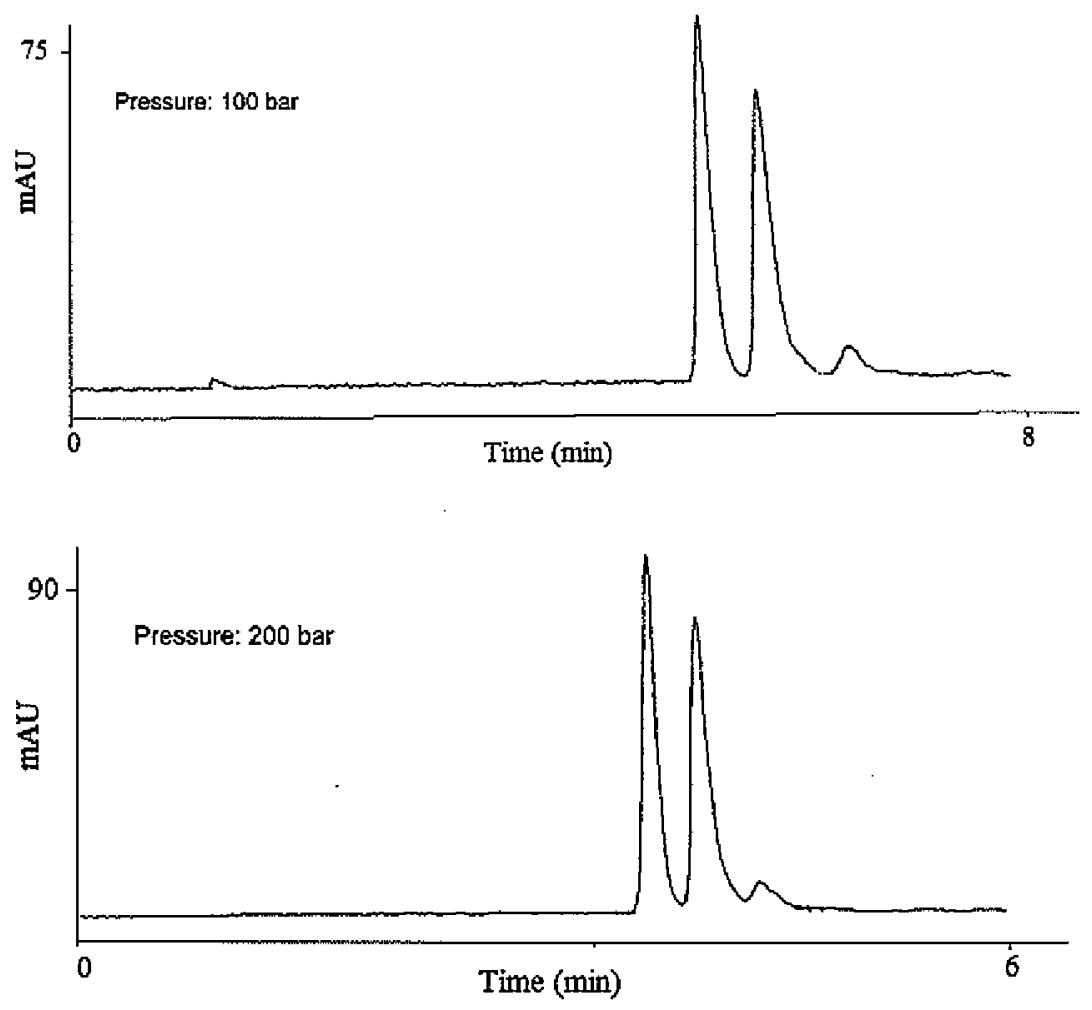

Figure 4. Effect of pressure on the separation of two enantiomers of compound A11.

Chromatographic conditions: Chirobiotic T column, $25 \times 0.46 \mathrm{~cm} \mathrm{I.D.,} 3.0 \mathrm{~mL} \cdot \mathrm{min}^{-1}, 10 \%(v / v)$ methanol added to supercritical $\mathrm{CO}_{2}, 31^{\circ} \mathrm{C}$, UV detection at $214 \mathrm{~nm}$.

The effect of pressure on these SFC separations was also investigated. Figure 4 shows the enantiomeric separation of compound Al1 performed at two different pressures. The retention time decreased as the pressure is increased from 100 bar to $200 \mathrm{bar}$, which consistent with literature reports $[10,39]$. For a given column and temperature, retention generally decreases as the operating pressure is increased because the fluid density increases 
at the high pressure. In addition, raising the pressure will slightly decrease the enantioresolution factors $[10,30]$. Thus, a constant outlet pressure of 100 bar was used in this study.
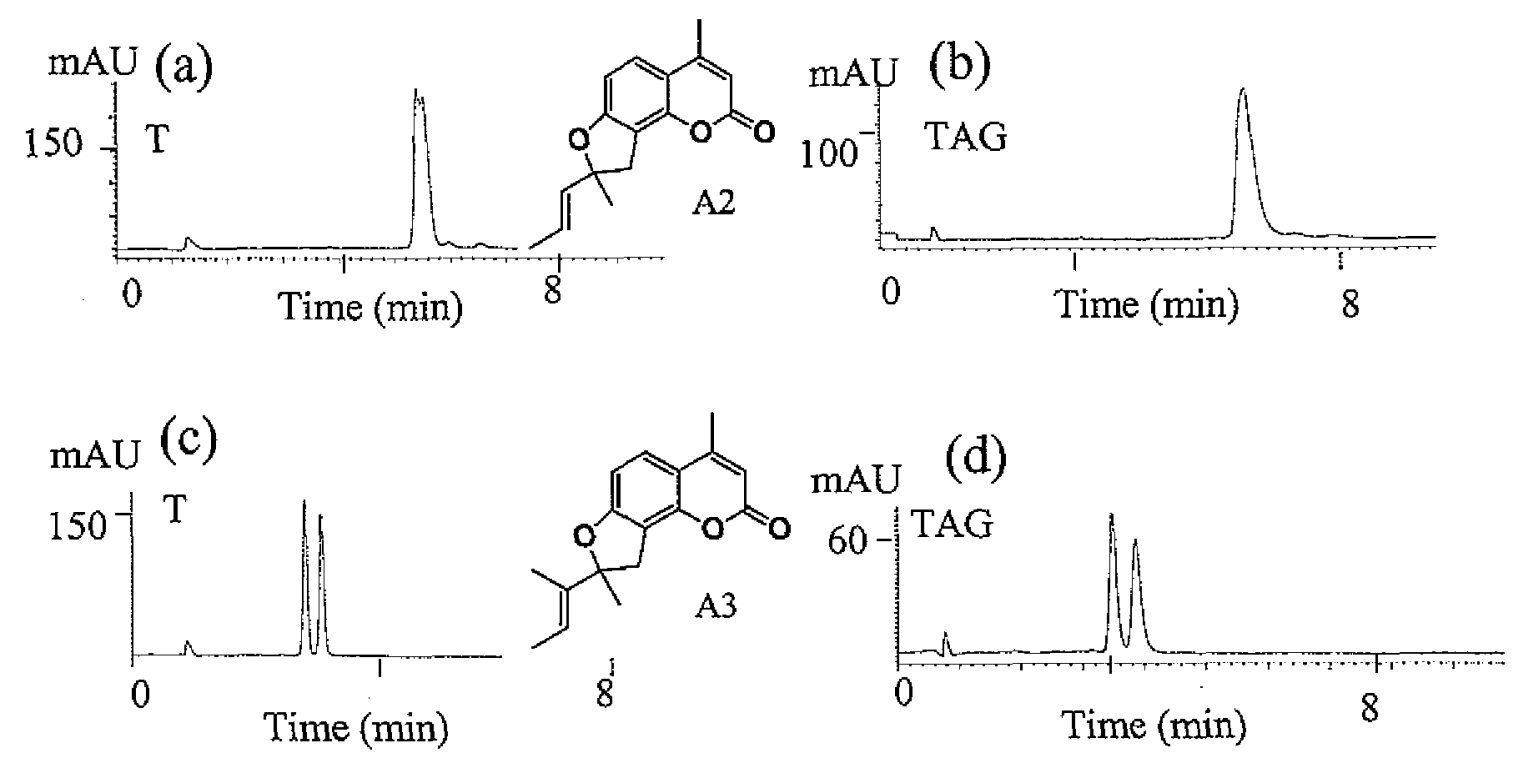

Figure 5. Effect of structure on enantioselectivity: a comparison of separations on two teicoplanin based CSPs. Chromatographic conditions: $3.0 \mathrm{~mL} \cdot \min ^{-1}$ with methanol additive of (a) $5 \%$ (b) 10 $\%$, (c) $10 \%$, (d), $15 \%(v / v)$ to supercritical $\mathrm{CO} 2,100$ bar, $31^{\circ} \mathrm{C}$, UV detection at $214 \mathrm{~nm}$.

\section{Structure-enantioselectivity relationships}

The large number of structurally related compounds in this study provides a means to examine the effect of small structural changes on enantioseparation. In particular, structural differences near the stereogenic center had a significant effect on the enantiomeric separation of these compounds. Figure 5 shows the enantiomeric separations of compounds A2 and A3 on the teicoplanin-based CSPs. These two compounds vary only in the substituent alpha to the stereogenic center. There is only a slight separation of compound A2 on the Chirobiotic $\mathrm{T}$ column. With the addition of a methyl group next to the stereogenic center, compound $\mathrm{A} 3$ 
can be baseline resolved on both columns. Clearly, the addition of the methyl group next to the stereogenic center greatly enhanced the enantiomeric separation.

It is also interesting to compare the separation of compounds A4 and A3. They differ by a methyl substituent on the stereogenic center. No enantiomeric separations were observed for compound A4 on the Chirobiotic TAG and R CSPs, while only partial separation was observed on the Chirobiotic T column. When a methyl group is substituted for hydrogen on the stereogenic center (compound A3), the enantioresolution is greatly enhanced. Baseline separations were observed on both of the teicoplanin-based CSPs and a partial separation was also found with the Chirobiotic R column. Overall, the increase in steric bulk (methyl group compared to hydrogen) on the stereogenic center or alpha to it enhanced the enantiomeric separation. However, chiral recognition was affected differently if the bulky substituent is further from the stereogenic center. For example, comparing compounds A5 and A6, with A7, the substituents vary in size from a dimethyl group to an ethyl group to a phenyl group in the position beta to the stereogenic center. The enantioselectivity of the compound with the largest group, a bulky phenyl substituent (A7), dramatically decreased on the Chirobiotic TAG column, although the retention time increased. No significant difference in enantiomeric separation is observed between compounds A5 and A6, since the dimethyl and ethyl groups have comparable size. Similar results were found for compounds B1, B2, and B5 as well. No enantiomeric separation was observed on the Chirobiotic TAG CSP for the phenyl-substituted compound (B2), although the retention time doubled under similar experimental conditions. 
In these experiments, higher enantioresolution factors were obtained for compounds Al1, A12, and A13, compared to most other investigated dihydrofurocoumarins. This is, presumably, due to the greater rigidity of these compounds about their stereogenic centers (see structures in Table I). Most other compounds studied have free rotation of a hydrocarbon substituent attached to the stereogenic center by a single bond. The synthetic mechanism allows only formation of the cis-configuration giving one pair of enantiomers for this set of compounds. Compound A12, bearing a seven-member ring, displayed the highest enantioresolution factor of all the analytes on all three Chirobiotic columns.

\section{Comparison with Normal Phase HPLC separation}

Enantiomeric separations of the same series of compounds have also been done by normal phase HPLC using the same Chirobiotic columns [40]. When comparing the normal phase HPLC with SFC, the separation results for these two techniques tended to follow similar trends. When a high degree of enantioselectivity was achieved for a particular compound in HPLC, similar behavior was also observed in SFC. For example, in both cases, the Chirobiotic R column is the least effective chiral stationary phase tested, but it is the only column that can baseline separate compounds $\mathrm{C} 1$ and $\mathrm{C} 4$ [40]. However, the similarities in enantioselectivity between the HPLC results and the SFC results were not absolute. For example, the Chirobiotic R CSP can be used to separate compound B7 using a SFC mobile phase, but no separation was observed using hexane/ethanol (98.5/1.5\%) as the mobile phase in HPLC [40]. Oppositely, compound B2 can be separated with the Chirobiotic TAG column when using hexane/ethanol as the mobile phase in HPLC, but the enantioseparation is lost when $\mathrm{CO}_{2}$-based mobile phases are used in SFC. 


\subsection{Conclusions}

The speed of the enantiomeric separations and solvent removal are advantages of using SFC compared to HPLC. Twenty-four coumarin derivatives can be separated individually in less than $15 \mathrm{~min}$, and most in less than 10 min with subcritical mobile phases and Chirobiotic columns. Column equilibration is much faster with $\mathrm{CO}_{2}$ containing mobile phases than with normal phase HPLC. SFC is advantageous for preparative separations with easy solute recovery and solvent disposal. This work also shows that the macrocyclic based CSPs are able to rapidly and successfully separate enantiomers of dihydrofurocoumarin derivatives and structurally related compounds. In this case, the Chirobiotic $T$ column showed the best overall enantioselectivity with SFC mobile phases, followed by the Chirobiotic TAG column.

\section{Acknowledgments}

Pfizer Inc. (La Jolla, CA) is thanked for providing the full analytical SFC system. Support of this work by the National Institutes of Health (NIH RO1 GM53825-08) is gratefully acknowledged. R. V. Rozhkov and R. C. Larock also acknowledge the donors of the Petroleum Research Fund, administered by the American Chemical Society, for partial support of this research and Johnson Matthey Inc., and Kawaken Fine Chemicals Co. Ltd., for donations of palladium acetate used in the preparation of the compounds studied.

\section{References}

[1] Food and Drug Administration (1992) Chirality 4: 338-340

[2] Maier NM, Franco P, Lindner W (2001) J Chromatogr A 906 (1-2): 3-33 
[3] Fillet M, Hubert P, Crommen J (2000) J Chromatogr A 875 (1-2): 123-134

[4] Armstrong DW, Zhang B (2001) Anal Chem 73 (19): 557A-561A

[5] Phinney KW (2000) Anal Chem: 204A-211A

[6] Mourier PA, Eliot E, Caude M, Rosset R, Tambute A (1985) Anal Chem 57: 2819-2823

[7] Berger TA (1997) J Chromatogr A 785: 3-33

[8] Berger TA (1995) Packed Column SFC, The Royal Society of Chemistry, Cambridge

[9] Williams KL, Sander LC (1997) J Chromatogr A 785: 149-158

[10] Liu Y, Berthod A, Mitchell CR, Xiao TL, Zhang B, Armstrong DW (2002) J

Chromatogr A 978: 185-204

[11] Dönnecke J, Svensson LA, Gyllenhaal O, Karlsson K, Karlsson A, Vessman J (1999) J

Microcolumn Sep 11 (7): 521-533

[12] Svensson LA, Owens PK (2000) Analyst 125: 1037-1039

[13] Toribio L, David F, Sandra P (1999) Quim Anal (Barcelona) 18 (3): 269-273

[14] Medvedovici A, Sandra P, Toribio L, David F (1997) J Chromatogr A 785: 159-171

[15] Gyllenhaa O, Karlsson A, Vessman J (1998) In: Supercritical fluid chromatography with packed columns, Anton K, Berger C (eds) Marcel Dekker, New York

[16] Berger TA, Smith J, Fogelman K, Kruluts K (2002) Am Lab: 14-20

[17] Armstrong DW, Tang X, Chen S, Zhou X, Bagwill C, Chen J (1994) Anal Chem 66: $1273-1484$

[18] Berthod A, Liu Y, Bagwill C, Armstrong DW (1998) J Chromatogr A 731: 123-137

[19] Peter A, Torok G, Armstrong DW (1998) J Chromatogr A 793: 283-296

[20] Ekborg-Ott KH, Armstrong DW (1997) in: Chiral separations: Application and Technology, ACS, Washington, DC, pp. 201, Chapter 9. 
[21] Ekborg-Ott KH, Liu Y, Armstrong DW (1998) Chirality 10: 434-483

[22] Armstrong DW, He L, Yu T, Lee JT, Liu Y (1999) Tetrahedron: Asymmetry 10: 37-60

[23] Ward TJ, Farris III AB (2001) J Chromatogr A 906: 73-89

[24] Goding LA, West BD (1969) J Med Chem 12: 517-518

[25] Desai P, Champaneri AC, Desai KR (2000) Asian J Chem 12 (4): 1327-1329

[26] Oketch-Rabah HA, Lemmich E, Dossaji SF, Theander TG, Olsen CE, Cornett C,

Kharazmi A, Christensen SB (1997) J Nat Prod 60: 458-461

[27] Kashman Y, Gustafson KR, Fuller RW, Cardellina JH, McMahon JB, Currens MJ,

Buckheit RW, Hughes SH, Cragg GM, Boyd MR (1992) J Med Chem 35: 2735-2743

[28] Shikishima Y, Takaishi Y, Honda G, Ito M, Takeda Y, Kodzhimatoy OK, Ashurmetov

O, Lee K (2001) Chem Pharm Bull 49 (7): 877-880

[29] Kontogiorgis C, Hadjipaylou-Litina D (2003) J Enzyme Inhib Med Chem 18 (1): 63-69

[30] Tsai I, Lin W, Teng C, Ishikawa T, Doong S, Huang M, Chen Y, Chen I (2000) Planta Med 66 (7): 618-623

[31] Oganesya ET, Gushchin IS, Simonyan AV, Saraf AS, Popov AN. U.S.S.R. (1993)

(Patent written in Russian), Application: SU 87-4288068 19870721

[32] Rozhkov RV, Larock RC (2003) Org Lett 5 (6): 797-800

[33] De Vries J, Schmitz-Kummer E (1993) J Chromatogr A 644 (2): 315-320

[34] De Vries J, Veolker U (1989) J Chromatogr A 493 (1): 149-156

[35] Terfloth G (2001) J Chromatogr A 906: 301-307

[36] Blackwell JA, Stringham RW, Weckwerth JD (1997) Anal Chem 69: 409-415

[37] Schurig V, Fluck M (2000) J Biochem Biophys Methods 43: 223-240

[38] Berthod A, Chen X, Kullman JP, Armstrong DW (2000) Anal Chem 72: 1767-1780 
[39] Robards K, Haddad PR, Jackson PE (1994) Principles and Practice of modern chromatographic methods, Boston: Academic Press

[40] Xiao TL, Rozhkov RV, Larock RC, Armstrong DW (2003) Anal Bioanal Chem online first, DOI: $10.1007 / \mathrm{s} 00216-003-2110-\mathrm{z}$ 
Table I. Enantiomeric separations on three chirobiotic CSPs by subcritical fluid chromatography

\begin{tabular}{|c|c|c|c|c|c|c|c|}
\hline Code & Structure & $\operatorname{CSP}^{a}$ & $\begin{array}{l}t_{r 1}^{b} \\
(\min )\end{array}$ & $k_{1}^{c}$ & $\alpha$ & $R_{\mathrm{s}}$ & $\begin{array}{l}\mathrm{MeOH}^{\mathrm{d}} \\
(\mathrm{v} / \mathrm{v} \%)\end{array}$ \\
\hline \multicolumn{8}{|c|}{ Class A: dihydrofuroangelicins } \\
\hline \multirow[t]{3}{*}{$\mathrm{A} 1$} & & $\bar{R}$ & 10.09 & 7.77 & 1.00 & 0.0 & 2 \\
\hline & & $\mathrm{T}$ & 9.15 & 6.96 & 1.13 & 1.8 & 3 \\
\hline & & TAG & 7.56 & 6.34 & 1.12 & 1.4 & 7 \\
\hline \multirow[t]{3}{*}{ A2 } & & $\mathrm{R}$ & 6.41 & 4.88 & 1.00 & 0.0 & 3 \\
\hline & & $T$ & 9.63 & 7.37 & 1.03 & 0.7 & 3 \\
\hline & & TAG & 6.20 & 5.20 & 1.00 & 0.0 & 10 \\
\hline \multirow[t]{3}{*}{$\mathrm{A} 3$} & & $\mathrm{R}$ & 3.93 & 2.85 & 1.03 & 0.5 & 5 \\
\hline & & $\mathrm{T}$ & 3.08 & 2.08 & 1.13 & 1.8 & 10 \\
\hline & & TAG & 3.48 & 3.00 & 1.15 & 1.6 & 15 \\
\hline \multirow[t]{3}{*}{ A4 } & & $\mathrm{R}$ & 7.33 & 5.72 & 1.00 & 0.0 & 3 \\
\hline & & $\mathrm{T}$ & 10.38 & 8.03 & 1.05 & 0.9 & 3 \\
\hline & & TAG & 9.58 & 8.30 & 1.00 & 0.0 & 7 \\
\hline \multirow[t]{3}{*}{ A5 } & & $\mathrm{R}$ & 7.53 & 5.91 & 1.06 & 0.9 & 3 \\
\hline & & $\mathrm{T}$ & 3.52 & 2.52 & 1.11 & 1.8 & 10 \\
\hline & & TAG & 9.99 & 8.70 & 1.11 & 1.5 & 7 \\
\hline \multirow[t]{3}{*}{ A6 } & & $\mathrm{R}$ & 7.46 & 5.84 & 1.00 & 0.0 & 3 \\
\hline & & $T$ & 6.11 & 4.61 & 1.10 & 1.7 & 5 \\
\hline & & TAG & 8.95 & 7.69 & 1.07 & 1.0 & 7 \\
\hline \multirow[t]{3}{*}{ A7 } & & $\mathrm{R}$ & 9.89 & 5.59 & 1.00 & 0.0 & 5 \\
\hline & & $\mathrm{T}$ & 9.81 & 7.92 & 1.03 & 0.8 & 7 \\
\hline & & TAG & 10.98 & 11.62 & 1.00 & 0.0 & 15 \\
\hline
\end{tabular}


Table I (continued)

\begin{tabular}{|c|c|c|c|c|c|c|c|}
\hline Code & Structure & $\mathrm{CSP}^{\mathrm{a}}$ & $\begin{array}{l}t_{r}^{\circ} \\
(\min )\end{array}$ & $\overline{k_{i}{ }^{c}}$ & $\alpha$ & $R_{\mathfrak{s}}$ & $\begin{array}{l}\mathrm{MeOH}^{\sigma} \\
(v / W \%)\end{array}$ \\
\hline \multirow[t]{6}{*}{$\mathrm{A} 8$} & & $\mathrm{R}$ & 4.88 & 3.48 & 1.06 & 0.8 & 3 \\
\hline & & & 5.74 & 4.27 & 1.07 & 0.9 & \\
\hline & & $\mathrm{T}$ & 2.91 & 1.65 & 1.14 & 1.3 & 7 \\
\hline & & & 3.28 & 1.98 & 1.18 & 2.2 & \\
\hline & & TAG & 4.75 & 3.61 & 1.42 & 4.4 & 7 \\
\hline & & & 5.60 & 4.44 & 1.57 & 5.8 & \\
\hline \multirow[t]{3}{*}{$\mathrm{A} 9$} & & $\mathrm{R}$ & 11.01 & 9.79 & 1.09 & 1.5 & 5 \\
\hline & & $T$ & 6.77 & 5.77 & 1.18 & 2.8 & 10 \\
\hline & & TAG & 10.25 & 10.78 & 1.12 & 1.2 & 15 \\
\hline \multirow[t]{3}{*}{ A10 } & & $\mathrm{R}$ & 7.88 & 6.23 & 1.05 & 0.8 & 3 \\
\hline & & $T$ & 10.79 & 8.38 & 1.06 & 1.4 & 3 \\
\hline & & TAG & 9.37 & 8.10 & 1.11 & 1.3 & 7 \\
\hline \multirow[t]{3}{*}{ A11 } & & $\mathrm{R}$ & 11.83 & 9.29 & 1.05 & 0.8 & 2 \\
\hline & & $\mathrm{T}$ & 3.30 & 2.30 & 1.11 & 1.7 & 10 \\
\hline & & $\mathrm{TAG}$ & 3.90 & 3.48 & 1.51 & 2.3 & 15 \\
\hline \multirow[t]{3}{*}{$\mathrm{A} 12$} & & $\mathrm{R}$ & 8.12 & 6.45 & 1.10 & 1.5 & 3 \\
\hline & & $T$ & 3.37 & 2.37 & 1.21 & 3.2 & 10 \\
\hline & & TAG & 6.98 & 5.98 & 1.50 & 5.4 & 10 \\
\hline \multirow[t]{3}{*}{$\mathrm{A} 13$} & & $R$ & 9.10 & 7.35 & 1.07 & 1.3 & 3 \\
\hline & & $T$ & 3.78 & 2.78 & 1.11 & 1.8 & 10 \\
\hline & & TAG & 5.36 & 5.16 & 1.25 & 2.6 & 15 \\
\hline
\end{tabular}


Table I (continued)

\begin{tabular}{|c|c|c|c|c|c|c|c|}
\hline \multicolumn{2}{|c|}{ Code Structure } & $\mathrm{CSP}^{\mathrm{a}}$ & $\begin{array}{l}t_{r}{ }^{6} \\
(\min )\end{array}$ & $k_{1}^{c}$ & $\alpha$ & $\overline{R_{\mathrm{s}}}$ & $\begin{array}{l}\mathrm{MeOH}^{\mathrm{d}} \\
(\mathrm{V} / \mathrm{V} \%)\end{array}$ \\
\hline \multicolumn{8}{|c|}{ Class B: dihydrofuropsoralens } \\
\hline \multirow[t]{3}{*}{ B1 } & & $\mathrm{R}$ & 8.78 & 7.61 & 1.00 & 0.0 & 5 \\
\hline & & $\mathrm{T}$ & 10.37 & 8.51 & 1.07 & 1.5 & 5 \\
\hline & & TAG & 9.97 & 8.97 & 1.04 & 0.8 & 10 \\
\hline \multirow[t]{3}{*}{ B2 } & & $\mathrm{R}$ & 7.77 & 6.77 & 1.03 & 0.6 & 10 \\
\hline & & $T$ & 8.53 & 7.53 & 1.10 & 2.1 & 10 \\
\hline & & TAG & 9.15 & 9.76 & 1.00 & 0.0 & 20 \\
\hline \multirow[t]{3}{*}{ B3 } & & $\mathrm{R}$ & 6.72 & 5.59 & 1.00 & 0.0 & 5 \\
\hline & & $\mathrm{T}$ & 15.76 & 12.70 & 1.05 & 0.9 & 3 \\
\hline & & TAG & 8.00 & 7.00 & 1.00 & 0.0 & 10 \\
\hline \multirow[t]{3}{*}{ B4 } & & $\mathrm{R}$ & 8.19 & 7.03 & 1.00 & 0.0 & 5 \\
\hline & & T & 10.25 & 8.40 & 1.08 & 1.5 & 5 \\
\hline & & TAG & 9.90 & 8.90 & 1.04 & 0.7 & 10 \\
\hline \multirow[t]{3}{*}{ B5 } & & $\mathrm{R}$ & 8.60 & 7.43 & 1.00 & 0.0 & 5 \\
\hline & & $\mathrm{T}$ & 9.66 & 7.86 & 1.12 & 2.1 & 5 \\
\hline & & TAG & 9.36 & 8.36 & 1.05 & 0.8 & 10 \\
\hline \multirow[t]{6}{*}{ B6 } & & $\mathrm{R}$ & 10.78 & 8.89 & 1.07 & 1.1 & 3 \\
\hline & & & 12,68 & 10.63 & 1.04 & 0.8 & \\
\hline & & $T$ & 4.01 & 3.01 & 1.00 & 0.0 & 10 \\
\hline & & & 4.27 & 3.27 & 1.14 & 2.4 & \\
\hline & & TAG & 7.22 & 6.22 & 1.05 & 0.8 & 10 \\
\hline & & & 8.16 & 7.16 & 1.14 & 1.8 & \\
\hline
\end{tabular}


Table I (continued)

\begin{tabular}{|c|c|c|c|c|c|c|c|}
\hline Code & Structure & $\operatorname{cSP}^{3}$ & $\begin{array}{l}t_{r r} \\
(\min )\end{array}$ & $k_{1}^{c}$ & $\alpha$ & $\overline{R_{\mathrm{s}}}$ & $\begin{array}{l}\mathrm{MeOH}^{\mathrm{\sigma}} \\
(\mathrm{V} / \mathrm{V} \%)\end{array}$ \\
\hline \multirow[t]{3}{*}{ B7 } & & $\mathrm{R}$ & 5.47 & 4.47 & 1.11 & 2.0 & 10 \\
\hline & & $\mathrm{T}$ & 7.71 & 6.01 & 1.12 & 2.4 & 7 \\
\hline & & TAG & 5.95 & 5.84 & 1.09 & 1.0 & 15 \\
\hline \multicolumn{8}{|c|}{ Class C: Other structurally related coumarin derivatives } \\
\hline \multirow[t]{3}{*}{$\mathrm{C1}$} & & $\mathrm{R}$ & 8.42 & 7.25 & 1.13 & 2.1 & 5 \\
\hline & & $\mathrm{T}$ & 7.65 & 6.65 & 1.00 & 0.0 & 10 \\
\hline & & TAG & 6.99 & 7.32 & 1.00 & 0.0 & 25 \\
\hline \multirow[t]{3}{*}{$\mathrm{C} 2$} & & $\mathrm{R}$ & 5.05 & 3.95 & 1.04 & 0.8 & 5 \\
\hline & & $T$ & 8.74 & 7.02 & 1.00 & 0.0 & 5 \\
\hline & & TAG & 9.40 & 8.40 & 1.00 & 0.0 & 10 \\
\hline \multirow[t]{3}{*}{$\mathrm{C} 3$} & & $\mathrm{R}$ & 4.91 & 3.91 & 1.16 & 2.0 & 10 \\
\hline & & $\mathrm{T}$ & 6.76 & 5.76 & 1.07 & 1.4 & 10 \\
\hline & & TAG & 5.07 & 5.04 & 1.26 & 2.2 & 25 \\
\hline \multirow[t]{3}{*}{$\mathrm{C} 4$} & & $\mathrm{R}$ & 10.01 & 8.18 & 1.09 & 1.3 & 3 \\
\hline & & $T$ & 8.12 & 6.45 & 1.00 & 0.0 & 5 \\
\hline & & TAG & 8.93 & 7.93 & 1.00 & 0.0 & 10 \\
\hline
\end{tabular}

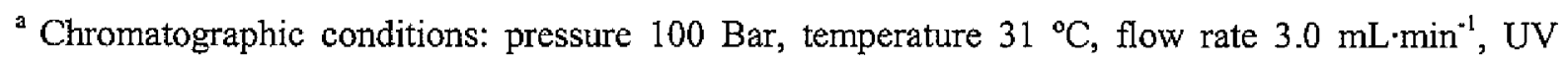
detection at $214 \mathrm{~nm}$ with a diode array detector.

${ }^{\mathrm{b}}$ Retention time for the first eluted enantiomer

${ }^{c}$ Retention factor for the first eluted enantiomer (calculated using equation $k_{I}=\left(t_{r I}-t_{0}\right) / t_{0}$, where $t_{0}$ is dead volume)

${ }^{\mathrm{d}}$ Volume percentage of methanol added to the supercritical carbon dioxide. 


\title{
CHAPTER 4
}

\section{ENANTIOSEPARATIONS OF DIHYDROFUROCOUMARIN DERIVATIVES BY VARIOUS SEPARATION MODES OF CAPILLARY ELECTROPHORESIS}

\author{
A paper published in Electrophoresis \\ Matthew D. Egger, Ying Liu, Juraj Ševčík ${ }^{1}$, Eva Tesařová ${ }^{2}$, Roman Rozhkov, Richard C. \\ Larock, Daniel W. Armstrong
}

\begin{abstract}
Chiral dihydrofurocoumarin compounds are currently the focus of industrial and pharmacological research. These derivatives have been shown to possess many physiological properties that could be medically beneficial. This work proposes four different chiral separation methods using capillary electrophoresis and micellar capillary electrophoresis (MCE). Several different cyclodextrin chiral selectors were examined to evaluate their effectiveness in the enantioseparation of dihydrofurocoumarins. In addition, the effects of the chiral selector concentration, the presence of an organic modifier, run buffer $\mathrm{pH}$, and in two cases, the ratio between the chiral selector and an additional charged pseudophase were investigated. Overall, the best separations for this class of chiral compounds were achieved using sulfated $\beta$-cyclodextrins at low $\mathrm{pH}$ in the reversed polarity mode.
\end{abstract}

\footnotetext{
${ }^{1}$ On leave from Department of Analytical Chemistry, Palacký University, 77146 Olomouc, Czech Republic

${ }^{2}$ On leave from Department of Phys. and Macromol Chemistry, Charles University, 12843 Prague, Czech Republic
} 
Abbreviations: MCE, micellar capillary electrophoresis, NPM, normal polarity mode, RPM, reverse polarity mode, $\mathbf{S}-\beta$-CD, sulfated $\beta$-cyclodextrin, $\mathbf{H P}-\beta-\mathbf{C D}$, hydroxypropyl $\beta-$ cyclodextrin, CM- $\beta-\mathbf{C D}$, carboxymethyl $\beta$-cyclodextrin, SBE- $\beta$-CD, sulfobutyl ether $\beta$ cyclodextrin, SDS, sodium dodecyl sulfate, EOF, electroosmotic flow

\subsection{Introduction}

Coumarins and coumarin derivatives have been of great interest to researchers in both industry and medicine for many years. The anticoagulant activity of warfarin and its analogues has been known for decades [1]. Other coumarin derivatives have been found to act as vasodilators [2]. More recently, dihydrofurocoumarin analogues have been found to have several other beneficial physiological properties. There have been reports in which these compounds have shown antibacterial and anti-tumor activity $[3,4]$. Within the past few years, dihydrofurocoumarin compounds isolated from natural sources have been shown to possess anti-HIV activity $[5,6]$. In addition, enzymatic studies have shown that some of these molecules possess protein kinase inhibition activity as well as cytokinase release activity [3,7]. Due to the wide array of biological properties attributed to dihydrofurocoumarin derivatives, much effort has been made for the synthesis of these molecules.

General synthetic routes for the production of dihydrofurocoumarins have been reported [8]. However, these suffer from low yields and are limited in the range of compounds that can be produced. Recently, Rozhkov and Larock have proposed an approach for the synthesis of chiral dihydrofurocoumarins by palladium-catalyzed annulation of 1,3-dienes by o- 
iodoumbelliferones [9]. This approach typically offers high yields $(\sim 70-95 \%)$ of a broad range of chiral dihydrofurocoumarins [9]. However, as with other synthetic approaches, only the racemate is produced. Thus far no successful asymmetric syntheses have been reported for this class of molecules.

There have been several previous reports on the LC enantiomeric separation of the common coumarin derivatives of warfarin and its analogues [10-14]. Several studies have reported the enantioseparation of warfarin, and warfarin analogues with capillary electrophoresis [15-19]. Unfortunately, the methods used in these studies were not as effective for the dihydrofurocoumarins analyzed in this work. Warfarin and warfarin analogues are somewhat soluble in aqueous solutions and have functional groups that may possess a charge. The dihydrofurocoumarin compounds analyzed in this study are all neutral molecules and very hydrophobic which greatly limits their water solubility (see structures in Table 1). In this work we report the use of both cyclodextrins and micelles to achieve the first $\mathrm{CE}$ enantiomeric separations of several dihydrofurocoumarin compounds.

\subsection{Experimental}

\section{Materials}

Sulfated $\beta$-cyclodextrin (S- $\beta$-CD) and hydroxypropyl $\beta$-cyclodextrin (HP- $\beta$-CD) were purchased from the Aldrich Chemical Company (Milwaukee, WI, USA). Carboxymethyl $\beta$ cyclodextrin (CM- $\beta$-CD) was purchased from American Maize Products (Hammond, $\mathbb{N}$, USA). Sulfobutyl ether $\beta$-cyclodextrin (SBE- $\beta$-CD) was obtained from CyDex, Inc. (Overland Park, KS, USA). Sodium dodecyl sulfate (SDS), sodium phosphate, HPLC-grade 
methanol, HPLC-grade acetonitrile, hydrochloric acid, and sodium hydroxide were all obtained through Fisher Scientific (St. Louis, MO, USA). The racemic dihydrofurocoumarin compounds were synthesized as reported previously [9]. The capillaries used in these experiments were purchased from Polymicro Technologies (Phoenix, AZ, USA).

\section{Methods}

The system used for all CE experiments was a P/ACE MDQ system from Beckman Coulter (Fullerton, CA, USA). The separation capillary had a $50 \mu \mathrm{m} \mathrm{ID}$, a $30 \mathrm{~cm}$ total length and a 20 effective length. A $3 \mathrm{~mm}$ portion of the polyamide coating of the capillary was burned off to create a window for detection. The MDQ instrument has a photodiode array detector, however all electropherograms obtained for this work were detected at a wavelength of 214 nm. Samples were injected by pressure and rinsing was performed at a pressure of $20 \mathrm{psi}$. The capillary was conditioned first with water for $1 \mathrm{~min}$, then with $1 \mathrm{M}$ sodium hydroxide for $5 \mathrm{~min}$, and again with water for $5 \mathrm{~min}$. In between every run, the capillary was rinsed with water for $0.5 \mathrm{~min}, 1 \mathrm{M}$ sodium hydroxide for $0.5 \mathrm{~min}$, water for $0.5 \mathrm{~min}$, and finally rinsed with the run buffer for $2 \mathrm{~min}$. The samples in this experiment were dissolved in methanol and diluted with run buffer. The optimized separation voltage applied was $15 \mathrm{kV}$. The MCE experiments were all performed on a P/ACE System 5000 from Beckman Coulter (Fullerton, CA, USA). The separation capillary had a $50 \mu \mathrm{m} \mathrm{D}$, with a $40 \mathrm{~cm}$ length and an effective length of $32 \mathrm{~cm}$. The applied voltage was also $15 \mathrm{kV}$. The analytes were detected at a wavelength of $214 \mathrm{~nm}$ with this instrument. Prior to use, the capillary was conditioned for 1 min with water, $3 \mathrm{~min}$ with sodium hydroxide, and finally 3 min with water. Prior to every run, the capillary was rinsed with $0.1 \mathrm{M}$ sodium hydroxide for $2 \mathrm{~min}$, water for $2 \mathrm{~min}$, and 
the run buffer for $3 \mathrm{~min}$. The samples in the MCE experiments were dissolved in the run buffer, with the exception of compounds 8 and 9 that had to be dissolved in a small volume of acetonitrile that was then diluted with the run buffer. Running buffer for the reversed polarity mode $\mathrm{CE}$ experiments were prepared by dissolving the required amount of the cyclodextrins in $50 \mathrm{mM}$ sodium phosphate stock solution. Running buffers for MCE study were prepared by dissolving the required amount of the cyclodextrin and/or SDS in $10 \mathrm{mM}$ sodium phosphate stock solution. The $\mathrm{pH}$ was adjusted by adding aqueous sodium hydroxide or aqueous hydrochloric acid. The buffers were degassed by sonication prior to use. The organic modifier was added on a volume-to-volume basis.

\subsection{Results and Discussion}

\subsubsection{Enantioseparation of coumarins by $\mathrm{CE}$}

The use of cyclodextrins to achieve enantioseparations in $\mathrm{CE}$ was originally borrowed from liquid chromatography $[14,20]$. Subsequently, cyclodextrins and their derivatives have developed into the most prevalent and broadly useful class of chiral selectors in CE [17, 2125]. It is well understood that for separations to occur, either the analyte or the cyclodextrin must possess a charge otherwise the cyclodextrin-enantiomer complex will move with the electroosmotic flow (EOF) and no enantioseparation will be observed. In the case of the chiral dihydrofurocoumarin derivatives (Table 1), the analytes are neutral, therefore the cyclodextrins used for this separation must be charged. 


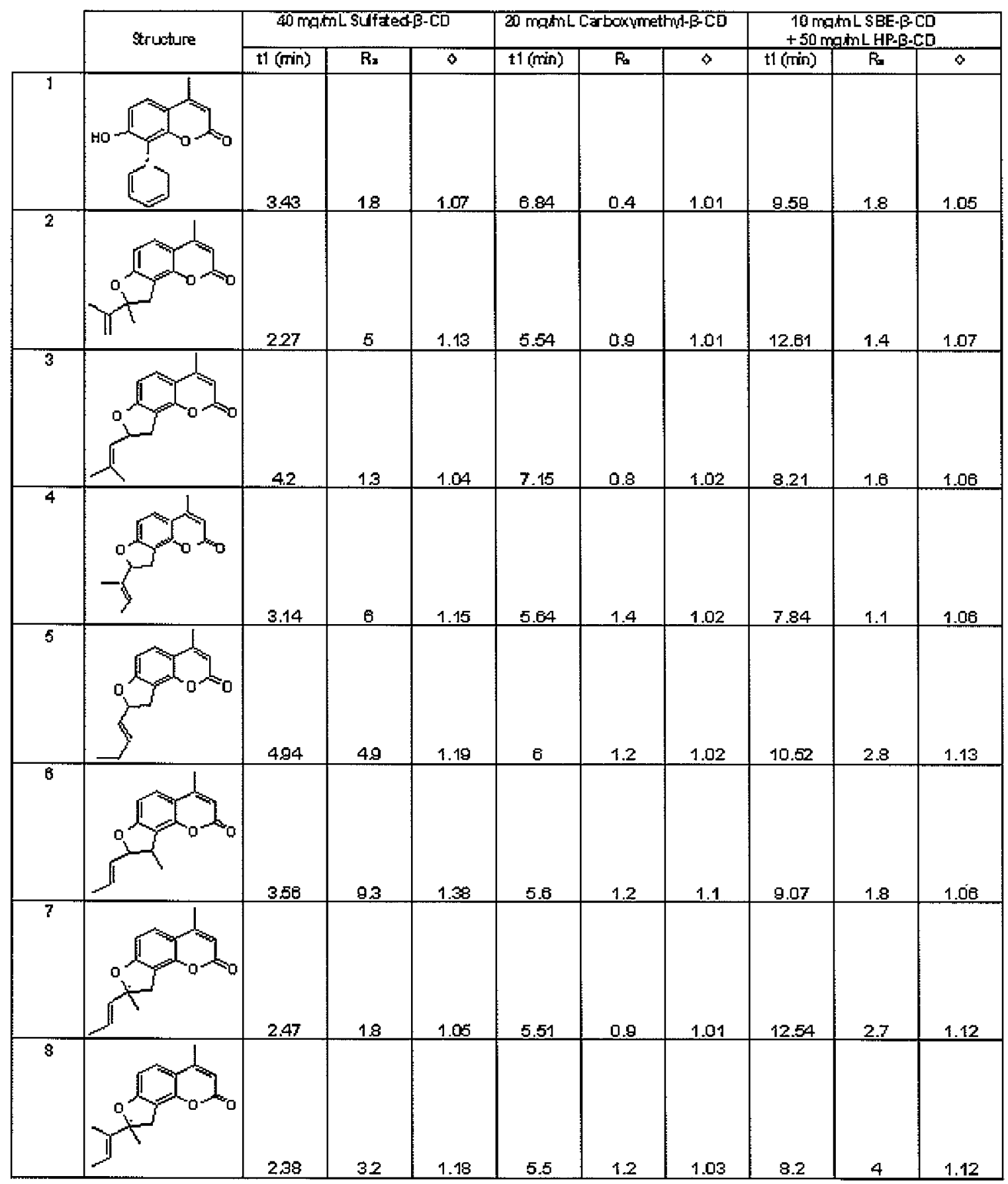

Table 1. Results of the enantioseparation of coumarins for each anionic chiral selector under optimized conditions 
In the normal polarity mode, and at higher pHs, some negatively charged CDs produce poor enantioseparations of the racemic dihydrofurocoumarin analytes. At lower $\mathrm{pHs}$, the electrophoretic mobility of the negatively charged $\mathrm{CD}$ towards the anode (at the inlet) can be higher than that of the EOF (directed to the cathode) and prevents the analyte/CD complex from reaching the detector. To overcome this problem, the separations were conducted in the reversed polarity mode (RPM). The EOF can be reduced significantly by using a running buffer at low $\mathrm{pH}$.
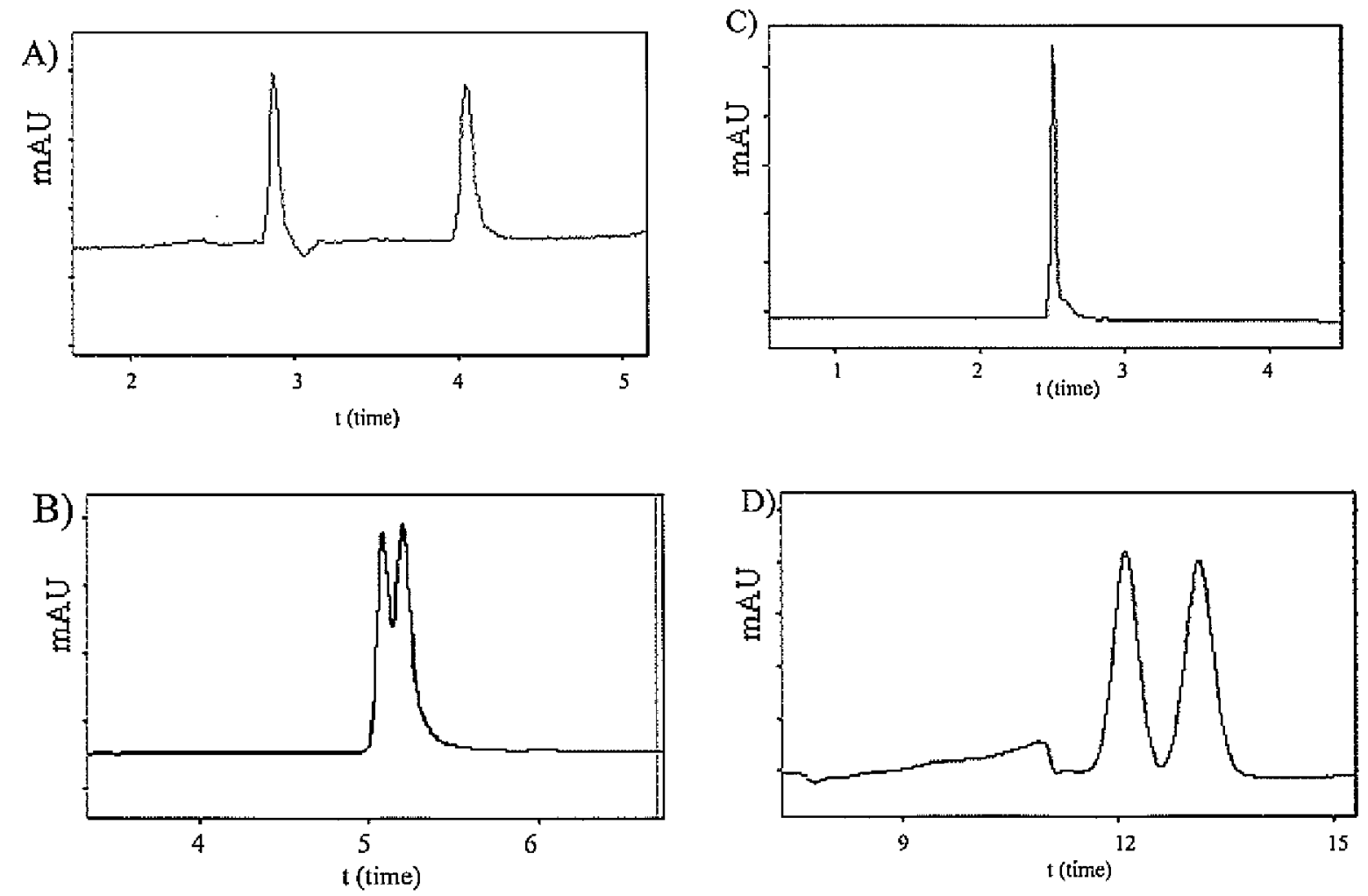

Figure 1. CE enantioseparation of a coumarin derivative using $A$ ) $S-\beta-C D, B) C M-\beta-C D, C) S B E-\beta-$ $\mathrm{CD}$, and $\mathrm{D}) \mathrm{SBE}-\beta-\mathrm{CD}+\mathrm{HP}-\beta-\mathrm{CD}$. The background electrolyte was $50 \mathrm{mM}$ phosphate buffer, at $\mathrm{pH}$ 2.5. The applied voltage was $-15 \mathrm{kV}$. Detection was performed at $214 \mathrm{~nm}$. Sample: racemate of chiral coumarin derivative \#7. 


\section{Effect of Different Negatively Charged Derivatized Cyclodextrins on Dihydrofurocoumarin Enantioseparations}

The nature of the anionic functional group(s) on the derivatized $\beta$-CD and their degree of substitution often affect enantiomeric separations. In this work, three different anionic CDs were examined: $\mathrm{S}-\beta-\mathrm{CD}, \mathrm{CM}-\beta-\mathrm{CD}, \mathrm{SBE}-\beta-\mathrm{CD}$ (see Materials and Methods section for further details). These anionic CDs showed very different enantioselectivities for the dihydrofurocoumarins listed in Table 1 . In nearly every case, the sulfated- $\beta$-cyclodextrin gave better resolution than either carboxymethyl- $\beta$-cyclodextrin or the combination of sulfobutylether- $\beta$-cyclodextrin with hydroxypropyl- $\beta$-cyclodextrin $\quad(H P-\beta-C D)$. The effectiveness of different derivatized cyclodextrins on the separation of enantiomers of dihydrofurocoumarin derivatives is shown in Figure 1. Note that the SBE- $\beta$-CD rarely produced a separation by itself. It required the addition of the uncharged HP- $\beta-\mathrm{CD}$. The neutral HP- $\beta-\mathrm{CD}$ provided the enantioselectivity while the negatively charged SBE- $\beta-\mathrm{CD}$ provided electrophoretic mobility.

\section{Effect of Chiral Selector Concentration on Enantioseparation}

The concentration of the chiral selector can have a significant effect on the resolution and efficiency of the enantioseparation. As stated earlier, the enantiomers of these chiral, substituted dihydrofurocoumarins were best separated when using sulfated- $\beta$-cyclodextrin as the chiral selector in the RPM. In this case, as the concentration of S- $\beta$-CD increased, the migration time of the analyte decreased (Figure 2). This was due to an increase in the apparent electrophoretic mobility towards the outlet brought about by the presence of a greater amount of the anionic chiral selector (S- $\beta-C D)$ in the run buffer which, in turn, 
resulted in a greater percentage of the analyte being complexed (Figure 2). At both 20 and $40 \mathrm{mg} / \mathrm{mL}$ S- $\beta-\mathrm{CD}$, this approach produced good, efficient separations. However, due to the fact that the run times were typically shorter with a concentration of $40 \mathrm{mg} / \mathrm{mL} \mathrm{S}-\beta-\mathrm{CD}$, this was the concentration used for all subsequent separations.

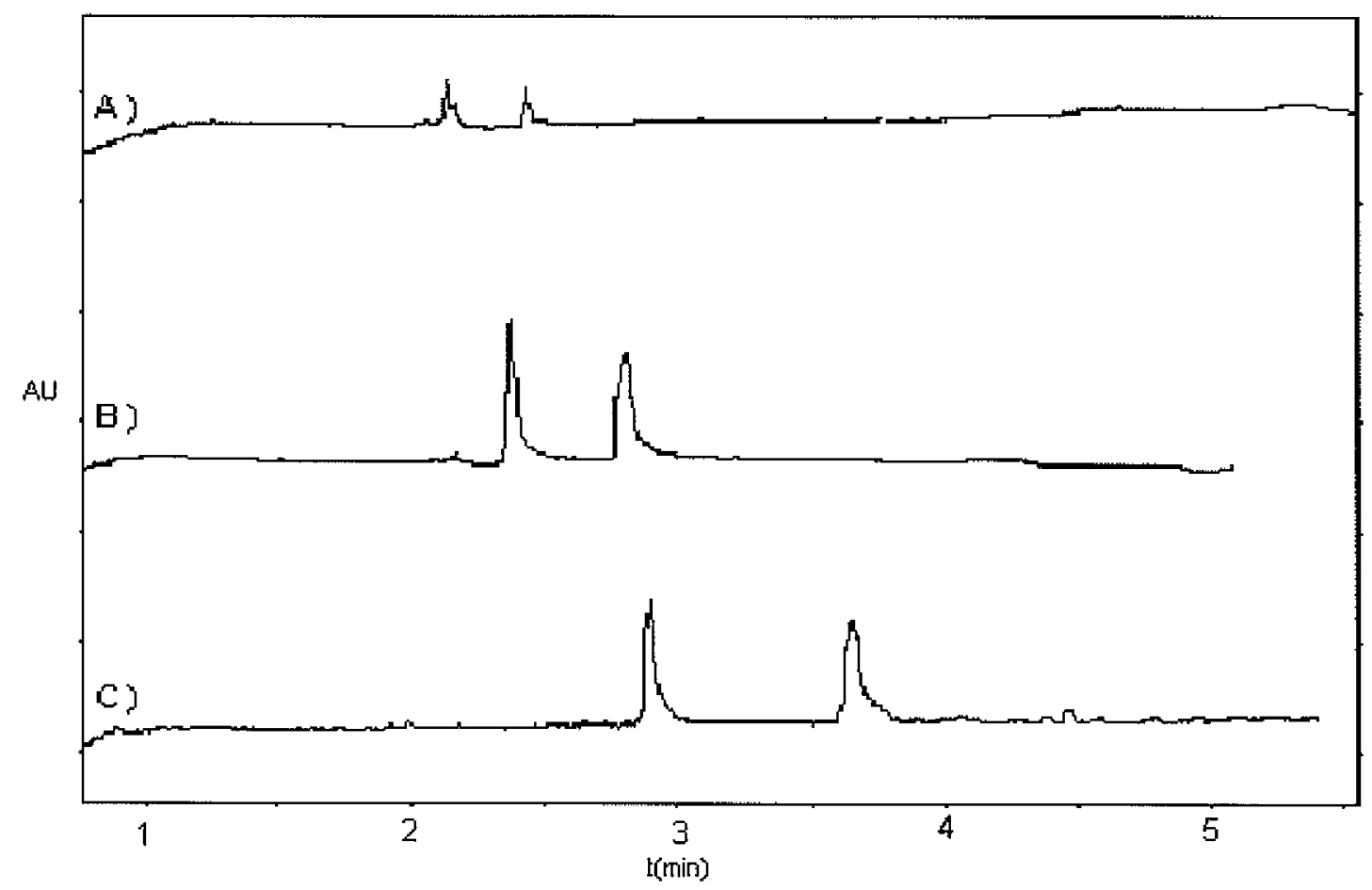

Figure 2. CE enantioseparation of coumarin derivative with A) $60 \mathrm{mg} / \mathrm{mL}$ of S- $\beta-C D, B) 40 \mathrm{mg} / \mathrm{mL}$ of $\mathrm{S}-\beta-\mathrm{CD}$, and C) $20 \mathrm{mg} / \mathrm{ml}$ of $\mathrm{S}-\beta-\mathrm{CD}$. Other conditions are as described in Figure 1.

The ratio of $\mathrm{HP}-\beta-\mathrm{CD}$ to $\mathrm{SBE}-\beta-\mathrm{CD}$ is also important for the separation of dihydrofurocoumarins. As discussed earlier, the $\mathrm{SBE}-\beta-\mathrm{CD}$ provides for the mobility, and the HP- $\beta$-CD provides the enantioselective complexation. As the amount of the anionic SBE- $\beta$-CD increases, the dihydrofurocoumarin analyte will have a greater interaction with the anionic pseudophase, decreasing the interaction with the enantioselective HP- $\beta-C D$. This produced a faster analysis but a diminished separation. If the ratio were changed such that 
there was a greater amount of HP- $\beta-\mathrm{CD}$, the analyte would have had less interaction with the anionic pseudophase, thus leading to an improved separation. From this work, it became apparent that it may be possible for other achiral anionic carriers, such as micelles (specifically SDS micelles), to provide the needed counter-current effect thereby eliciting a similar separation. This will be discussed in a subsequent section of this paper.

\section{Effect of Addition of Methanol to the Run Buffer}

In most cases using the normal electrode polarity mode in $\mathrm{CE}$ with cyclodextrins as chiral selectors, the addition of organic modifiers in the run buffer has an adverse effect on enantioselectivity. This is due to the fact that the organic additive will form a competing inclusion complex with the chiral selector, thus displacing the analyte [21-24]. Figure 3 shows the results of added methanol to an enantioseparation with S- $\beta-C D$ in the RPM.

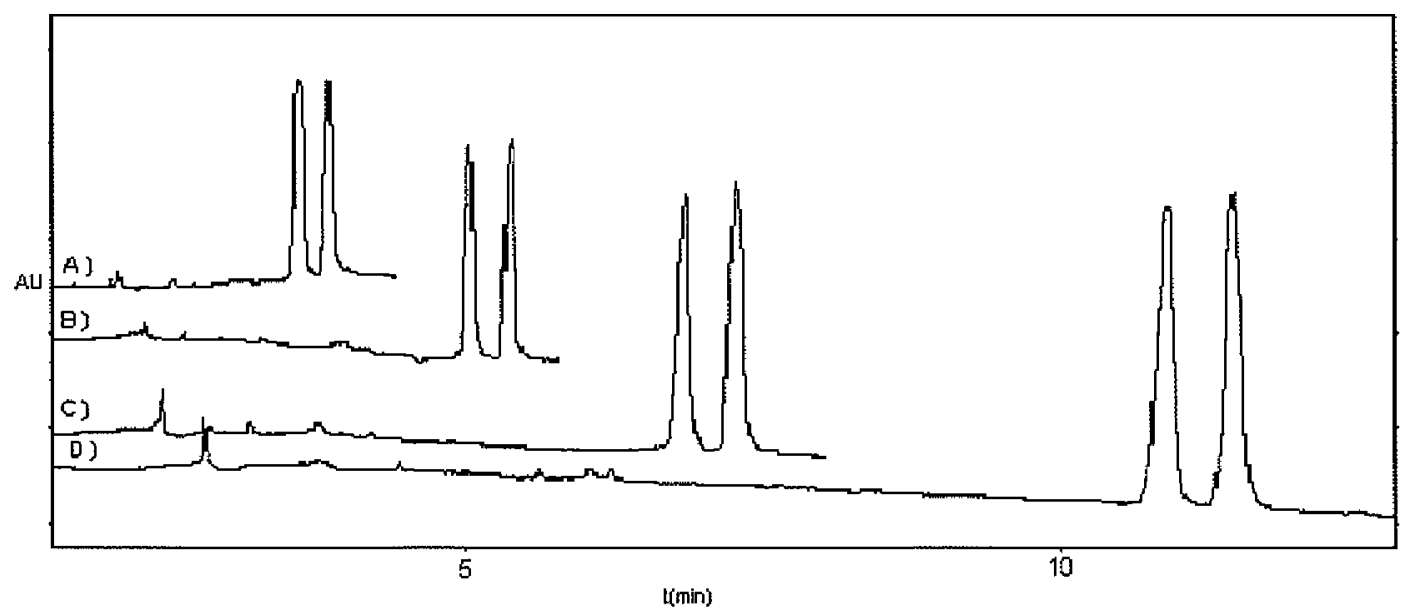

Figure 3. CE enantioseparation of coumarin derivative with A) $0 \%$ methanol , B) $5 \%$ methanol, C) $10 \%$ methanol, and D) 15\% methanol. All other separation conditions are as described in Figure 1. Note that the peak areas on electropherograms C and D are somewhat greater because a saturated solution of the sparingly soluble sample was used, and its solubility varied slightly with the composition of the running buffer. 
The single most obvious effect is the significant increase in the migration times. This effect can be attributed to the previously mentioned competition of the analyte and methanol for inclusion into the cyclodextrin cavity. Also the increased viscosity and lower conductivity of the organic-aqueous run buffer can slow the migration of analytes. Interestingly, the selectivities (all $\alpha$ 's $\sim 1.1$ ), efficiencies (n's $\sim 12,000$ plates), and resolutions (all Rs $\sim 2.3$ ) do not change appreciably under these conditions. Based on these results, it appears that the best separation of these analytes is obtained when no methanol is added to the run buffer.

\section{Effect of Run Buffer pH}

By using the RPM under acidic conditions for the separation of coumarin derivatives, a decreased EOF will occur. This is desirable since it will result in shorter run times (Figure 4). As discussed previously, these separations benefit from the counter-current movement of the analyte and chiral selector, as the EOF goes from the outlet to the inlet, and the electrophoretic mobility of the anionic cyclodextrin derivative is toward the detector. At lower run buffer $\mathrm{pH}$ values, the dominant motive force in the capillary is the electrophoretic mobility of the anionic cyclodextrin derivative. However, when the run buffer $\mathrm{pH}$ reaches approximately 6.5 , the EOF becomes the main motive force in the capillary, and the effective mobility of the negatively charged analyte/cyclodextrin complex will be directed toward the inlet buffer vial, thus the analyte is never seen at the detector. In order to see the analyte signal at $\mathrm{pHs} \geq 6.5$, the normal electrode polarity must be used. Performing the separation in this mode produced little or no enantioseparation. 


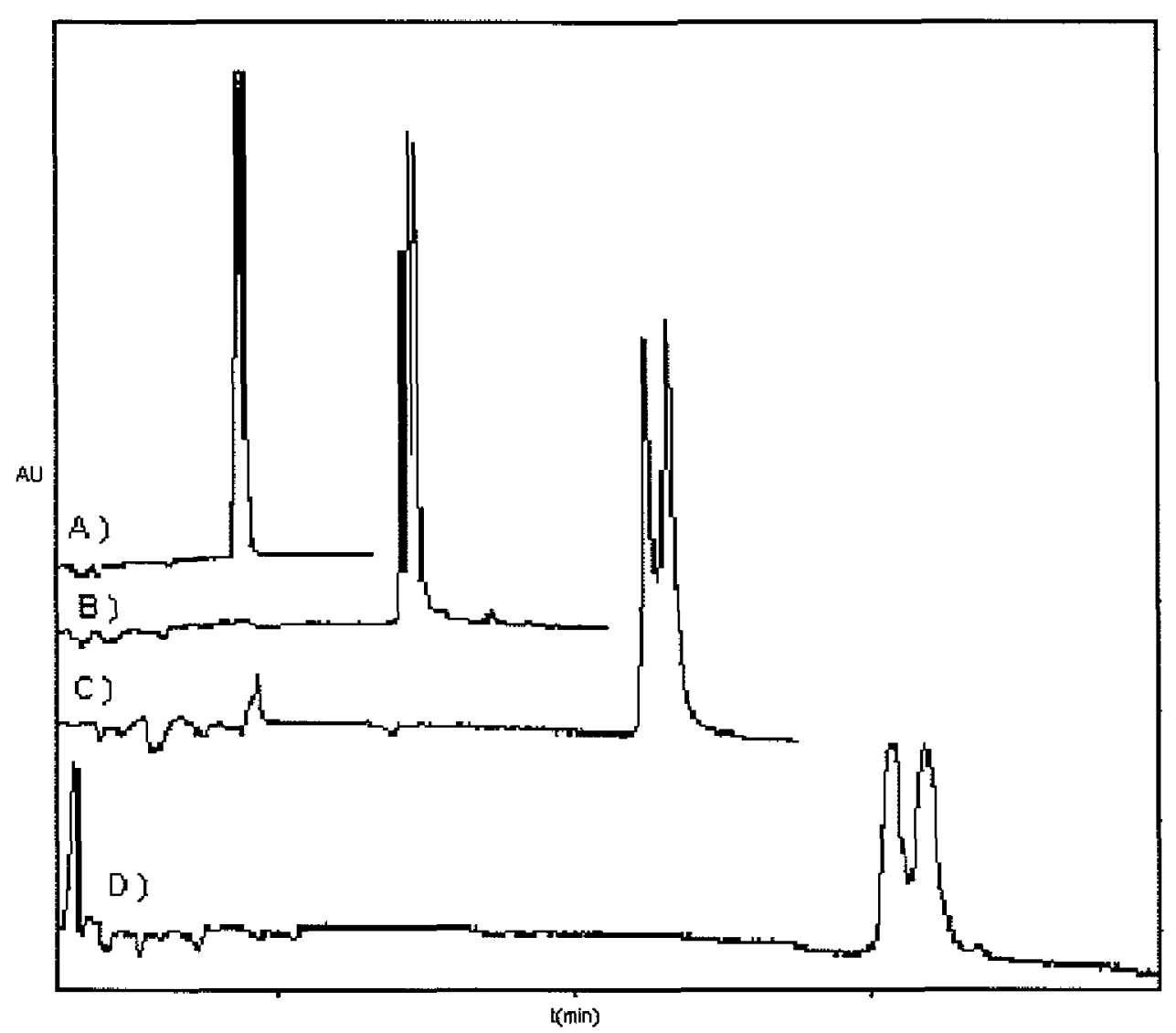

Figure 4. $\mathrm{CE}$ enantioseparation of coumarin derivative in the $\mathrm{RPM}$ at $\mathrm{A}$ ) $\mathrm{pH}=2.5, \mathrm{~B}) \mathrm{pH}=3.1, \mathrm{C}$ ) $\mathrm{pH}=4.2, \mathrm{D}) \mathrm{pH}=5.0$. The background electrolyte was $50 \mathrm{mM}$ phosphate buffer at different $\mathrm{pH}$ values. The chiral selector used in this experiment was CM- $\beta-\mathrm{CD}$. The applied voltage was $-15 \mathrm{kV}$. Detection was performed at $214 \mathrm{~nm}$. Sample: racemate of chiral coumarin derivative \#7.

\subsubsection{Enantioseparation of dihydrofurocoumarin derivatives using micellar capillary electrophoresis (MCE)}

The addition of micelles to the CE system as a pseudophase was borrowed from HPLC in 1984 by Terabe et al. [26]. The addition of surfactant to the run buffer to produce micelles creates a negatively charged pseudophase. As discussed previously, for the enantiomeric separation of these neutral compounds to occur in $\mathrm{CE}$, there must be a charged species in the run buffer for the analyte to interact with. This condition was previously illustrated in 
Section 3.1.1 when separating dihydrofurocoumarins using a combination of HP- $\beta$-CD with SBE- $\beta$-CD.

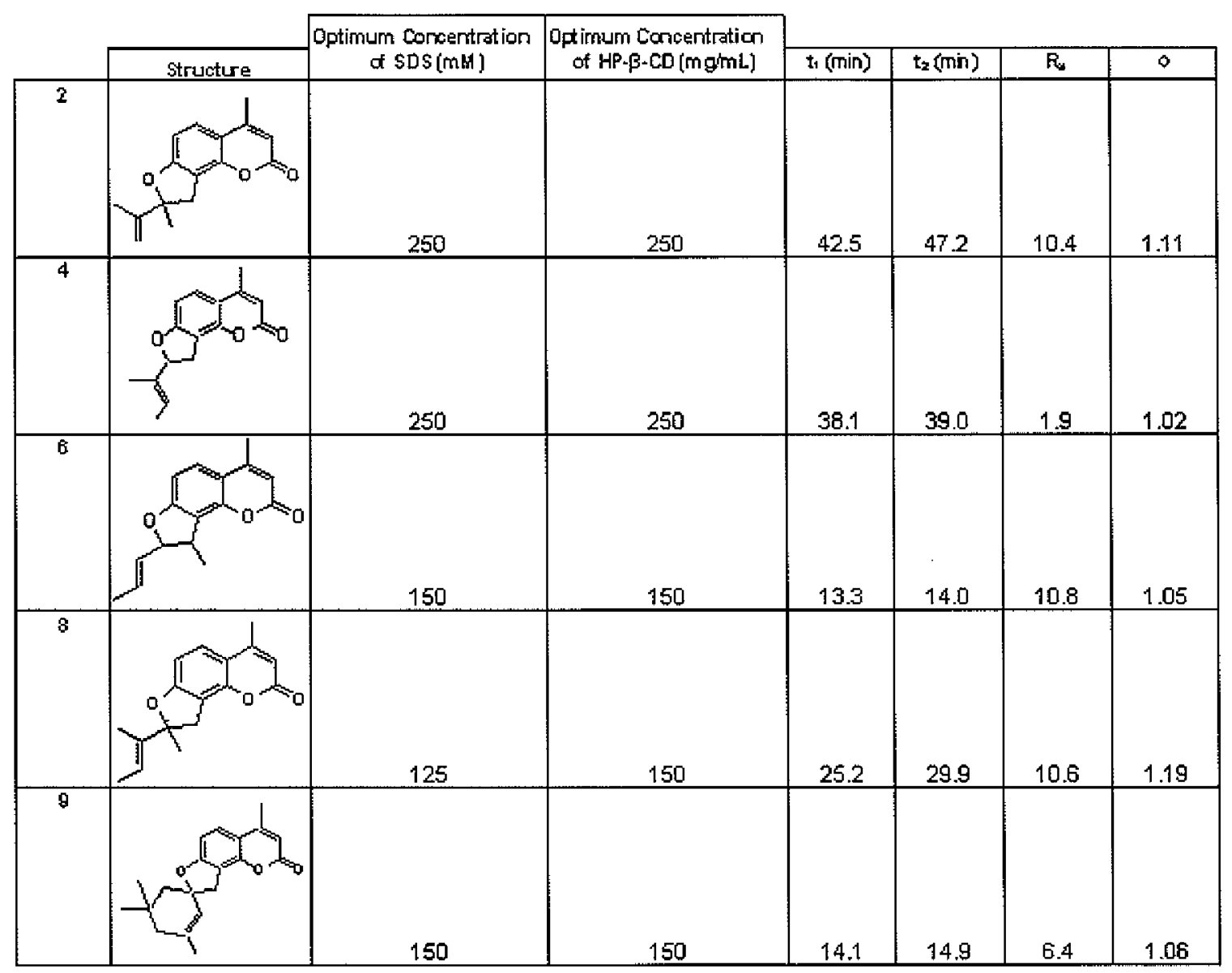

Table 2 Optimum conditions for the enantioseparation of coumarins by MCE

SDS micelles can also provide an anionic pseudophase in the run buffer and thus permit the use of an uncharged cyclodextrin as the chiral selector. Hydroxypropyl- $\beta$-CD was shown previously to yield efficient enantiomeric separations of dihydrofurocoumarins by HPLC [27]. Therefore, the same chiral selector was used in these experiments. Using MCE to separate the coumarin derivatives in the normal electrode polarity mode produced poor enantioseparations. For this reason, the RPM was used for these experiments. To decrease 
the EOF, the run buffer was prepared with a $\mathrm{pH}$ of 2.5 so that the dominant motive force in the capillary was the electrophoretic mobility of the micelle. In addition to providing a negatively charged pseudophase, the presence of micelles also increases the solubility of the hydrophobic coumarin derivatives in the run buffer, thereby decreasing the need for organic co-solvents to dissolve the analyte. Similarly to the effects of the charged and uncharged cyclodextrins, described in 3.1.2, there was a certain concentration ratio of SDS to hydroxypropyl $\beta$-CD that gave optimum separations (Table 2). It is obvious from Table 2 that the concentration of SDS to HP- $\beta$-CD differs for different derivatives. If the amount of SDS were increased, the dihydrofurocoumarin compound would partition more extensively to the micelle and less to the HP- $\beta-\mathrm{CD}$.

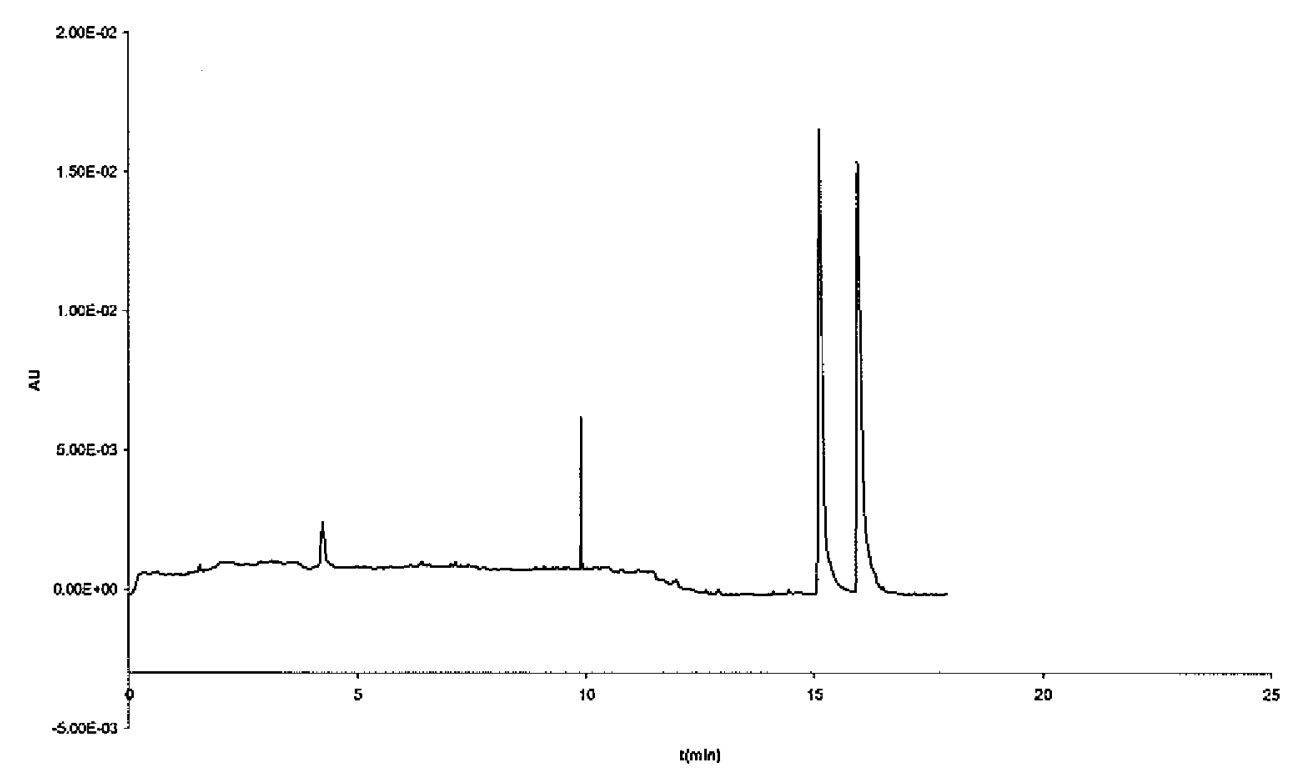

Figure 5. MCE enantioseparation of coumarin analogue. The background electrolyte was $10 \mathrm{mM}$ phosphate buffer at $\mathrm{pH} 2.5$ and $150 \mathrm{mM}$ SDS. The chiral selector use in this experiment was 150 $\mathrm{mg} / \mathrm{mL} \mathrm{HP}-\beta$-CD. The applied voltage was $15 \mathrm{kV}$. Detection was performed at $214 \mathrm{~nm}$. Sample: racemate of chiral coumarin derivative \#8. 
Because the HP- $\beta-C D$ provides the enantioselectivity, these conditions yield diminished or no separations. If the relative amount of $\mathrm{HP}-\beta-\mathrm{CD}$ were increased, the analyte interaction with the chiral selector would increase, thus decreasing the interactions with the micellar pseudophase. Since the micelle provides the counter-current mobility in this system, a greatly diminished interaction with the micelle also yields diminished or no enantioseparation. The main drawback to separations with this method was the extended run times (Figure 5). However, this approach produced high enantioselectivities and good efficiencies for the chiral dihydrofurocoumarins (Table 2).

\subsection{Conclusions}

Several coumarin derivatives were analyzed using various systems of CE and MCE. When comparing the techniques, the optimum enantioseparation was obtained in the reversed polarity mode with sulfated- $\beta$-cyclodextrin as the chiral selector. $S-\beta-C D$ gave better separations than the carboxymethyl- $\beta$-cyclodextrin due to its greater enantioselectivity for these analytes. The $S-\beta-C D$ was also more successful than either the sulfobutylether- $\beta$ cyclodextrin in combination with hydroxypropyl- $\beta$-cyclodextrin, and it produced shorter run times when compared to the micelle-based enantioseparation method. This work also showed that optimization of the $\mathrm{pH}$, and chiral selector concentration had substantial effects on the enantioseparation of dihydrofurocoumarins. 


\section{Acknowledgements}

Support of this research funded by the National Institute of Health, NIH RO1 GM53825-06 is gratefully acknowledged. J. S. and E. T. gratefully acknowledge support of their stay at the Iowa State University, Ames, USA, by the Ministry of Education of the Czech Republic and by research project No. J13/98: 113100001. R. V. R. and R. C. Larock also acknowledge the donors of the Petroleum Research Fund, administered by the American Chemical Society for partial support of this research as well as Johnson Matthey Inc., and Kawaken Chemicals Co. Ltd. for donations of palladium acetate.

\section{References}

[1] Goding, L. A., West, B. D., J. Med. Chem. 1969, 12, 517-18.

[2] Bariana, D. S., J. Med. Chem. 1970, 13, 544-546.

[3] Tada, Y., Shikishima, Y., Takaishi, Y., Shibata, H., Higuti, T., Honda, G., Ito, M., Takeda, Y., Kodzhimatov, O. K., Ashurmetov, O., Ohmoto, Y., Phytochemistry. $2002,59,649-654$.

[4] Nofal, Z. M., El-Zahar, M. I., El-Karim, S. S., Molecules 2000, 5, 99-113.

[5] Kashman, Y., Gustafson, K. R., Fuller, R. W., Cardellina, J. H., I, McMahon, J. B., Currens, M. J., Buckheit, R. W., Jr., Hughes, S. H., Cragg, G. M., Boyd, M. R., J. Med. Chem. 1992, 35, 2735-2743.

[6] Shikishima, Y., Takaishi, Y., Honda, G., Ito, M., Takfda, Y., Kodzhimatov, O. K., Ashurmetov, O., Lee, K. H., Chem. Pharm. Bull. 2001, 49, 877-880. 
[7] Yang, E. B., Zhao, Y. N., Zhang, K., Mack, P., Biochem. Biophys. Res. Commun. $1999,260,682-685$.

[8] Bisagni, E., J. Photochem. Photobil. B: Biol. 1992, 14, 23-46.

[9] Rozhkov, Roman V., Larock, Richard C., Org. Lett. 2003, 5, 797-800.

[10] De Vries, J. X., Voelker, U., J. Chromatogr. 1989, 493, 149-156.

[11] De Vries, J. X., Schmitz-Kummer, E., J. Chromatogr. 1993, 644, 315-320.

[12] Sun, Q., Olesik, S. V., Anal. Chem. 1999, 71, 2139-2145.

[13] Chirobiotic Handbook, Advanced Separations Technologies. Inc., $4^{\text {th }}$ Edition, Whippany, NJ.

[14] Cyclobond Handbook, Advanced Separations Technologies. Inc., $6^{\text {th }}$ Edition, Whippany, NJ.

[15] D'Hulst, A., Verbeke, N., J. Chromatogr. 1992, 608, 275-287.

[16] D'Hulst, A., Verbeke, N., Chirality. 1994, 6, 225-229.

[17] Stalcup, A. M., Gahm, K. H., Anal Chem. 1996, 68, 1360-1368.

[18] Gareil, P., Gramond, J. P., Guyon, F., J. Chromatogr. 1993, 615, 317-325.

[19] Bouzige, M., Okafo, G., Dhanak, D., Camilleri, P., Chem. Commun. 1996, 671-672

[20] Armstrong, D.W., De Mond, W., J. Chromatogr. Sci. 1984, 22, 411-416

[21] Chang, S. C., Reid, G. L., III, Chen, S., Chang, C. D., Armstrong, D. W. Trends Anal. Chem. 1993, 12, 144-53.

[22] Wren S. A., Rowe R. C. J. Chromatogr. 1993, 635, 113-8.

[23] Fanali, S., J. Chromatogr. A. 2000, 875, 89-122.

[24] Rodriguez, M. A., Liu, Y., McCulla, R., Jenks, W. S., Armstrong, D. W., Electrophoresis 2002, 23, 1561-1570. 
[25] Diagone, C. A., Ogawa, C. A., Lancas, F. M., J Liq Chromatogr \& Relat Technol. $2003,26,505-516$.

[26] Terabe, S., Otsuka, K., Ichikawa, K., Tsuchiya, A., Ando, T., Anal. Chem. 1984, 56, 111

[27] Schumacher, D., Mitchell, C., Rozhkov, R., Larock, R. C., Armstrong, D. W. $\quad J$. Chromatogr. A 2003, In Press 


\title{
CHAPTER 5
}

\section{BINDING CONSTANT STUDIES OF DRUGS AND PROTEINS USING FRONTAL ANALYSIS CAPILLARY ELECTROPHORESIS- LASER INDUCED FLUORESCENCE}

\begin{abstract}
Capillary electrophoresis has been recognized as an attractive analytical tool for examining the nature and strength of biological interactions between drugs and proteins. Various CE methods exist for measuring binding constants. Capillary electrophoresis-frontal analysis (FA) has been particularly used for measuring the interactions between drugs with plasma proteins, particularly when limited analytes of the pure substrates are available. Two drug/protein systems have been studied using the frontal analysis method. More sensitive laser induced fluorescence detection (LIF) was used in this assay, which overcame the problem of low sensitivity that is common when using UV detection for drug-protein studies. In addition, the use of a UV argon laser (Excitation at $257 \mathrm{~nm}$ ) coupled with CCD camera as a frontal analysis detection method enabled the simultaneous observation of the drug fluorescence as well as the protein fluorescence. Also, this more sensitive detection method has demonstrated the potential usefulness of CE-FA for the study of a wide variety of drugplasma protein binding processes.
\end{abstract}




\subsection{Introduction}

Drug-protein binding is an important process in determining the activity and fate of a drug once it enters the body. In biological systems, unbound drugs in plasma can easily reach the target organ, whereas bound drugs are hard to pass through the blood-capillary wall. Therefore, understanding the binding behavior between plasma proteins and drugs is essential for drug development because the concentration of unbound drugs shows a better correlation to the pharmacological activity than the total drug concentration [1]. In addition, many pharmacokinetic properties such as hepatic metabolism rate, renal excretion rate, biomembrane partition rate and steady-state distribution volume are a function of the unbound drug fraction (unbound/bound concentration ratio) [2,3]. Therefore, a better understanding of drug-protein binding is also essential to pharmacokinetic studies and optimum therapeutic dosing regimens.

Determining an individual analyte in complex biological samples often requires some type of separation as a prerequisite for their measurement. A number of separation techniques exist for the determination of binding constants, and most separation methods are done under equilibrium conditions [4-9]. Capillary electrophoresis (CE) has shown to be an attractive analytical tool for evaluating binding behavior. Its beneficial characteristics include short analysis times, high efficiency, high selectivity, high resolving power, low sample and reagent consumption, and ease of automation [4-10]. Various CE methods have been applied to determine the unbound (free) drug or the bound drug concentration in solution. It includes affinity capillary electrophoresis (ACE), the frontal analysis (FA) method, the HummelDreyer Method (HD), the vacancy peak (VP) and the vacancy affinity capillary 
electrophoresis (VACE). With the exception of VACE, most of these methods were originally developed for high-performance liquid chromatography (HPLC) and then transferred to CE $[11,12]$.

Measuring binding constants using the ACE method can be done by adding a protein to the CE running buffer and measuring the change in electrophoretic mobility of an injected drug. This method requires that the drug's electrophoretic mobility undergoes a significant change upon complexation [6]. In the Hummel-Dreyer method, the capillary is filled with running buffer containing a drug at varying concentrations, creating a high detector background response [4-6]. When a small amount of sample consisting of both protein and drugcontaining running buffer is injected, the complexed drug-protein migrates out of the injection plug, leaving a zone of reduced drug concentration behind. This zone is detected as a negative peak, and the area is directly related to the amount of drug bound to the protein. A positive peak corresponds to the drug-protein complex and the free protein [4-6]. Both internal calibration and external calibration methods can be used in this assay.

In a vacancy peak (VP) experiment, the capillary is filled with running buffer consisting of both the protein and the drug. When a small amount of plain buffer is injected, two negative peaks were observed. One peak arises due to a vacancy in free drug, and another peak arises due to a vacancy in the drug-protein complex and the free protein. The free drug concentration can be determined by the peak area (or height). The binding constant is calculated for the free drug concentration as a function of protein concentrations. The vacancy affinity capillary electrophoresis is performed in an identical experimental set-up as 
the VP method. However, the binding constant is calculated based on the change in electrophoretic mobility of the drug peak at varying concentrations of protein in the buffer, because the migration time of negative peaks is correlated to the fraction of free and complexed drug.

(a)

(a)

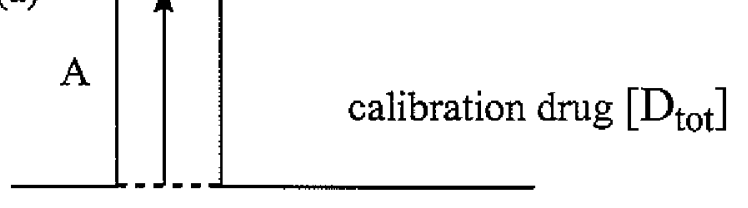

(b)

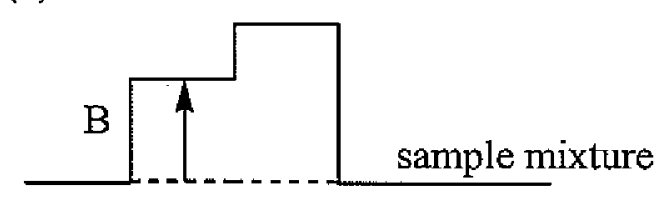

Figure 1. Mlustration of the calibration procedures for the capillary electrophoresis-frontal analysis method.

Abbreviation: A, Peak height when only injecting calibration drug; B, Peak height when injecting drug-protein mixture; $\left[D_{t o t}\right]$, concentration of total drug; $\left[D_{i}\right]$, concentration of unbound drug; $\left[D_{b}\right]$, concentration of bound drug; [P], concentration of protein; $r$, fraction of bound drug per protein.

In the FA, the capillary is filled with running buffer, and subsequently a large sample plug is injected [4-6]. This sample plug consists of both drug and protein in equilibrium. In this assay, the electrophoretic mobility of the free drug must be different from the mobility of the protein and the protein-drug complex. The protein and the protein-drug complex usually have same electrophoretic mobility because proteins are very large molecules, therefore, the mobility (depending on the size or charge) of proteins won't change when binding with a 
small molecule drug. After injection of a large mixed sample plug, the free drug will migrate away from the protein, and equilibrium is maintained where the zones temporarily overlap [4-6]. The equilibrium free drug concentration is calculated from the height of the resulting plateau. The plateau height of free drug at [protein] $=0$ is used as the standard. With the addition of protein to the injected sample plug, the height of the free drug plateau decreases due to the binding of the drug to the protein [4-7]. From the known total and the measured free drug concentration, the association parameters can be calculated. The calibration procedure is schematically presented in Figure 1. Varying drug concentrations with a fixed protein concentration in the large sample plug allows the determination of binding constant according to the following equation: $r=\mathrm{n} \mathrm{K}_{\mathrm{b}}\left[\mathrm{D}_{\mathrm{f}}\right] /\left\{1+\mathrm{K}_{\mathrm{b}}\left[\mathrm{D}_{\mathrm{f}}\right]\right\}$, where $\mathrm{r}$ is the fraction of bound drug per protein; $n$ is the number of binding sites; $[D]_{f}$ is the free drug concentration in the running buffer, and $\mathrm{K}_{\mathrm{b}}$ is the binding constant between drug and protein. For 1: 1 binding, equation can be simplified to $\mathrm{r} /(1-\mathrm{r})=\mathrm{K}_{\mathrm{b}}\left[\mathrm{D}_{\mathrm{f}}\right]$, and the binding constant can be easily determined from the slope.

The CE methods for the determination of binding constants and their experimental setups are summarized in Table 1. In the ACE and VACE methods, the binding parameters can be calculated from the change in the electrophoretic mobility of the drug on complexation with a protein. In the frontal analysis and vacancy peak methods, the free drug concentration is measured, while in the Hummel-Dreyer method the amount of bound drug is measured. Overall, most of the CE methods require the addition of either drug or protein to the running buffer, as seen in Table 1. Therefore, relatively large amounts of either drug and/or protein are needed for these measurements since buffer vials are usually large. Although ACE was 
found most useful for the measurement of binding constants, the frontal analysis method is the only method that requires a relatively small amount of sample (using plain buffer as the running buffer). Therefore, due to the sample limitation, frontal analysis method was chosen for the measurement of binding constants for the following two protein-drug systems.

\begin{tabular}{llll}
\hline Method & Sample injected & Running buffer & Estimation of $\mathrm{K}$ \\
\hline ACE & D & Buffer $+\mathrm{P}$ & Changes in mobility of $\mathrm{D}$ \\
VACE & Buffer & Buffer $+\mathrm{D}+\mathrm{P}$ & $\begin{array}{l}\text { Changes in mobility of } \mathrm{D} \text { or } \mathrm{P} \\
\text { (vacancy peak) }\end{array}$ \\
& & Buffer + D+P & $\begin{array}{l}\text { Peak area of vacancy peak } \\
\text { corresponding to }\left[\mathrm{D}_{\mathrm{f}}\right]\end{array}$ \\
VP & Buffer & & $\begin{array}{l}\text { Plateau height corresponding to } \\
{\left[\mathrm{D}_{\mathrm{f}}\right]}\end{array}$ \\
FA & Buffer $+\mathrm{D}+\mathrm{P}$ & Buffer & $\begin{array}{l}\text { Peak area of vacancy peak } \\
\text { corresponding to }\left[\mathrm{D}_{\mathrm{b}}\right]\end{array}$ \\
& & & Buffer $+\mathrm{P}$ (or $\mathrm{D})$ \\
HD & Buffer+D+P & &
\end{tabular}

Table 1. CE methods and their experimental setups for the estimation of binding constants. Abbreviation: ACE, affinity capillary electrophoresis; VACE, vacancy affinity capillary electrophoresis; HD, Hummel-Dreyer method; VP, vacancy peak method; FA, frontal analysis; D, ligand such as drug; $P$, receptor such as protein; $\left[D_{b}\right]$, concentration of bound drug; $\left[D_{f}\right]$, concentration of free drug. (Revised from Table 1 in Ref. 7. Tanaka, Y., Terabe, S. J. Chromatogr. B, $2002,768,81-92)$

\subsection{Binding constant study between coumarin 153 and apomyoglobin}

Understanding a protein's dielectric response requires both a theoretical model and a welldefined experimental system. The complex of coumarin 153 (C153) with apomyoglobin (ApoMb) provides a fruitful system for studying the protein dielectric response. C 153 has 
been exhaustively studied and has proven to be an excellent probe of the solvation dynamics of polar solvents. Myoglobin is one of the most thoroughly studied proteins. In addition, the availability of mutant proteins with amino acid replacements near the heme-binding site of myoglobin will eventually permit a quantitative evaluation of local contributions of specific residues to the solvation dynamics of proteins. Because protein is clearly a heterogeneous environment with spatially dependent polarizability, a precise knowledge of where and how the fluorescence probe binds is crucial to any thorough analysis of the protein's response from that of the solvent. In this assay, equilibrium binding studies by capillary electrophoresis frontal analysis was used as one of the tools to demonstrate the existence of a robust C 153-ApoMb system.

\subsubsection{Experimental}

\subsubsection{Apparatus}

The frontal analysis CE experiments were performed on a Beckman Coulter P/ACE MDQ capillary electrophoresis system equipped with $488 \mathrm{~nm}$ laser-induced fluorescence (LIF) detector. Untreated fused-silica capillary with $50 \mu \mathrm{m} \mathrm{ID}$ and $360 \mu \mathrm{m}$ OD was purchased from Polymicro Technologies, Inc. (Phoenix, AZ). The capillary was $30 \mathrm{~cm}$ in length $(20 \mathrm{~cm}$ to detection window). When a capillary was first used, it was rinsed for 1 min with water, 5 min with $1 \mathrm{M} \mathrm{NaOH}$, and 1 min with water at the pressure of $20 \mathrm{psi}$. Prior to each injection, capillary was washed for $0.5 \mathrm{~min}$ with water, $0.5 \mathrm{~min}$ with $1 \mathrm{M} \mathrm{NaOH}$, and $0.5 \mathrm{~min}$ with water, followed by 2 min with running buffer. The premixed C153-ApoMb samples were injected at $0.5 \mathrm{psi}$ for 40 seconds to the capillary. Experiments were performed at $10 \mathrm{kV}$ and 
a temperature of $25^{\circ} \mathrm{C}$. The emission of the sample was collected at $520 \mathrm{~nm}$. Data were collected by P/ACE system MDQ software.

\subsubsection{Reagents and solutions}

Coumarin 153 was purchased from Aldrich Chem. Co. (Milwaukee, WI), and used without further purification. Apomyoglobin was prepared using the procedure described elsewhere [13]. Sodium phosphate and phosphoric acid were purchased from Fisher Scientific (Fair Lawn, NJ). 0.2 M Na-phosphate buffer at pH 9.0 was used. The phosphate buffer was filtered through $0.22 \mu \mathrm{m}$ non-pyrogenic filter (Costar, Corp. Corming, NY).

\subsubsection{Results and Discussion}

\subsubsection{Capillary electrophoresis-frontal analysis of coumarin 153 and apomyoglobin}

In the frontal analysis technique, $\mathrm{C} 153$ and $\mathrm{ApoMb}$ were premixed and injected as a large sample plug after waiting sufficient time $(45 \mathrm{~min})$ to ensure the formation of an equilibrium complex. At $\mathrm{pH} 9$, the apomyoglobin $(\mathrm{pI}=8.72)$ is negatively charged. The electrophoretic mobility of the free $\mathrm{C} 153$ is different from the mobility of the ApoMb and ApoMb-C153 complex. Figure 2 shows the electropherograms for C 153-ApoMb system: the height of the free coumarin plateau decreases with the addition of apomyoglobin because of the binding of the coumarin to the protein. The plateau height of free coumarin at $[\mathrm{ApoMb}]=0 \mu \mathrm{M}$ was used as the coumarin standard. In this assay, a series of sample mixtures with a fixed ApoMb concentration and varying $\mathrm{C} 153$ concentrations $(0.2-4.0 \mu \mathrm{M})$ were injected. Since 
the ApoMb concentration used is about at least one order of magnitude higher than that of $\mathrm{C}$ 153, we assume that the binding between ApoMb and C 153 is 1:1.

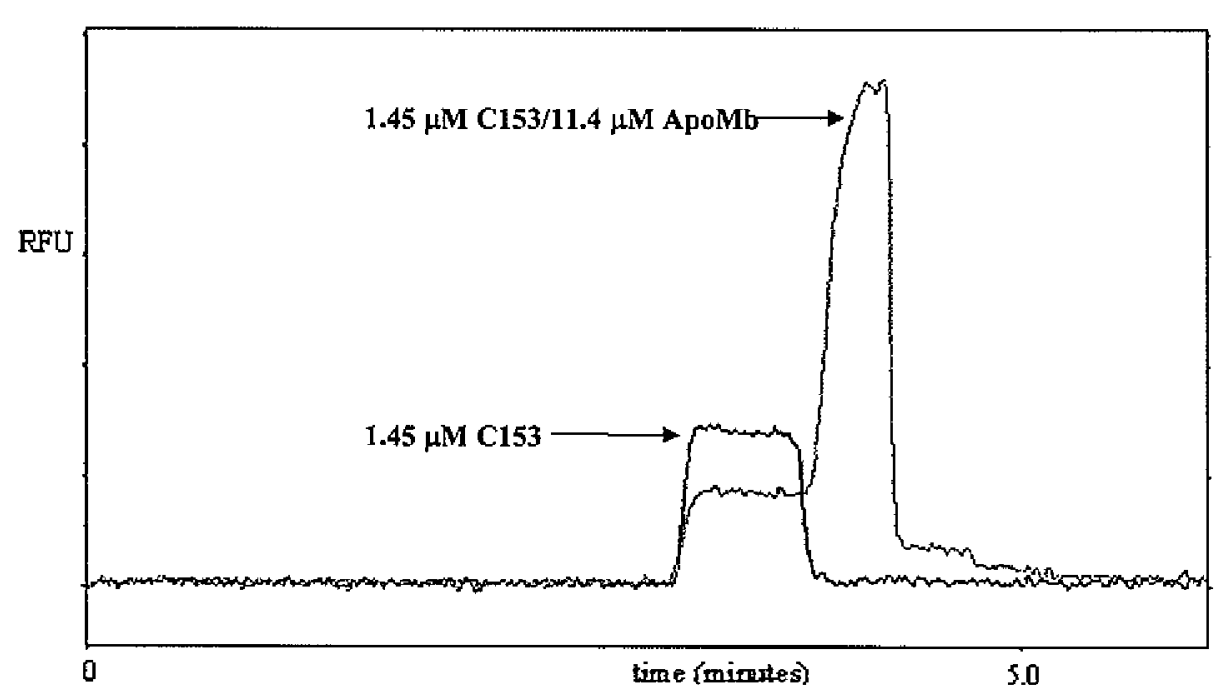

Figure 2. Electropherograms obtained using the frontal analysis $\mathrm{CE}$ method with coumarinapomyoglobin. Experimental conditions: pressure injection at $0.5 \mathrm{psi}$ for $40 \mathrm{~s}$; separation voltage, 10 $\mathrm{KV}$; LIF detector with excitation at $488 \mathrm{~nm}$ and emission at $520 \mathrm{~nm} ; 0.2 \mathrm{M} \mathrm{Na}$ - phosphate buffer at pH 9.0 .

Three individual experiments were carried out, and duplicate data were collected for each set of experiments. The calculated binding constant between $\mathrm{C} 153$ and $\mathrm{ApoMb}$ is $7.7 \times 10^{4} \mathrm{M}^{-1}$ (STD, 0.011 ; RSD, $14.30 \%$ ). This final result is based on the average of three individual experiments, and each experiment was done at different $\mathrm{ApoMb}$ concentrations (results shown in Figure 3 and Table 2). 


\subsubsection{Effect of injection time}

In $\mathrm{CE}$, injection time is directly related to the injection volume. When the injection is small, the drug will be eluted as a normal CE peak followed by the protein peak. If the injection is large enough, the release of bound drug from the protein forms a plateau region. Therefore, the unbound drug concentration can be determined from the height of the plateau region. According to this principle, different injection times (in the range of $5 \mathrm{~s}$ to $60 \mathrm{~s}$ ) were investigated with a sample solution that remained constant $(1.6 \mu \mathrm{g} / \mathrm{ml} \mathrm{C} 153$ in $8.1 \mu \mathrm{M}$ ApoMb).

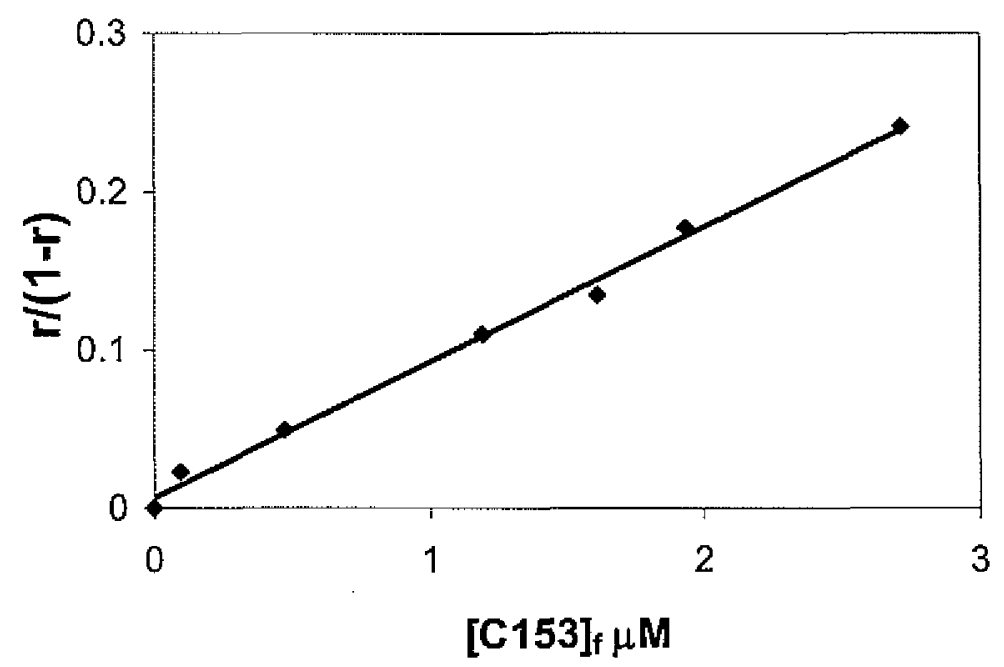

Figure 3. Plot of $\{r /(1-r)\}$ against free coumarin, where $\mathrm{r}$ is the fraction of $\mathrm{C} 153$ bound per $\mathrm{ApoMb}$. The slope of a linear fit to the experimental data points gives the binding constant $\left(\mathrm{K}_{\mathrm{b}}\right)$ of $\mathrm{Cl} 153$ in the complex. (The value of $\mathrm{K}_{\mathrm{b}}$ obtained from this figure is $8.6 \times 10^{4} \mathrm{M}^{-1}$.)

Figure 4 shows the effect of injection time on the migration profile. When the injection time is short, $\mathrm{C} 153$ is well separated from ApoMb. Only the C 153 peak was observed in this case, 
Table 2. Repeatability of FA-CE method for the determination of binding constants between C 153 and ApoMb. Abbreviation: $\mathrm{K}_{\mathrm{b}}$, binding constant; $\mathrm{K}_{\mathrm{d}}$, dissociation constant.

\begin{tabular}{llll}
\hline Results & ApoMb concentration $(\mu \mathrm{M})$ & $\mathrm{K}_{\mathrm{b}}\left(\mathrm{M}^{-1}\right)$ & $\mathrm{K}_{\mathrm{d}}(\mu \mathrm{M})$ \\
\hline I & 8.5 & $8.6 \times 10^{4}$ & 11.6 \\
II & 10.5 & $6.5 \times 10^{4}$ & 15.4 \\
III & 11.4 & $8.0 \times 10^{4}$ & 12.5 \\
Avg. & $\cdots-$ & $7.7 \times 10^{4}$ & 13.2 \\
\hline
\end{tabular}
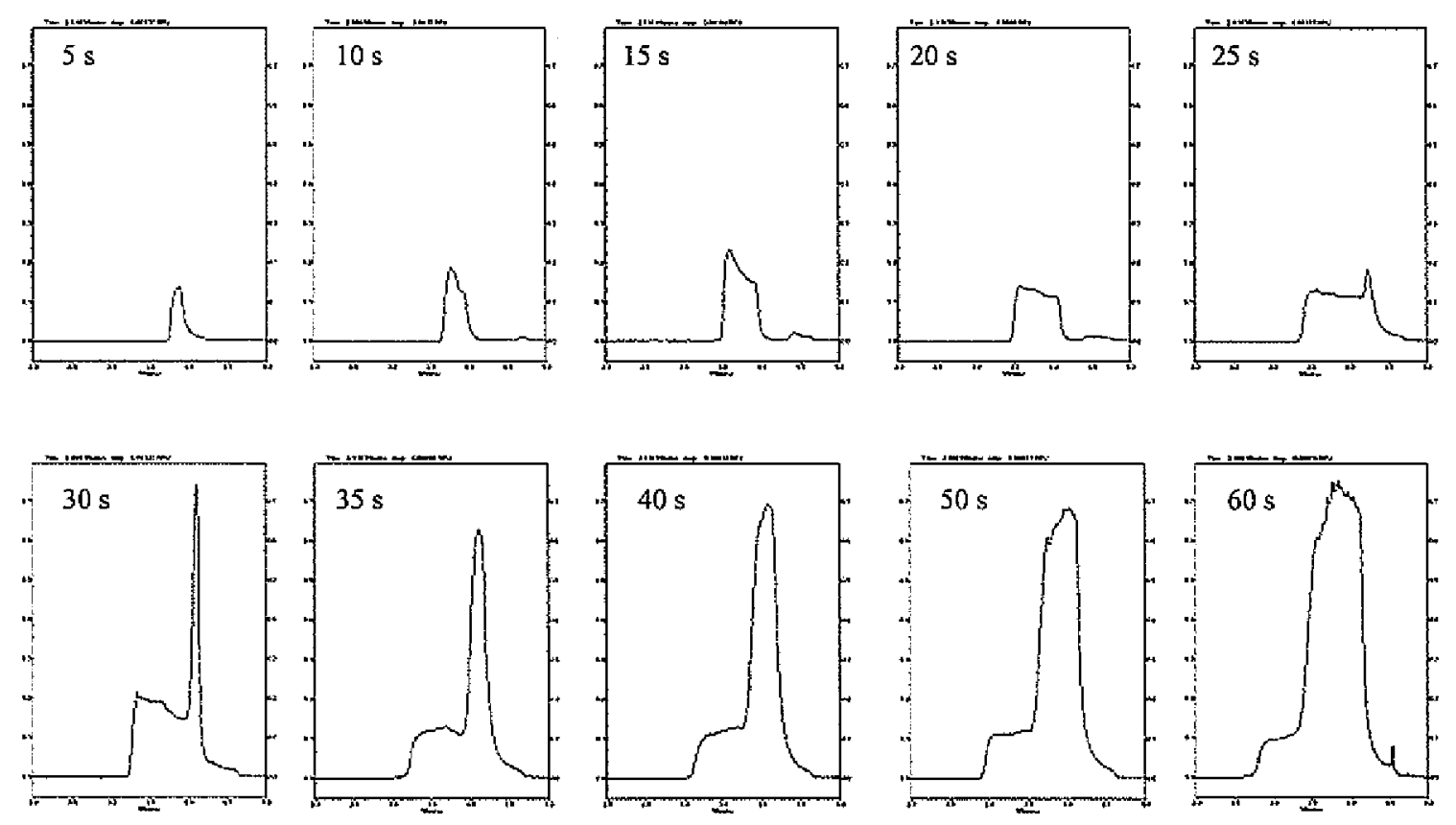

Figure 4. The effect of injection time on migration profile of C153-ApoMb mixed solution (1.6 $\mu \mathrm{g} / \mathrm{ml} \mathrm{C} 153$ in $8.1 \mu \mathrm{M}$ ApoMb). Capillary: $50 \mu \mathrm{m} \times 30(20) \mathrm{cm}$; running buffer: $0.2 \mathrm{M}$ sodium phosphate buffer at pH $9.0 ; 10 \mathrm{KV}$; injection time: $5 \mathrm{~s}$ to $60 \mathrm{~s}$.

because $\mathrm{ApoMb}$ does not have strong fluorophores, therefore, it cannot be detected using a fluorescence detector. However, with an increase in the injection time, the C153-ApoMb complex peak started to show up, and then produced a very strong signal when the injection 
time was increased to $30 \mathrm{~s}$. Further study of the fluorescence spectra explains this phenomenon. Figure 5 gives fluorescence spectra of $\mathrm{C} 153$ both in neat water and in the presence of $\mathrm{ApoMb}$. The fluorescence intensity of C 153 greatly increases (about three times) when the $\mathrm{C} 153$ forms equilibrium complex with $\mathrm{ApoMb}$. When the injection time is short, no complex is formed because coumarin 153 and ApoMb are well separated. Therefore, no signal was observed from ApoMb. With an increase in the injection time, the coumarin 153 zone and the $\mathrm{ApoMb}$ zone overlap, therefore, the ApoMb signal due to complexation appeared. In addition, when the injection time is above $35 \mathrm{~s}$, a zonal profile with an obvious plateau appears. Further increasing the injection time hardly changes the peak height. Therefore, an injection time of $40 \mathrm{~s}$ was chosen for all the experiments.

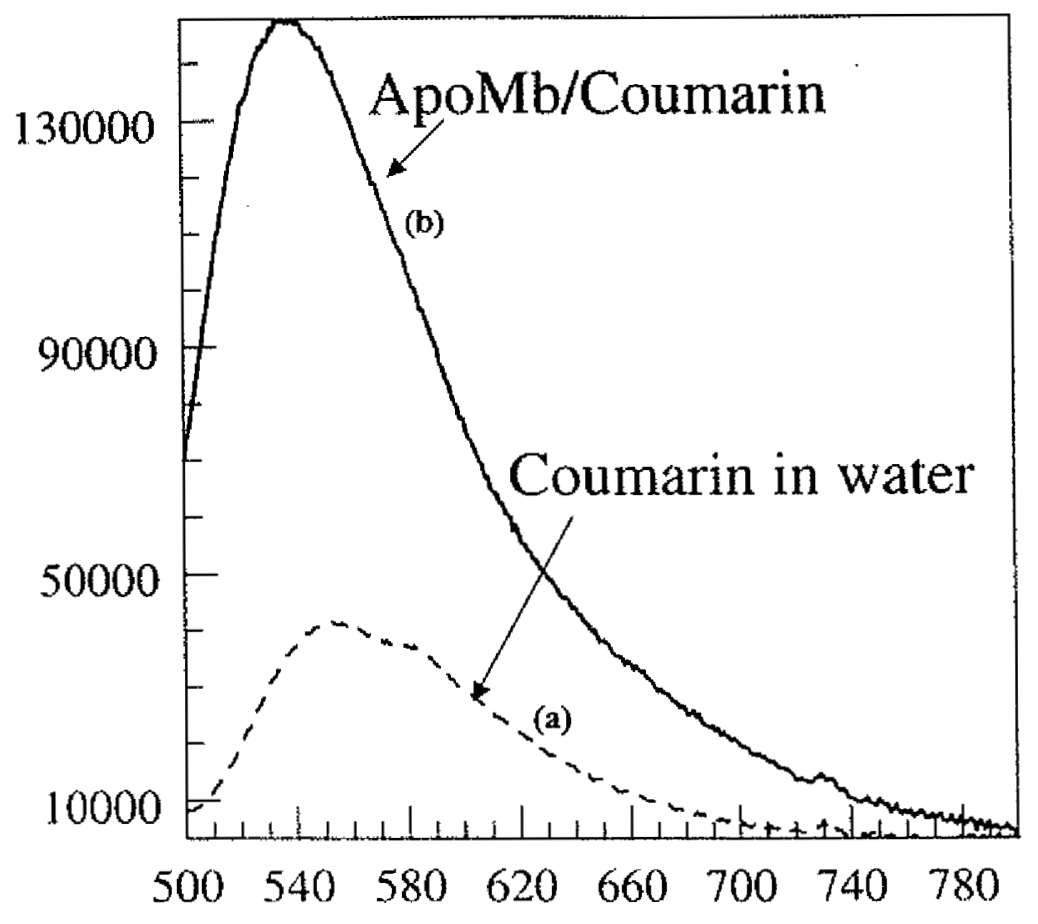

Figure 5. Fluorescence spectra of coumarin 153 in neat water (a) and in the presence of ApoMb (b). Excitation wavelength is $488 \mathrm{~nm}$. 


\subsection{Binding constant study between BP-tetrols and Anti-PAH MAb}

Antibody-antigen complexation is believed to be one of the most specific biological events. The two pairs of chiral diastereoisomers tested are derived from benzo(a) pyrene (BP), namely $( \pm$ ) r-7,t-8,t-9,t-10-tetrahydroxy-7,8,9,10-tetrahydrobenzo(a) pyrene or cis-BP tetrol (c-BPT) and $( \pm$ ) $\mathrm{x}-7, \mathrm{t}-8,9, \mathrm{c}-10$-tetrahydroxy-7,8,9,10-tetrahydrobenzo(a) pyrene or trans-BP tetrol (t-BPT) (Figure 6). While BP adduction (through its ultimate mutagenic diol epoxide<smiles>c1ccc2c(c1)cc1ccc3cccc4ccc2c1c34</smiles><smiles></smiles>

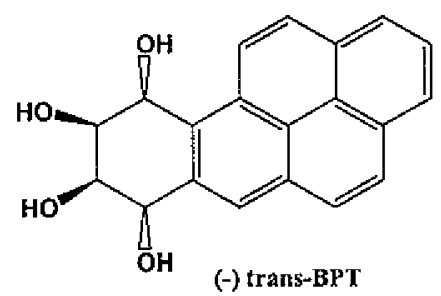<smiles>O=C1C(=O)c2c(cc3ccc4cccc5ccc2c3c45)[C@H](O)C1=O</smiles><smiles></smiles>

Figure 6. Molecular structures of benzo(a)pyrene (BP), $( \pm$ ) r-7,t-8,t-9,t-10-tetrahydroxy-7,8,9,10tetrahydrobenzo(a) pyrene (cis-BPT) and $( \pm$ )r-7,t-8,9,c-10-tetrahydroxy-7,8,9,10-tetrahydrobenzo(a) pyrene (trans-BPT). 
form, BPDE) to $\mathrm{p} 53$ tumor suppressor gene is claimed to be one of the reasons for the induction of certain types of chemically induced lung cancer $[14,15]$, BP tetrols are the final hydrolytic products of so formed BP-derived DNA adducts [16]. An anti-PAH monoclonal antibody (MAb) was used in this study, which cross-reacts with a number of polycyclic aromatic hydrocarbons (PAH), i.e. pyrene and benzo(a)pyrene.
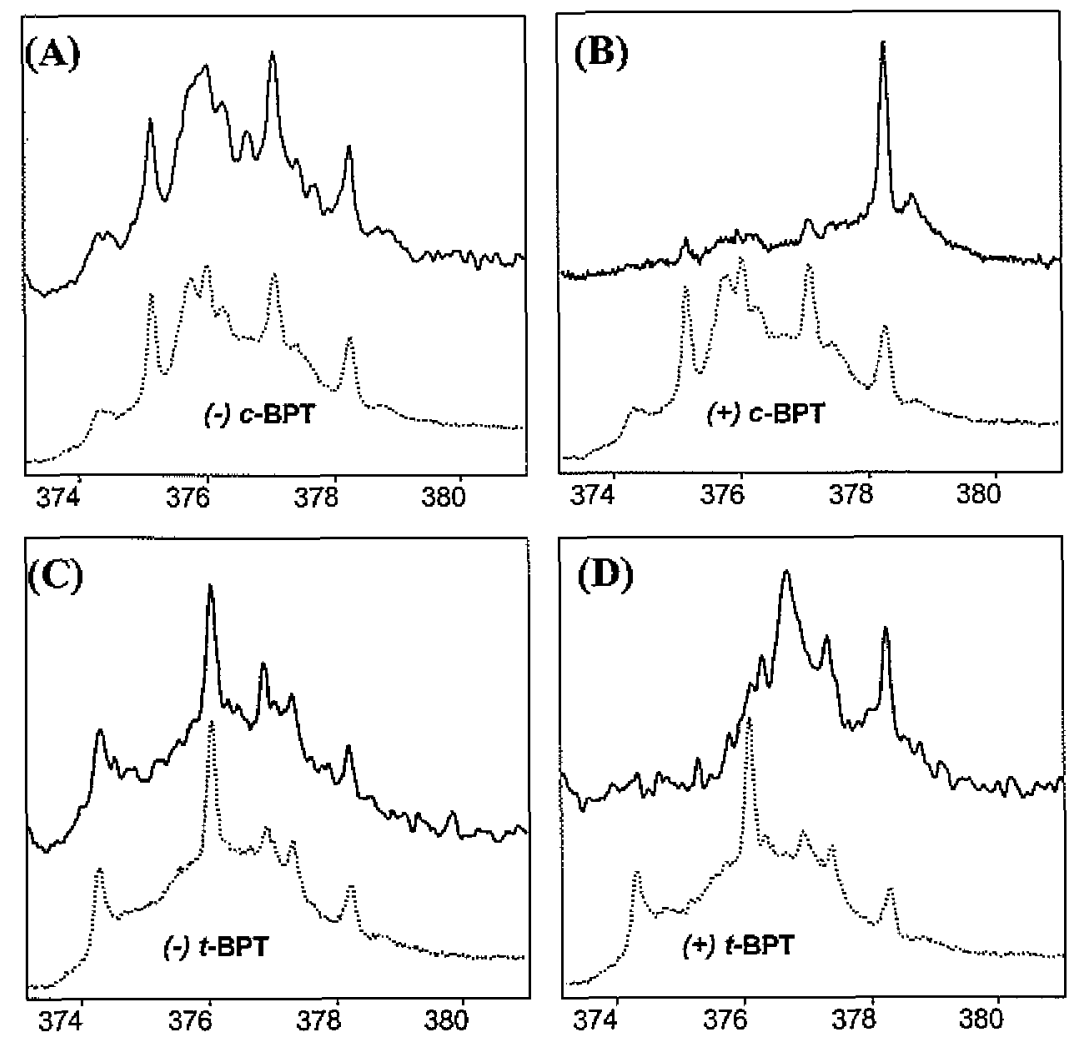

Figure 7. High-resolution fluorescence spectra of free diastereomeric and immunocomplexed BPtetrols. $\lambda_{\text {exc }}=363.0 \mathrm{~nm}, \mathrm{~T}=4.2 \mathrm{~K}, 40 \mathrm{~ns}$ delayed detection. Broken and solid lines represent spectra of free and immunocomplexed ligands, respectively. Frame A: $(-) c$-BPT, Frame B: $(+) c$-BPT, Frame $\mathrm{C}:(-) t$-BPT, Frame D: $(+) t$-BPT. 
Figure 7 shows the high-resolution fluorescence spectra of free diastereomeric and immunocomplexed tetrols. Noticeable spectra changes in the fluorescence line-narrowing spectroscopy (FLNS) spectra (due to the shifts and/or alterations in relative intensities of vibrational frequencies) were observed for $(+)$ enantiomers of both c-BPT and t-BPT complexes (broken line in Figure 7) when compared to the spectra of uncomplexed species (solid line in Figure 7) respectively. On the other hand, there were no significant spectra changes for (-) enantiomers when incubating with antibody molecules. Overall, upon incubation of enantiomeric ligands with anti-PAH MAb, variations in spectral features between immunocomplexed species are highly developed, enabling total resolution of the 4 stereoisomers. In order to correlate the spectral behavior of ligands upon interaction with the antibody, binding constants for each ligand-antibody couple were determined using the frontal analysis method of capillary electrophoresis.

\subsubsection{Experimental}

\subsubsection{Apparatus}

Capillary electrophoresis - frontal analysis (FA) experiments were performed on a modular capillary electrophoresis system (Crystal 300 series, Model 310, ATI Unicam, Boston, MA, USA) coupled with laser induced fluorescence detector. The detection system consisted of $\mathrm{CW}$ excitation at $257 \mathrm{~nm}$ provided by Lexel $95-\mathrm{SHG}$ laser operated at intensity of $100 \mathrm{~mW}$. Fluorescence was collected with a reflecting objective (N.A. 0.28), dispersed by a monochromator, and detected by an intensified CCD camera. Electropherograms were generated by on-line integration of the $320-450 \mathrm{~nm}$ spectral region in fluorescence emission window. Excitation used and spectral region observed enabled simultaneous observation of 
tetrol fluorescence as well as the native antibody fluorescence using WinSpec/32 software, Roper Scientific. UV-transparent capillaries ( $85 \mathrm{~cm} \times 75 \mu \mathrm{m}$ i.d. and $365 \mu \mathrm{m}$. o.d.) were obtained from Polymicro Technologies with a length of $70 \mathrm{~cm}(55 \mathrm{~cm}$ to the detection window). Samples were hydrodynamically injected with 20 -mbar for $60 \mathrm{~s}$ and separated at $18 \mathrm{kV}$ (resulting current $140.0 \mu \mathrm{A}$ ) at room temperature $\left(25^{\circ} \mathrm{C}\right.$ ). When a capillary was first used, it was rinsed for $1 \mathrm{~min}$ with water, $5 \mathrm{~min}$ with $1 \mathrm{M} \mathrm{NaOH}$, and $1 \mathrm{~min}$ with water. Prior to each injection, capillary was washed for $2 \mathrm{~min}$ with running buffer.

\subsubsection{Reagents and Solutions}

Purified Anti-PAH MAb was purchased from Strategic Biosolutions (Newark, DE, USA). Methanol (Aldrich, Milwaukee, WI) and glycerol (Spectrum Chemical MFG. Corp., Gardena, CA) were used as received. Sodium phosphate, and phosphoric acid were purchased from Fisher Scientific (Fair Lawn, NJ) and were used for preparation of a running buffer for capillary electrophoresis. The $\mathrm{CE}$ running buffer (50 $\mathrm{mM}$ Na-phosphate buffer at $\mathrm{pH} 8.8$ ) was filtered through $0.22 \mu \mathrm{m}$ non-pyrogenic filter (Costar, Corp.Corming, NY). All buffers and samples were prepared using water purified by a Milli-Q Water Purification System (Millipore).

Racemic r-7, t-8,t-9,t-10-tetrahydroxy-7,8,9,10-tetrahydrobenzo(a) pyrene (c-BPT) and ( \pm )r7,t-8,9,c-10-tetrahydroxy-7,8,9,10-tetrahydrobenzo(a) pyrene (t-BPT) were purchased from Midwest Research Institute, NCI Chemical Carcinogen Reference Standard Repository, Kansas City, Missouri. Enantiomers were obtained by HPLC separations of racemic standards on the $\gamma$-cyclodextrin chiral stationary phase (Cyclobond II, $250 \times 4.6 \mathrm{~mm}$, Astec, 
Whippany, NJ, USA). Shimadzu HPLC system coupled with a UV detector (SPD-6A, Shimadzu) was used. Detection wavelength was set at $246 \mathrm{~nm}$, which corresponds to the absorption maxima of the two compounds. The preparative separation conditions used to obtain milligrams of the pure enantiomers of c-BPT and t-BPT are as follows. Racemates were dissolved in methanol at a concentration of $32 \mathrm{mg} / \mathrm{ml}$. $10 \mu \mathrm{L}$ of each sample were injected into a $\gamma$-cyclodextrin column and eluted with methanol/water, $20 / 80(\mathrm{v} / \mathrm{v})$. The enantiomers were collected manually and concentrated under vacuum at $60^{\circ} \mathrm{C}$. The mobile phase was degassed before use and the flow rate was $1.0 \mathrm{ml} / \mathrm{min}$. The polarimetric detector (Chiralyser, Astec, Whippany, NJ, USA) was used to determine the elution order. The wavelength is $430 \mathrm{~nm}$. For both compounds, the (-) enantiomer was eluted first, followed by the $(+)$ isomer.

\subsubsection{Results and Discussion}

In the frontal analysis technique, the purified chiral tetrols and the anti-PAH MAb were premixed and injected as a large sample plug ( $20 \mathrm{mbar}$ for $60 \mathrm{~s})$ into the capillary column. At $\mathrm{pH} 8.8$, the anti-PAH MAb is negatively charged. The electrophoretic mobility of the free tetrol is different from the mobility of the antibody and tetrol-antibody complex. After the injection of large mixed sample plug, the free tetrol will migrate away from the antibody. Equilibrium is maintained where the zones temporarily overlap. The equilibrium free tetrol concentration is calculated from the height of the resulting plateau. The height of the free tetrol plateau decreases with the addition of antibody because of the binding of tetrol to the antibody. The plateau height at [antibody] $=0 \mathrm{uM}$ was used as the standard. In this assay, a series of sample mixtures with a fixed antibody concentration and varying tetrol 
concentrations are injected. Repeating such experiments at different tetrol concentrations allows the determination of binding constant according to the simplified equation: $r /(1-r)=$ $\mathrm{K}_{\mathrm{b}}[\mathrm{Df}]$, where $\mathrm{r}$, fraction of bound drug per protein; $\left[\mathrm{D}_{\mathrm{f}}\right]$, concentration of free drug; $\mathrm{K}_{\mathrm{b}}$, binding constant.

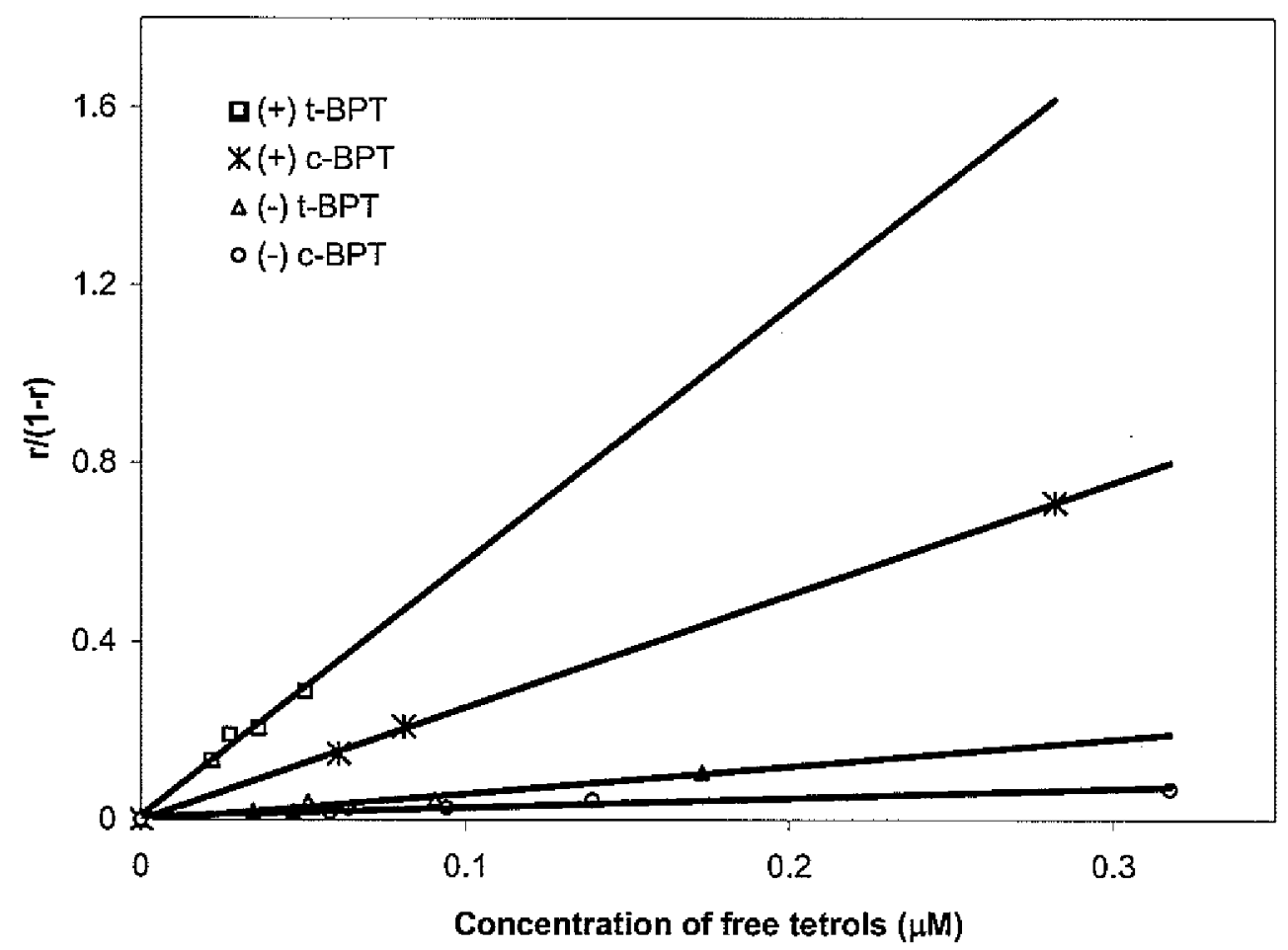

Figure 8. Plot of $\{r /(1-r)\}$ against free tetrol, where $r$ is the fraction of tetrol bound per antibody. The slope of a linear fit to the experimental data points gives the binding constant $\left(\mathrm{K}_{\mathrm{b}}\right)$ of tetrol in the complex.

Figure 8 shows the plot of fraction of ligand bound to the antibody vs free tetrol concentrations for the series of CE injections of four antibody-ligand mixtures. The binding constant for each enantiomer can be calculated from the slope, and the numerical values are as follows: $\mathrm{K}(+) \mathrm{t}-\mathrm{BPT}=6.0 \times 10^{6} \mathrm{M}^{-1}, \mathrm{~K}(-) \mathrm{t}-\mathrm{BPT}=6.1 \times 10^{5} \mathrm{M}^{-1}, \mathrm{~K}(+) \mathrm{c}-\mathrm{BPT}=2.4 \mathrm{x}$ $10^{6} \mathrm{M}^{-1}$ and $\mathrm{K}(-) \mathrm{c}-\mathrm{BPT}=2.1 \times 10^{5} \mathrm{M}^{-1}$. The (+)-enantiomers of the diastereomeric tetrols 
have significantly larger binding constants (about one order of magnitude higher) compared to their enantiomeric counterparts. Higher binding constants correspond to noticeable spectral differences between free and immunocomplexed $(+)$ species, while lower binding constants and the lack of spectral alterations in the case of free and complexed (-) enantiomers suggest weaker, external interactions with the protein molecule. Overall, it is evident from our data that the interaction of anti-PAH MAb with the optical isomers of cisand trans-BP tetrols involves different complex geometries. Therefore, these different ligandprotein interactions result in different alterations in the vibronic structures of the FLNS spectra of these enantiomers.

\subsection{Conclusion}

Capillary electrophoresis-frontal analysis is applicable to the binding constant assay of both the apomyoglobin/coumarin 153 and the tetrol/anti-PAH Mab systems. Due to the rapid analysis and small injection volumes, the frontal CE method proved to be extremely useful for the binding study of plasma proteins since they are not suitable for the long-term preservation and large-scale separation. In addition, this method uses more sensitive Iaser induced fluorescence detection. Therefore, it overcame the low sensitivity problem, which commonly occurs when using UV detection for drug-protein studies. Also, this work first introduced the use of a UV argon laser (excitation at $257 \mathrm{~nm}$ ) coupled with a CCD camera as a detection method for the FA-CE method. The excitation wavelength used and the spectral region observed enabled simultaneous observation of drug fluorescences as well as the protein fluorescences. 


\section{References}

[1] Oravcová, J., Böhs, B., Lindner, W. J. Chromatogr. B, 1996, 677, 1

[2] Kwong, T.C. Clinica Chimica Acta 1985, 151(3), 193-216.

[3] Vallner J.J. J. Pharma. Sci. 1977, 66(4), 447-465.

[4] Busch, M.H.A., Carels, L.B., Boelens, H.F.M., Kraak, J.C., Poppe, H. J. Chromatogr. A, $1997,777,311-328$.

[5] Rundlett, K.L., Armstrong, D.W. Electrophoresis, 1997, 18 (12-13), 2194-2202.

[6] Rundlett, K. L., Armstrong, D. W. Electrophoresis, 2001, 22, 1419-1427.

[7] Tanaka, Y., Terabe, S. J. Chromatogr.B, 2002, 768, 81-92.

[8] Heegaard, N.H.H., Nilsson, S., Guzman, N. A. J. Chromatogr. B 1998, 715, 29-54.

[9] Heegaard, N.H.H., Kennedy, R.T. J. Chromatogr.B, 2002, 768 (1), 93-103.

[10] Oravcová, J., Böhs, B., Lindner, W., J. Chromatogr. B 1996, 677, 1-28.

[11]Busch, M.H. A., Boelens, H.F.M., Kraak, J.C., Poppe, H. J. Chromatogr.A 1997, 775 313.

[12] Oravcova, J., Sojkova, D., Lindner, W. J. Chromatogr. B, 1996, 682, 349.

[13] Hargrove, M.S., Singleton, E.W., Quillin, M.L., Ortiz, L.A., Phillips, G.N., Olson, J.S., Mathews, A. J.J. Biol.Chem. 1994, 269, 4207-4214.

[14] Denissenko, M.F., Pao, A., Tang, M., Pfeifer, G.P. Science, 1996, 274, 430-432.

[15] Pfeifer, G.P., Denissenko, M.F., Olivier, M., Tretyakoya, N., Hecht, S.S., Hainaut, P. Oncogene, 2002, 21 (48), 7435-7451.

[16] Kim, S.K., Brenner, H.C., Soh, B.J., Geacintov, N.E. Photochem Photobiol. 1989, 50, 327-337. 


\title{
CHAPTER 6
}

\section{SEPARATION AND CHARACTERIZATION OF UNDERIVATIZED OLIGOSACCHARIDES USING LC AND LC-ESI-MS}

\author{
A paper submitted to Journal of Chromatography A.
}

Ying Liu, Daniel W. Armstrong

\begin{abstract}
Native cyclodextrin-based columns are particularly useful for the analysis of oligosaccharides because the retention of these carbohydrates is based mainly on the hydrogen bonding interactions of oligosaccharide hydroxyl groups with the stationary phase. Thus, the retention time predictably increases with the number of analyte hydroxyl groups, which corresponds to the elongation of the oligosaccharide chain. High-performance liquid chromatography (HPLC) coupled to electrospray ionization (ESI) mass spectrometry (MS) was used for the separation and characterization of underivatized oligosaccharide mixtures. With the limits of detection as low as 50 picograms, all individual components of oligosaccharide mixtures (up to 11 glucose-units long) were baseline resolved on a Cyclobond I 2000 column and detected using ESI-MS. Low flow rates and narrow ID columns increase the ESI-MS sensitivity significantly. The method showed potential usefulness for the sensitive and quick analysis of hydrolysis products of polysaccharides, and for trace levels of individual oligosaccharides or oligosaccharide isomers from biological systems.
\end{abstract}




\section{Keywords:}

LC, LC-ESI-MS, underivatized oligosaccharides, separation, cyclodextrin stationary phases

\subsection{Introduction}

The separation and characterization of underivatized oligosaccharides have continued to gain attention in recent years due to their ubiquity in nature and their significant roles and uses in industry, consumer products and biology where they are crucial for the development, growth, function or survival of an organism [1,2]. Identification of the carbohydrate substituents on glycoproteins and glycopeptides (which affect or control their function) is an important and often difficult endeavor $[3,4]$. A variety of chromatographic methods have been used to separate saccharides and oligosaccharides. They include ligand exchange chromatography $[5,6]$; chromatography based on size exclusion [7-9], and widely used hydrophilic chromatography on silica-based bonded polar stationary phases [10-12]. Often the separations of underivatized carbohydrates require specific types of columns such as alkylated silica bonded phases [13-15], amino-bonded stationary phases [12, 16-18] or various ion-exchange media [19-22] in which specific counter ions are added to affect the separations. However, most of the columns have problems, particularly in terms of column stability, lifetime and separation reproducibility. Stable cyclodextrin bonded stationary phase columns were first introduced for oligosaccharide analysis by Armstrong and Jin [23] in 1989. It has been shown that these native cyclodextrin bonded columns are particularly useful for the analysis of oligosaccharides [23-25]. In this paper, a native beta-cyclodextrin stationary phase (Cyclobond I 2000) was used to separate a variety of related oligosaccharides using MS compatible mobile phases. The retention of oligosaccharides in 
high acetonitrile-containing mobile phases on cyclodextrin-bonded phases is based on the hydrogen bonding interactions between the oligosaccharide hydroxyl groups and the cyclodextrin hydroxyl groups that constitute part of the stationary phase. In this separation approach, the retention time predictably increases with the number of the hydroxyl groups possessed by the saccharide or oligosaccharide. Hence, longer/larger saccharides/oligosaccharides tend to be retained more than shorter/smaller ones. In addition, cyclodextrin-based stationary phases are stable, have good efficiency and good reproducibility, and do not react with reducing sugars/carbohydrates as do amine-type bonded stationary phases. Consequently, they are very good for quantitative analysis.

Several LC detection methods have been used for carbohydrate analysis. Oligosaccharides have been labeled with a wide variety of derivatization reagents in order to enhance detectability during chromatographic analysis [26-29]. However, most derivatization techniques require tedious procedures, and often suffer from poor reproducibility. Therefore, detection of underivatized oligosaccharides remains extremely important.

Although underivatized oligosaccharides do not have strong chromophores, they are still detectable by UV absorption at low wavelengths, e.g., $195 \mathrm{~nm}$, with detection limits in the microgram range [23]. Refractive index (RI) detection was frequently used with slightly higher sensitivity compared to UV detection. The limits of detection by RI have been reported to below 25 nanograms [30]. However, this detector has a major disadvantage, namely, that the signal is related to the solvent composition, which prevents the use of gradient elution. Also even greater sensitivity is desirable. Evaporative light scattering 
detection (ELSD) is another preferred universal detector for carbohydrate analysis $[31,32]$ because its response is independent of the spectral properties of the analyte and solvent. Therefore, ELSD is compatible with the solvent variations and it produces stable baselines. However, the non-linear response of ELSD limits the detector's use for high-accuracy quantitative analysis [33].

Recently, mass spectrometry has gained increasing importance as a detection method for oligosaccharide analysis and characterization. So far, several mass spectrometric techniques have been used for the determination of oligosaccharide structure. They are matrix-assisted laser desorption/ionization (MALDI) [34-37], fast-atom bombardment (FAB) [38,39], and electrospray ionization (ESI) mass spectrometry [40-43]. All of aforementioned MS techniques have an advantage over chemical or chromatographic methods in that they yield molecular mass information with relatively high sensitivity. Coupled mass spectrometry HPLC became the most widely used technique in proteomics and is now beginning to make an impact on the analysis of complex carbohydrates in many fields of biotechnology [44-47]. However, the ionization and sensitive detection of carbohydrates via this approach is not as facile as it has been for proteins and peptides. So far, ESI-MS is known as one of the most suitable interfacing techniques for online LC/MS.

Online-LC-ESI-MS analyses of underivatized oligosaccharides have so far been performed using graphitized carbon chromatography (GCC) [48], and a nanoscale amide-80 column [43]. We applied a native beta-cyclodextrin stationary phase to the online LC-ESI-MS analysis of a variety of underivatized oligosaccharides. This system is characterized by high 
chromatographic resolution, high column stability, and low mass spectrometric detection limit at picogram (femtomole) sensitivity. In addition, this method showed potential usefulness for the sensitive and quick analysis of hydrolysis products of polysaccharides, and individual oligosaccharides from biological systems.

\subsection{Experimental}

\section{Chemicals and reagents}

HPLC grade acetonitrile and water was purchased from Fisher (Pittsburgh, PA, USA), formic acid from J.T. Baker (Philipsburg, NJ, USA). Cellooligosaccharides, maltooligosaccharides, dextran, and all other underivatized oligosaccharides were all purchased from Sigma. Most of the oligosaccharides were dissolved in water at $1 \mathrm{mg} / \mathrm{ml}$, and then further diluted before injection.

\section{Chromatography}

Three Cyclobond I 2000 columns with different IDs $(250 \times 4.6 \mathrm{~mm}$ i.d.; $250 \times 2.0 \mathrm{~mm}$ i.d.; and $250 \times 1.0 \mathrm{~mm}$ i.d.) were from Advanced Separation Technology (Astec, Whippany, NJ, USA). Most separations were performed at room temperature on the $250 \times 4.6 \mathrm{~mm} \mathrm{M}$ Cyclobond I 2000 column. Mobile phase compositions were acetonitrile- $0.1 \%$ formic acid in water at varying concentrations. Flow rates varied from 100 to $800 \mu 1 \mathrm{~min}^{-1}$ and $195 \mathrm{~nm}$ was used for UV detection. 


\section{Mass Spectrometry}

\section{ESI Conditions for Shimadzu LCMS-2010}

Most LC-MS experiments were performed on a Shimadzu LCMS-2010 coupled with an electrospray (ESI) ion source. The single stage quadruple mass spectrometer provides an upper mass unit limit of 2000 daltons and unit mass resolution.

Nebulizer gas flow was $4.50 \mathrm{~L} / \mathrm{min}$ and MS parameters were optimized to the following: probe bias $=4.5 \mathrm{KV}, \mathrm{CDL}=25.0 \mathrm{~V}$, aperture $=0 \mathrm{~V}, \mathrm{CDL}$ temperature $=250^{\circ} \mathrm{C}$, and block temperature was $200^{\circ} \mathrm{C}$.

\section{ESI conditions for Thermo Finnigan LCQ Advantage MS}

The effect of column IDs on sensitivity experiments were performed on a Thermo Finnigan (San Jose, CA, USA) Surveyor LC system coupled to a Thermo Finnigan LCQ advantage API ion-trap mass spectrometer with ESI ion source.

Sheath and auxiliary gases were at 50 and 40 arbitrary units, respectively. MS parameters were optimized to the following: source voltage $=4.5 \mathrm{kV}$, capillary voltage $=25.00 \mathrm{~V}$, tube lens offset $=0.0 \mathrm{~V}$ and capillary temperature $=250^{\circ} \mathrm{C}$. 


\subsection{Results and discussion}

\subsubsection{LC-ESI-MS of underivatized oligosaccharide mixtures on the Cyclobond I 2000 column}

It is well known that mass spectrometry is one of the most sensitive LC detection methods for many ionizable organic compounds, especially those with a poor UV-absorptivity. In this paper, cyclodextrin based LC-ESI-MS was examined as a way to rapidly separate and characterize underivatized oligosaccharides using a MS-compatible mobile phase.

Figure 1 shows the mass spectra of sodium adduct peaks observed in the ESI positive ion mode for standards of different oligosaccharides (initial test analytes). Cello-oligosaccharide and malto-oligosaccharide with the same degree of polymerization (d.p.), or the same number of glucose units, have similar mass spectra (results not shown). Figure 2 shows the LC-ESI-MS separation of an underivatized cello-oligosaccharide standard mixture (d.p 2-7) using selected ion chromatography. The retention of cello-oligosaccharides increases with the elongation of the dextran chain, because the retention of the oligosaccharides on cyclodextrin bonded phases are based on the hydrogen bonding interactions of oligosaccharide hydroxyl groups with those of the stationary phase. In general, the more hydroxyl groups the oligosaccharide has, the greater the number of hydrogen bonding interactions with the stationary phase and the longer is the retention. Within a homologous series, this allows the prediction of elution positions in terms of the number of the analyte's constituent monosaccharide units. 
Figure 1. Mass spectra of sodium adduct peaks observed in ESI positive ion mode for each underivatized oligosaccharide.
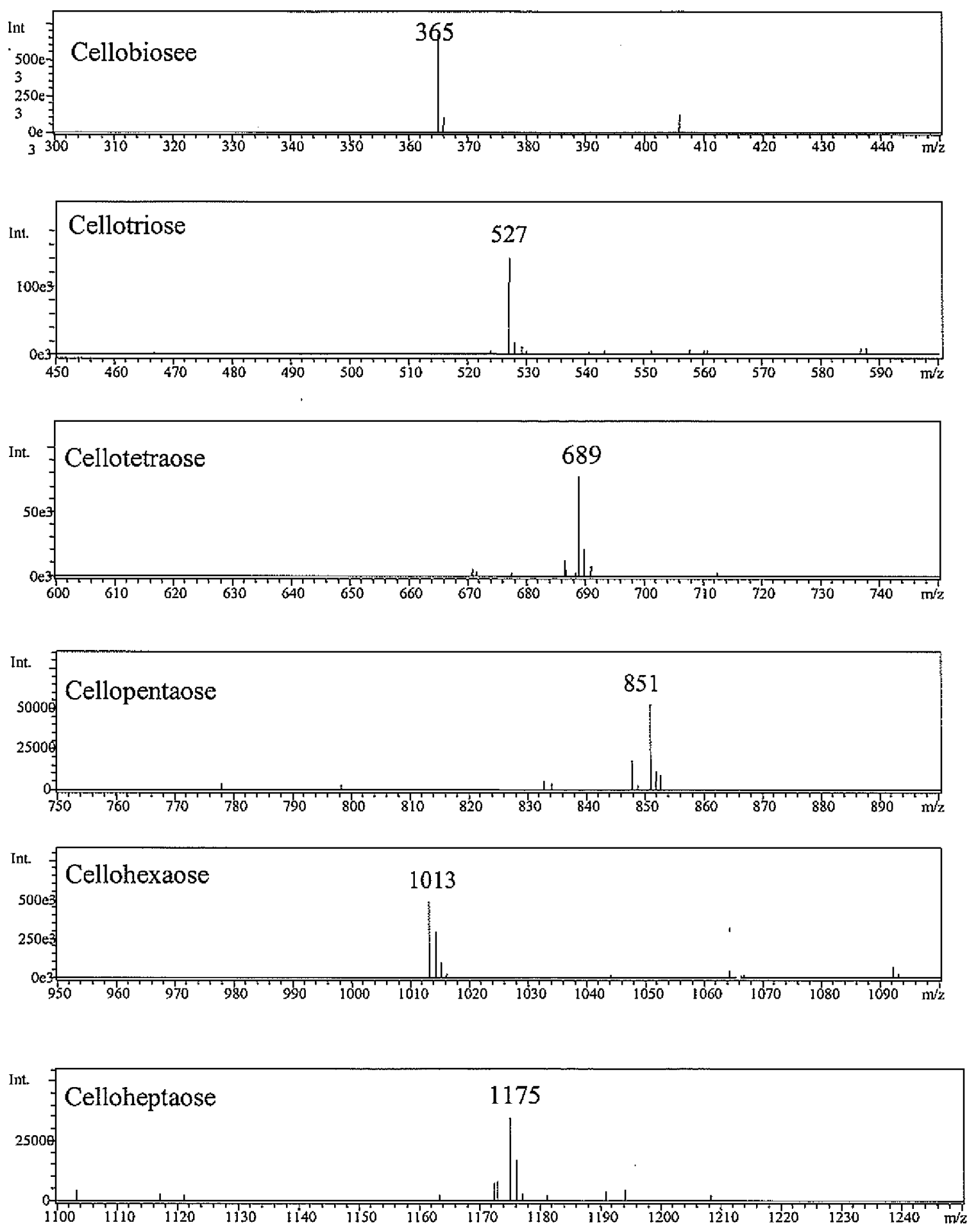


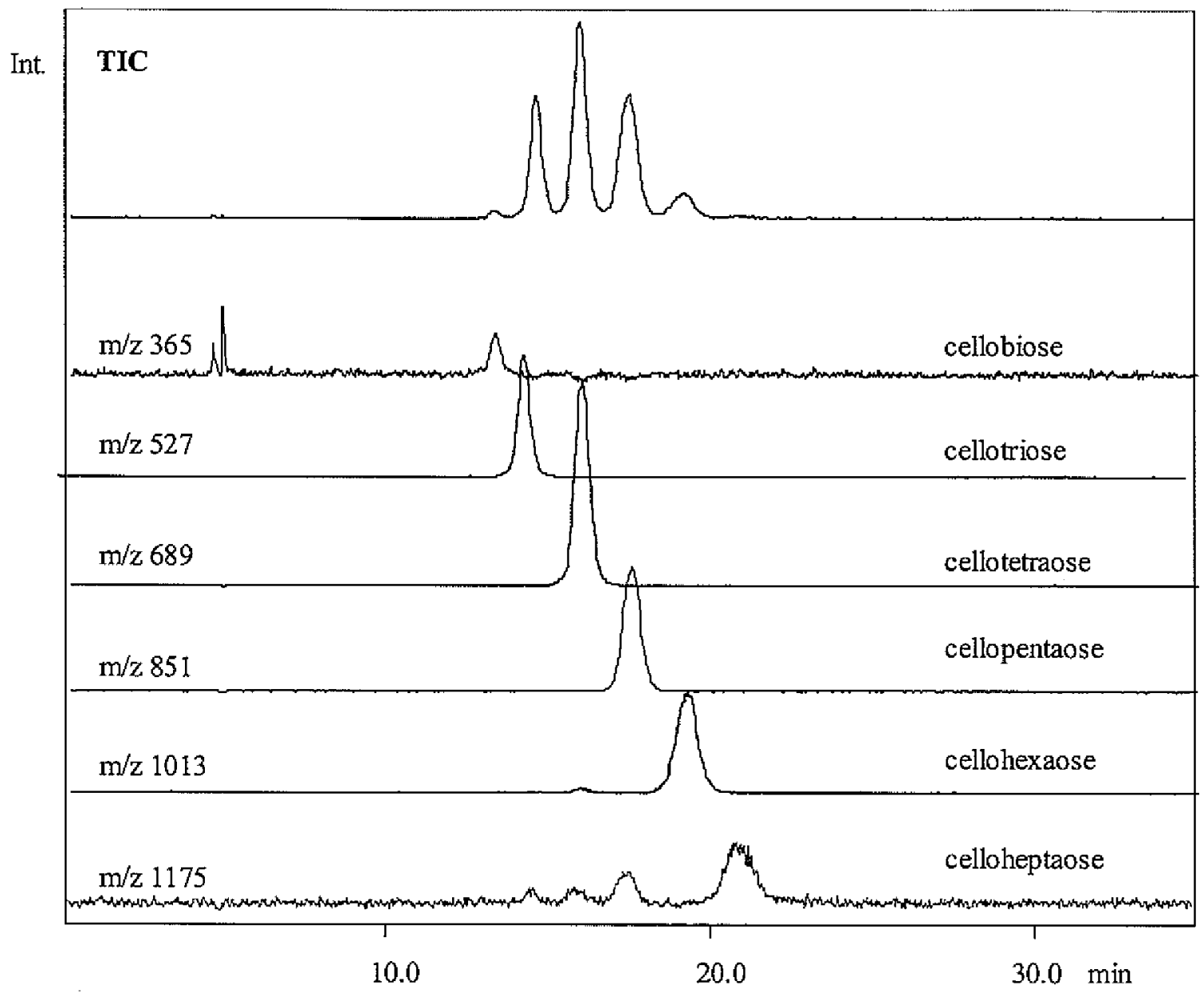

Figure 2. LC-ESI-MS of underivatized cellooligosaccharide standard mixture (d.p. 2-7). Selected ion chromatography at $[\mathrm{M}+\mathrm{Na}]^{+}$. Column: Cyclobond $\mathrm{I} 2000$ column $(250 \times 4.6 \mathrm{~mm}$ ID), flow rate at 400 $\mu \mathrm{l} / \mathrm{min}$. Mobile phase: $65: 35$ acetonitrile-water ( $0.1 \%$ formic acid)

\subsubsection{LC-ESI-MS separation of disaccharides}

The separation of structural isomers in mixtures of oligosaccharides is frequently not easy. Cellobiose, maltose, lactose, and sucrose are all disaccharides with the same molecular weight of 342 , and they all gave the same $365 \mathrm{~m} / \mathrm{z}$ peak $\left([\mathrm{M}+\mathrm{Na}]^{+} \mathrm{MS}\right.$ response) in the ESI positive ion mode. Therefore, it was not possible to identify each disaccharide from the 
mixture simply using mass spectrometry. Figure 3 shows the LC-ESI-MS separation of mixtures of the four isomeric disaccharides. Three peaks were
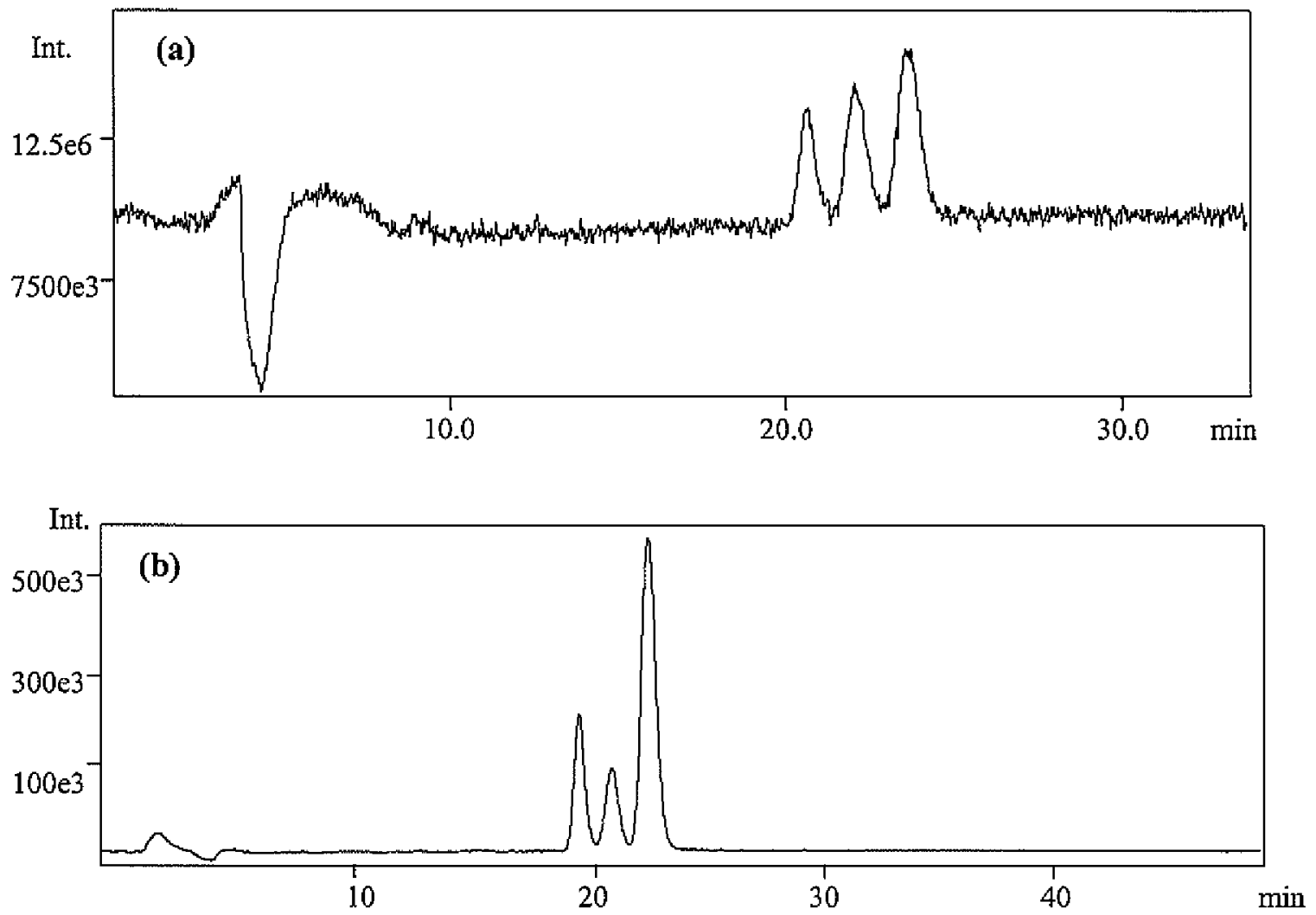

Figure 3. LC-ESI-MS of disaccharide separation.

(a) Total ion chromatography. Scanned from $\mathrm{m} / \mathrm{z} 200$ to 500.

(b) Selected ion chromatography at $365,[\mathrm{M}+\mathrm{Na}]^{+}$

Under both conditions, peaks from left to right correspond sucrose, a mixture of cellobiose and maitose, and lactose, respectively.

Column: Cyclobond I 2000 column $(250 \times 4.6 \mathrm{~mm} \mathrm{DD})$, flow rate at $400 \mu \mathrm{l} / \mathrm{min}$. Mobile phase is $80: 20$ acetonitrile-water ( $0.1 \%$ formic acid).

observed. By spiking pure standards, it was found that cellobiose could be separated from sucrose and lactose, but could not be separated from maltose. Sucrose has the shortest retention time because it has the smallest size due to the combination of six-member ring 
(glucose) and five-member ring (fructose), while lactose has the longest retention time. Cellobiose and maltose are both composed of two glucose units and differ only in the type of linkage. Cellobiose is connected by a beta $(1,4)$ glycosidic linkage, while maltose has an alpha $(1,4)$ glycosidic linkage. It seems that the native cyclodextrin column can only differentiate the position of hydroxyl groups, but can not differentiate the type of linkage. Similar results were also obtained for mixtures of maltotriose and cellotriose, mixtures of maltotetraose and cellotetraose, etc. Separation of compounds with identical molecular weights and numbers of hydroxyl groups can be accomplished by cyclodextrin based stationary phases provided each compound has different numbers of hydroxyl groups available for simultaneous interactions with the stationary phase. This can occur for geometrical reasons since different saccharides with the same number of hydroxyl groups can have different ring sizes, configurations and stereochemistry.

\subsubsection{Effect of acetonitrile concentration on capacity factor}

The concentration of organic modifier in the mobile phase controls the retention and selectivity of oligosaccharides on cyclodextrin columns. Unlike traditional reversed-phase $\mathrm{LC}$, the retention of each underivatized oligosaccharide increases when acetonitrile concentration increases from $50 \%$ to $90 \%$, as shown as in Figure 4. This is because the retention of oligosaccharides on cyclodextrin columns is based on the hydrogen bonding interactions between the oligosaccharide hydroxyl groups and the stationary phase. A high percentage of acetonitrile (a poor hydrogen bonding solvent) accentuates hydrogen-bonding interactions between the analyte and the stationary phase. With higher percentages of water in the mobile phase, the hydroxyl groups of the oligosaccharides are preferentially solvated 
by the water in the mobile phase, thus, diminishing hydrogen bonding interactions between the oligosaccharide and the stationary phase, resulting in shorter retention times. In addition, better solubility in water (of the mobile phase) also shortens retention times. Finally, the retention/solvent effect is always greater for longer disaccharides compared with their smaller analogues as seen by the steeper slopes in Figure 4. This retention behavior is analogous to that reported for sugars on alkylamine, polyol and diol columns.

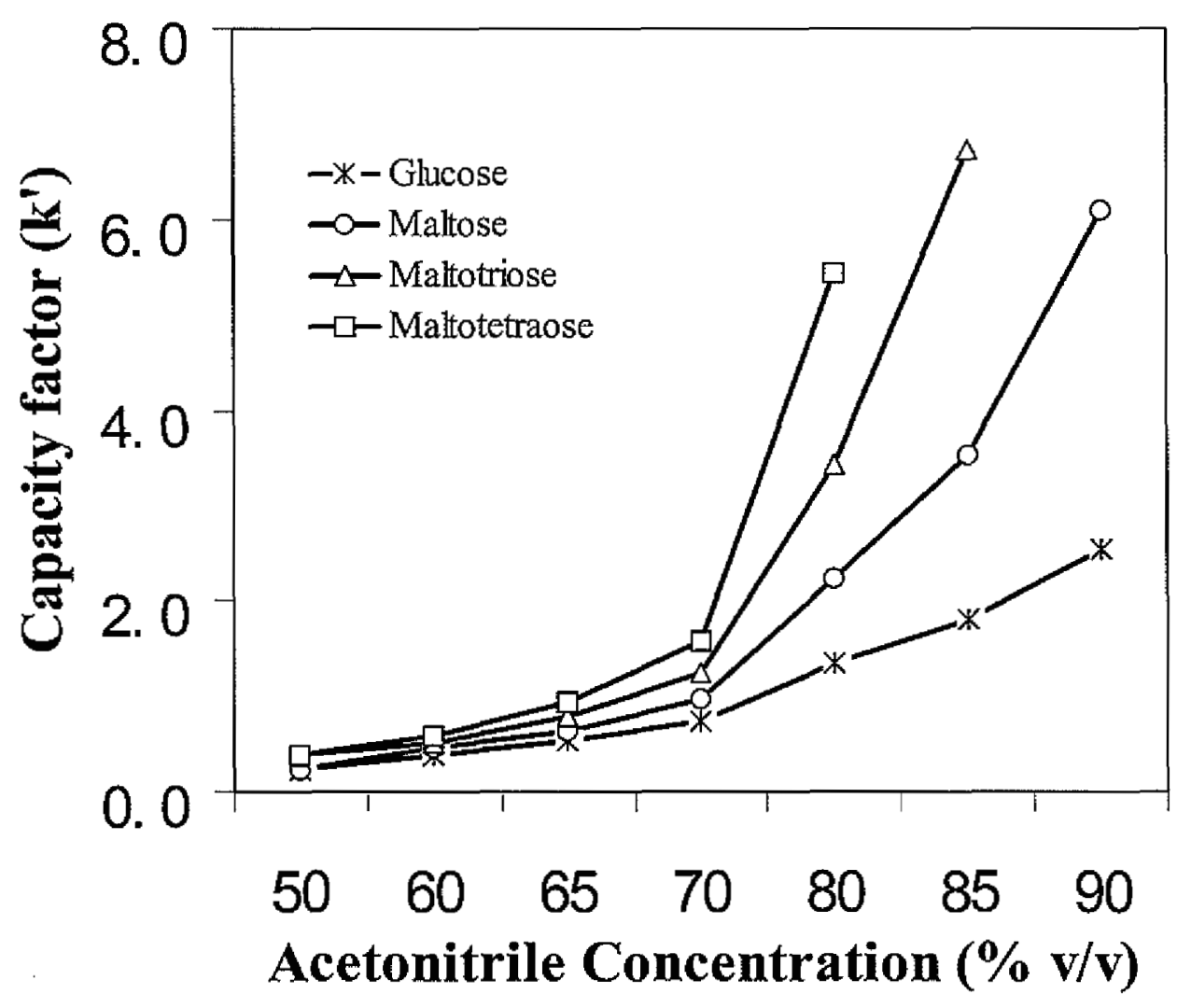

Figure 4. Effect of acetonitrile concentration on capacity factor.

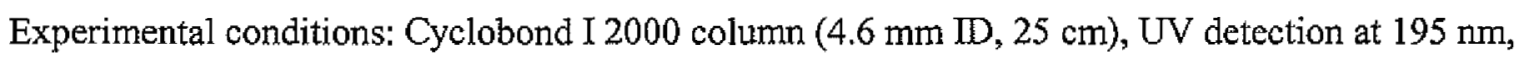
sample concentration for each oligosaccharide is $10 \mathrm{mg} / \mathrm{mL}$, injection volume is $10 \mu \mathrm{l}$. 


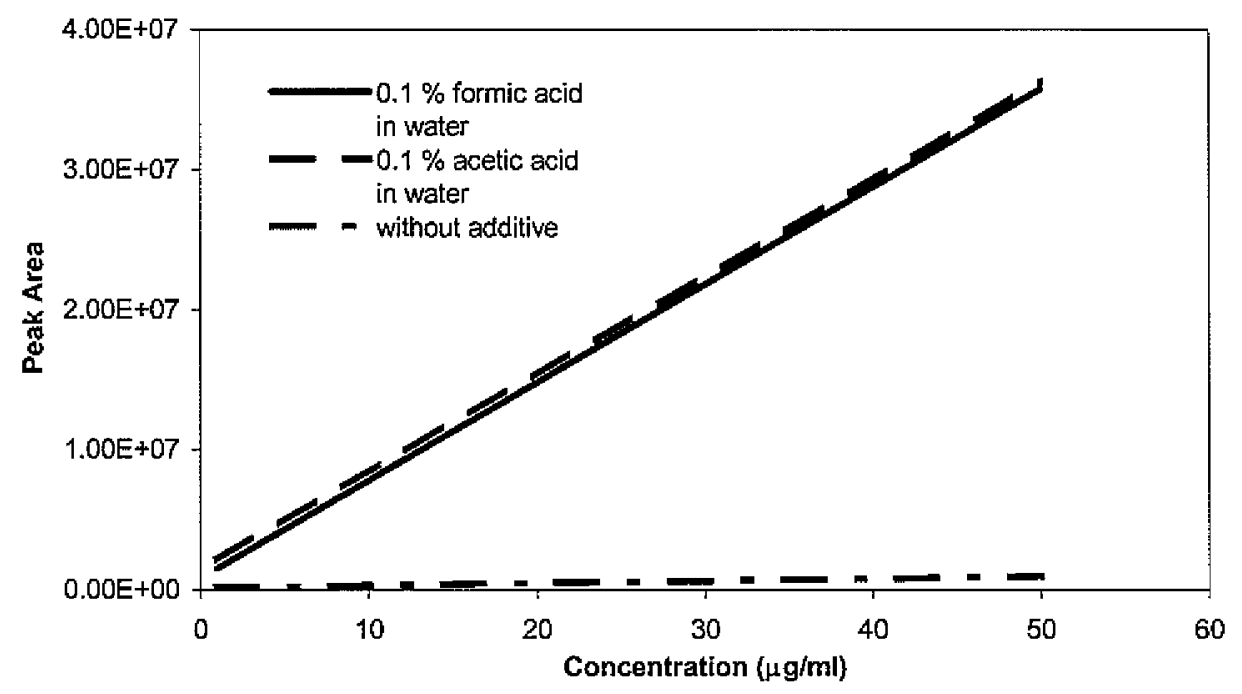

Figure 5. Effect of additive on sensitivity for maltotriose. Column: Cyclobond I 2000 column ( $250 \mathrm{x}$ $4.6 \mathrm{~mm}$ ID). Mobile phase: $60: 40$ acetonitrile-water ( $0.1 \%$ formic acid). Flow rate: $400 \mu 1 / \mathrm{min}$. MS: ESI positive SIM at $[\mathrm{M}+\mathrm{Na}]^{+}, 527$.

\subsubsection{Effect of additives on sensitivity}

The effect of acidic additives on MS detection sensitivity was investigated, as shown in Figure 5. The addition of small amount of acidic additives to the mobile phase greatly increased MS sensitivity in the positive ion mode (to over ten times that without the additive). The addition of either formic acid or acetic acid produces a similar enhancement in sensitivity. The concentration of the additives does not have a significant effect on sensitivity since the role of the additive is to aid in ionization in ESI-MS techniques. Therefore, all the experiments were performed with the addition of an acidic additive for enhanced sensitivity. 


\subsubsection{Effect of flow rates on sensitivity}

The effect of flow rates on the detection sensitivity of maltotriose was investigated using the Cyclobond I 2000 column $(25 \mathrm{~cm} \mathrm{x} 4.6 \mathrm{~mm} \mathrm{ID}$ ). The flow rate was varied from $200 \mu \mathrm{l} / \mathrm{min}$ to $800 \mu \mathrm{l} / \mathrm{min}$. As seen in Figure 6, the sensitivity at $200 \mu \mathrm{l} / \mathrm{min}$ is about 5 times higher than that found at $400 \mu \mathrm{I} / \mathrm{min}$, and about 20 times higher than that found at $800 \mu 1 / \mathrm{min}$. This observed behavior has been discussed previously [49-52]. A lower flow rate

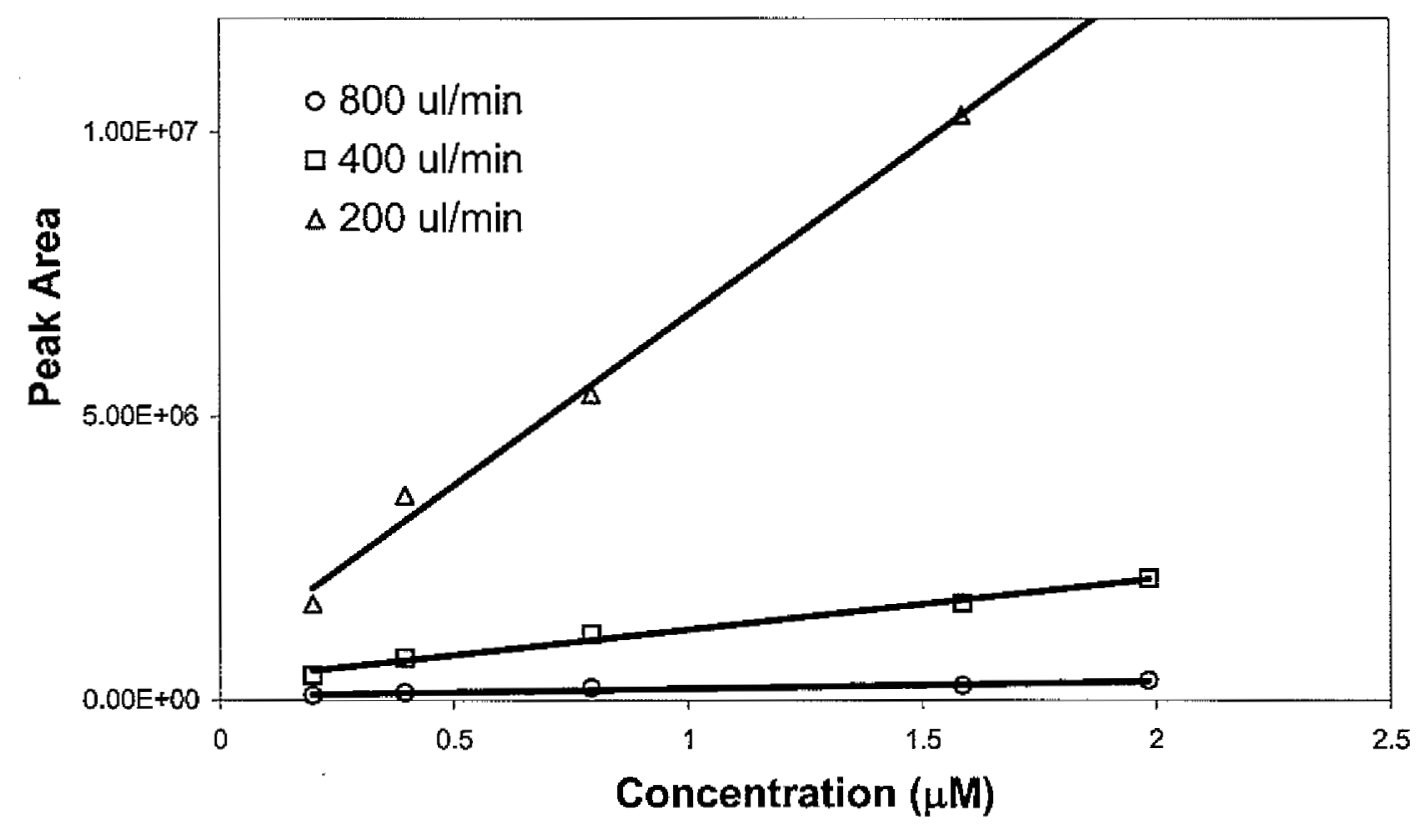

Figure 6. Effect of flow rate on sensitivity for maltotriose. Mobile phase: 60:40 ACN-water $(0.1 \%$ formic acid). Column: Cyclobond I $2000\left(250 \times 4.6 \mathrm{~mm}\right.$ ID). MS: ESI positive SIM at [M+Na] ${ }^{+}, 527$.

is known to reduce the size of the charged droplets initially produced in the electrospraying process. These smaller initial droplets require fewer droplet fission events and less solvent evaporation prior to ion release into the gas phase. Thus, lower flow rates, especially with water-acetonitrile mobile phases, favor higher sensitivity in LC-ESI-MS. 


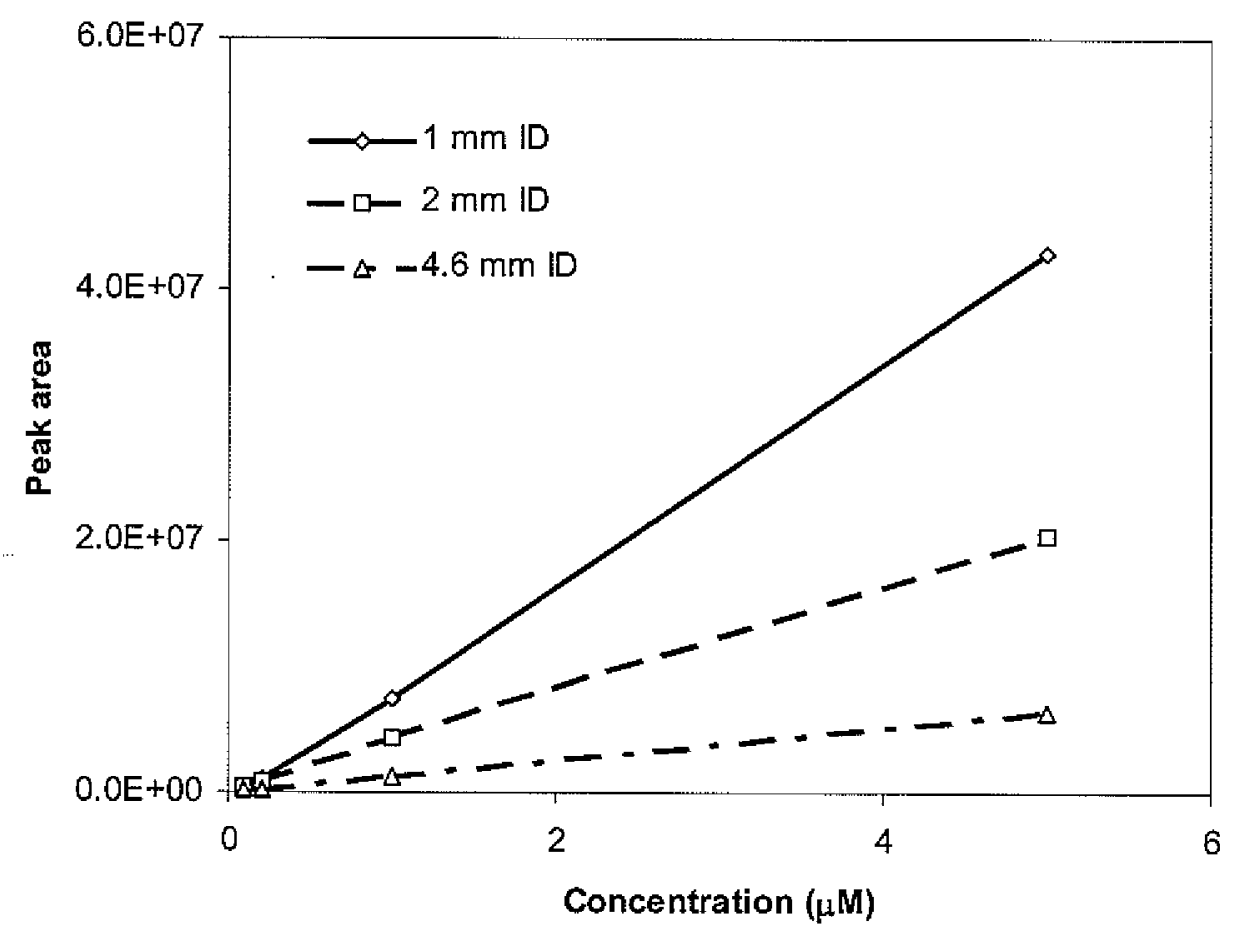

Figure 7. Effect of column IDs on sensitivity for maltotriose. Column: Cyclobond I 2000 column ( $250 \times 4.6 \mathrm{~mm} \mathrm{DD})$. Mobile phase: $60: 40$ acetonitrile-water ( $0.1 \%$ formic acid). Flow rate: 100 $\mu 1 /$ min. MS: ESI positive SIM at $[\mathrm{M}+\mathrm{Na}]^{+}, 527$.

\subsubsection{Effect of column internal diameters (IDs) on sensitivity}

The effect of column ID on sensitivity of maltotriose was also investigated. The experiments were performed on three different $25 \mathrm{~cm}$ long analytical columns with inner diameters of 1.0 $\mathrm{mm}, 2.0 \mathrm{~mm}$, and $4.6 \mathrm{~mm}$, respectively. As is known, columns of different sizes need different optimized experimental parameters to produce the optimum MS sensitivity. However, in order to simplify the experiment, all the LC and MS conditions were kept consistent for each individual column in this assay. For better comparison, a flow rate of 100 $\mu \mathrm{l} / \mathrm{min}$ was used in order to obtain an acceptable backpressure when using the small $\mathrm{ID}$ column. As seen in Figure 7, under the experimental conditions selected, the sensitivity on 
the $2 \mathrm{~mm} \mathrm{ID} \mathrm{column} \mathrm{is} \mathrm{about} \mathrm{two} \mathrm{times} \mathrm{higher} \mathrm{than} \mathrm{that} \mathrm{on} \mathrm{the} \mathrm{traditional} \mathrm{D}$ column (4.6 $\mathrm{mm}$ ID), while the sensitivity on the $1 \mathrm{~mm}$ ID column is about five times higher compared to that found with the traditional $\mathrm{D}$ column. Although each separation was not individually optimized, these experiments demonstrate the general trend that a smaller inner diameter column produces an increase in sensitivity over the conventional ID columns due to the relatively increased sample concentration at the detector.

Under microbore LC conditions, the flow rate is reduced by a factor of 4 , from $400 \mu 1$ to 100 $\mu l$ per minute. This reduction brings an increase in MS sensitivity of up to eight -fold (results not shown). Compared to the traditional ID column, the total gain in sensitivity using on-line LC-ESI-MS can be as high as forty times. The present data indicate that lower flow rates and narrow ID columns favor high ESI-MS sensitivity for these oligosaccharide analyses.

\subsubsection{Limits of detection compared to UV}

The limits of detection (LOD) for UV (at $195 \mathrm{~nm}$ ) were compared with those for ESI-SIMMS for selected underivatized oligosaccharides (Table 1) on the traditional size analytical Cyclobond I 2000 column $(250 \times 4.6 \mathrm{~mm}$ ID). The LC conditions were kept constant for both detection systems for each individual oligosaccharide. In most cases, the LOD using ESI-MS detection is about 3 or 4 orders magnitude lower than that for UV detection. In MS detection, maltotriose had the lowest detection limit (50 picograms), while the detection limits became higher with further elongation of the oligosaccharide chain. The relatively higher detection limit of maltose (5 nanograms) may partially be due to the high MS background that occurs when $\mathrm{m} / \mathrm{z}$ is below 500 . 
Table 1. Comparison of detection limits of ESI-MS vs UV.

\begin{tabular}{lll}
\hline \multirow{2}{*}{ Sample } & \multicolumn{2}{c}{ Detection Limits $^{1}$} \\
\cline { 2 - 3 } Maltose & $\mathrm{UV} / \mathrm{visible}^{2}$ & $\mathrm{MS}^{3}$ \\
Maltotriose & $5 \mu \mathrm{g}, \mathrm{S} / \mathrm{N}=4$ & $5 \mathrm{ng}, \mathrm{S} / \mathrm{N}=3$ \\
Maltotetraose & $1 \mu \mathrm{g}, \mathrm{S} / \mathrm{N}=3$ & $50 \mathrm{pg}, \mathrm{S} / \mathrm{N}=4$ \\
Maltopentaose & $5 \mu \mathrm{g}, \mathrm{S} / \mathrm{N}=3$ & $250 \mathrm{pg}, \mathrm{S} / \mathrm{N}=3$ \\
\hline
\end{tabular}

${ }^{1}$ Detection limit experiments were done on the Cyclobond 12000 column $(4.6 \mathrm{~mm} \mathrm{ID,} 25 \mathrm{~cm})$, mobile phase composition $60: 40 \mathrm{ACN}: \mathrm{H}_{2} \mathrm{O}, 0.1 \%$ formic acid was added to water for ESI-MS.

${ }^{2}$ Detection at $195 \mathrm{~nm}$. Flow rate at $1.0 \mathrm{ml} / \mathrm{min}$.

${ }^{3}$ ESI-MS SIM at $[\mathrm{M}+\mathrm{Na}]^{+}$for each underivatized oligosaccharide. Flow rate at $400 \mu \mathrm{l} / \mathrm{min}$.

\subsubsection{LC-ESI-MS of hydrolysis products of dextrin}

Fifty milligrams of dextran were treated in $1 \mathrm{ml}$ of $0.1 \mathrm{M}$ trifluoacetic acid for 16 hrs at room temperature, and the hydrolysis products were analyzed using online LC-ESI-MS (Figure 8). All oligosaccharides (up to 11 glucose units in the mixture) were separated and identified. With this simple dextran "ladder", all of the elution positions in terms of the number of glucose units are fixed and easily determined. The hydrolysis product of mannan was also analyzed using this method. Mannan digestion products were prepared by incubating mannan in $0.5 \mathrm{M}$ hydrochloride acid in a microwave oven $(1.1 \mathrm{kV})$ for 30 seconds. Figure 9 shows the LC-ESI-MS of mannan digest separated on the Cyclobond I 2000 column. Up to eight mannose units of the oligosaccharide mixture were observed. Clearly, this method is very suitable for most low to moderate molecular weight oligosaccharide mixtures produced by digestion of polysaccharides. 

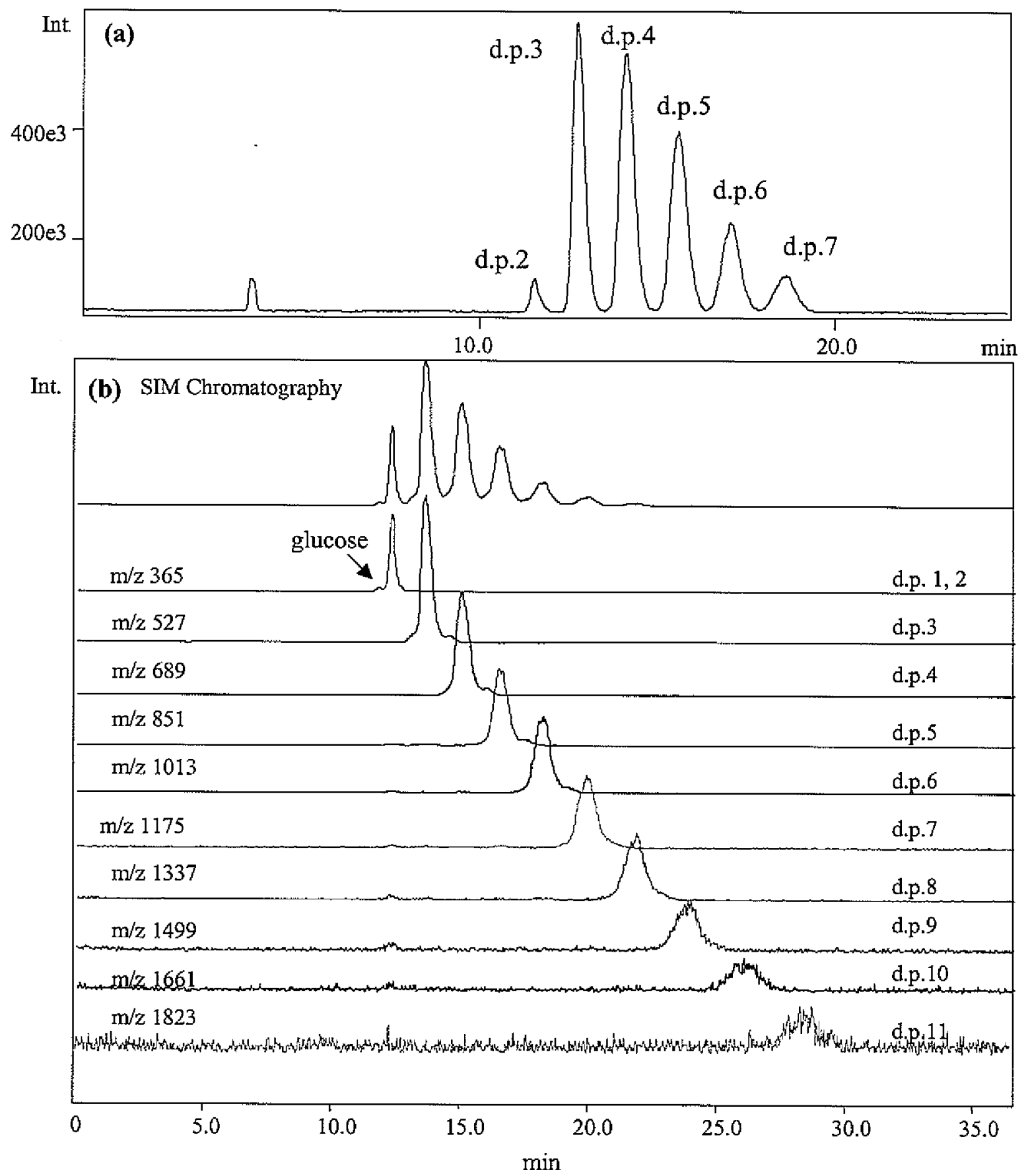

Figure 8. LC-ESI-MS of dextran "ladder" on Cyclobond I 2000 column ( $250 \times 4.6 \mathrm{~mm} \mathrm{ID})$

(a) LC-ESI-MS of underivatized malto-oligosaccharide standard mixture (d.p. 2-7).

(b) LC-ESI-MS of hydrolysis product of dextran. Experimental conditions: selected ion chromatography at $[\mathrm{M}+\mathrm{Na}]^{+} ; 65: 35$ acetonitrile-water $(0.1 \%$ formic acid) mobile phase; flow rate at $400 \mu \mathrm{l} / \mathrm{min}$. 


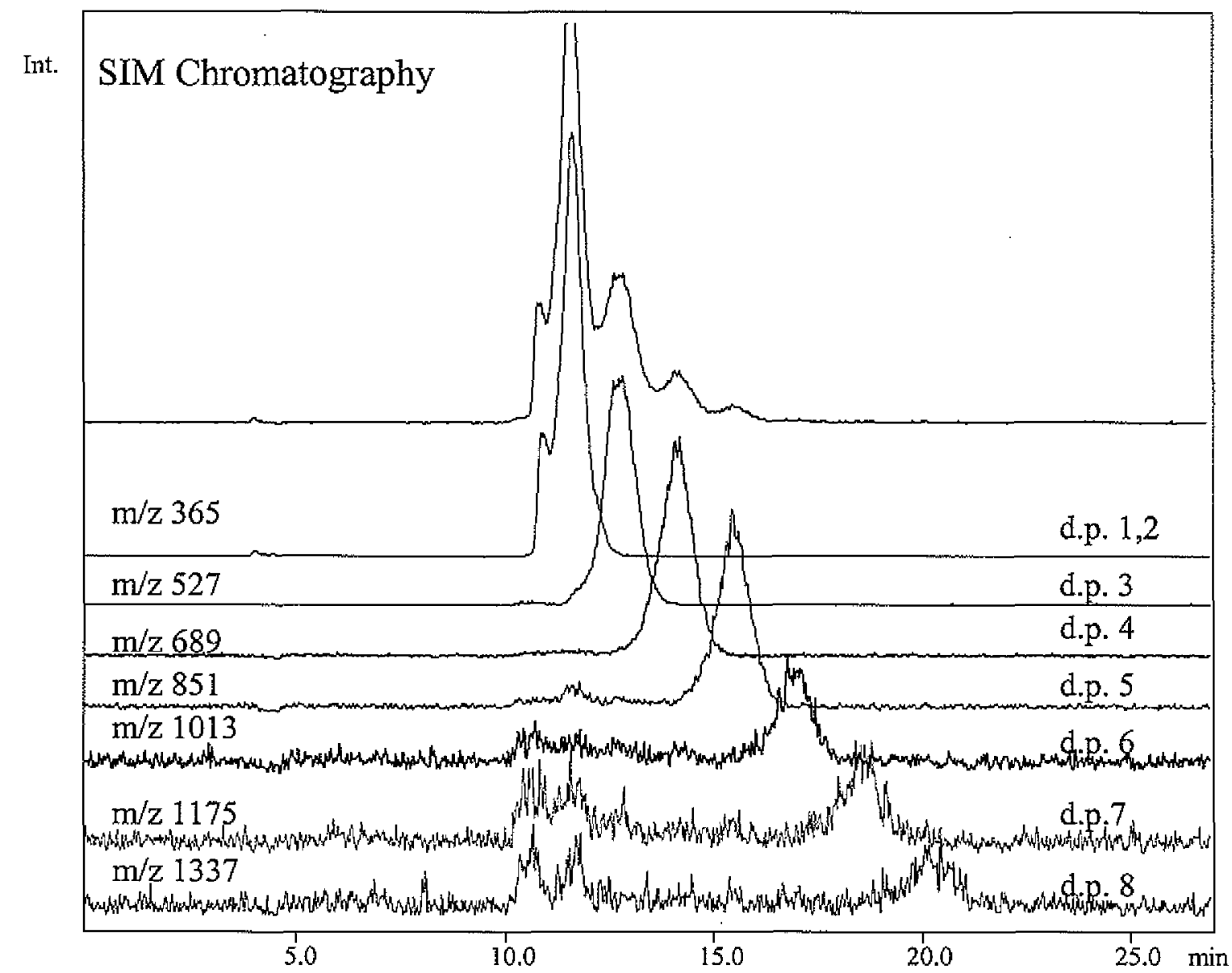

Figure 9. LC-ESI-MS of mannan digest on Cyclobond I 2000 column $(250 \times 4.6 \mathrm{~mm} \mathrm{ID})$ Mannan was prepared by incubating mannan in $0.5 \mathrm{M}$ hydrochloride acid in a microwave oven $(1.1 \mathrm{kV})$ for $30 \mathrm{~s}$. Mobile phase composition: $65: 35$ acetonitrile-water $(0.1 \%$ formic acid). ESI SIM mode, flow rate at $0.4 \mathrm{ml} / \mathrm{min}$.

\subsection{Conclusions}

Native beta cyclodextrin stationary phases have proven to be particularly useful for the analysis of oligosaccharides because the retention of these carbohydrates is based on the hydrogen bonding interactions of the oligosaccharide hydroxyl groups with those of the stationary phases. Thus, the retention time predictably increases with the elongation of 
oligosaccharide chain. This system is characterized by its selectivity, which also allows the separation of certain isomers, e.g., of some disaccharides. HPLC coupled with MS was shown to be a viable alternative to traditional detection techniques for the separation and characterization of underivatized oligosaccharides. The limits of detection can go down to as low as picogram levels for ESI-MS, which are orders of magnitude lower than low wavelength UV detection. The use of low flow rates and narrow bore columns can further enhance ESI-MS sensitivity. All individual components of oligosaccharide mixtures (up to 11 glucose units long) can be successfully separated using this method in less than 30 minutes. The method showed potential usefulness for the sensitive and quick analysis of hydrolysis products of polysaccharides, and individual oligosaccharides from biological systems as well.

\section{Acknowledgements}

This manuscript has been authored by Iowa State University of Science and Technology under Contract No. W-7405-ENG-82 with the U.S. Department of Energy. The publisher, by accepting the article for publication, acknowledges that the United States Government retains a non-exclusive, paid-up, irrevocable, world-wide license to publish or reproduce the published form of this manuscript, or to allow others to do so, for United States Government purposes.

\section{References}

[1] T.W. Radamacher, R.B. Parekh, R.A. Dwek, Annu. Reu. Biochem, 57 (1988) 785. 
[2] A, Varki, Glycobiology, 3 (1993) 97.

[3] Y. Huang, Y.S. Mechref, M.V. Novotny, U.S. Pat. Appl. Publ. (2004) 13 pp.

[4] Y. Mechref, M.V. Novotny, Chem. Rev. 102 (2002) 321.

[5] M. Stefansson, J. Chromatogr. 630 (1992) 123.

[6] M. Stefansson, D. Westerlund, J. Chromatogr. A 720 (1996), 127.

[7] R.G. Beri, L.S. Hacche, C.F. Martin, Gel permeation chromatography. HPLC: Practical and Industrial Applications (1997) 245.

[8] M.M.H. Huisman, L.P. Brull, J.E. Thomas-Oates, J. Haverkamp, H.A. Schols, A.G.

Voragen, J. Carbohydr. Res. 330 (2001) 103.

[9] S.C. Churms, J. Chromatogr. A, 720 (1996) 151.

[10] S.C. Churms, J. Chromatogr.A, 720 (1996) 75.

[11] A.J. Alpert, M. Shukla, A.K. Shukla, L.R. Zieske, S.W. Yuen, M.A.J. Ferguson, A. Mehlert, M. Pauly, R. Orlando, J. Chromatogr. A, 676 (1994) 191.

[12] S. Lin, W. Lee, J. Chromatogr. A 803 (1998) 302.

[13] N.W.H. Cheetham, P. Sirimanne, W.R. Day, J. Chromatogr. 207 (1981) 439.

[14] A. Klein, C. Carnoy, J.M. Lo-Guidice, G. Lamblin, P. Roussel, Carbohydr. Res. 236 (1992) 9.

[15] C. Brons, C. Olieman, J. Chromatogr. 259 (1983) 79.

[16] F.M. Rabel, A.G. Caputo, E.T. Butts, J. Chromatogr. 126 (1976) 731.

[17] Z.L. Nikolov, P.J. Reilly, J. Chromatogr. 325 (1985) 287.

[18] W.M. Blanken, M.L.E. Bergh, P.L. Koppen, D.H. Van den Eijnden, Anal. Biochem. 145 (1985) 322.

[19] L.E. Fitt, W. Hassler, D.E. Just, J. Chromatogr. 187 (1980) 381. 
[20] K. Brunt, J. Chromatogr. 246 (1982) 145.

[21] S. Tabata, Y. Dohi, Carbohydr. Res. 230 (1992) 179.

[22] N. Ztorto, T. Buttler, L. Gorton, G. Marko-Varga, H. Stalbrand, F. Tjerneld, Anal.

Chim. Acta, 313 (1995) 15.

[23] D.W. Armstrong, H.L. Jin, J. Chromatogr. 462 (1989) 219.

[24] A. Berthod, S.S.C. Chang, J.P.S. Kullman, D.W. Armstrong, Talanta, 47 (1998) 1001.

[25] P.J. Simms, R.M. Haines, K.B. Hicks, J. Chromatogr. 648 (1993) 131.

[26] J. Xu, Q. Zhang, W. Zhang, F. Wang, T. Li, Sepu 21 (2003) 115.

[27] A. Caceres, S. Cardenas, M. Gallego, A. Rodriguez, M. Valcarcel, Chromatographia 52 (2000) 314.

[28] C. Thanawiroon, K.G. Rice, T. Toida, R.J. Linhardt, J. Biol, Chem. 279 (2004) 2608.

[29] M. Pauly, W.S. York, R. Guillen, P. Albersheim, A.G. Darvill, Carbohydr. Res. 282 (1996) 1 .

[30] K.B. Hicks, Adv. Carbohydr. Chem. Biochem., 46 (1988) 17.

[31] P. Lehtonen, R. Hurme, J. Inst. Brew, 100 (1994) 343.

[32] Y. Wei, M.-Y. Ding, J. Chromatogr., A 904 (2000) I13.

[33] C.S. Young, J.W. Dolan, LC GC 21 (2003) 120.

[34] B. Spengler, D. Kirsch, R. Kaufmann, J. Lemoine, Org. Mass Spectrom. 29 (1994) 782.

[35] R. Kaufmann, P. Chaurand, D. Kirsch, B. Spengler, Rapid Commun. Mass Spectrom., $10(1996) 1199$.

[36] M.C. Huberty, J.E. Vath, W. Yu, S.A. Martin, Anal. Chem. 65 (1993) 2791.

[37] A. Reis, M.R.M. Domingues, A.J. Ferrer-Correia, M.A. Coimbra, Carbohydr. Polym., $53(2003) 101$. 
[38] H. Egge, J. Peter-Katalinic, Mass Spectrom. Rev. 6 (1987) 331.

[39] G. Pohlentz, I. Marlis, H. Egge, J. Carbohydr. Chem. 17 (1998) 1151.

[40] M.J. Deery, E. Stimson, C.G. Chappell, Rapid Commun. Mass Spectrom. 15 (2001) 2273.

[41] A. Reis, M.A. Coimbra, P. Domingues, A.J. Ferrer-Correia, M. Domingues, M. Rosario, Carbohydr. Polym. 55 (2004) 401.

[42] U. Bahr, A. Pfenninger, M. Karas, B. Stahl, Anal.Chem. 69 (1997) 4530.

[43] M. Wuhrer, C.A.M. Koeleman, A.M. Deelder, C.H. Hokke, Anal. Chem. 76 (2004) 833.

[44] W. Chai, V. Piskarev, A.M. Lawson, Anal. Chem. 73 (2001) 651.

[45] B. Barroso, R. Dijkstra, M. Geerts, F. Lagerwerf, P. Van Veelen, A. De Ru, Rapid Commun. Mass Spectrom. 16 (2002) 1320.

[46] A. Antonopoulos, P. Favetta, W. Helbert, M. Lafosse, Carbohydr. Res. 339 (2004) 1301.

[47] G.E. Black, A. Fox, ACS Symposium Series 619 (1996) (Biochemical and

Biotechnological Applications of Electrospray Ionization Mass Spectrometry) 81.

[48] S. Itoh, N. Kawasaki, M. Ohta, M. Hyuga, S. Hyuga, T. Hayakawa, J. Chromatogr. A $968(2002) 89$.

[49] J. Abian, A.J. Oosterkamp, E. Gelpi, J. Mass Spectrom. 34 (1999) 244.

[50] A. Schmidt, M. Karas, T. Dülcks, J. Am. Sco. Mass Spectrom, 14 (2003) 492.

[51] M.J. Desai, D.W. Armstrong, J. Mass Spectrom. 39 (2004) 177.

[52] M.J. Desai, D.W. Armstrong, J. Chromatogr. A 1035 (2004) 203. 


\section{CHAPTER 7}

\section{GENERAL CONCLUSIONS}

The research outlined in Chapter 2 of this dissertation demonstrates an in-depth evaluation of the enantiomeric separation capabilities of macrocyclic glycopeptides CSPs with SFC mobile phases by using a set of over 100 chiral compounds. It was found that the macrocyclic based CSPs were able to separate enantiomers of widely different compounds with various functionalities and polarities, such as heterocycles, analgesics (nonsteroidal antiinflammatory compounds), $\beta$-blockers, sulfoxides, $\mathrm{N}$-protected amino acids and native amino acids. Seventy percent of all separations were achieved in less than 4 min due to the high flow rate $(4.0 \mathrm{ml} / \mathrm{min})$ that can be used in SFC.

The research described in Chapter 3 gives an example of a successful enantiomeric separation of a series of unique chiral compounds, substituted dihydrofurocoumarins and related derivatives using macrocyclic antibiotic-based CSPs. The factors that influenced enantioseparations were: organic modifier concentration, temperature and pressure, all of which were investigated in detail. In this work, bulky groups that cause steric repulsion are found to be important for chiral recognition. The increase in steric bulk on the stereogenic center or on the carbon alpha to it enhanced the enantiomeric separation. However, chiral recognition was affected differently if the bulky substituent is further from the stereogenic center. 
We can conclude, from the results in Chapters 2 and 3, that the teicoplanin aglycone and teicoplanin CSPs seem to be the most effective chiral stationary phases when used with SFC mobile phases. The two major advantages of packed column SFC (pSFC) are fast separation speed (high flow rate that can be used in the SFC) and good compatibility with preparative mode (less solvent used, which makes solute recovery and solvent disposal easy). pSFC with macrocyclic glycopeptides based CSPs shows a great potential to become a promising chiral separation technique that will be used increasingly in industrial applications.

Capillary electrophoresis (CE) is an alternative and complementary enantiomeric separation technique. The CE enantiomeric separations of chiral substituted dihydrofurocoumarin derivatives extended the applications of chiral separations in CE. In this assay, we proposed four different chiral separation methods using $\mathrm{CE}$ and micellar capillary electrophoresis (MCE). The best separation was obtained in the reversed polarity mode with sulfated- $\beta$ cyclodextrin as the chiral selector. MCE can also be used to separate these neutral dihydrofurocoumarin derivatives. In MCE, the addition of micelles (SDS) provides an anionic pseudophase in the running buffer, and thus permits the use of an uncharged cyclodextrin as the chiral selector. The presence of micelles increases the solubility of the hydrophobic coumarin derivatives in the run buffer. However, this method suffers from longer separation times. Overall, sulfated- $\beta$-cyclodextrin is the best chiral selector for this class of chiral compounds, but the MCE method produced good efficiencies.

Chapter 5 expanded the applications of $\mathrm{CE}$ as a very useful analytical tool for examining the nature and strength of biological interactions between drugs and proteins. Frontal analysis 
(FA) method has been used to evaluate analyte binding behavior in two sample systems. Our results matched those obtained previously, in which a Job's plot spectroscopy method was used (Apomyoglobin/coumarin 153 system). In the second system, our results better explained and supported the FLNS spectroscopic phenomena observed for a chiral benzo(a)pyrenes tetrols/Anti-PAH MAb system. In addition, the more sensitive fluorescent detection induced by a UV argon laser greatly enhanced the capabilities of this method for a wide variety of drug-protein systems.

The last part of this dissertation (Chapter 6) demonstrates a successful separation and characterization of underivatized oligosaccharides using LC and LC-ESI-MS. Native beta cyclodextrin stationary phases have been used in this assay because the retention of these carbohydrates is based on the hydrogen bonding interactions of the oligosaccharide hydroxyl groups with those of the stationary phases. Thus, the retention predictably increases with the elongation of the oligosaccharide chain. This system is characterized by high chromatographic resolution, high column stability, and low mass spectrometric detection limits at picogram (femtomole) sensitivity. In addition, this method shows potential usefulness for the sensitive and quick analysis of hydrolysis products of polysaccharides, and individual oligosaccharides from biological systems. Separation of certain isomers can also be achieved using this assay. 


\section{ACKNOWLEDGEMENTS}

As I finished my dissertation, I felt there were so many people that I would like to thank. Here, I just name some of them who have paved the path toward the pursuit of my Ph.D. degree.

First of all, it has been my great honor to do my Ph.D. study under the guidance and supervision of my major professor, Dr. Daniel W. Armstrong, a brilliant scientist and a great mentor. His scientific intelligence and attitude toward science greatly influenced me and stimulated my interest in science and technology. It is his inspiration and encouragement that made my graduate study here at Iowa State unforgettable and worthwhile.

Secondly, my sincere thanks go to my POS committee members, Prof. Robert S. Houk, Prof. Victor Shang-Yi Lin. Prof. Jacob W. Petrich, and Prof. Bonita A. Glatz for their time and support.

Thirdly, my appreciation goes to all of our collaborators during my research, Prof. Larock's research group, Prof. Jenks' research group, Prof. Petrich's research group, Prof. Verkade's research group, and Prof. Small's research group at Iowa State University for their work and collaborations. In addition, I would like to thank Dr. Alain Berthod, a visiting professor from University of Lyon 1, France, for his help and enlightening discussions involving my research. I would also thank all of Professor Armstrong's group members who provided help and collaborations. I really enjoyed working as a part of this great team.

Finally, I would especially like to thank my husband, Yu Ding, for his support.

This work was performed at Ames Laboratory under Contract No. W-7405-Eng-82 with U.S. Department of Energy. The United States government has assigned the DOE Report number IS-T 2107 to this thesis. 